Florida International University FIU Digital Commons

\title{
Design and Synthesis of Novel Nucleoside Analogues: Oxidative and Reductive Approaches toward Synthesis of 2'-Fluoro Pyrimidine Nucleosides
}

Ramanjaneyulu Rayala

Florida International University, rraya002@fiu.edu

DOI: $10.25148 /$ etd.FIDC000129

Follow this and additional works at: https:// digitalcommons.fiu.edu/etd

Part of the Carbohydrates Commons, Heterocyclic Compounds Commons, and the Nucleic Acids, Nucleotides, and Nucleosides Commons

\section{Recommended Citation}

Rayala, Ramanjaneyulu, "Design and Synthesis of Novel Nucleoside Analogues: Oxidative and Reductive Approaches toward Synthesis of 2'-Fluoro Pyrimidine Nucleosides" (2015). FIU Electronic Theses and Dissertations. 2172.

https://digitalcommons.fiu.edu/etd/2172 


\title{
FLORIDA INTERNATIONAL UNIVERSITY
}

Miami, Florida

\section{DESIGN AND SYNTHESIS OF NOVEL NUCLEOSIDE ANALOGUES: OXIDATIVE AND REDUCTIVE APPROACHES TOWARD SYNTHESIS OF 2'-FLUORO PYRIMIDINE NUCLEOSIDES}

\author{
A dissertation submitted in partial fulfillment of \\ the requirements for the degree of \\ DOCTOR OF PHILOSOPHY \\ in \\ CHEMISTRY \\ by \\ Ramanjaneyulu Rayala
}

2015 
To: Dean Michael R. Heithaus

College of Arts and Sciences

This dissertation, written by Ramanjaneyulu Rayala, and entitled Design and Synthesis of Novel Nucleoside Analogues: Oxidative and Reductive Approaches toward Synthesis of 2'-Fluoro Pyrimidine Nucleosides, having been approved in respect to style and intellectual content, is referred to you for judgment.

We have read this dissertation and recommend that it be approved.

Kathleen S. Rein

David A. Becker

Anthony P. DeCaprio

Salvatore D. Lepore

Stanislaw F. Wnuk, Major Professor

Date of Defense: June 17, 2015

The dissertation of Ramanjaneyulu Rayala is approved.

Dean Michael R. Heithaus College of Arts and Sciences

Dean Lakshmi N. Reddi University Graduate School

Florida International University, 2015 


\section{DEDICATION}

This Ph.D. is dedicated to:

Padma Rayala, Nagaiah Rayala, Aneela Rayala, Yashitha Rayala, Radhika Mandapalli, Muralidhar Mandapalli, Rishitha Chowdary Mandapalli, and Srikarprasad Chowdary Mandapalli.

You have been a great inspiration. 


\section{ACKNOWLEDGMENTS}

I would like to thank my mentor Professor Stanislaw F. Wnuk for giving me the opportunity to work in his research group and for his constant support over the years. Also, I am really thankful to my dissertation committee members for their constructive criticism and guidance throughout my $\mathrm{PhD}$. I also want to thank senior group members Jean-Philippe Pitteloud, Adam Sobczak, and Aparna Malladi for their guidance during my initial days in the lab. I would like to give many special thanks to my friends at FIU Jesse Pulido, Jessica Zayas, Yong Liang, Mukesh Mudgal, Nagarju Birudukota, Cesar Gonzalez, and Sazzad Hossain for their support and tolerance, they have been an extended family to me. I would like to acknowledge my undergraduate students Patricia Theard, Brenna Walsh and Maria Barrios for assisting me during different stages of my dissertation.

I would like to express my sincere gratitude to the following people and institutions who supported me and provided me with guidance at various phases of my life: Ravi Convent, Ms. Mamatha, Naveen and all the wonderful people of Vuyyalawada, Dornakal; Mr. Venkateshwarlu, and other faculty and staff at Sri Vivekananda Vidyalayam, Dornakal; Faculty and staff at Spectra Junior College, Khammam; Faculty and staff at DRS Degree College, Khammam; Faculty and staff at PG College of Science, Saifabad; Faculty and staff at KLR Degree College, Palwancha; Mr. Harikrishna and Ms. Bhuwaneshwari, and other faculty and staff at VISU, Hyderabad; Mr. Verma and Ms. Padma at Periscope, Hyderabad; Seniors from my M.Sc., Ramesh, Raghu, and Satheesh; My friends Hareesh, Srikanth, Anil, Harish, Sudhakar, Vijay, Santosh, Surya, Alankar, Madhukar, and Chandu. 
I want to show my gratitude to the Department of Chemistry and Biochemistry at Florida International University for providing me with Teaching Assistantship for major part of my PhD. I would like to thank the University Graduate School for the Dissertation Year Fellowship Award which was immensely helpful during my last year as a graduate student. Last, but not the least, I would like to thank Florida International University and the United States of America. 


\section{ABSTRACT OF THE DISSERTATION \\ DESIGN AND SYNTHESIS OF NOVEL NUCLEOSIDE ANALOGUES: OXIDATIVE \\ AND REDUCTIVE APPROACHES TOWARD SYNTHESIS OF 2'-FLUORO \\ PYRIMIDINE NUCLEOSIDES \\ by}

Ramanjaneyulu Rayala

Florida International University, 2015

Miami, Florida

Professor Stanislaw F. Wnuk, Major Professor

Fluorinated nucleosides, especially the analogues with fluorine atom(s) in the ribose ring, have been known to exert potent biological activities. The first part of this dissertation was aimed at developing oxidative desulfurization-fluorination and reductive desulfonylation-fluorination methodologies toward the synthesis of 2'-mono and/or 2',2'difluoro pyrimidine nucleosides from the corresponding 2'-arylthiopyrimidine precursors. Novel oxidative desulfurization-difluorination methodology was developed for the synthesis of $\alpha, \alpha$-difluorinted esters from the corresponding $\alpha$-arylthio esters, wherein the arylthio group is present on a secondary internal carbon. For the reductive desulfonylation studies, cyclic voltammetry was utilized to measure the reduction potentials at which the sulfone moiety of substrates can be cleaved.

The 5-bromo pyrimidine nucleosides and 8-bromo purine nucleosides act as crucial intermediates in various synthetic transformations. The second part of the present dissertation was designed to develop a novel bromination methodology using 1,3dibromo-5,5-dimethylhydantoin $(\mathrm{DBH})$. Various protected and deprotected pyrimidine 
and purine nucleosides were converted to their respective $\mathrm{C} 5$ and $\mathrm{C} 8$ brominated counterparts using DBH. The effect of Lewis acids, solvents, and temperature on the efficiency of bromination was studied. Also, $N$-bromosuccinimide (NBS) or DBH offered a convenient access to 8-bromotoyocamycin and 8-bromosangivamycin.

Third part of this research work focuses on the design and synthesis of 6-Nbenzylated derivatives of 7-deazapurine nucleoside antibiotics, such as tubercidin, sangivamycin and toyocamycin. Target molecules were synthesized by two methods. First method involves treatment of 7-deazapurine substrates with benzylbromide followed by dimethylamine-promoted Dimroth rearrangement. The second method employs fluoro-diazotization followed by $\mathrm{S}_{\mathrm{N}} \mathrm{Ar}$ displacement of the 6-fluoro group by a benzylamine. The 6-N-benzylated 7-deazapurine nucleosides showed type-specific inhibition of cancer cell proliferation at micromolar concentrations and weak inhibition of human equilibrative nucleoside transport protein (hENT1).

In the fourth part of this dissertation, syntheses of $\mathrm{C} 7$ or $\mathrm{C} 8$ modified 7deazapurine nucleosides, which might exhibit fluorescent properties, were undertaken. 8Azidotoyocamycin was synthesized by treatment of 8-bromotoyocamycin with sodium azide. Strain promoted click chemistry of 8-azidotoyocamycin with cyclooctynes gave the corresponding 8-triazolyl derivatives. Alternatively, 7-benzotriazolyl tubercidin was synthesized by iodine catalyzed $\mathrm{CH}$ arylation of tubercidin with benzotriazole. 


\section{TABLE OF CONTENTS}

CHAPTER

PAGE

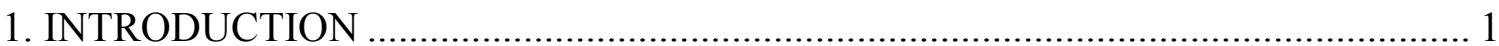

1.1. Notable nucleoside analogues with anticancer and antiviral activity ................. 2

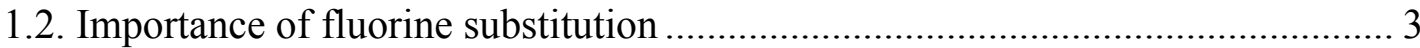

1.3. Prominent nucleoside analogues with fluorine atom in sugar moiety................. 4

1.4. Gemcitabine, a critical anticancer drug .......................................................... 5

1.4.1. Existing methods for the synthesis of gemcitabine ....................................... 5

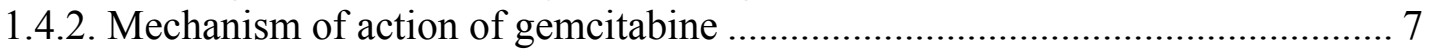

1.5. Short survey on desulfurization-fluorination reactions ................................ 10

1.6. 5-Bromopyrimidines and 8-bromopurines: Syntheses and importance ............. 12

1.6.1. 1,3-dibromo-5,5-dimethylhydantoin, an important brominating reagent........ 13

1.7. Selected aspects of the chemistry of 7-deazapurine nucleosides ...................... 14

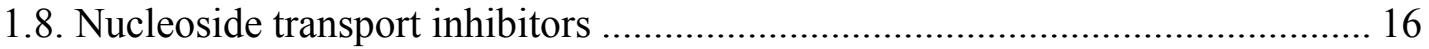

2. RESEARCH OBJECTIVES .......................................................................... 17

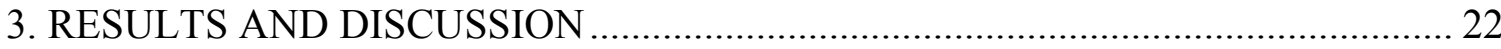

3.1. Bromination of nucleobases with 1,3-dibromo-5,5-dimethylhydantoin ........... 22

3.1.1 Bromination at $\mathrm{C} 5$ position of pyrimidine nucleosides with $\mathrm{DBH}$................. 22

3.1.2 Bromination at $\mathrm{C} 8$ position of purine nucleosides with $\mathrm{DBH}$........................ 28

3.1.3. Bromination at $\mathrm{C} 8$ position of 7-deazapurine nucleosides with NBS and

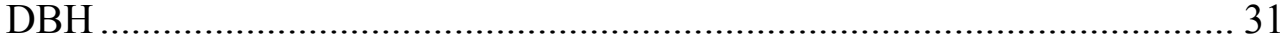

3.1.4. Plausible mechanism of bromination of nucleobases with $\mathrm{DBH}$.................... 33

3.2. Attempted synthesis of 2'-deoxy-2',2"-difluoropyrimidine nucleosides ............ 35

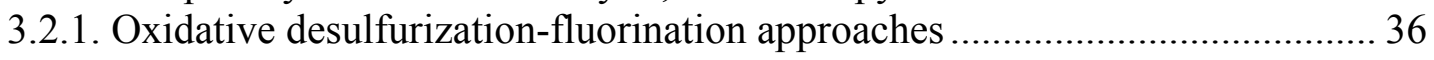

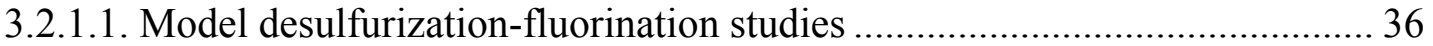

3.2.1.2. Oxidative desulfurization-fluorination approaches with uridine derivatives 43

3.2.2. Reductive desulfonylation-fluorination approaches................................. 47

3.2.2.1. Cyclic voltammetry studies of 2 -arylsulfonyl uridine derivatives .............. 48

3.2.2.2. Reductive desulfonylation-fluorination studies of 2'-deoxy-2'-arylsulfonyl uridine and 2'-deoxy-2'-fluoro-2'-arylsulfonyl uridine substrates............... 51

3.3. One electron oxidation of gemcitabine and analogues.................................... 59

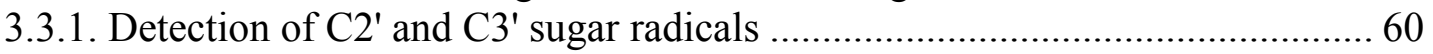

3.4. Synthesis and biological activity of 6- $N$-benzyl-7-deazapurine nucleoside

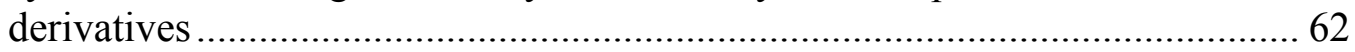

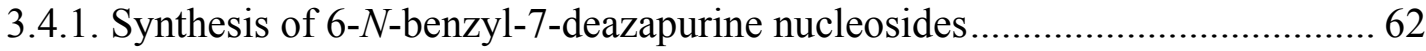

3.4.2. Biological activity of $6-N$-benzyl-7-deazapurine nucleoside derivatives ....... 68

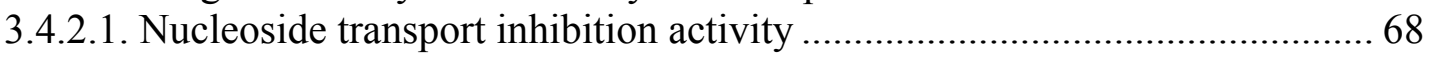

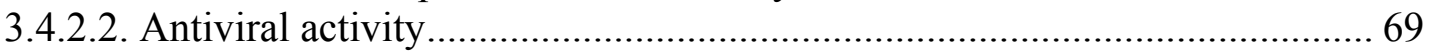

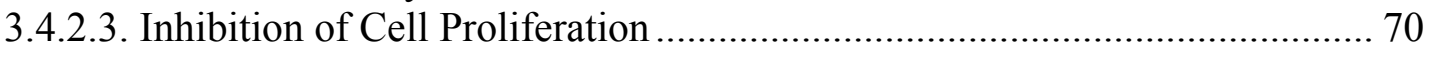

3.5. C7- and C8-modified-7-deazapurine nucleoside derivatives ......................... 71 
3.5.1. Strain promoted click reactions of 8-azido-7-deazanucleosides with cyclooctynes........................................................................................ 71

3.5.1. Attempted synthesis of 8-alkynyl-7-deazanucleosides via Sonagashira

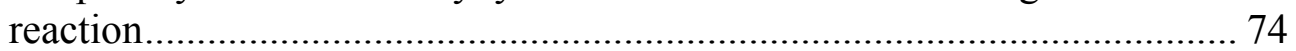

3.5.2. Iodine catalyzed direct $\mathrm{C}-\mathrm{H}$ activation of 7-deazapurine nucleosides ............ 79

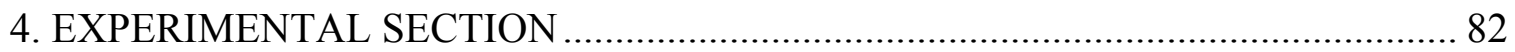

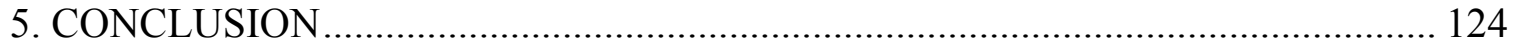

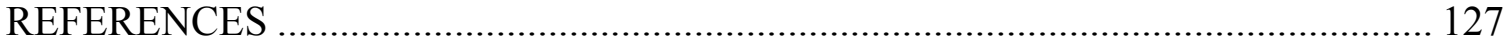




\section{LIST OF TABLES}

TABLE

PAGE

Table 1. FDA approved anticancer purine and pyrimidine nucleoside analogues. ........... 2

Table 2. Antiviral properties of purine and pyrimidine nucleoside analogues. ................. 3

Table 3. Effect of various reaction parameters on C5-bromination of 2',3',5'-tri-Oacetyluridine $45 \mathrm{a}$ with $\mathrm{DBH}^{\mathrm{a}}$

Table 4. Bromination at C5 position of the pyrimidine based nucleosides $45 \mathrm{a}-\mathrm{f}$ and $57-59^{a}$

Table 5. Bromination of selected purine nucleosides at ambient temperature (see Figure 11 for structures) $)^{\mathrm{a}}$

Table 6. Desulfurization-difluorination studies of $\alpha$-thioester derivatives with $\mathrm{DBH} / \mathrm{Py} .9 \mathrm{HF}^{a}$ 38

Table 7. Antiviral activity in human embryonic lung (HEL) cell cultures-part 1 .......... 69

Table 8. Antiviral activity human embryonic lung (HEL) cell cultures-part 2 .............. 70

Table 9. Inhibitory effects on the proliferation of cells in culture ................................ 71

Table 10. Reaction conditions for the attempted Sonagashira cross-coupling reactions on 8-bromo tubercidin and toyocamycin ${ }^{\mathrm{a}}$ 


\section{LIST OF FIGURES}

FIGURE

PAGE

Figure 1. Structures of RNA and DNA nucleosides 1

Figure 2. Examples of the prominent nucleoside drugs with fluorine modifications in sugar moieties. 4

Figure 3. Original synthesis of gemcitabine developed by Hertel. 5

Figure 4. Synthesis of 2'-difluorocytidine derivatives from 2'-keto derivatives by deoxyfluorination.

Figure 5. Synthesis of 2'-deoxy-2'-2'-difluorouridine derivative by desulfurizationdifluorination of the corrssponding $2^{\prime}$-dithioketal derivative 7

Figure 6. Gemcitabine cellular metabolism........................................................ 9

Figure 7. Mechanism for the covalent inhibition of RNR by dFdCDP in the absence and in the presence of reductant, proposed by Prof. Stubbe, et al. 10

Figure 8. Structures of DBH and NBS. 14

Figure 9. Structures of 7-deazapurine nucleosides 14

Figure 10. Important base-modified 7-deazapurine nucleoside derivatives. 15

Figure 11. Structures of Important nucleoside transport inhibitors. 17

Figure 12. Different classes of 2'-arylthionucleosides for oxidative desulfurizationfluorination and reductive desulfonylation-fluorination procedures. 18

Figure 13. Various aryl-alkyl thioether substrates for model oxidative desulfurizationdifluorination reactions

Figure 14. Gemcitabine and its analogues for one electron oxidation studies. 20

Figure 15. Structures of 7-deazapurine antibiotics and the proposed 6-N-benzyl analogues.

Figure 16. Structures of various 8-modified-7-deazapurine derivatives

Figure 17. Selected pyrimidine nucleoside precursors (series a) and their brominated products (series b). 28

Figure 18. Selected purine nucleoside precursors (series a) and their brominated products (series b). 
Figure 19. General scheme for the proposed C2'-quarternization of 2'-arylthiouridine

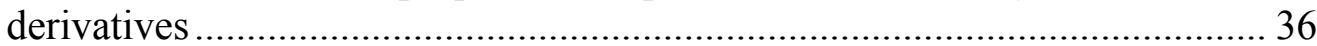

Figure 20. $\alpha$-Thioaldehyde, $\alpha$-thioketone and $\alpha$-thioalkane substrates for attempted desulfurization-(di)fluorination reactions.

Figure 21. Products for attempted fluorination of 2'-S-(4-chlorophenyl)-2'-thiouridine derivatives $89 \mathrm{a}$ and $89 \mathrm{~b}$

Figure 22. Cyclic voltammetry of $\alpha$-sulfones $92 \mathrm{a}(C=2.25 \mathrm{mM}$, blue curve $)$ and $92 \mathrm{~b}$ $(C=2.75 \mathrm{mM}$, pink curve $)$; in $\mathrm{DMF}+n-\mathrm{Bu}_{4} \mathrm{NPF}_{6} 0.1 \mathrm{M} ; \mathrm{v}=0.2 \mathrm{~V} / \mathrm{s} \ldots \ldots \ldots . . .49$

Figure 23. Cyclic voltammetry of $\alpha$-fluorosulfones $95 \mathrm{a}(2.64 \mathrm{mM})$ and $95 \mathrm{~b}(2.91 \mathrm{mM}) 50$

Figure 24. Structures of organic electron donors used for the reductive desulfonylation. 53

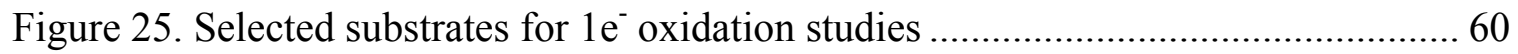




\section{LIST OF SCHEMES}

SCHEME

PAGE

Scheme 1. Oxidative desulfurization-difluorination of aldehyde, ketone dithiolanes; and alkyl aryl thioethers. 11

Scheme 2. Hara's oxidative desulfurization-difluorination of benzylic sulfides. 12

Scheme 3. Synthesis of 4- $N$-methyltubercidin by Dimroth-rearrangement approach ...... 16

Scheme 4. Bromination of uracil-derived nucleosides 1 with 1,3-dibromo-5,5dimethylhydantoin (DBH). See Table 3 and 4 for specific reaction parameters. 23

Scheme 5. Synthesis of 8-bromo-7-deazanucleosides. Reagents and conditions: d) NBS (1.1-1.5 eq), DMF, rt, 1-2.5 h; e) DBH (0.75-1.1 eq), $\mathrm{MeOH}$, rt, 30-45 min. 32

Scheme 6. Plausible mechanism of C-5 bromination of pyrimidine nucleosides by $\mathrm{DBH}$. 33

Scheme 7. Plausible mechanism of C-8 bromination of purine nucleosides by DBH. .... 34

Scheme 8. Plausible mechanism of TMSOTf enhanced DBH bromination. 35

Scheme 9. General scheme for Haufe's desulfurization-difluorination of aryl-alkyl thioethers. 36

Scheme 10. Desulfurization-difluorination of $\alpha$-thioesters. 37

Scheme 11. Proposed mechanism for the oxidative desulfurization-difluorination of alkyl-aryl thioethers by DBH/Py.9HF.

Scheme 12. Attempted synthesis of $\alpha, \alpha$-difluoro- $\delta$-valerolactone 82 .

Scheme 13. Attempted synthesis of $\alpha, \alpha$-difluoro- $\gamma$-butyrolactone 86.

Scheme 14. Synthesis of 2'-arylthio substrates for the desulfurization-fluorination reactions.

Scheme 15. Oxidative desulfurization-difluorination of 2'-S-aryl-2'-thiouridine analogue 89a. Conditions $A$ : DBH (1.1 eq), Py.9HF (excess), $\mathrm{CH}_{2} \mathrm{Cl}_{2}$, $-78{ }^{\circ} \mathrm{C}, 2 \mathrm{~h}$; Conditions $B$ : NIS (3 eq), DAST (6 eq), $\mathrm{CH}_{2} \mathrm{Cl}_{2}, 0{ }^{\circ} \mathrm{C}(6 \mathrm{~h})$, then rt (32 h); Conditions $C$ : NIS (3 eq), DAST (6 eq), $\mathrm{CH}_{2} \mathrm{Cl}_{2}, 35^{\circ} \mathrm{C}$, $24 \mathrm{~h}$. 
Scheme 16. Attempted oxidative desulfurization-fluorination of 2 '-S-(4-methoxyphenyl)-2'-thiouridine analogue 90b. Conditions $A$ : NIS (2.1 eq), Py.9HF (3 eq); Conditions $B$ : NIS (2.1 eq), DAST (6 eq)..... 47

Scheme 17. Attempted oxidative desulfurization-fluorination of 2'-fluoro-2'-S-(4methoxyphenyl)-2'-thiouridine analogue $94 \mathrm{~b}$ with $\mathrm{DBH} / \mathrm{Py} .9 \mathrm{HF}$.

Scheme 18. Stability studies of sulfones $91 \mathrm{a}-\mathrm{b}$ on silica gel chromatography or with treatment of base.

Scheme 19. Reduction studies of acetyl protected sulfone substrates 91a with TDAE and Murphy's SED.

Scheme 20. Reduction studies of benzyl protected sulfone substrate $91 \mathrm{~b}$ with Murphy's SED.

Scheme 21. Stability studies of acetyl protected $\alpha$-fluorosulfone 95a with Murphy's SED. 56

Scheme 22. Stability studies of benzyl protected $\alpha$-fluorosulfones $95 \mathrm{~b}$ with Murphy's SED 57

Scheme 23. Attempted synthesis of 2'-2"-difluorouridine by reductive desulfonylationfluorination of 2'-arylsulfonyl-2'-deoxy-2'-fluorouridine 95a with TDAE/Selectrfluor 58

Scheme 24. Reductive-desulfonylation/methylation of 2'-arylsulfonyl-2'-deoxy-2'fluorouridine 95a with TDAE/MeI.

Scheme 25. One elctron oxidation of 2'-deoxy-2'-fluorocytidine 61

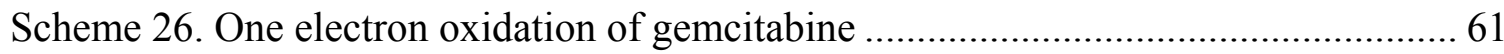

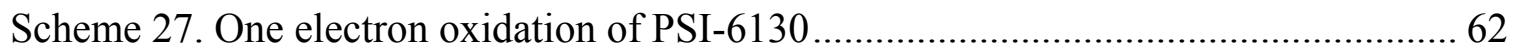

Scheme 28. General mechanism of Dimroth rearrangement on Adenosine ${ }^{183,184}$............ 63

Scheme 29. Synthesis of 4- $N$-benzylated tubercidin and sangivamycin by Dimroth rearrangement approach.

Scheme 30. Synthesis of 4- $N$-(4-nitrobenzyl)toyocamycin by direct alkylation. 65

Scheme 31. Synthesis of 2',3',5'-tri- $O$-acetyl-4-fluorotubercidin (124) by diazotivefluorodeamination.

Scheme 32. Synthesis of 4- $N$-(4-nitrobenzyl)tubercidin (122b) from 2',3',5'-tri- $O$-acetyl-4-fluorotubercidin (124). 
Scheme 33. Synthesis of 8-bromo-7-deazaadenosine and 8-azidotoyocamycin derivatives.

Scheme 34. Click reaction between 8-azidotoyocamycin and cyclooctynes 130 and 131. Reagents and conditions: g) Cyclooctyne 130 or 131 (1 eq), $\mathrm{ACN}: \mathrm{H}_{2} \mathrm{O}(3: 1), \mathrm{rt}, 4 \mathrm{~h}$.

Scheme 35. Proposed scheme for the synthesis and subsequent transformations of 8 alkynyl-7-deazapurine nucleoside analogues 135

Scheme 36. Attempted synthesis of 8-alkynyltoyocamycin derivative 140 via sonagashira coupling. 78

Scheme 37. Attempted synthesis of 8-alkynyltoyocamycin derivative 143 via sonagashira coupling.

Scheme 38. Iodine catalyzed oxidative cross-coupling of Indoles and Azoles.

Scheme 39. Iodine catalyzed oxidative cross-coupling of tubercidin and benzotrizole... 80

Scheme 40. Iodine catalyzed oxidative cross-coupling of acetylated tubercidin and benzotriazole

Scheme 41. Attempted synthesis of iodine catalyzed oxidative cross-coupling of sangivamycin or toyocamycin and benzotriazole. 82 


\section{LIST OF ABBREVIATIONS}

$\begin{array}{ll}\text { Ac } & \text { acetyl } \\ \text { Ar } & \text { aromatic (NMR) } \\ \beta & \text { beta } \\ \text { Bn } & \text { benzyl } \\ \text { br } & \text { broad (NMR) } \\ t \text {-But } & \text { tert-butyl } \\ \text { calcd } & \text { calculated (MS or HRMS) } \\ \text { CDA } & \text { cytidine deaminase } \\ { }^{\circ} \text { C } & \text { degrees Celsius } \\ \delta & \text { delta } \\ \text { d } & \text { doublet (NMR) or deuterium (in DMSO- } d_{6} \text { ) } \\ \text { DAST } & \text { diethylaminosulfur trifluoride } \\ \text { dCK } & \text { deoxycytidine kinase } \\ \text { DCM } & \text { dichloromethane } \\ \text { DCTD } & \text { deoxycytidylate deaminase } \\ \text { dFdC } & \text { 2',2'-difluoro-2'-deoxycytidine } \\ \text { dFdCMP } & \text { 2',2'-difluoro-2'-deoxycytidine monophosphate } \\ \text { dFdCDP } & \text { dimethylsulfifluoro-2'-deoxycytidine diphosphate } \\ \text { dFdCTP } & \text { DMAP }\end{array}$




\begin{tabular}{|c|c|}
\hline DNA & deoxyribonucleic acid \\
\hline dUMP & deoxyuridine monophosphate \\
\hline$\varepsilon$ & epsilon \\
\hline ESI & electrospray ionization \\
\hline Et & ethyl \\
\hline $\mathrm{FdC}$ & 2'-fluoro-2'-deoxycytidine \\
\hline $\mathrm{g}$ & $\operatorname{gram}(\mathrm{s})$ \\
\hline h or hr or hrs & hour(s) \\
\hline $\mathrm{Hz}$ & hertz \\
\hline hCNT & human concentrative nucleoside transporter \\
\hline hENT & human equilibrative nucleoside transporter \\
\hline HPLC & high performance liquid chromatography \\
\hline HRMS & high resolution mass spectroscopy \\
\hline $\mathrm{IC}_{50}$ & half maximal inhibitory concentration \\
\hline$J$ & coupling constant in $\mathrm{Hz}$ (NMR) \\
\hline$\lambda$ & lambda \\
\hline $\mathrm{L}$ & liter(s) \\
\hline LDA & lithium diisopropylamide \\
\hline $\mathrm{m}$ & milli; multiplet (NMR) \\
\hline$\mu$ & micro \\
\hline M & moles per liter \\
\hline $\mathrm{MeFdC}$ & 2'-deoxy-2'-fluoro-2'-C-methylcytidine \\
\hline $\min$ & minute(s) \\
\hline
\end{tabular}




\begin{tabular}{|c|c|}
\hline mol & mole(s) \\
\hline MS & mass spectrometry \\
\hline$m / z$ & mass to charge ratio (MS) \\
\hline NMR & nuclear magnetic resonance \\
\hline $\mathrm{nM}$ & nano Molar \\
\hline$p$ & para \\
\hline PET & Positron Emission Tomography \\
\hline pyr & pyridine \\
\hline$\%$ & percentage \\
\hline q & quartet (NMR) \\
\hline quin & quintet (NMR) \\
\hline RNA & ribonucleic acid \\
\hline RNR & Ribonucleotide reductase \\
\hline $\mathrm{rt}$ & room temperature \\
\hline $\mathrm{RP}$ & reverse phase (HPLC) \\
\hline $\mathrm{S}$ & second(s); singlet (NMR) \\
\hline SET & single electron transfer \\
\hline $\mathrm{t}$ & triplet (NMR) \\
\hline TBDMS & tert-butyldimethylsilyl \\
\hline TBDPS & tert-butyldiphenylsilyl \\
\hline TBAF & tetra-n-butylammonium fluoride \\
\hline TBHP & tert-butyl hydroperoxide \\
\hline TEA & triethylamine \\
\hline
\end{tabular}


THF

TLC

TMS

$t_{R}$

Tris

UV

VIS

vs tetrahydrofuran

thin layer chromatography

trimethylsilyl

retention time (HPLC)

tris(hydroxymethyl)aminomethane

ultraviolet

visible

versus 


\section{INTRODUCTION}

In 1909, the term "nucleoside" was proposed by Levene and Jacobs to describe carbohydrate derivatives of purines and pyrimidines. ${ }^{1}$ Nucleosides, held together by phosphodiester linkages, are the core components of the biopolymers DNA and RNA. Nucleosides are composed of a furanose sugar moiety, linked to either a purine or a pyrimidine heterocyclic base via a beta-glycosidic bond. The four nucleosides prevailing in RNA are adenosine, guanosine, cytosine and uridine. Whereas, 2'-deoxyadenosine, 2'deoxyguanosine, 2'-deoxycytidine and thymidine form the core part in DNA (see Figure 1 for structures of RNA and DNA nucleosides). Development of drug therapy progressed rapidly after the discovery of DNA as the primary genetic material in $1944^{2}$ and subsequent elucidation of its physical structure in $1953 .{ }^{3}$ Since then, DNA and RNA have been regarded as potential targets for drug design, as they play vital role in many biological processes. Since nucleosides form the major part of DNA and RNA, nucleosides have also been considered prospective targets.
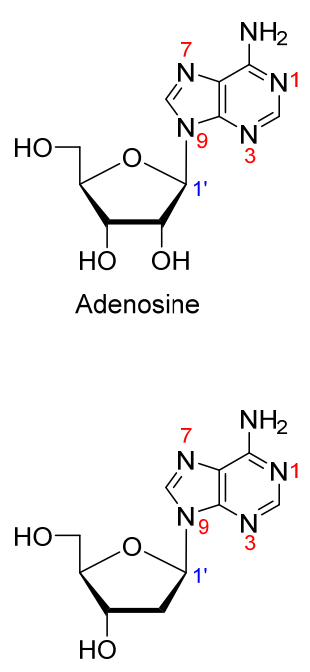

2'-Deoxyadenosine
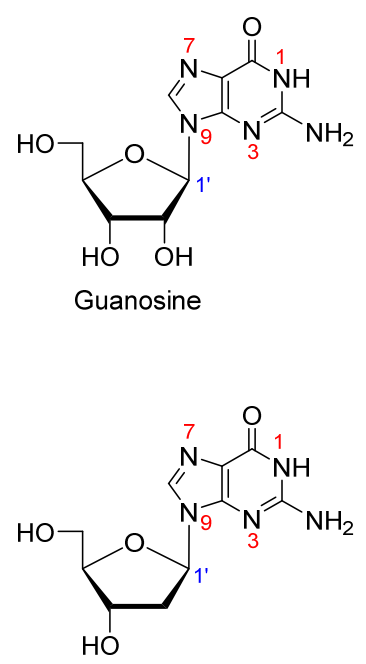

2'-Deoxyguanosine
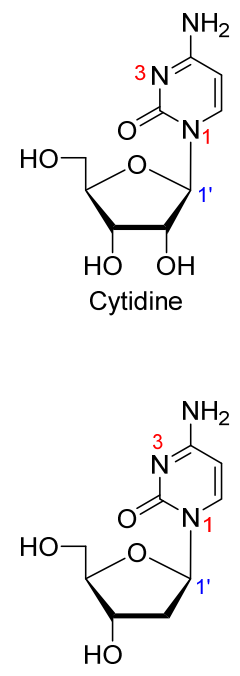

2'-Deoxycytidine
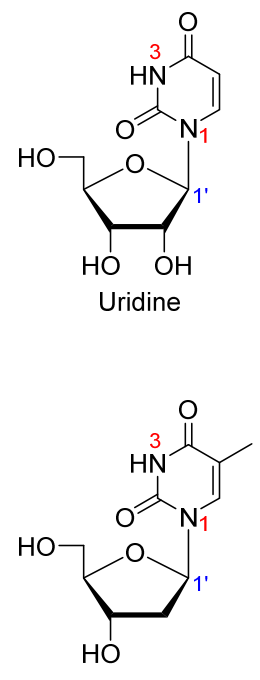

Thymidine

Figure 1. Structures of RNA and DNA nucleosides ${ }^{3}$ 


\subsection{Notable nucleoside analogues with anticancer and antiviral activity}

Pyrimidine nucleoside analogues such as 5-fluoro-2'-deoxyuridine (Floxuridine), 1-( $\beta$-D-arabinofuranosyl)cytosine $(\operatorname{araC})$ were among the initial nucleoside analogues approved by U.S. Food and Drug Administration (FDA) for cancer treatment (Table 1). Remarkable biological activity resulting from slight structural modifications to the normal nucleosides prompted various scientists all over the world to develop modified nucleoside analogues as anticancer agents. Currently, there are 11 nucleoside based drugs approved by FDA for the treatment of cancer.

Table 1. FDA approved anticancer purine and pyrimidine nucleoside analogues. ${ }^{4}$

\begin{tabular}{lll}
\hline \multicolumn{1}{c}{ Drug } & \multicolumn{1}{c}{ Category } & Year \\
\hline 5-aza-2'-deoxycytidine (Decitabine) & \multicolumn{1}{c}{ 2'-Deoxycytidine } & 2006 \\
O'-methylarabinofuranosyl guanine (Nelarabine) & Guanosine & 2005 \\
5-aza-cytidine (Vidaza) & 2'-Deoxyadenosine & 2004 \\
2'-fluoro-2'-deoxyarabinofuranosyl-2-chloroadenine (Clofarabine) & Cytidine & 2004 \\
N4-pentyloxycarbonyl-5'-deoxy-5-fluorocytidine (Capecitabine) & Cytidine & 1998 \\
2,2-difluoro-2'-deoxycytidine (Gemcitabine) & 2'-Deoxycytidine & 1996 \\
2-chloro-2'-deoxyadenosine (Cladribine) & 2'-Deoxyadenosine & 1992 \\
2'-deoxycoformycin (Pentostatin) & Adenosine & 1991 \\
Arabinofuranosyl-2-fluoroadenine (Fludarabine) & Purine analogue & 1991 \\
5-fluoro-2'-deoxyuridine (Floxuridine) & 2'-Deoxyuridine & 1970 \\
Arabinofuranosylcytosine (Cytarabine) & Cytidine & 1969 \\
6-thioguanine (Lanvis) & Guanine & 1966 \\
5-fluorouracil (Adrucil) & Uracil & 1962 \\
6-mercaptopurine (Purinethol) & Purine & 1953 \\
& & \\
\hline
\end{tabular}

Parallel to the anticancer drugs, researchers also developed various nucleoside analogues with antiviral properties. The sounding success of prominent antiviral drugs such as Acyclovir (anti-HSV), and Zidovudine (anti-HIV) revealed the potential value of 
modified nucleoside analogues as antiviral agents (Table 2). There are currently 13 FDA approved nucleoside based drugs used in the treatment of various viruses. Most recent of them being Sofosbuvir, an anti-HCV drug, which is considered to be a huge step forward in $\mathrm{HCV}$ treatment. ${ }^{5,6}$

Table 2. Antiviral properties of purine and pyrimidine nucleoside analogues. ${ }^{4}$

\begin{tabular}{lll}
\hline \multicolumn{1}{c}{ Drug } & Category & Year \\
\hline 2'-deoxy-2'-fluoro-2'-methyluridine-5'-phosphate (Sofosbuvir) & Uridine & 2013 \\
Tenofovir disoproxil fumarate, mixture of purine analogues (Tenofovir) & Purine & 2008 \\
1-2-deoxy- $\beta$-L-erythro-pentofuranosylthymine (Telbivudine) & Thymidine & 2006 \\
5-fluoro-1-(2R,5S)-[2-(hydroxymethyl)-1,3-oxathiolan-5-yl]cytosine (Emtricitabine) & Cytidine & 2003 \\
2',3'-didehydro-2',3'-dideoxythymidine (Stavudine) & Thymidine & 2001 \\
2',3'-dideoxy-3'-thiacytidine (Lamivudine) & Cytidine & 1998 \\
2',3'-didehydro-2',3'-dideoxythymidine (Stavudine) & Thymidine & 1994 \\
3'-azido-3'-deoxythymidine (Zidovudine) & Thymidine & 1987 \\
2-amino-1,9-dihydro-9-[(2-hydroxyethoxy)methyl]-6H-purin-6-one (Acyclovir) & Guanosine & 1982 \\
(E)-5-(2-bromovinyl)-2'-deoxyuridine (Brivudine) & Uridine & 1980 \\
9- $\beta$-D-arabinofuranosyladenine (Vidarabine) & Adenosine & 1976 \\
5-ethyl-2'-deoxyuridine (Edoxudine) & Thymidine & 1969 \\
5-iodo-2'-deoxyuridine (Idoxuridine) & Uridine & 1962 \\
\hline
\end{tabular}

\subsection{Importance of fluorine substitution}

Fluoro organic compounds have been known to possess a wide variety of biological activity and several of them are used as drugs for the treatment of various types of diseases. ${ }^{7,8}$ Introduction of fluorine atom(s) into the organic molecules dramatically changes their electronic and steric properties, which often leads to the molecules rendering potent biological activities. ${ }^{9,10}$ Though a fluorine atom is close in size to a hydrogen atom, presence of fluorine causes various electronic changes because of its electronegativity. Moreover, fluorine atoms can also act as hydrogen bond 
acceptors. Also, a fluorine atom can serve as a replacement for hydrogen, since the Van der Waals radius of fluorine (1.35 $⿱$ ) is so close to that of a hydrogen atom (1.1 $⿱$ ). . The C-F bond strength $(484 \mathrm{~kJ} / \mathrm{mol})$ is also greater than that of a C-H bond $(411 \mathrm{~kJ} / \mathrm{mol})$, offering a measure of increased biological and chemical stability to the structure.

\subsection{Prominent nucleoside analogues with fluorine atom in sugar moiety}

Of the variety of nucleoside analogues with biological activity, the class of fluoro nucleosides is known to possess a wide range of medicinal and biological activity. ${ }^{11}$ Prominent examples of fluorinated nucleoside analogues include: 2'-deoxy-2',2'difluorocytidine $(\mathbf{1} \text {, Gemcitabine })^{12,13}$ the phospharamidate analogue of 2'-deoxy-2'fluoro-2'- $C$-methyluridine $\quad(2, \quad$ Sofosbuvir $) \quad$ and $\quad$ 2-chloro-1-(2'-deoxy-2'fluoroarabinofuranosyl)uracil (3, Clofarabine) ${ }^{14,15}$ (Figure 2). Gemcitabine (1) and Clofarabine (3) are potent anti-cancer drugs that are commonly used in the treatment of various types of cancers. ${ }^{13,16}$ Sofosbuvir (3) acts as potent inhibitor of Hepatitis C virus replication. ${ }^{5,6}$
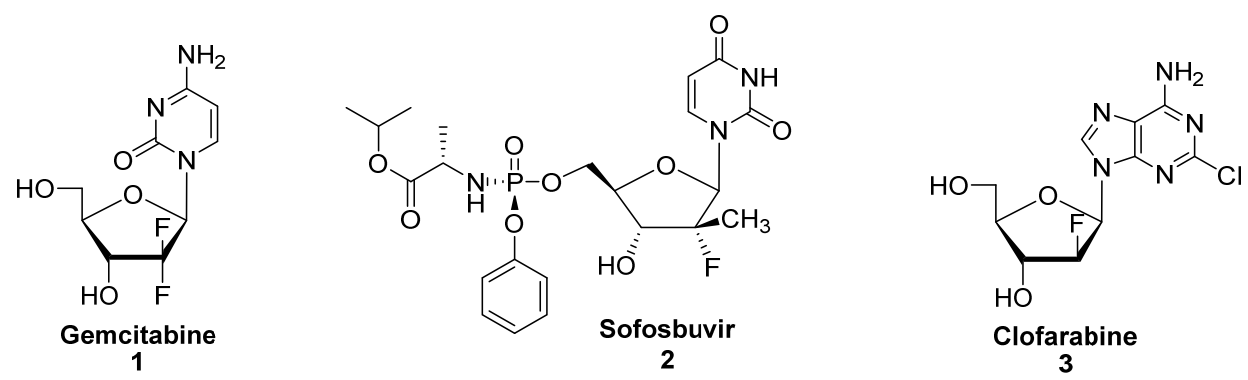

Figure 2. Examples of the prominent nucleoside drugs with fluorine modifications in sugar moieties. 


\subsection{Gemcitabine, a critical anticancer drug}

Gemcitabine is a nucleoside analog that has been used as a chemotherapeutic agent for last two decades. Gemcitabine is approved in the treatment of various types of cancers including pancreatic, breast, ovarian, and non-small cell lung cancer. ${ }^{13,16-20}$

\subsubsection{Existing methods for the synthesis of gemcitabine}

Gemcitabine was first synthesized by Hertel and co-workers in $1988 .^{12}$ Their method used ethyl bromodifluoro acetate and $(R)$-2,3-O-isopropylidene glyceraldehyde as the precursors for the construction of ribose sugar with two fluorine atoms at the 2position (Figure 3). Coupling of the latter to the heterocyclic base and subsequent deprotection gives 1. As shown in Figure 2, their approach suffers from two stereoselective setbacks: one being the Reformatsky reaction (the desired product is generated in $65 \%$ and required separation from the threo byproduct) and the other being the coupling of the sugar derivative to pyrimidine base (the desired $\beta$ anomer is generated in $10 \%)$.
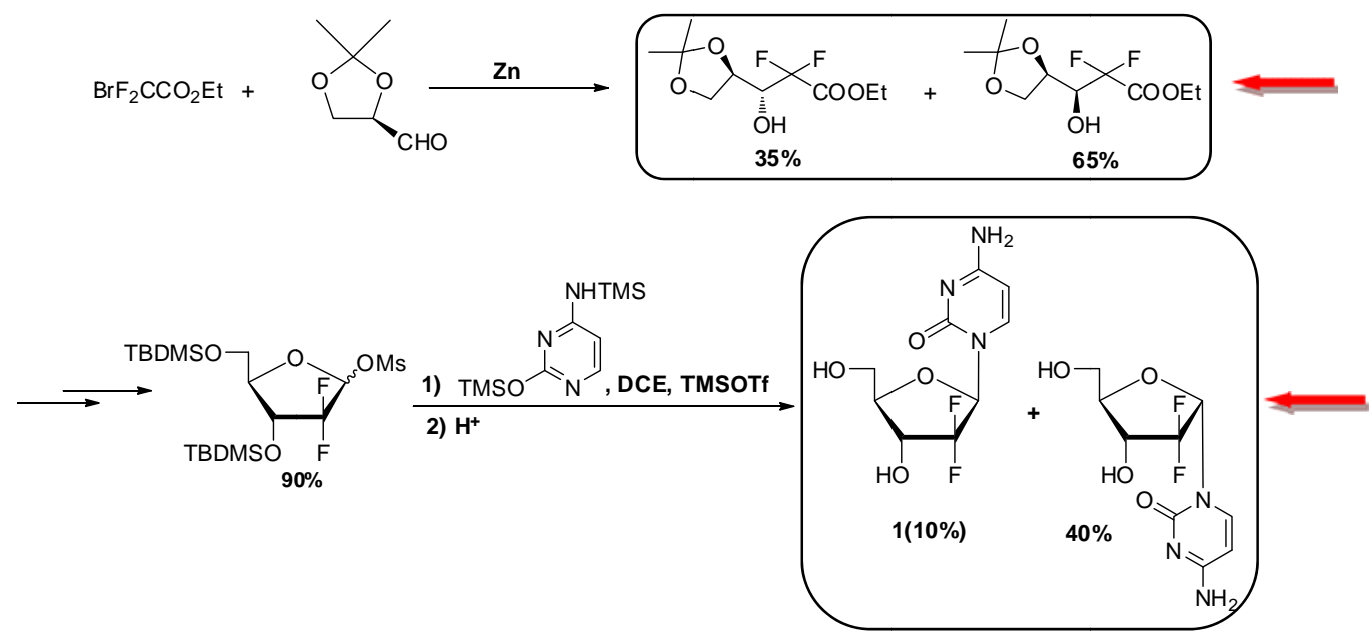

Figure 3. Original synthesis of gemcitabine developed by Hertel. ${ }^{12}$ 
Over the last 25 years, several research groups have published improved methods for the synthesis of gemcitabine. Some of these synthetic approaches followed Hertel's original approach and differ mainly in employing either different protecting groups on the ribose or different coupling conditions to improve stereoselectivity/isomer-separation. Additionally gemcitabine was also synthesized from various furanose and pyranose derivatives. The synthesis of gemcitabine has been subject to an excellent review published recently. ${ }^{21}$

Even though the synthesis of gemcitabine is widely studied from the stand point of sugar-base coupling, much less attention has been paid toward the synthesis from parent nucleosides. To our knowledge, only three literature examples have described the synthesis of gemcitabine via direct carbohydrate fluorination of the parent nucleoside derivatives.

A 1996 patent from Eli Lily reported the synthesis of 2'-deoxy-2',2'difluorocytidine derivative 6 by treating the corresponding 2'-keto cytidine derivative 5 with DAST and Pyr.HF reagent combination (Figure 4). Whereas a more recent Chinese patent (2013) described the similar transformation with the new deoxyfluorinating agents Xtalfluor-M and Xtalfluor-E.

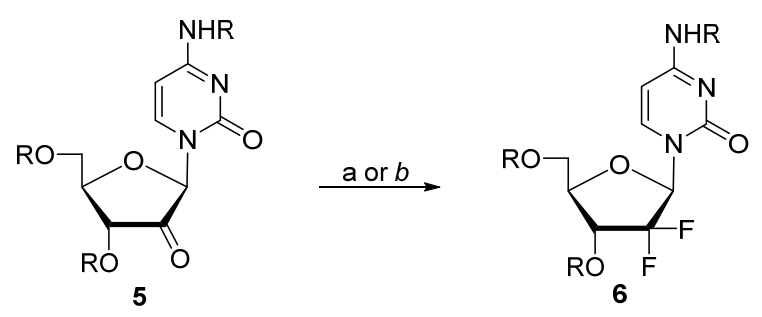

a: DAST, Py.HF, R = Ac; b = Xtalfluor (M/E), Et $\left.t_{3} N \cdot 3 H F, R=B z\right)$

Figure 4. Synthesis of 2'-difluorocytidine derivatives from 2'-keto derivatives by deoxyfluorination 
Synthesis of difluorouridine derivative $\mathbf{1 0}$ by desulfurization-difluorination of the corresponding dithiouridine derivative 9 with $\mathrm{DBH} / \mathrm{Py} .9 \mathrm{HF}$ reagent combination was reported in a 2007 patent (Figure 5). However, the crucial uridine-2'-dithioketal precursor 9, was prepared by coupling the uracil base with the pre-constructed dithioacetal ribose derivative $\mathbf{8}$, which in turn was prepared from the open chain ribonolactone derivative $7 .^{22}$

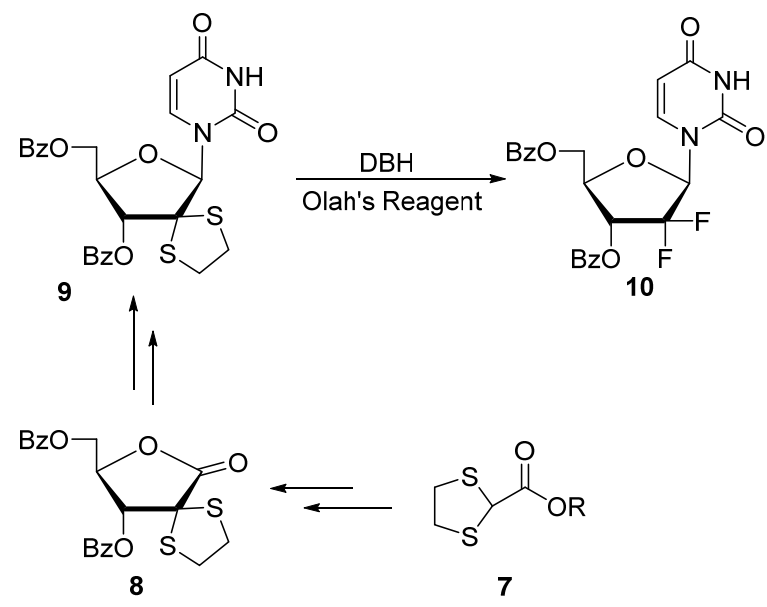

Figure 5. Synthesis of $2^{\prime}$-deoxy-2'-2'-difluorouridine derivative by desulfurizationdifluorination of the corrssponding 2 '-dithioketal derivative

\subsubsection{Mechanism of action of gemcitabine}

The mechanism of action of gemcitabine has been widely studied ${ }^{13,16-20}$ and is only discussed briefly here. Gemcitabine $(\mathrm{dFdC})$ is a prodrug and must be metabolized to the active triphosphate form $2^{\prime}, 2^{\prime}$-difluoro-2'-deoxycytidine triphosphate (dFdCTP) to exert biological activity (Figure 6). Human nucleoside transporters (hNTs), an important class of membrane proteins, mediate the cellular uptake of gemcitabine. Gemcitabine is converted into its monophosphate (dFdCMP) by deoxycytidine kinase (dCK); to its diphosphate (dFdCDP) by pyrimidine nucleoside monophosphate kinase (UMP-CMP kinase); and subsequently to the active metabolite triphosphate by nucleoside diphosphate 
kinase. Gemcitabine may become inactivated through deamination by cytidine deaminase (CDA) and, when in the monophosphate form by deoxycytidylate deaminase (dCTD). The product of gemcitabine deamination by $\mathrm{CDA}$ is $2^{\prime}, 2^{\prime}$-difluoro- $2^{\prime}$-deoxyuridine (dFdU), which is cytotoxic itself. Also, dFdU monophosphate (dFdUMP) could inhibit the activity of thymidylate synthase, directly effecting the deoxynucleotide triphosphate (dNTP) pool. Gemcitabine can also become inactivated by dephosphorylation of the monophosphate form by $5^{\prime}$-nucleotidases $\left(5^{\prime}\right.$-NTs), converting nucleotides back to nucleosides. These enzymes play a critical role in the balance of dNTP pools and, therefore, in gemcitabine metabolism. In this way, the rate-limiting step of phosphorylation by $\mathrm{dCK}$ may be also be affected, compromising the overall beneficial cytotoxicity of gemcitabine.

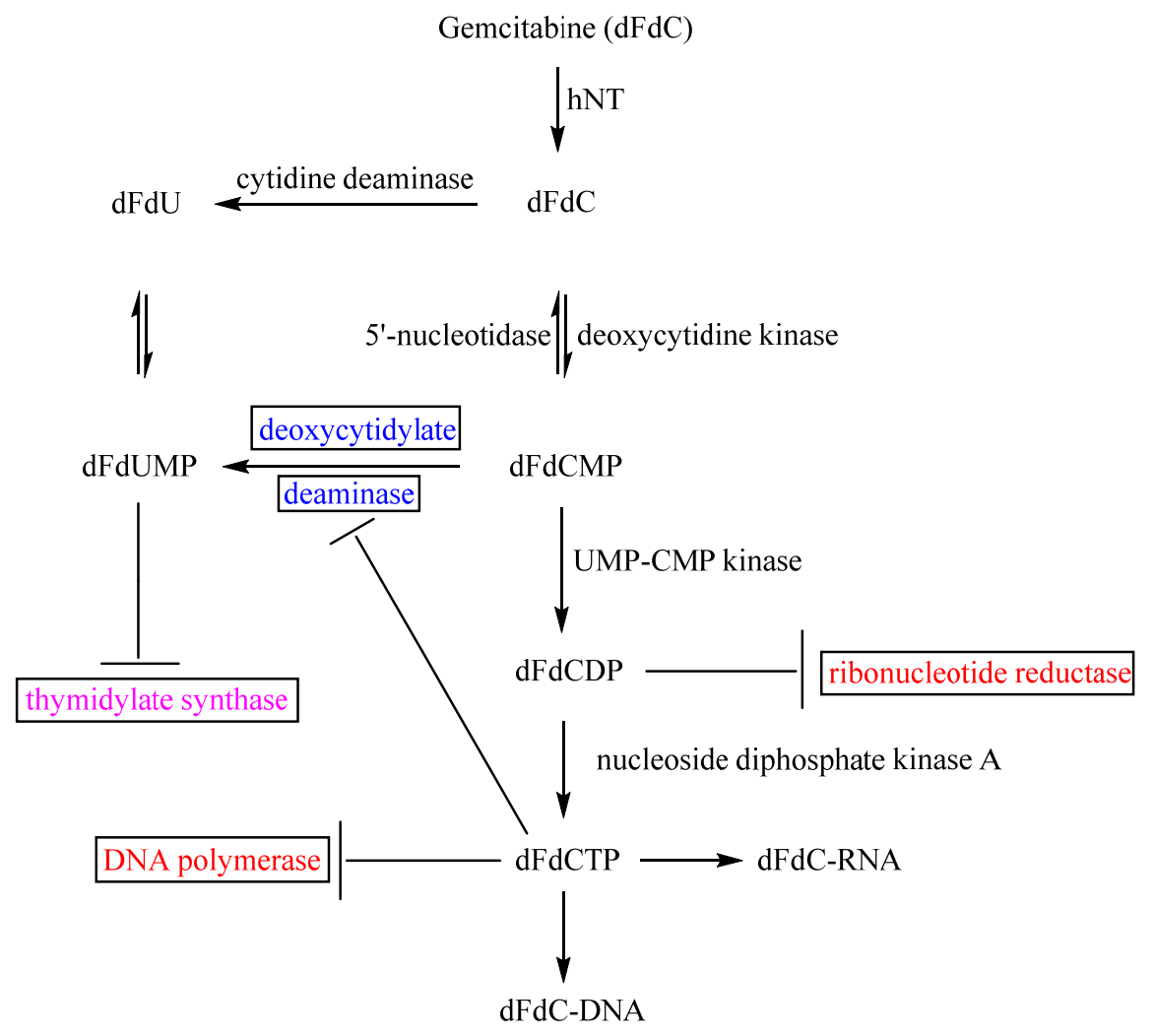


Figure 6. Gemcitabine cellular metabolism. ${ }^{18}$

hNT: human nucleoside transporter; dFdCMP: gemcitabine monophosphate; dFdCDP: gemcitabine diphosphate; dFdCTP: gemcitabine triphosphate; dFdU: 2',2'-difluoro-2'deoxyuridine, dFdUMP: 2',2'-difluoro-2'-deoxyuridine monophosphate.

The most important mechanism of action of gemcitabine is inhibition of DNA synthesis. When dFdCTP is incorporated into DNA, a single deoxynucleotide is incorporated afterwards, and stops chain elongation. The non-terminal position of gemcitabine makes DNA polymerases unable to proceed, as well as inhibits removal of gemcitabine by exonucleases.

An additional mechanism of action of gemcitabine is inhibition of deoxycytidylate deaminase (dCTD), by $\mathrm{dFdCTP}$ and indirectly by $\mathrm{dFdCDP}{ }^{23,24}$ By covalently binding to the active site, dFdCDP inhibits Ribonucleotide reductase (RNR), which catalyzes the reduction of ribonucleotides to deoxyribonucleotides. ${ }^{25-31}$ The covalent inhibition of RNR causes decrease in the dNTP pool and consequently reduces dCTD activity. ${ }^{32,33}$ In addition, decrease in the dNTP pool stimulates $\mathrm{dFdC}$ phosphorylation, thereby increasing the level of dFdCTP, making dFdCTP more likely to be incorporated into DNA competing with the NTPs. ${ }^{25,27}$ In addition, another important mechanism of gemcitabine is the induction of apoptosis through caspase signaling. In response to cellular stress, Gemcitabine activates p38 mitogen-activated protein kinase (MAPK) to trigger apoptosis in tumour cells, but not in normal cells.

The widely accepted mechanism of covalent inhibition of RNR by dFCDP in the presence and absence of reductant is shown in Figure- $7 .{ }^{31}$ Crucial steps in RNR mechanism include generation of tyrosine (Y122) radical from R2 subunit of RNR, abstraction of a hydrogen radical from Cysteine (C439) in R1 subunit of RNR by Y122 
radical to produce $\mathbf{A}$, subsequent abstraction of $\mathrm{H} 3$ ' by $\mathrm{C} 439$ radical to produce the crucial C3'-centered radical B (first two steps are not shown in figure). The C3'-centered radical then loses a molecule of $\mathrm{HF}$ to generate $\mathrm{C}^{2}$-centered radical $\mathbf{C}$, which is resonance stabilized by oxygen centered radical intermediate $\mathbf{D}$, which eventually leads to covalent inhibition of RNR.
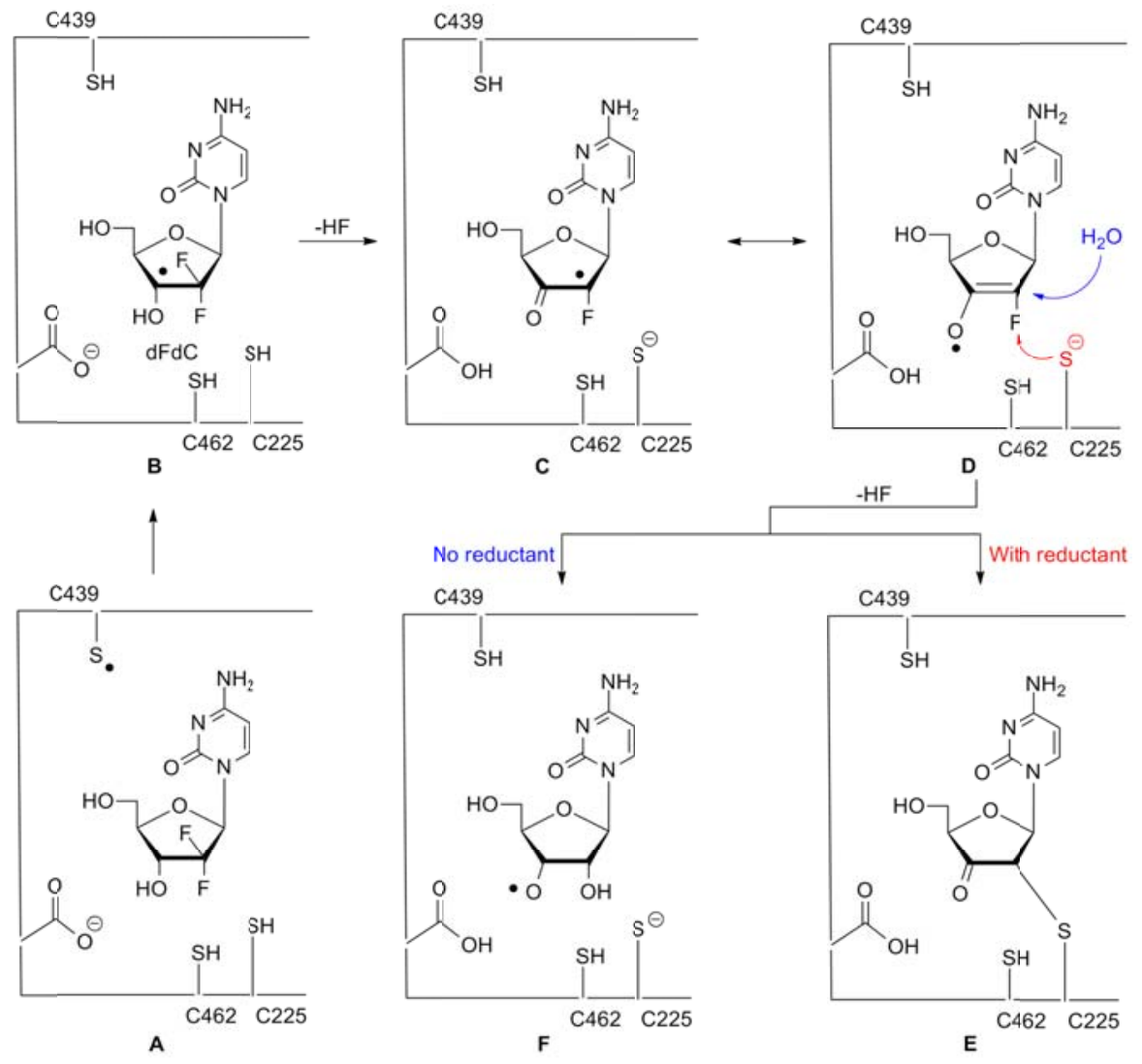

Figure 7. Mechanism for the covalent inhibition of RNR by dFdCDP in the absence and in the presence of reductant, proposed by Prof. Stubbe, et al. ${ }^{31}$

\subsection{Short survey on desulfurization-fluorination reactions}

Although the preparation of the organofluorine compounds remains a difficult task, in the last 40 years numerous methods of incorporating fluorine into organic molecules have been developed, as summarized in many excellent reviews. ${ }^{34-38}$ Oxidative desulfurization-(di)fluorination is one of the most important fluorination protocols for the 
preparation of numerous fluoro/gem-difluoro organic compounds. ${ }^{39,40}$ Various reagents or reagent-combinations have been developed for oxidative desulfurization-fluorination reactions over the years. Of which, desulfurization-difluorination of aldehyde and ketone dithiolanes with oxidants such as $N$-halosuccinimides (NBS, NIS) or 1,3-dibromo-5,5dimethylhydantoin (DBH) and pyridinium poly(hydrogen fluoride) $(\mathrm{PPHF})^{41}$ and desulfurization-difluorination of alkyl aryl thioethers with DBH and Olah's reagent $(\text { Py.9HF) })^{42,43}$ share similar mechanistic traits (Scheme 1).

\section{Katzenellenbogen's protocol:}

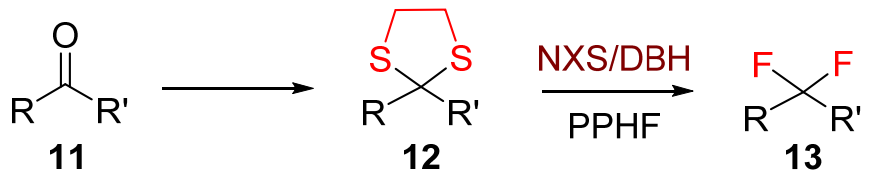

$$
\begin{aligned}
& \mathrm{R}=\text { alkyl } \\
& \mathrm{R}^{\prime}=\mathrm{H} \text { or alkyl }
\end{aligned}
$$

\section{Haufe's protocol:}

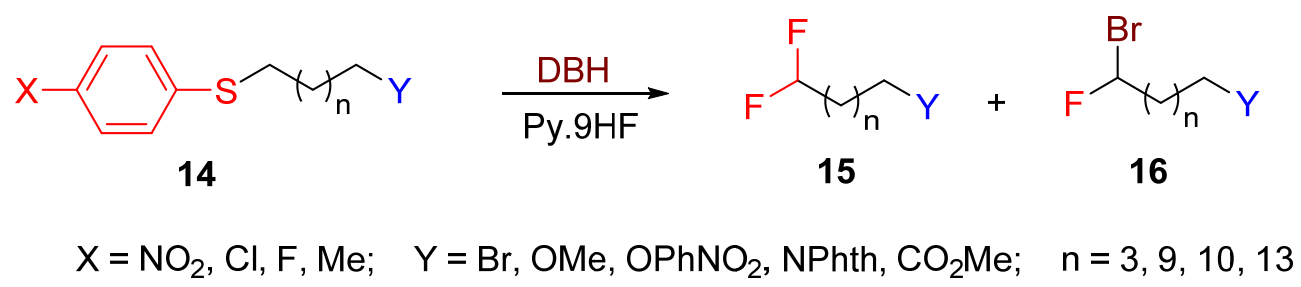

Scheme 1. Oxidative desulfurization-difluorination of aldehyde, ketone dithiolanes; and alkyl aryl thioethers.

Hara's research group has developed three reagents or reagent combinations for oxidative desulfurization-fluorination reactions. First among them was Iodine pentafluoride $\left(\mathrm{IF}_{5}\right){ }^{44-47}$ which mainly causes the desulfurization-difluorination of benzyl sulfides (Scheme 2). Later, an air- and moisture-stable $\mathrm{IF}_{5}$-pyridine-HF reagent ${ }^{48,49}$ was developed for the desulfurization-difluorination of benzyl sulfides, thioacetals, and dithianes. Recently, an air-stable fluorinating agent $\mathrm{BrF}_{3}-\mathrm{KHF}_{2}{ }^{50}$ was also developed for 
desulfurization-difluorination of benzyl sulfides, dithioacetals, and (phenylthio)glycosides.

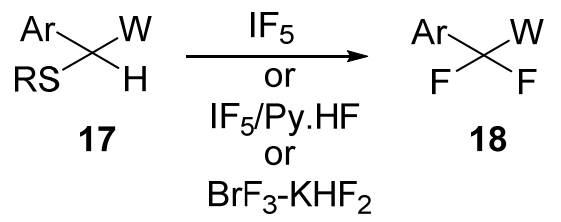

Scheme 2. Hara's oxidative desulfurization-difluorination of benzylic sulfides.

Interesting point to note is that none of the above mentioned methods provide access to gem-difluoro products from alkyl aryl thioethers where in the thioether is present on an internal secondary carbon atom (See Figure 13 in Section 2).

\subsection{5-Bromopyrimidines and 8-bromopurines: Syntheses and importance}

The C-5 halogenated pyrimidine and C-8 halogenated purine nucleosides are widely used as substrates in reactions involving direct displacement of halo groups with nucleophiles. $^{51,52}$ Especially, 5-bromopyrimidine and 8-bromopurine nucleoside derivatives have been shown to possess interesting synthetic and biological properties. $^{51,52}$ Also, the halogenated pyrimidine and purine nucleoside derivatives are often used in transition metal catalyzed cross-coupling reactions ${ }^{53}$ resulting in the syntheses of a variety of nucleoside analogues with biological activity and/or fluorescent probes. $^{54}$ For example, a number of 5-substituted uracil derivatives, especially arabinofuranosyl- and 2'-deoxyuridines, have been investigated extensively for the clinical treatment of viral diseases. ${ }^{55}$ The 5-bromo and 5-iodo uridine derivatives are used as substrates for high yield coupling with terminal alkynes to generate 5-alkynyluracil nucleosides with antiviral activity ${ }^{56,57}$ and the 5-alkynyl products can also be transformed into bifurane derivatives which possess potent and selective inhibition of Varicella-Zoster 
virus. $^{56,58}$ Moreover, radiolabeled 5-bromo- and 5-iodouracil nucleosides have applications in cellular biochemistry. ${ }^{59}$

Halogenated pyrimidine ${ }^{52}$ and purine ${ }^{51}$ nucleosides have been prepared by direct treatment with halogens or halonium ion $\left(\mathrm{X}^{+}\right)$sources but most of these methods utilize harsh reaction conditions. Various C5-bromouridine derivatives have been synthesized using $\mathrm{Br}_{2} / \mathrm{Ac}_{2} \mathrm{O} / \mathrm{AcOH}^{52}, \mathrm{Br}_{2} / \mathrm{H}_{2} \mathrm{O},{ }^{60} N$-bromosuccinimide (NBS) in $\mathrm{DMF}^{61}$ or ionic liquids, ${ }^{62}$ combination of 3 -chloroperoxybenzoic acid/HBr in aprotic solvents, ${ }^{63}$ ceric ammonium nitrate $(\mathrm{CAN}) / \mathrm{LiBr}$ in protic or aprotic solvents, ${ }^{64}$ or $\mathrm{KBr} / \mathrm{Oxone} .{ }^{65}$ The $\mathrm{C} 5$ bromination of cytidine nucleosides has been accomplished with $\mathrm{Br}_{2} / \mathrm{CCl}_{4} / \mathrm{h} v^{66}$ or NBS in $\mathrm{DMF}^{61}$ or ionic liquids. ${ }^{62}$ On the other hand, the synthesis of C8-bromo purine nucleosides has been typically achieved with $\mathrm{Br}_{2} / \mathrm{AcOH} / \mathrm{AcONa}^{67}$ or NBS/DMF. ${ }^{61}$ Hence, a universal brominating reagent for C5-bromination of pyrimidines and C8bromination of purines and also development of a bench-friendly bromination methodology is warranted.

\subsubsection{1,3-dibromo-5,5-dimethylhydantoin, an important brominating reagent}

The 1,3-dibromo-5,5-dimethylhydantoin (DBDMH or DBH, Figure 8) is a useful reagent for various organic transformations ${ }^{68-70}$ including aromatic bromination. ${ }^{71-75}$ Enhanced efficiency of DBH towards aromatic bromination in the presence of acids has been known. ${ }^{72-74}$ Moreover, Lewis acid-catalyzed benzylic bromination with DBH has also been reported. ${ }^{76} \mathrm{DBH}$ also efficiently oxidizes thiols to disulfides with $\mathrm{DBH} .{ }^{77,78} \mathrm{In}$ addition, $\alpha$-bromination of aliphatic ketones is achieved with DBH in combination with $p$-toluenesulfonic acid (TsOH) ${ }^{79}$ Interestingly, compared to NBS, DBH can donate two bromines and can be doubly efficient. 


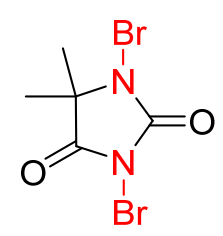

DBH<smiles>O=C1CCC(=O)N1Br</smiles>

NBS

Figure 8. Structures of DBH and NBS

\subsection{Selected aspects of the chemistry of 7-deazapurine nucleosides}

The 7-deazapurine nucleosides, namely, tubercidin, sangivamycin and toyocamycin (19a-c, Figure 9) are a group of natural products isolated from the species Streptomyces. Analogues and derivatives of these 7-deazapurine nucleoside antibiotics have been synthesized and subjected to extensive biological testing. ${ }^{80-84}$ Chemical modifications of the parent 7-deazapurine antibiotics as well as sugar-base coupling has provided access to a sizeable number of biologically active 7 -deazapurine compounds. ${ }^{85-}$ 96

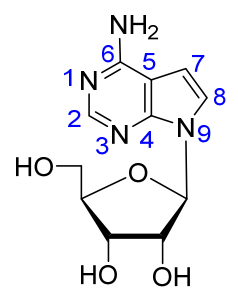

19a, Tubercidin purine numbering

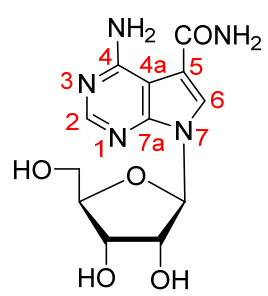

19b, Sangivamycin IUPAC numbering

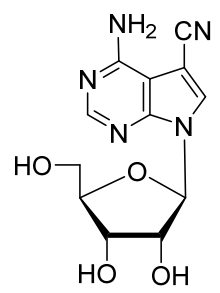

19c, Toyocamycin

Figure 9. Structures of 7-deazapurine nucleosides

Noteworthy examples of such molecules include: (a) 5-iodotubercidin $\mathbf{2 0},{ }^{97}$ an upfield activator of the p53 pathway; (b) sangivamycin analogues such as 6hydrazinosangivamycin $\mathbf{2 2}^{98}$ and 4-Amino-6-bromo-7-( $\beta$-L-xylofuranosyl)pyrrolo[2,3d]pyrimidine-5-carboxamide (xylocidine, 23) ${ }^{99}$ in vitro down-field inhibitors of PKC and CDK in cancer cell lines; (c) a methyl-substituted tubercidin $\mathbf{2 1},{ }^{100}$ which acts against the 
replication of polio and dengue viruses; (d) the anti-HSV agent xylotubercidin; ${ }^{101}$ (e) substituted toyocamycin analogues $24^{102}$ and $2^{\prime}-\beta-C$-methyl derivative of toyocamycin, ${ }^{103}$ sangivamycin, ${ }^{103}$ and tubercidin ${ }^{104,105}$ that have activity against HCV; (f) 2'-deoxy-2'fluoroarabinotubercidin ${ }^{106}$ and 2-amino-2'-deoxy-2'-fluoroarabinotubercidin, ${ }^{107,108}$ which exhibit antiviral activity; (g) 4N,5-diaryltubercidin derivatives 25, which act as adenosine kinase inhibitors; ${ }^{96,109,110}$ and (h) tubercidin derivatives such as 4-(het)aryl, ${ }^{111} 5$ (het)aryl ${ }^{112}$ and some 4-substituted-5-(het)aryl ${ }^{113}$ compounds 26 with nanomolar cytostatic activity against several cancer cell lines. Important base-modified analogues are shown in Figure 10.
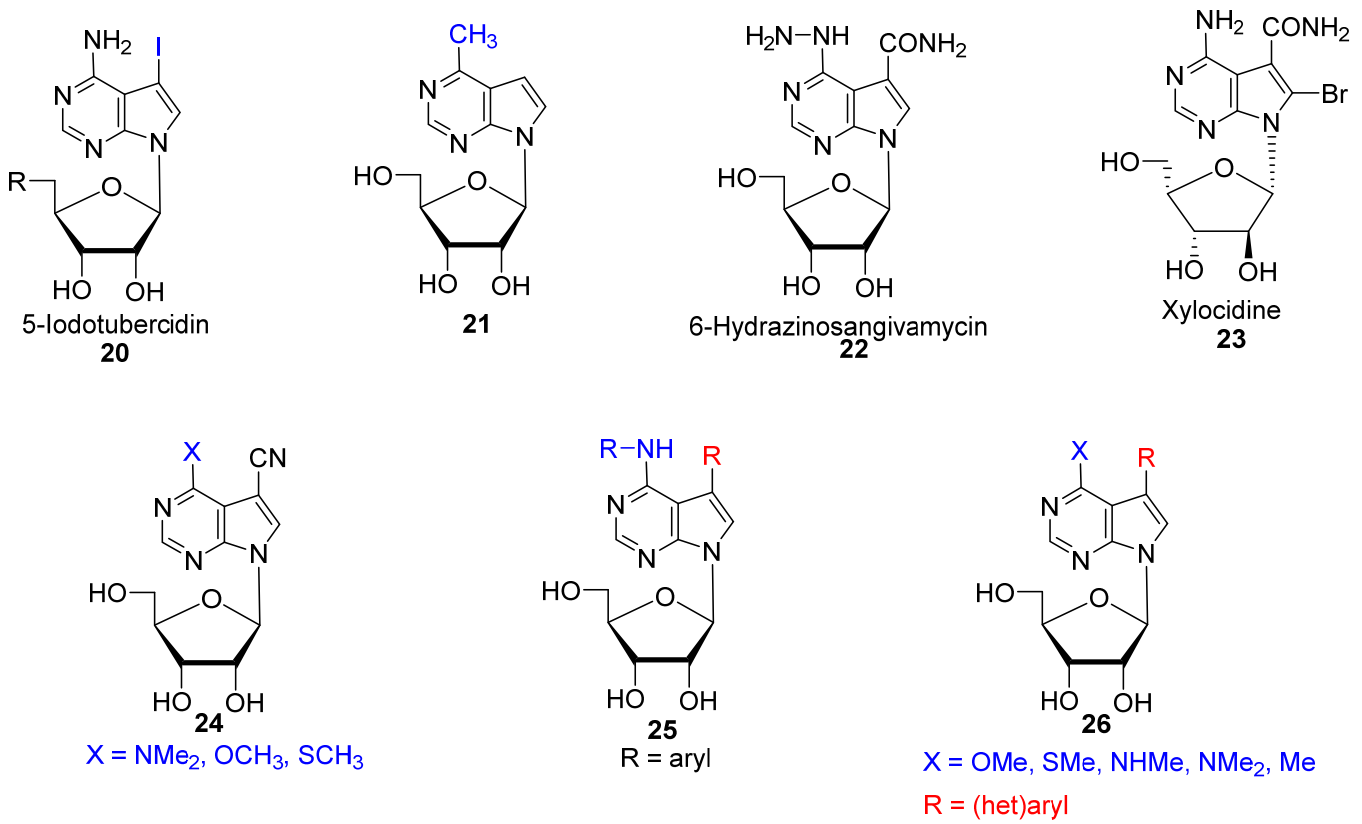

Figure 10. Important base-modified 7-deazapurine nucleoside derivatives.

Direct alkylation of exocyclic amino groups on 7-deazapurine nucleosides has not been noted. However, 4- $N$-methyltubercidin (6- $N$-methyl-7-deazaadenosine) 28 was reported to be synthesized from the reaction of tubercidin with methyl iodide followed by $1 \mathrm{~N}$ sodium hydroxide (Scheme 3). ${ }^{86}$ Thus, treatment of tubercidin with $\mathrm{CH}_{3} \mathrm{I}$ (rt, $24 \mathrm{~h}$, 
DMA) gave the corresponding N1-methyltubercidin hydroiodide 27 after recrystallization from methanol. Base treatment of this cationic intermediate $\left(1 \mathrm{~N} \mathrm{NaOH} 100{ }^{\circ} \mathrm{C}, 1.25 \mathrm{~h}\right)$ produced 4-N-methyltubercidin 28 via Dimroth rearrangement. ${ }^{86}$
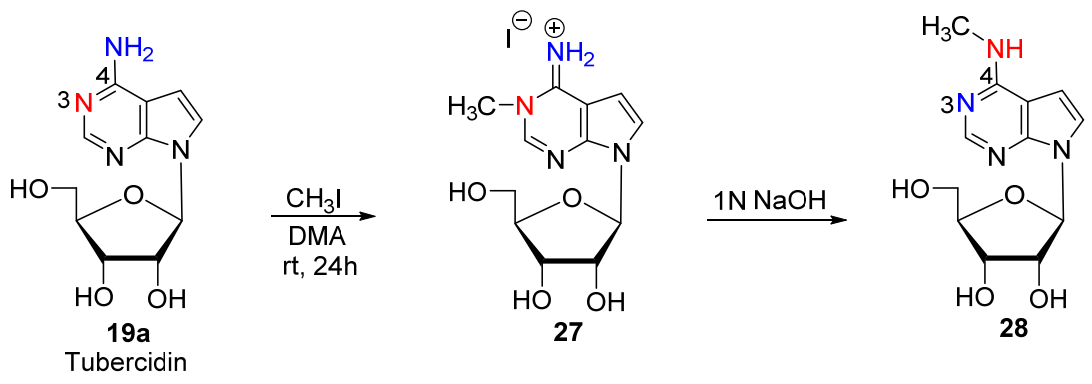

Scheme 3. Synthesis of 4- $N$-methyltubercidin by Dimroth-rearrangement approach

Even though direct alkylation or Dimroth type rearrangement has been scarce in 7-deazapurine chemistry, the 4- $N$-substituted-7-deazapurine derivatives have been widely prepared by aromatic nucleophilic substitution $\left(\mathrm{S}_{\mathrm{N}} \mathrm{Ar}\right)$. For example, $\mathrm{S}_{\mathrm{N}} \mathrm{Ar}$ displacement of chloro group from 4-cholo analogues ${ }^{86,113}$ or triazolyl group from 4- $N$-(1,2,4-triazol-4yl) intermediates ${ }^{114}$ gave access to various other $4-N$-modified tubercidin derivatives. Also, 4- $N$-substituted toyocamycin derivatives were prepared from the $\mathrm{S}_{\mathrm{N}} \mathrm{Ar}$ displacement of chloro group from the corresponding 4-chloro compounds. ${ }^{102}$ Likewise, the 7- $N$-benzylformycin was prepared via 7-chloro derivative of the $C$-nucleoside antibiotic formycin (3- $\beta$-D-ribofuranosylpyrazolo[4,3- $d]$ pyrimidine). ${ }^{115}$

\subsection{Nucleoside transport inhibitors}

As discussed in previous sections (Chapter 1, Sections 1.1-1.3), nucleoside based drugs have been in use for the treatment of various infections. Since the hydrophilic nature of nucleosides limits their cell permeability, nucleoside-specific membrane transport carriers (NT) facilitate and regulate the cellular uptake and therapeutic actions 
of many nucleoside based drugs. ${ }^{116,117}$ The nucleoside transporter proteins are classified into two categories: equilibrative NT (ENT) and concentrative NT (CNT). Human equilibrative NTs (hENTs) are found in the outer plasma membrane and some intracellular membranes of most, if not all, human cells. ${ }^{118}$

Nitrobenzylmercaptopurine ribonucleoside (NBMPR, 29a) and structurally related hENT1 probes such as 6- $N$-(4-nitrobenzyl)adenosine (29b) $)^{119}$ and 5'-S- $\{2-(6-[3-$ (fluorescein-5-yl)thioureido-1-yl]hexanamido)\} ethyl-6- $N$-(4-nitrobenzyl)-5'thioadenosine (FITC-SAHENTA) ${ }^{120}$ inhibit hENT1 with $\mathrm{nM}$ affinity (Figure 11). Discovery and development of such nucleoside transport inhibitors has greatly aided investigations on the structure, function, and cell surface abundances of hENT1 proteins. ${ }^{116,120,121}$

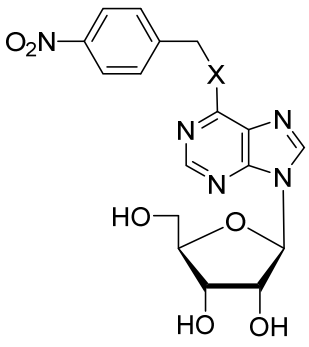

29a, $X=S$, NBMPR 29b, $X=\mathrm{NH}, 6-\mathrm{N}-(4-$ nitrobenzyl)adenosine

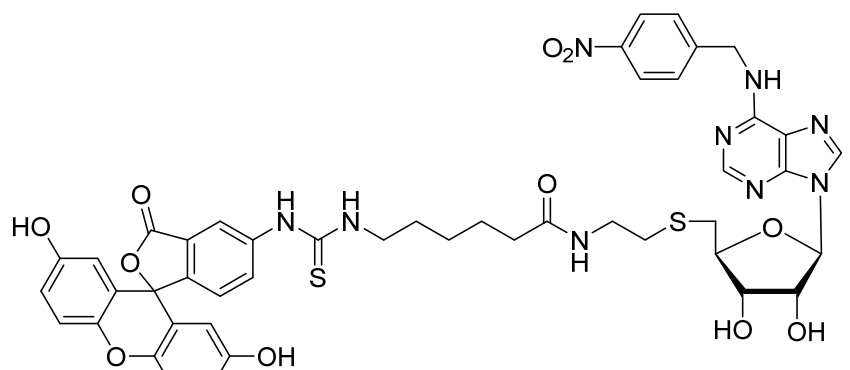

FITC-SAHENTA

Figure 11. Structures of Important nucleoside transport inhibitors.

\section{RESEARCH OBJECTIVES}

(i) The first research objective of this dissertation was to develop novel fluorination methodologies for the synthesis of mono-fluoro and geminal-difluoro uridine analogues from their parent nucleoside precursors. These strategies were envisioned to eliminate the current need to couple fluorinated sugar precursors with nucleosides bases, a process which has severe regiochemical and stereochemical limitations. On the basis of literature 
precedence, ${ }^{122}$ I would explore the possibility of insertion of the fluorine or geminaldifluoro unit into the 2'-position of ribose moiety of nucleosides using oxidative desulfurization-fluorination of substrates of type $\mathbf{3 0}$ and $\mathbf{3 1}$ with 1,3-dibromo-5,5dimethylhydantoin (DBDMH or DBH) and Olah's reagent (Py.9HF) (Figure 12).

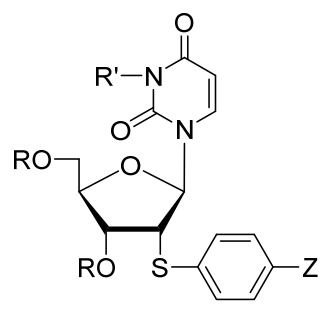

30

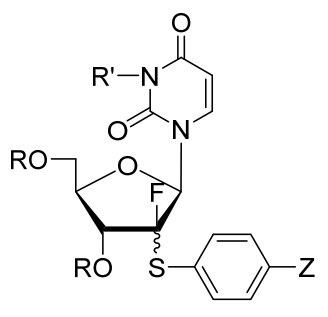

31

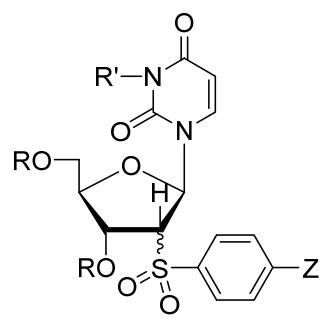

32

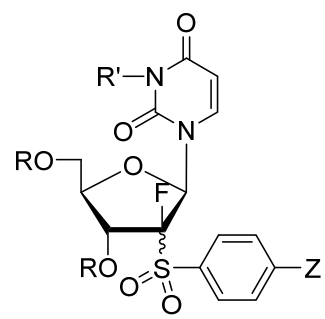

33 $\mathrm{R}=\mathrm{Ac}, \mathrm{R}^{\prime}=\mathrm{H}$ or $\mathrm{R}, \mathrm{R}^{\prime}=\mathrm{Bn} ; \mathrm{Z}=\mathrm{Cl}, \mathrm{OCH}_{3}$

Figure 12. Different classes of 2'-arylthionucleosides for oxidative desulfurizationfluorination and reductive desulfonylation-fluorination procedures.

A complementary approach was designed based on reductivedesulfonylation/fluorination processes of 2'-arylsulfonyl-2'-deoxyuridine 32 or 2'arylsulfonyl-2'-deoxy-2'-fluorouridine $\mathbf{3 3}$ with electrophilic fluorine reagents (Figure 12). Treatment of sulfone $\mathbf{3 2}$ or $\alpha$-fluorosulfone $\mathbf{3 3}$ with organic electron donors such as tetrakis(dimethylamino)ethylene (TDAE), Murphy's reagent, would be expected to lead to the reductive cleavage of sulfone moiety and generation of $\mathrm{C} 2$ '-centered carbanion. The intermediate carbanion would then be quenched with fluoronium ion $(\mathrm{F}+)$ to give mono- or di- fluorinated uridine derivatives. Alternatively, treatment of 2'-arylsulfonyl-2'deoxyuridine 32 with a base would lead to abstraction of the most acidic proton $\mathrm{H} 2$ ' and then the intermediary carbanion would be quenched with electrophilic fluorine $\left(\mathrm{F}^{+}\right)$to give products of type $\mathbf{3 3}$. 
(ii) Since nucleosides are complex molecules and also because of the lack of literature precedence for the desulfurization-difluorination of aryl-alkyl thioethers wherein the arylthio unit is positioned on a secondary internal carbon atom, I planned to perform model studies on simpler aryl-alkyl thioether substrates of type 34-37 (Figure 13). The proposed substrates would have different functional groups such as ester (34), keto (35), alkane (36) and lactone (37), and mimic the $\mathrm{C} 2$ ' of ribose unit in the pyrimidine nucleoside precursor (30, Figure 12), which also has a carbon at the carbonyl oxidation state (as an aminal group) on the $\alpha$-carbon atom.

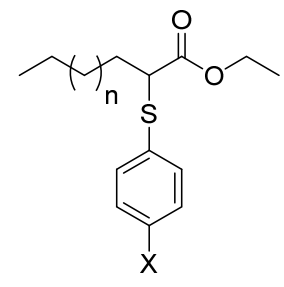

34

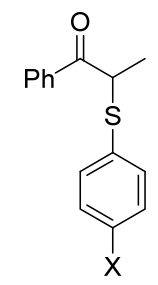

35

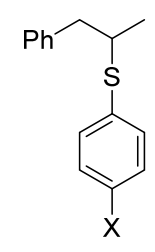

36

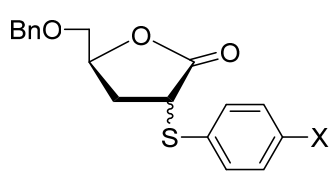

37 $\mathrm{X}=\mathrm{H}, \mathrm{Cl}, \mathrm{OCH}_{3}$

Figure 13. Various aryl-alkyl thioether substrates for model oxidative desulfurizationdifluorination reactions

(iii) Since DBH is a source of electrophilic bromine $\left(\mathrm{Br}^{+}\right)$and as bromonium ions are known to brominate pyrimidines at C-5 position and purines C-8 position, I explored the bromination at C-5 of pyrimidines and C-8 of purines with DBH. The goal of this part of my dissertation was to develop an efficient bromination methodology, which could be applicable for the bromination of all DNA and RNA nucleosides, and which would also be compatible with commonly used protection groups in nucleoside chemistry.

(iv) The next goal of my dissertation was to investigate the behavior of gemcitabine and its 2'-modified analogues such as 2'-deoxy-2'-fluorocytidine (38) and 2'-deoxy-2'-fluoro2'-C-methylcytidine (PSI-6130, 39) in one electron oxidation systems and evaluate if 
stereo electronic differences at C2'-position among these substrates would allow us to detect $\mathrm{C}^{\prime}$ and/or $\mathrm{C}^{\prime}$ ' sugar radicals using electron spin resonance (ESR) spectroscopy studies (Figure 14). This part of my dissertation was planned in collaboration with Dr. Michael D. Sevilla's research group of Oakland University.
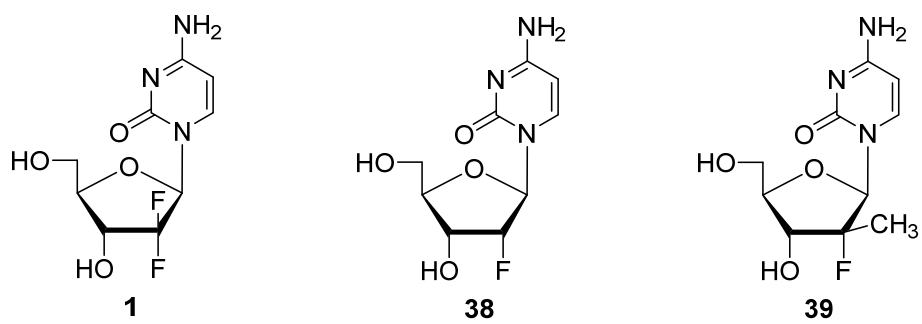

Figure 14. Gemcitabine and its analogues for one electron oxidation studies

(v) Since 6-N-(4-nitrobenzyl) derivatives of adenosine and other adenine nucleosides possess potent nucleoside transport inhibition activity, in the next goal, I proposed to synthesize novel 6- $N$-benzyl-7-deazapurine nucleoside derivatives (40a-d) of 7deazaadenosine antibiotics (19a-c) in order to test their biological activity (Figure 15). I envisioned two methods for achieving the synthesis of the target molecules (40a-d). One involved alkylation of the 7-deazaadenosine antibiotics (19a-c) at N1 with a benzyl bromide followed by a base-promoted Dimroth rearrangement. The second route employed diazotization-fluorodediazoniation followed by $\mathrm{S}_{\mathrm{N}} \mathrm{Ar}$ displacement of fluoride with a benzyl amine. 


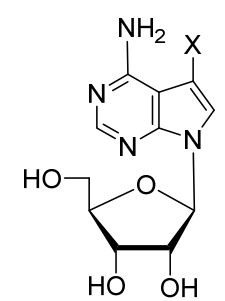

19a, $X=H$, Tubercidin

19b, $\mathrm{X}=\mathrm{CONH}_{2}$, Sangivamycin

$19 \mathrm{c}, \mathrm{X}=\mathrm{CN}$, Toyocamycin

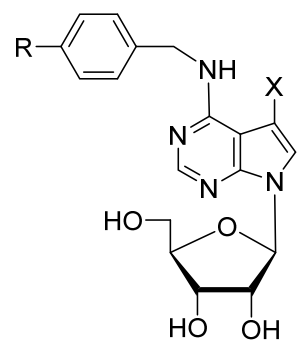

40a: $\mathrm{X}=\mathrm{H} ; \mathrm{R}=\mathrm{H}$

40b: $X=\mathrm{H} ; \mathrm{R}=\mathrm{NO}_{2}$

40c: $X=\mathrm{CONH}_{2} ; \mathrm{R}=\mathrm{NO}_{2}$

40d: $X=C N ; R=\mathrm{NO}_{2}$

Figure 15. Structures of 7-deazapurine antibiotics and the proposed 6-N-benzyl analogues.

(vi) I also intended to synthesize 7-deazapurine nucleoside derivatives with various novel modifications at C-8 and C-7 position (Figure 16). For example, 8-bromo-7-deazapurine derivatives $(41, \mathrm{Y}=\mathrm{Br})$ are envisioned as substrates for the synthesis of novel 8-azido-7deazapurine analogues $\left(41, \mathrm{Y}=\mathrm{N}_{3}\right)$. These 8-azido-7-deazapurine nucleosides might act as substrates for Copper-catalyzed and copper-free click reactions with alkynes and cycloalkynes respectively. The resultant novel 8-triazolyl-7-deazapurine derivatives (41, $\mathrm{Y}=$ triazolyl) might possess fluorescent properties because of extended conjugation.
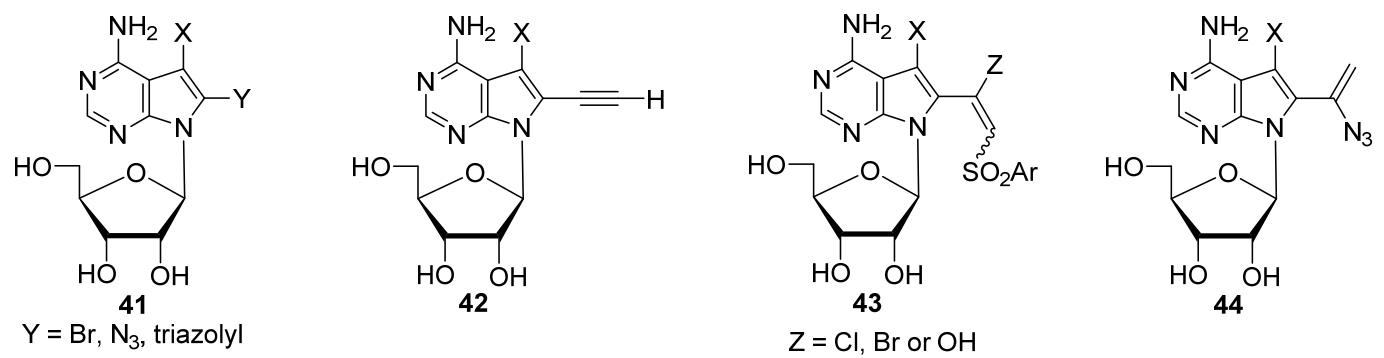

$$
\mathrm{X}=\mathrm{H}, \mathrm{CN}, \mathrm{CONH}_{2}
$$

Figure 16. Structures of various 8-modified-7-deazapurine derivatives

Also, the 8-bromo-7-deazapurine substrates $(41, \mathrm{Y}=\mathrm{Br})$ can be converted to the corresponding 8-alkynyl-7-deazapurine counterpart 42. The crucial 8-alkynyl intermediates 42 might give access to $\alpha$-halovinyl $(43, \mathrm{Z}=\mathrm{Cl}, \mathrm{Br}), \beta$-ketosulfone $(43, \mathrm{Z}=$ 
$\mathrm{OH}$ ), and $\alpha$-vinylazide (44) derivatives, analogous to recent findings on similar modifications at C5-position of pyrimidines (unpublished results from our research group).

\section{RESULTS AND DISCUSSION}

\subsection{Bromination of nucleobases with 1,3-dibromo-5,5-dimethylhydantoin}

Since DBH is known to be a good source of bromonium ion $\left(\mathrm{Br}^{+}\right)$, I envisioned a novel bromination protocol toward $\mathrm{C} 5$-bromination of pyrimidines and $\mathrm{C} 8$-bromination of purines.

\subsubsection{Bromination at $\mathrm{C} 5$ position of pyrimidline nucleosides with $\mathrm{DBH}$}

To test my hypothesis, I initially treated 2',3',5'-tri- $O$-acetyluridine 45 a with 1.1 equivalents of $\mathrm{DBH}$ in $\mathrm{CH}_{2} \mathrm{Cl}_{2}$ at ambient temperature (Scheme 4; Table 3, entry 1). After $28 \mathrm{~h}$ of reaction time TLC showed conversion of most of the substrate to a new spot, which was less polar than the substrate spot. The less polar spot was isolated by aqueous workup (95\%) and ${ }^{1} \mathrm{H}-\mathrm{NMR}$ of the crude material was very clean and implied a single compound. Characteristic doublet for $\mathrm{H} 5$ at 5.73 ppm was missing in ${ }^{1} \mathrm{H}-\mathrm{NMR}$ and the doublet for H6 (7.33 ppm) collapsed to a singlet (7.82 ppm), indicating the formation of 2',3',5'-tri- $O$-acetyl-5-bromouridine (46a; $95 \%)$. Furthermore, structure of the product was confirmed by comparing NMR data with literature NMR data for 2',3',5'-tri-Oacetyl-5-bromouridine. ${ }^{64}$ To optimize the amount of DBH required for the bromination, I treated $45 \mathbf{a}$ with 0.55 eqiuv. of DBH. But the TLC showed only $60 \%$ conversion to $46 \mathbf{a}$ even after $48 \mathrm{~h}$ of reaction time. Although, two bromonium ions $\left(\mathrm{Br}^{+}\right)$can be delivered by one equivalent of $\mathrm{DBH}$, it seemed that 1.1 equiv. of $\mathrm{DBH}$ is required for complete conversion of $45 \mathbf{a}$ to $46 \mathbf{a}$ at room temperature. 


\section{Role of Lewis acids}

Since it was reported that Lewis acids enhance the efficiency of bromination by $\mathrm{DBH},{ }^{76} \mathrm{I}$ decided to compare the rate of bromination in presence of Lewis acids. Remarkably, treatment of $\mathbf{4 5 a}$ with 0.55 equiv. of DBH in presence of 0.55 equiv. of trimethylsilyl trifluoromethanesulfonate (TMSOTf) significantly enhanced the rate of bromination yielding $46 \mathrm{a}$ after only $6 \mathrm{~h}$ (94\% yield) (entry 2). The efficiency of bromination did not differ much when 1.1 equiv. of TMSOTf was used (entry 3). Also, replacing TMSOTf with other organic acids such as $p$-toluenesulfonic acid (TsOH, 0.75 equiv.) required 0.75 equiv. of DBH for complete conversion of $45 \mathrm{a}$ to $46 \mathrm{a}$ (entry 4). Next, I studied the effect of temperature and role of solvents on bromination in order to establish optimal reaction conditions.

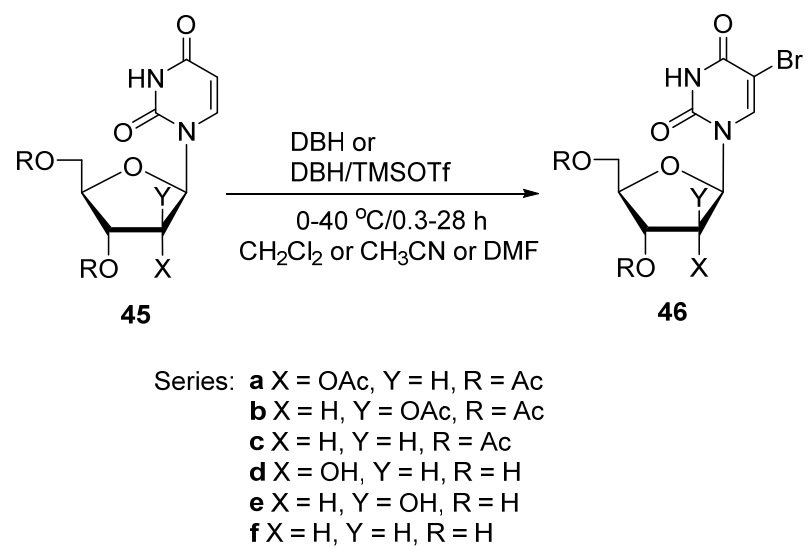

Scheme 4. Bromination of uracil-derived nucleosides 1 with 1,3-dibromo-5,5dimethylhydantoin (DBH). See Table 3 and 4 for specific reaction parameters.

\section{Effect of Temperature}

Treatment of 45a with equimolar quantities of DBH and TMSOTf ( 0.55 equiv.) at $40{ }^{\circ} \mathrm{C}$ in $\mathrm{CH}_{2} \mathrm{Cl}_{2}$ afforded $46 a$ quantitatively in only $2 \mathrm{~h}$ (entry 5). Whereas, analogous 
treatment of $45 \mathrm{a}$ with DBH/TMSOTf at $0{ }^{\circ} \mathrm{C}$ gave $46 \mathbf{a}$ in only $65 \%$ yield after $8 \mathrm{~h}$ (TLC) and required 1.1 equiv. of DBH for complete conversion (entry 6).

\section{Role of Solvents}

Treatment of $45 \mathrm{a}$ with 0.55 equiv. of $\mathrm{DBH}$ at room temperature in $\mathrm{CH}_{3} \mathrm{CN}$ gave 46a after $11 \mathrm{~h}$ (entry 7). Analogous treatment of 45a with DBH in presence of TMSOTf (0.55 equiv.) yielded 46a after only $2.5 \mathrm{~h}$ (entry 8). Moreover, the DBH/DMF system was much more effective than $\mathrm{CH}_{3} \mathrm{CN}$ or $\mathrm{CH}_{2} \mathrm{Cl}_{2}$ affording 46a in much shorter time (entries 9-10). In addition, bromination of $\mathbf{4 5 a}$ with DBH in the presence or absence of TMSOTf was less efficient in polar protic solvent $\mathrm{MeOH}$, producing 46a in low yields. Hence, it can be concluded that bromination of $\mathbf{4 5 a}$ with DBH and/or TMSOTf was very efficient in polar aprotic solvents such as $\mathrm{CH}_{3} \mathrm{CN}$ or DMF. However, it is noteworthy that prior removal of these polar solvents from crude reaction mixture was required before proceeding to aqueous workup, which is not the case with $\mathrm{CH}_{2} \mathrm{Cl}_{2}$.

Table 3. Effect of various reaction parameters on C5-bromination of 2',3',5'-tri-Oacetyluridine $45 \mathbf{a}$ with $\mathrm{DBH}^{\mathrm{a}}$

\begin{tabular}{|c|c|c|c|c|c|c|}
\hline Entry & Solvent & $\begin{array}{c}\text { Temp. } \\
\left({ }^{\circ} \mathrm{C}\right)\end{array}$ & $\begin{array}{c}\text { DBH } \\
\text { (equiv.) }\end{array}$ & $\begin{array}{c}\text { TMSOTf } \\
\text { (equiv.) }\end{array}$ & $\begin{array}{c}\text { Time } \\
(\mathrm{h})\end{array}$ & $\begin{array}{c}\text { Y6a (\%) } \\
{ }^{b, c}\end{array}$ \\
\hline 1 & $\mathrm{CH}_{2} \mathrm{Cl}_{2}$ & 25 & 1.1 & - & 28 & 95 \\
\hline 2 & $\mathrm{CH}_{2} \mathrm{Cl}_{2}$ & 25 & 0.55 & $0.55^{d}$ & 6 & 94 \\
\hline 3 & $\mathrm{CH}_{2} \mathrm{Cl}_{2}$ & 25 & 0.55 & 1.10 & 6 & 91 \\
\hline 4 & $\mathrm{CH}_{2} \mathrm{Cl}_{2}$ & 25 & 0.75 & $0.75^{e}$ & 8 & 94 \\
\hline 5 & $\mathrm{CH}_{2} \mathrm{Cl}_{2}$ & 40 & 0.55 & 0.55 & 2 & 98 \\
\hline
\end{tabular}




\begin{tabular}{|c|c|c|c|c|c|c|}
\hline 6 & $\mathrm{CH}_{2} \mathrm{Cl}_{2}$ & 0 & $1.1^{f}$ & 0.55 & 3 & 98 \\
\hline 7 & $\mathrm{CH}_{3} \mathrm{CN}$ & 25 & 0.55 & - & 11 & $86^{g}$ \\
\hline 8 & $\mathrm{CH}_{3} \mathrm{CN}$ & 25 & 0.55 & 0.55 & 2.5 & 90 \\
\hline 9 & DMF & 25 & 0.55 & - & 0.6 & 95 \\
\hline 10 & DMF & 25 & 0.55 & 0.55 & 0.3 & 98 \\
\hline
\end{tabular}

${ }^{a}$ Bromination was performed on $0.1 \mathrm{mmol}$ scale of 45a. ${ }^{b}$ Isolated yield after aqueous work-up. ${ }^{c}$ Purity of the product 46 a was determined by TLC and ${ }^{1} \mathrm{H}$ NMR and was higher than $97 \%$ unless otherwise noted. ${ }^{d}$ Reaction without TMSOTf showed $60 \%$ conversion to 46a (TLC) after $48 \mathrm{~h}$ and complete conversion after $68 \mathrm{~h}$ with purity over $90 \%$ ( ${ }^{1} \mathrm{H}$ NMR). ${ }^{e}$ TsOH was used instead of TMSOTf. ${ }^{f}$ Reaction with 0.55 eq. of DBH was complete in $65 \%$ after $8 \mathrm{~h}$. ${ }^{g}$ With purity over $90 \%$.

\section{Extension to other protected uridine nucleosides}

I also wanted to test the applicability of the optimized bromination procedure for the 5-bromination of the other uracil nucleosides. Thus, treatment of 1-(2,3,5-tri-Oacetyl- $\beta, D$-arabinofuranosyl)uracil $\mathbf{4 5 b}$ with $\mathrm{DBH}$ and TMSOTf yielded the corresponding C5-brominated analogue 46b in 91\% yield after 10 h (Scheme 4; Table 4, entry 2). Replacing $\mathrm{CH}_{2} \mathrm{Cl}_{2}$ with polar aprotic solvent such as $\mathrm{CH}_{3} \mathrm{CN}$ generated $46 \mathbf{b}$ in $98 \%$ yield after only $2 \mathrm{~h}$ (entry 3 ). In addition, treatment of 3',5'-di- $O$-acetyl-2'deoxyuridine 45c with DBH produced the 5-bromo counterpart 46c in 72\% isolated yield after $18 \mathrm{~h}$ (entry 4). 46c was also obtained after only $2.5 \mathrm{~h}$ in the presence of TMSOTf (entry 5). Moreover, the rate of bromination increased five-fold when the reaction was carried out at $40{ }^{\circ} \mathrm{C}$ (entry 6).

\section{C5-Bromination of unprotected uridine nucleosides with DBH}


On the basis of the successful C5-bromination of protected uridine nucleosides, I envisioned the extension of $\mathrm{DBH}$ bromination protocol for the $\mathrm{C} 5$-bromination of unprotected uridine nucleosides. Thus, bromination of uridine 45d with DBH in DMF yielded 5-bromouridine $46 \mathrm{~d}$ in $75 \%$ crystallized yield after only 20 minutes (Scheme 4; Table 4, entry 7). Analogously, treatment of 1-( $\beta, D$-arabinofuranosyl)uracil 45e and the acid sensitive 2'-deoxyuridine $\mathbf{4 5 f}$ with $\mathrm{DBH}$ at ambient temperature produced the corresponding 5-brominated products in good yields (entries 8 and 9).

\section{Extension to cytidine nucleosides}

With the successful application of C5-bromination of uridine nucleosides with $\mathrm{DBH}$, I imagined the extension of the DBH-bromination methodology toward the synthesis of C5-brominated cytidine analogues. Thus, treatment of cytidine 47a with 0.55 equiv. of $\mathrm{DBH}$ at room temperature in DMF produced 5-bromocytidine $\mathbf{4 7 \mathbf { b }}$ after only 30 minutes ( $72 \%$ yield, Figure 17 ; Table 4, entry 10$)$.

Table 4. Bromination at $\mathrm{C} 5$ position of the pyrimidine based nucleosides 45a-f and 57$\mathbf{5 9}^{a}$

\begin{tabular}{|c|c|c|c|c|c|c|c|c|}
\hline Entry & Substrate & Product & Solvent & $\begin{array}{c}\text { Temp. } \\
\left({ }^{\circ} \mathrm{C}\right)\end{array}$ & $\begin{array}{c}\text { DBH } \\
\text { (equiv.) }\end{array}$ & $\begin{array}{c}\text { TMSOTf } \\
\text { (equiv.) }\end{array}$ & $\begin{array}{c}\text { Time } \\
(\mathrm{h})\end{array}$ & $\begin{array}{c}\text { Yield }^{b} \\
(\%)\end{array}$ \\
\hline 1 & $\mathbf{4 5 a}$ & $\mathbf{4 6 a}$ & $\mathrm{CH}_{2} \mathrm{Cl}_{2}$ & 25 & 0.55 & 0.55 & 6 & $94^{c}$ \\
\hline 2 & $\mathbf{4 5 b}$ & $\mathbf{4 6 b}$ & $\mathrm{CH}_{2} \mathrm{Cl}_{2}$ & 25 & 0.55 & 0.55 & 10 & $91^{c}$ \\
\hline 3 & $\mathbf{4 5 b}$ & $\mathbf{4 6 b}$ & $\mathrm{CH}_{3} \mathrm{CN}$ & 25 & 0.55 & 0.55 & 2 & $98^{c}$ \\
\hline 4 & $\mathbf{4 5 c}$ & $\mathbf{4 6 c}$ & $\mathrm{CH}_{2} \mathrm{Cl}_{2}$ & 25 & 1.10 & - & 18 & $72^{d}$ \\
\hline 5 & $\mathbf{4 5 c}$ & $\mathbf{4 6 c}$ & $\mathrm{CH}_{2} \mathrm{Cl}_{2}$ & 25 & 0.55 & 0.55 & 2.5 & $90^{c}$ \\
\hline
\end{tabular}




\begin{tabular}{|c|c|c|c|c|c|c|c|c|}
\hline 6 & $\mathbf{4 5 c}$ & $\mathbf{4 6 c}$ & $\mathrm{CH}_{2} \mathrm{Cl}_{2}$ & 40 & 0.55 & 0.55 & 0.5 & $93^{c}$ \\
\hline 7 & $\mathbf{4 5 d}$ & $\mathbf{4 6 d}$ & $\mathrm{DMF}$ & 25 & 0.55 & - & 0.33 & $75^{e}$ \\
\hline 8 & $\mathbf{4 5 e}$ & $\mathbf{4 6 e}$ & $\mathrm{DMF}$ & 25 & 0.55 & - & 1 & $65^{d}$ \\
\hline 9 & $\mathbf{4 5 f}$ & $\mathbf{4 6 f}$ & $\mathrm{DMF}$ & 25 & 0.55 & - & 0.75 & $80^{d}$ \\
\hline 10 & $\mathbf{4 7 a}$ & $\mathbf{4 7 b}$ & $\mathrm{DMF}$ & 25 & 0.55 & - & 0.5 & $72^{d}$ \\
\hline 11 & $\mathbf{4 8 a}$ & $\mathbf{4 8 b}$ & $\mathrm{DMF}$ & 25 & 0.55 & - & 0.5 & $74^{d, f}$ \\
\hline 12 & $\mathbf{4 9 a}$ & $\mathbf{4 9 b}$ & $\mathrm{DMF}$ & 25 & 0.55 & - & 0.5 & $98^{c}$ \\
\hline 13 & $\mathbf{4 5 d}$ & $\mathbf{4 6 d}$ & $\mathrm{MeOH}$ & 25 & 0.55 & - & 1 & $70^{e}$ \\
\hline 14 & $\mathbf{4 7 a}$ & $\mathbf{4 7 b}$ & $\mathrm{MeOH}$ & 25 & 0.55 & - & 1 & $68^{d}$ \\
\hline
\end{tabular}

${ }^{a}$ Bromination was performed on $0.25-2.0$ mmol scale. $^{b}$ Isolated yield. ${ }^{c}$ After aqueous work-up with purity higher than $97 \%\left({ }^{1} \mathrm{H}\right.$ NMR). ${ }^{d}$ After column chromatography. ${ }^{e}$ After crystallization. ${ }^{f}$ Direct crystallization of the crude reaction mixture from $\mathrm{MeOH}$ gave $48 b$ in $46 \%$ yield.

Analogously, bromination of 4- $N$-benzoylcytidine 48a proceeded smoothly generating $\mathbf{4 8 b}$ (entry 11), which implies that the presence of an electron withdrawing group on the cytosine ring ( $\mathrm{N} 4$-benzoyl) does not affect the efficiency of bromination.

\section{Protection group compatibility}

I also found that DBH bromination methodology was compatible with common protection groups used in nucleoside chemistry. Thus, treatment of 5'-O-(tertbutyldimethylsilyl)-2',3'-O-isopropylideneuridine 49a with 0.55 equiv. of $\mathrm{DBH}$ in DMF afforded the corresponding 5-bromo product 49b in quantitative yield (Figure 17; Table 4, entry 12). It was already shown that base-labile acetyl groups were stable during DBH-bromination (e.g., Table 3). Therefore, it can be concluded that acid 
labile as well as base labile protection groups are stable toward DBH-bromination protocol.

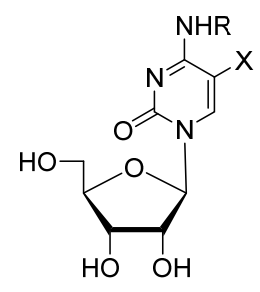

$47 \mathrm{a} X=\mathrm{H}, \mathrm{R}=\mathrm{H}$

$47 \mathrm{~b} X=\mathrm{Br}, \mathrm{R}=\mathrm{H}$

$48 \mathrm{a} X=\mathrm{H}, \mathrm{R}=\mathrm{Bz}$

48b $X=B r, R=B z$

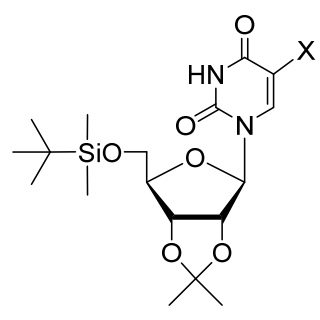

49a $X=H$

Figure 17. Selected pyrimidine nucleoside precursors (series a) and their brominated products (series b).

\section{C5-Bromination of unprotected pyrimidine nucleosides with $\mathrm{DBH}$ in $\mathrm{MeOH}$}

Since DMF has to be removed from the crude reaction mixture before purification of the brominated products, I used a low-boiling polar solvent such as $\mathrm{MeOH}$ as a replacement for DMF. To my surprise, treatment of uridine 45d with DBH (0.55 equiv.) in $\mathrm{MeOH}$ at room temperature for $1 \mathrm{~h}$ yielded 5-bromouridine $\mathbf{4 6 d}$ in $70 \%$ yield (crystallization) (Scheme 4; Table 4, entry 13). Analogously, cytidine 47a was also brominated using $\mathrm{DBH}$ in $\mathrm{MeOH}$ generating 5-bromocytidine 47b (Figure 17; Table 4, entry 14) after only $1 \mathrm{~h}$ in $68 \%$ yield (column chromatography). Therefore, it can be concluded that $\mathrm{DBH} / \mathrm{MeOH}$ system offers a convenient access to the unprotected 5bromopyrimidine nucleosides.

\subsubsection{Bromination at C8 position of purine nucleosides with DBH}

Next, I planned the extension of the DBH and DBH/TMSOTf combination toward the synthesis of 8-bromo purine nucleosides. Thus, treatment of adenosine 50a with DBH (1.75 equiv.) in DMF at room temperature gave 8-bromoadenosine 50b (48\% yield) after $5 \mathrm{~h}$ at ambient temperature (Figure 18, Table 5, entry 1). Analogous treatment of 2'- 
deoxyadenosine 51a with DBH (1.5 equiv.) afforded 8-bromo-2'-deoxyadenosine 51b in $68 \%$ yield in $3.5 \mathrm{~h}$ (entry 2 ).

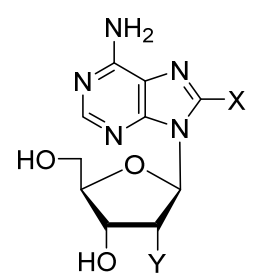

50a $X=\mathrm{H}, \mathrm{Y}=\mathrm{OH}$

50b $X=\mathrm{Br}, Y=\mathrm{OH}$

51a $X=H, Y=H$

51b $X=B r, Y=H$

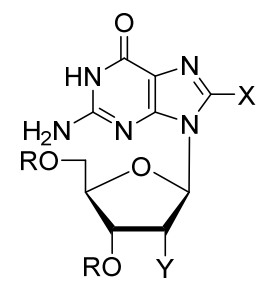

52a $X=H, Y=O A c, R=A c$

52b $\mathrm{X}=\mathrm{Br}, \mathrm{Y}=\mathrm{OAc}, \mathrm{R}=\mathrm{Ac}$

53a $X=H, Y=O H, R=H$

53b $X=\mathrm{Br}, Y=\mathrm{OH}, \mathrm{R}=\mathrm{H}$

54a $X=\mathrm{H}, \mathrm{Y}=\mathrm{H}, \mathrm{R}=\mathrm{H}$

54b $X=B r, Y=H, R=H$

Figure 18. Selected purine nucleoside precursors (series a) and their brominated products (series b).

The 2',3',5'-tri- $O$-acetylguanosine $\mathbf{5 2 a}$ was converted to the 8-bromo derivative 52b upon treatment with 0.55 equiv. of $\mathrm{DBH}$ in $\mathrm{DMF}$ at room temperature for $2.5 \mathrm{~h}$ (entry 3). Replacement of DMF with $\mathrm{CH}_{3} \mathrm{CN}$ decreased the rate of bromination yielding 52b after $4 \mathrm{~h}$ at room temperature (entry 4). On the other hand, treatment of guanosine with 0.75 equiv. of $\mathrm{DBH}$ in DMF at ambient temperature produced 8-bromoguanosine in $48 \%$ yield after recrystallization from water (entry 5). Use of TMSOTf did not improve the yield of 8-bromoguanosine $\mathbf{5 3 b}$, though less equiv. of $\mathrm{DBH}$ was required for complete conversion (entry 6). Treatment of inosine or acetyl protected inosine with $\mathrm{DBH}$ or DBH/TMSOTf in DMF failed to afford 8-bromoinosine, which was in accordance with the reported failed bromination attempts of inosine with NBS in DMF. $^{123}$ 
Table 5. Bromination of selected purine nucleosides at ambient temperature (see Figure 11 for structures) ${ }^{\mathrm{a}}$

\begin{tabular}{|c|c|c|c|c|c|c|c|}
\hline Entry & Substrate & Product & Solvent & $\begin{array}{c}\text { DBH } \\
\text { (equiv.) }\end{array}$ & $\begin{array}{c}\text { TMSOTf } \\
\text { (equiv.) }\end{array}$ & $\begin{array}{c}\text { Time } \\
(\mathrm{h})\end{array}$ & $\begin{array}{c}\text { Yield }^{b} \\
(\%)\end{array}$ \\
\hline 1 & $\mathbf{5 0 a}$ & $\mathbf{5 0 b}$ & DMF & 1.75 & - & 5 & $48^{c, d}$ \\
\hline 2 & $\mathbf{5 1 a}$ & $\mathbf{5 1 b}$ & DMF & 1.50 & - & 3.5 & $68^{c, d}$ \\
\hline 3 & $\mathbf{5 2 a}$ & $\mathbf{5 2 b}$ & $\mathrm{DMF}$ & 0.55 & - & 2.5 & $83^{c}$ \\
\hline 4 & $\mathbf{5 2 a}$ & $\mathbf{5 2 b}$ & $\mathrm{CH}{ }_{3} \mathrm{CN}$ & 0.55 & - & 4 & $98^{c}$ \\
\hline 5 & $\mathbf{5 3 a}$ & $\mathbf{5 3 b}$ & $\mathrm{DMF}$ & $0.75^{f}$ & - & 2.5 & $51^{g}$ \\
\hline 6 & $\mathbf{5 3 a}$ & $\mathbf{5 3 b}$ & $\mathrm{DMF}$ & 0.60 & 0.55 & 0.5 & $48^{g}$ \\
\hline 7 & $\mathbf{5 0 a}$ & $\mathbf{5 0 b}$ & $\mathrm{MeOH}$ & 1.75 & - & 16 & $47^{c, j}$ \\
\hline 8 & $\mathbf{5 1 a}$ & $\mathbf{5 1 b}$ & $\mathrm{MeOH}$ & 1.50 & - & 3.5 & $70^{j}$ \\
\hline 9 & $\mathbf{5 3 a}$ & $\mathbf{5 3 b}$ & $\mathrm{MeOH}$ & 0.55 & - & 1 & $50^{g}$ \\
\hline 10 & $\mathbf{5 4 a}$ & $\mathbf{5 4 b}$ & $\mathrm{MeOH}$ & 0.55 & - & 0.5 & $72^{i}$ \\
\hline & & & & & & & \\
\hline
\end{tabular}

${ }^{a}$ Bromination was performed on $0.5-1 \mathrm{mmol}$ scale. ${ }^{b}$ Isolated yield. ${ }^{c}$ After column chromatography. ${ }^{d}$ Reaction showed formation of the product in approximately $80 \%$ yield (TLC). ${ }^{e}$ Isolated yield after aqueous work-up. ${ }^{f}$ Reaction with 0.55 equiv. of DBH was completed in $24 \mathrm{~h} .{ }^{g}$ After crystallization from water. Bromination was quantitative as judged by TLC. ${ }^{i}$ After filtration from reaction. ${ }^{j}$ Reaction showed formation of the product in approximately $70 \%$ yield (TLC).

In conclusion, $\mathrm{DBH}$ and/or DBH/TMSOTf also effected bromination of purine nucleosides at the $\mathrm{C} 8$-position, although reactions usually required higher equivalency of $\mathrm{DBH}$, longer reaction times, and produced the corresponding brominated products in lower yields when compared to the pyrimidine analogues.

\section{C8-Bromination of unprotected purine nucleosides with $\mathrm{DBH}$ in $\mathrm{MeOH}$}


Next, I designed the extension of the $\mathrm{DBH} / \mathrm{MeOH}$ system toward the synthesis of 8-bromo purine nucleosides. Thus, treatment of adenosine 50a with DBH (1.75 equiv.) in $\mathrm{MeOH}$ at room temperature gave 8 -bromoadenosine $\mathbf{5 0 b}$ (47\% yield) after $16 \mathrm{~h}$ at ambient temperature (Figure 18, Table 5, entry 7). Analogous treatment of 2'deoxyadenosine 51a with DBH (1.5 equiv.) showed only $\sim 70 \%$ conversion to 8 bromo-2'-deoxyadenosine 51b (entry 8 , TLC scale reaction). Interestingly, treatment of guanosine 53a with $\mathrm{DBH}$ (0.55 equiv.) in $\mathrm{MeOH}$ at room temperature yielded 8bromoguanosine 53b in 50\% yield after recrystallization of the crude reaction mixture from water (entry 9). In contrast, treatment of 2'-deoxyguanosine 54a with DBH in $\mathrm{MeOH}$ at room temperature for 30 minutes led to the solidification of product $\mathbf{5 4 \mathbf { b }}$ from the reaction. The resultant solid was collected by vacuum filtration and was $>95 \%$ pure on ${ }^{1} \mathrm{H}-\mathrm{NMR}$ (entry 10 ). In conclusion, $\mathrm{DBH} / \mathrm{MeOH}$ system works very efficiently with guanine nucleosides and moderately efficient with adenine nucleosides.

\subsubsection{Bromination at $\mathrm{C} 8$ position of 7-deazapurine nucleosides with NBS and DBH}

Encouraged by my findings of bromination of purine nucleosides at $\mathrm{C} 8$ position with DBH, I further explored possibility of bromination of 7-deazapurine antibiotics (19b-c) with DBH as well as with NBS (Scheme 5). Previously, 8-bromotoyocamycin (55) was prepared either from coupling 8-bromo-7-deazapurine derivative to the ribose sugar derivative ${ }^{124}$ or by treating 19c with $\mathrm{Br}_{2} / \mathrm{H}_{2} \mathrm{O}^{125}$. I achieved the synthesis of compound $\mathbf{5 5}$ by two procedures, both proceeding by electrophilic aromatic substitution. One involved electrophilic aromatic substitution using $N$-bromosuccinimide (NBS) in anhydrous dimethylformaldehyde (DMF). The second route employed substitution using 
1,3-dibromo-5,5-dimethylhydantoin (DBH/DBDMH) in $\mathrm{MeOH}$. Thus, treatment of $\mathbf{1 9 c}$ with NBS in DMF at ambient temperature for $2.5 \mathrm{~h}$ yielded $\mathbf{5 5}$ in $45 \%$ after column chromatography. Reaction took $4 \mathrm{~h}$ to complete when $\mathrm{DMF}$ was replaced with $\mathrm{MeOH}$ to give 55 in $64 \%$ after recrystallization. However, bromination of 19c using DBH in $\mathrm{MeOH}$ proceeded efficiently in $30 \mathrm{~min}$ by which time product solidified out of solution, was collected by vacuum filtration and the mother liquor was recrystallized to give $\mathbf{5 5}$ in $85 \%$ overall yield. The $\mathrm{DBH} / \mathrm{MeOH}$ method was the most efficient of the three for synthesizing $\mathbf{5 5}$ in terms of yield, reaction time, product isolation.

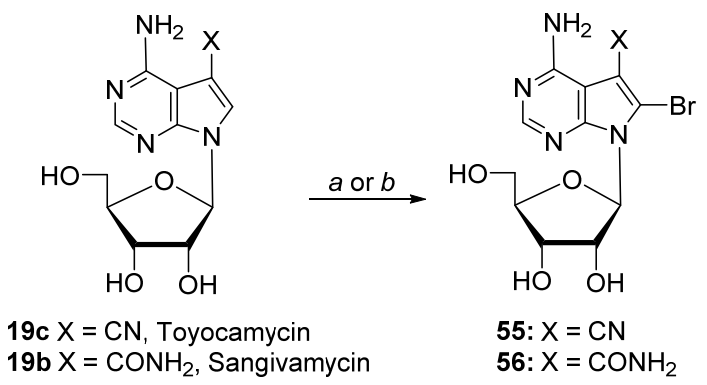

Scheme 5. Synthesis of 8-bromo-7-deazanucleosides. Reagents and conditions: d) NBS (1.1-1.5 eq), DMF, rt, 1-2.5 h; e) DBH (0.75-1.1 eq), MeOH, rt, 30-45 min.

Over the years, the synthesis of 8-bromosangivamycin $\mathbf{5 6}$ has mainly been achieved by conversion of $\mathbf{5 5}$ to $\mathbf{5 6}$ using concentrated ammonium hydroxide and $50 \%$ hydrogen peroxide solution. ${ }^{124}$ Owing to the successful preparation of $\mathbf{5 5}$, we envisioned the synthesis of 56 using $\mathrm{NBS} / \mathrm{DMF}$ and $\mathrm{DBH} / \mathrm{MeOH}$ systems. Thus, treatment of sangivamycin (19b) with NBS in DMF at ambient temperature for $1.5 \mathrm{~h}$ gave 8bromosangivamycin (56) in 63\% yield after column chromatography. Even though the reaction proceeded faster in $\mathrm{DBH} / \mathrm{MeOH}$ system $(30 \mathrm{~min})$ the yield was low $(40 \%)$, which can be attributed to the presence of some unidentified byproducts. Fortunately, there is literature precedence for convenient synthesis of $\mathbf{5 6}$ from $\mathbf{5 5} .{ }^{124}$ Thus, treatment 
of $\mathbf{5 5}$ with $\mathrm{NH}_{4} \mathrm{OH} / 50 \% \mathrm{H}_{2} \mathrm{O}_{2}$ system gave $\mathbf{5 6}$ in $86 \%$ yield after vacuum filtration from the reaction mixture. In summary, an efficient bromination methodology for the synthesis of 8-bromotoyocamycin and 8-bromosangivamycin was developed using NBS/DMF and DBH/MeOH systems.

\subsubsection{Plausible mechanism of bromination of nucleobases with DBH}

Bromination of nucleosides using DBH is expected to proceed via aromatic electrophilic bromination pathway with bromonium ion $\left(\mathrm{Br}^{+}\right)$as the bromine source from DBH.

Plausible mechanism for C-5 bromination of pyrimidines by DBH

Carbocation intermediate (type $\mathbf{A}$ ) is generated upon reaction of pyrimidine base 57 with DBH (Scheme 6). The intermediate $\mathbf{A}$ is highly unlikely to exist in resonance with the intermediate $\mathbf{B}$, because of the presence of electropositive carbonyl group adjacent to the N1 centered cation. Abstraction of the proton from $\mathrm{C} 5$ by the anion $\mathbf{C}$ regenerates the aromaticity, thus providing the 5-bromopyrimidine product $\mathbf{5 8}$.

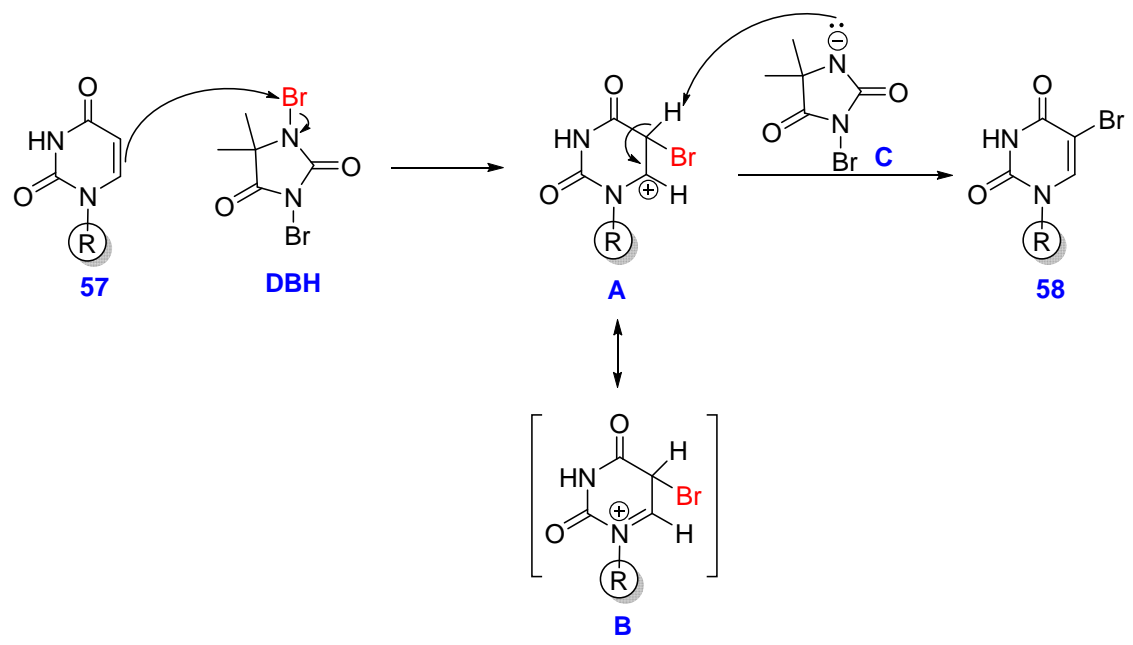

Scheme 6. Plausible mechanism of C-5 bromination of pyrimidine nucleosides by DBH. Plausible mechanism for $\mathrm{C}-8$ bromination of purines by $\mathrm{DBH}$ 
I hypothesize that the $\mathrm{N}_{7}-\mathrm{C}_{8}$ double bond of purine $\mathbf{5 9}$ abstracts a bromonium ion $\left(\mathrm{Br}^{+}\right)$from DBH to give nitrogen centered cation $\mathbf{A}$, which is stabilized by three resonance structures B-D (Scheme 7). Then aromaticity is regenerated by abstraction of proton at $\mathrm{C} 8$ position in $\mathbf{A}^{\prime}$, probably by hydantoin intermediate $\mathbf{E}$, to give the 8bromopurine product $\mathbf{6 0}$.

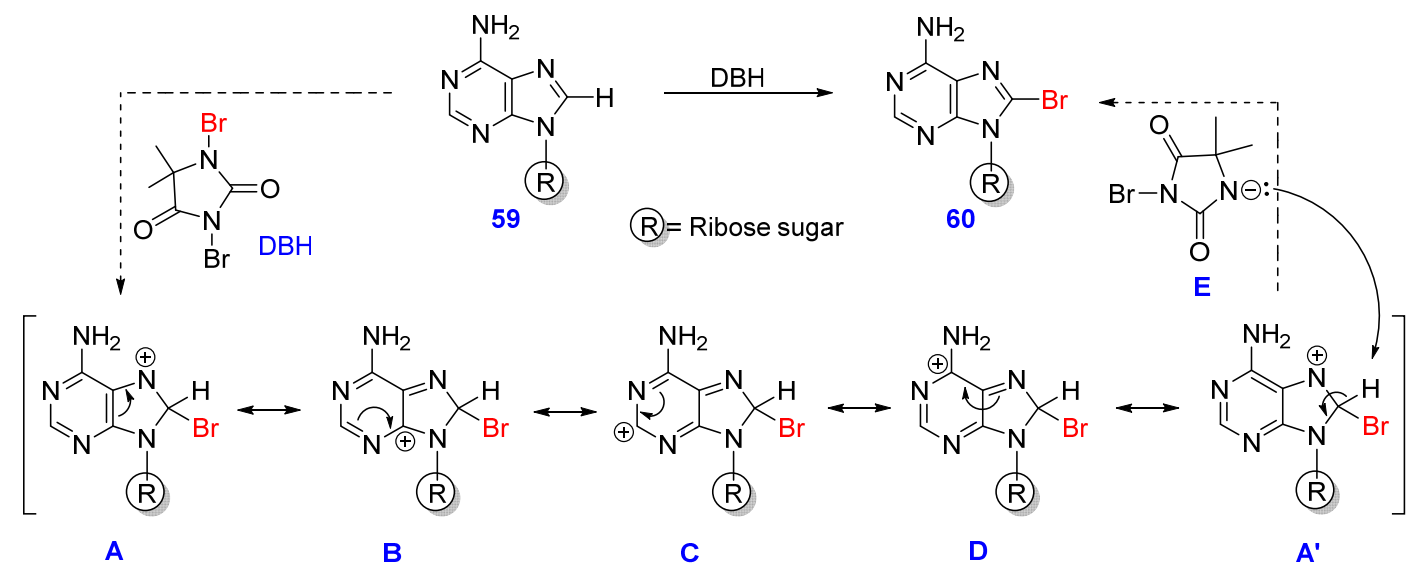

Scheme 7. Plausible mechanism of C-8 bromination of purine nucleosides by DBH.

Plausible mechanism for TMSOTf activation of DBH: ${ }^{126}$

Upon reaction with TMSOTf (61), DBH generates a silylenol intermediate A along with a reactive bromonium triflate ( $\mathrm{TfOBr}$ ) intermediate $\mathbf{B}$. Intermediate $\mathbf{B}$ acts as the actual bromonium ion $\left(\mathrm{Br}^{+}\right)$source for the bromination of the pyrimidine/purine substrate $\mathbf{6 2}$ to generate the corresponding brominated product $\mathbf{6 3}$ along with triflic acid (TfOH, $\mathbf{C}$ ) (Scheme 8). Triflic acid $\mathbf{C}$ is reacts with the silylenol intermediate $\mathbf{A}$ to give another silylenol intermediate $\mathbf{D}$ and one more equivalent of $\mathrm{TfOBr}(\mathbf{E})$. Second equivalent of substrate $\mathbf{6 2}$ gets brominated with $\mathbf{E}$ to release $\mathrm{TfOH}(\mathbf{F})$, which then reacts with the silylenol intermediate $\mathbf{D}$ to give 5,5-dimethylhydantoin (DMH, G) and TMSOTf. 

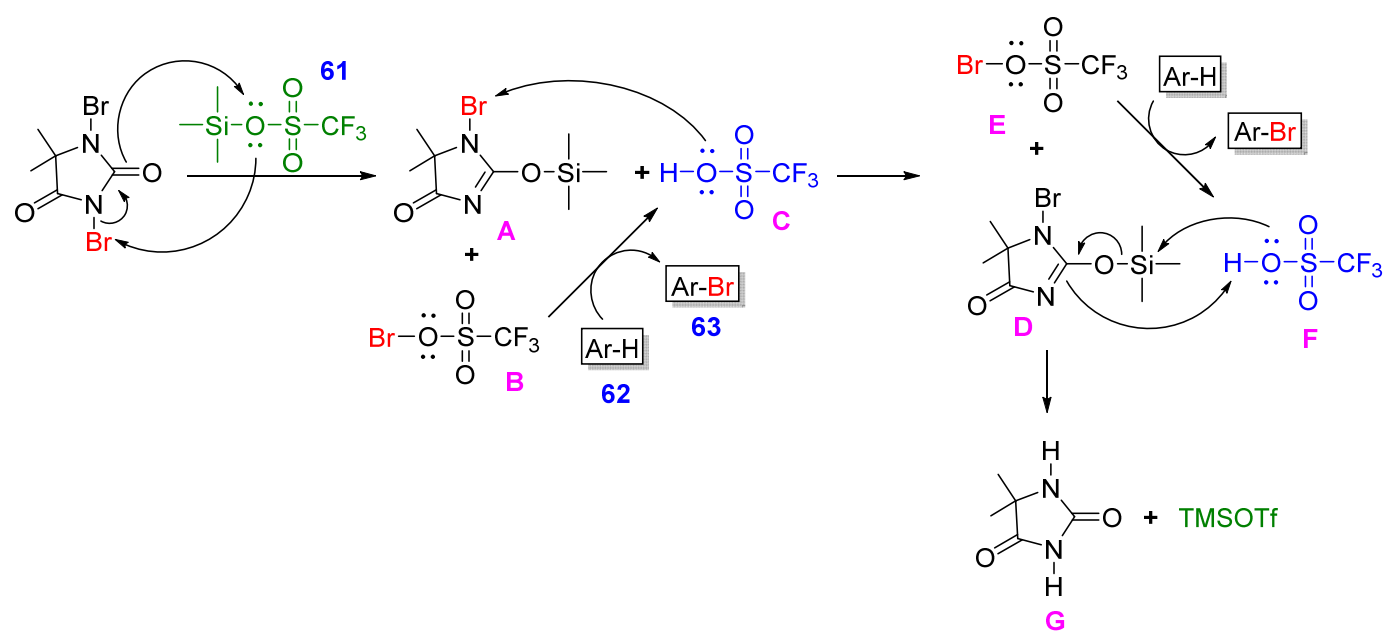

Scheme 8. Plausible mechanism of TMSOTf enhanced DBH bromination.

\subsection{Attempted synthesis of 2 '-deoxy-2', 2"-difluoropyrimidine nucleosides}

Because of the ease of preparation of 2'-S-aryl-2'-deoxy-2'-thiouridine (64, Figure 19) and 2'-deoxy-2'- $\alpha$-fluorosulfone derivative (65), I explored the possibility of introduction of mono and/or difluoro unit into the $\mathrm{C} 2$ ' position using oxidative desulfurization-(di)fluorination and reductive desulfonylation-fluorination methods. The oxidative fluorination processes were envisioned to proceed via (i) desulfurizationdifluorination of the uridine-2'-thioethers (substrate $64, \mathrm{X}=\mathrm{H}$ ) or (ii) desulfurizationfluorination of uridine $\alpha$-fluorothioethers (substrate $\mathbf{6 4}, \mathrm{X}=\mathrm{F}$ ) by using halonium ion $\left(\mathrm{Br}^{+}, \mathrm{I}^{+}\right)$reagents as oxidants and a nucleophilic fluorine source $\left(\mathrm{F}^{-}\right)$for quenching the intermediary C2'-carbocation. Whereas, the reductive fluorination processes were proposed to proceed via (i) abstraction of the $\mathrm{C} 2^{\prime}$-proton (from substrate $\mathbf{6 5}, \mathrm{X}=\mathrm{H}$ ) using a base and quenching the intermediary $\mathrm{C}^{\prime}$-carbanion with electrophiles such as $\mathrm{F}^{+}, \mathrm{H}^{+}$, $\mathrm{CH}_{3}{ }^{+}$, etc.; or (ii) cleavage of the sulfonyl moiety (from substrate $\mathbf{6 5}, \mathrm{X}=\mathrm{H}$ or F) with single electron transfer reagents and quenching the resultant $\mathrm{C} 2$ '-carbanion with electrophiles such as $\mathrm{F}^{+}, \mathrm{H}^{+}, \mathrm{CH}_{3}{ }^{+}$, etc. 


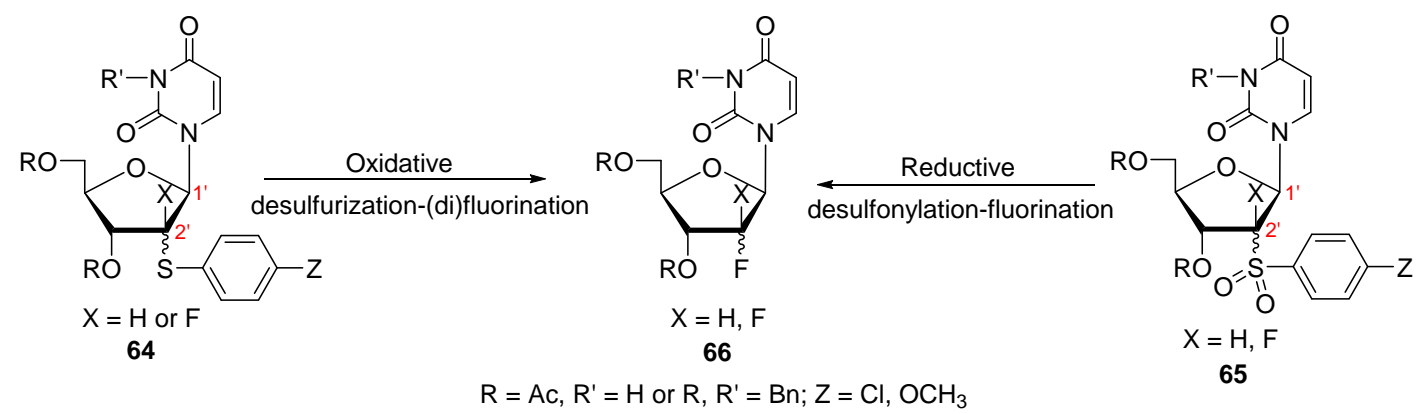

Figure 19. General scheme for the proposed C2'-quarternization of 2'-arylthiouridine derivatives

\subsubsection{Oxidative desulfurization-fluorination approaches}

The oxidative fluorination approach is modeled on Haufe's desulfurizationdifluorination of aryl-alkyl thioethers using DBH and Olah's reagent (Py.9HF) for the synthesis of gem-difluoroalkanes (Scheme 9). ${ }^{42,43}$

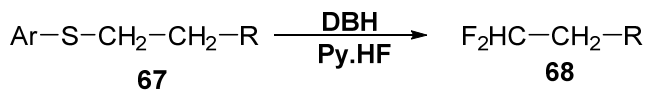

Scheme 9. General scheme for Haufe's desulfurization-difluorination of aryl-alkyl thioethers.

\subsubsection{Model desulfurization-fluorination studies}

To apply Haufe's desulfurization-difluorination methodology to nucleoside substrates, it is necessary to test the general applicability of the method on model compounds first. As the $\mathrm{C} 2$ '-position, where the thioether functionality is present, is in $\alpha$ position to an aminal carbon, substrates with an aminal or electron withdrawing group on the $\alpha$-position should be used in model studies. Another reason for conducting model reactions on such substrates which would mimic $\mathrm{C} 2$ ' of ribose unit in the pyrimidine nucleoside substrates is because all previous desulfurization-difluorination protocols were successful only for the compounds where the sulfenyl/phenylthio group is present on the 
terminal and primary carbon. Therefore, I developed a desulfurization-difluorination protocol of $\alpha$-thioesters, where in the sulfenyl group is present in the middle of the chain on a secondary carbon.

Initially, open chain aryl-alkyl thioethers (of type 72-75, Scheme 10) with an ester group on the $\alpha$-position (prepared conveniently from commercially available ethyl 2bromoalkanoate 71a or 71b) were tested for desulfurization-difluorination protocol. Thus, treatment of ethyl 2-(phenylthio)octanoate 72 with DBH (3 eq.) and Olah's reagent (6 eq.) in $\mathrm{CH}_{2} \mathrm{Cl}_{2}$ at ambient temperature for $2 \mathrm{~h}$ gave ethyl 2,2-difluorooctanoate 77 in $80 \%$ yield after only aqueous workup (Table 6 , entry 1 ). However, analogous treatment of $\mathbf{7 2}$ with DBH/Py.9HF for $4 \mathrm{~h}$ gave $\mathbf{7 7}$ in 90\% yield after aqueous workup (entry 2). To study the effect of temperature, phenylthioether $\mathbf{7 2}$ was treated with DBH (3 eq.) and Olah's reagent (6 eq.) in $\mathrm{CH}_{2} \mathrm{Cl}_{2}$ at $35{ }^{\circ} \mathrm{C}$ and the difluoro product 77 was obtained in $85 \%$ yield after only $1 \mathrm{~h}$ (entry 3 ). But 77 was obtained in $95 \%$ yield after stirring the reaction for $2 \mathrm{~h}$ at $35^{\circ} \mathrm{C}$ (entry 4$)$.

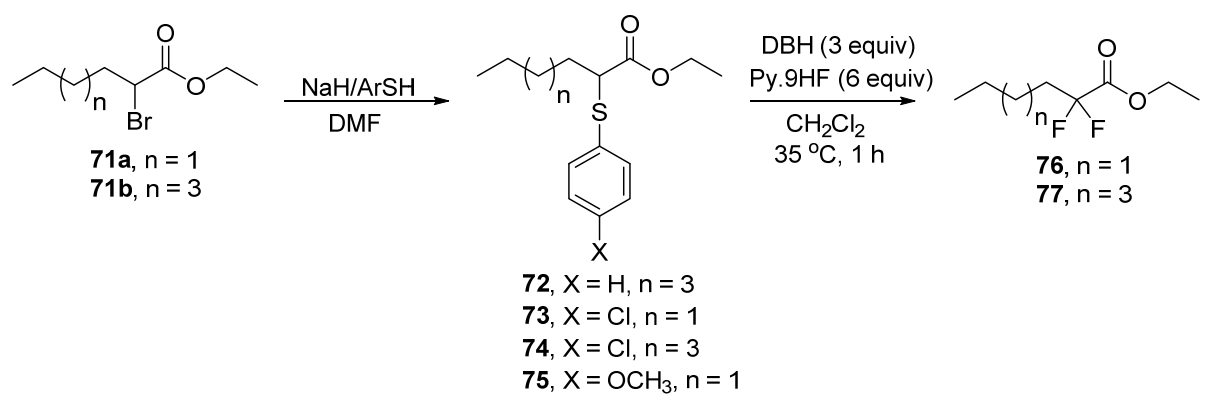

Scheme 10. Desulfurization-difluorination of $\alpha$-thioesters.

To test the influence of the substituent on the para position of aromatic ring of the thioether substrates, 4-chlorophenyl thioether (73-74) and 4-methoxyphenyl thioether (75) were selected. Thus, treatment of ethyl 2-((4-chlorophenyl)thio)hexanoate $\mathbf{7 3}$ with 
DBH (3 eq.) and Olah's reagent (6 eq.) in $\mathrm{CH}_{2} \mathrm{Cl}_{2}$ at ambient temperature for $1 \mathrm{~h}$ gave ethyl 2,2-difluorohexanoate $\mathbf{7 6}$ in $80 \%$ yield after only aqueous workup (Table 6, entry 5). However, difluoro ester $\mathbf{7 6}$ was obtained in $90 \%$ yield when the reaction was stirred for $2 \mathrm{~h}$ (entry 6). In addition, treatment of 4-chlorophenyl thioether $\mathbf{7 3}$ with DBH (3 eq.) and Olah's reagent (6 eq.) in $\mathrm{CH}_{2} \mathrm{Cl}_{2}$ at $35{ }^{\circ} \mathrm{C}$ generated the difluoro product 76 in $95 \%$ yield after only $1 \mathrm{~h}$ (entry 7). Interestingly, no geminal bromo-fluoro by product was observed in crude NMR and GC-MS. When less equivalents of DBH (3 equiv. vs 2 equiv.) and Olah's reagent ( 6 equiv. vs 4 equiv.) were used, decreased yield of the difluoro product $76(80 \%)$ was observed (entry 8$)$. Thus, 3 equiv. of DBH and 6 equiv. of Olah's reagent were found to be optimal for the desulfurization-difluorination reactions.

\section{$\underline{\mathrm{DBH}} v_{s}$ NBS $v_{s}$ NIS}

Treatment of ethyl 2-((4-chlorophenyl)thio)octanoate 74 with $\mathrm{N}$ bromosuccinimide (NBS; 3 eq.) and Olah's reagent (6 eq.) in $\mathrm{CH}_{2} \mathrm{Cl}_{2}$ at $35{ }^{\circ} \mathrm{C}$ for $2 \mathrm{~h}$ followed by aqueous workup showed complex ${ }^{1} \mathrm{H}-\mathrm{NMR}$ spectrum and the difluoroocatnoate 77 was only found to be $25 \%$ according to the ${ }^{19}$ F-NMR of the crude. There was no increase in $\%$ of difluoro product 77 even after stirring for $4 \mathrm{~h}$ at $35{ }^{\circ} \mathrm{C}$ (entry 9). Analogous treatment of $\mathbf{7 4}$ with $N$-iodosuccinimide (NIS; 3 eq.) and Olah's reagent (6 eq.) in $\mathrm{CH}_{2} \mathrm{Cl}_{2}$ at $35{ }^{\circ} \mathrm{C}$ for $24 \mathrm{~h}$ gave very complex ${ }^{1} \mathrm{H}$-NMR and ${ }^{19} \mathrm{~F}-\mathrm{NMR}$, with the difluoroproduct 77 was found to be $5 \%$ (entry 10). Thus, DBH was proven to be more effective than other halogen oxidants such as NBS or NIS, as observed by Haufe, et al. $^{43}$

Table 6. Desulfurization-difluorination studies of $\alpha$-thioester derivatives with $\mathrm{DBH} / \mathrm{Py} .9 \mathrm{HF}^{a}$ 


\begin{tabular}{|c|c|c|c|c|c|c|c|}
\hline Entry & Substrate & $\mathrm{X}$ & $\begin{array}{c}\text { Oxidant } \\
(\mathrm{eq})\end{array}$ & $\begin{array}{c}\text { Py.9HF } \\
(\mathrm{eq})\end{array}$ & $\begin{array}{c}\text { Temp. } \\
\text { ( }\end{array}$ & $\begin{array}{c}\text { Time } \\
(\mathrm{h})\end{array}$ & Yield $^{b}$ \\
\hline 1 & $\mathbf{7 2}$ & $\mathrm{H}$ & $\mathrm{DBH}(3)$ & 6 & 25 & 2 & $80 \%$ \\
\hline 2 & $\mathbf{7 2}$ & $\mathrm{H}$ & $\mathrm{DBH}(3)$ & 6 & 25 & 4 & $90 \%$ \\
\hline 3 & $\mathbf{7 2}$ & $\mathrm{H}$ & $\mathrm{DBH}(3)$ & 6 & 35 & 1 & $85 \%$ \\
\hline 4 & $\mathbf{7 2}$ & $\mathrm{H}$ & $\mathrm{DBH}(3)$ & 6 & 35 & 2 & $95 \%$ \\
\hline 5 & $\mathbf{7 3}$ & $\mathrm{Cl}$ & $\mathrm{DBH}(3)$ & 6 & 25 & 1 & $85 \%$ \\
\hline 6 & $\mathbf{7 3}$ & $\mathrm{Cl}$ & $\mathrm{DBH}(3)$ & 6 & 25 & 2 & $90 \%$ \\
\hline 7 & $\mathbf{7 3}$ & $\mathrm{Cl}$ & $\mathrm{DBH}(3)$ & 6 & 35 & 1 & $95 \%$ \\
\hline 8 & $\mathbf{7 3}$ & $\mathrm{Cl}$ & $\mathrm{DBH}(2)$ & 4 & 35 & 1 & $80 \%$ \\
\hline 9 & $\mathbf{7 4}$ & $\mathrm{Cl}$ & $\mathrm{NBS}(3)$ & 6 & 35 & 4 & $25 \%$ \\
\hline 10 & $\mathbf{7 4}$ & $\mathrm{Cl}$ & $\mathrm{NIS}(3)$ & 6 & 35 & 24 & $5 \%$ \\
\hline 11 & $\mathbf{7 5}$ & $\mathrm{OCH}_{3}$ & DBH (3) & 6 & 35 & 16 & $70 \%$ \\
\hline
\end{tabular}

${ }^{a}$ Reactions were typically carried out in $0.5 \mathrm{mmol}$ scale in $\mathrm{CH}_{2} \mathrm{Cl}_{2}$

${ }^{b}$ Yields were determined based on conversion of substrate to product as determined by ${ }^{1} \mathrm{H},{ }^{13} \mathrm{C},{ }^{19} \mathrm{~F}$ NMR and/or GC-MS.

Continuing with my optimization studies, I then treated ethyl 2-((4methoxyphenyl)thio)hexanoate $\mathbf{7 5}$ under the established conditions of DBH/Py.9HF (3equiv./6equiv.) in $\mathrm{CH}_{2} \mathrm{Cl}_{2}$ at $35{ }^{\circ} \mathrm{C}$. However, the reaction was very sluggish in nature and gave ethyl 2,2-difluorohexanoate 76 in 70\% NMR purity after $16 \mathrm{~h}$ of stirring (entry 11). Thus, it was concluded that 4-chlorophenyl thioethers reacted faster than the corresponding phenyl and 4-methoxyphenyl thioethers, as noted by Haufe, et al. ${ }^{43}$

The variations in reactivity with change in the para substituent of the aromatic group of the thioether can be explained by the plausible mechanism proposed by Haufe, et al., for the desulfurization-difluorination reactions. ${ }^{43}$ 


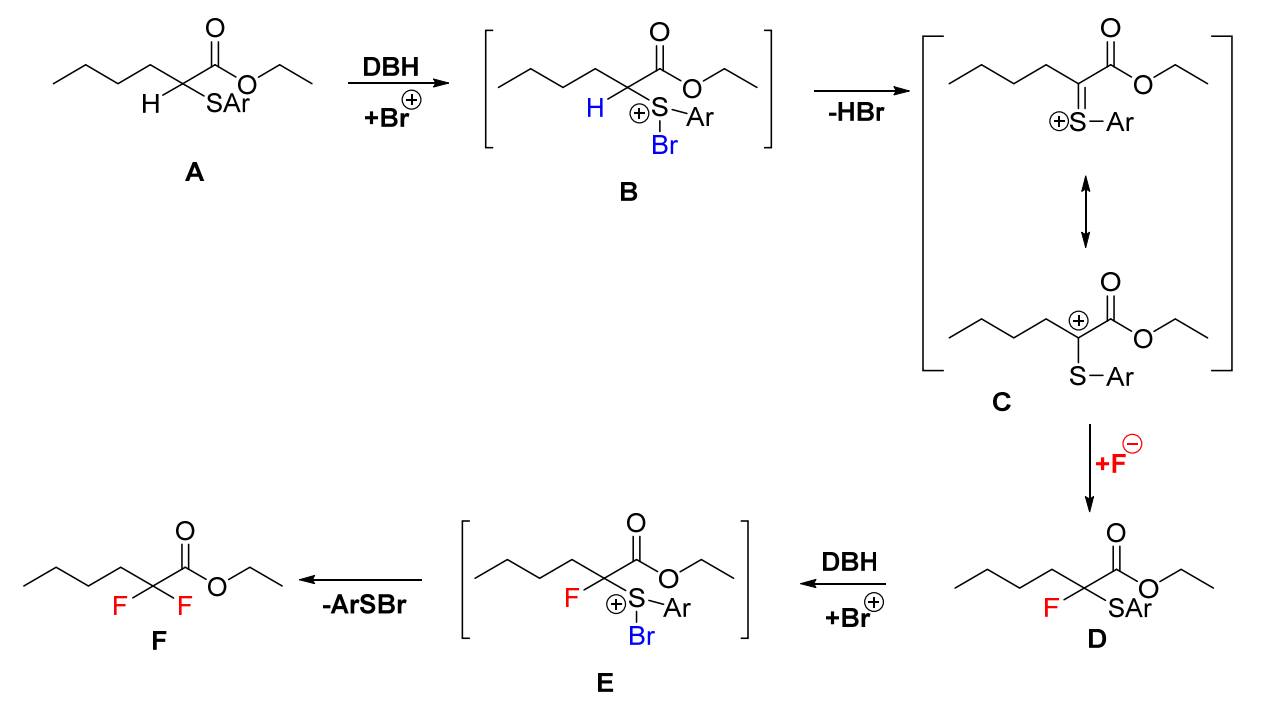

Scheme 11. Proposed mechanism for the oxidative desulfurization-difluorination of alkyl-aryl thioethers by DBH/Py.9HF

The electron-donating groups (such as $\mathrm{OMe}$ ) on the phenyl ring are thought to stabilize the cationic charge on the resonance stabilized carbenium-sulfonium ion intermediate (type $\mathbf{C}$, Scheme 11) and thus promote the first fluorination step; while electron-withdrawing substituents (such as $\mathrm{Cl}$ ) are thought to ease the elimination of arylsulfenyl bromide (from type $\mathbf{E}$ ) in the last step and therefore promote the second fluorination step. The proposed mechanism was supported by the observation that 4chlorophenyl thioether took half the time than the regular phenyl thioether (Table 6, entries 1-4 vs 5-7); whereas 4-methoxyphenyl thioether reaction never went to completion under analogous reaction conditions (entry 11).

Ester $v s$ aldehyde $v s$ ketone $v s$ alkane

Next, I attempted to extend the desulfurization-difluorination of $2^{\circ}$ alkyl-aryl thioethers to substrates with other functional groups on the $\alpha$-position of the thioether moiety. Thus, the 2-((4-chlorophenyl)thio)-3-phenylpropanal (78) $)^{127}$ and 2-((4- 
chlorophenyl)thio)-1-phenylpropan-1-one (79), ${ }^{128}$ which have a carbonyl functional group on the $\alpha$-carbon similar to an ester; and $\alpha$-thioalkane $(\mathbf{8 0})$, which does not have a carbonyl group on the $\alpha$-carbon; were prepared from their corresponding $\alpha$-bromo counterparts (Figure 20).
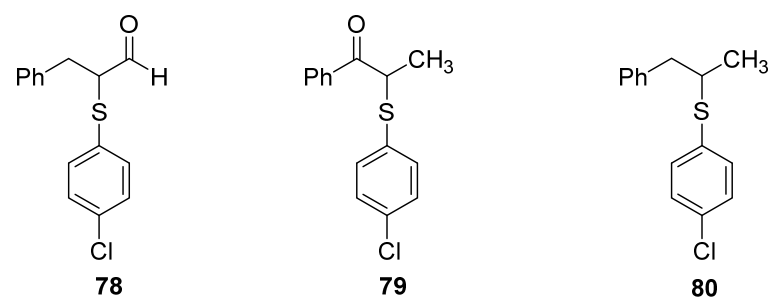

Figure 20. $\alpha$-Thioaldehyde, $\alpha$-thioketone and $\alpha$-thioalkane substrates for attempted desulfurization-(di)fluorination reactions.

However, treatment of $\alpha$-thioaldehyde $\mathbf{7 8}$ with DBH (3 equiv.) and Py.9HF (6 equiv.) in $\mathrm{CH}_{2} \mathrm{Cl}_{2}$ at $35{ }^{\circ} \mathrm{C}$ for $1 \mathrm{~h}$, followed by aqueous workup showed complex ${ }^{1} \mathrm{H}$ NMR spectrum and no signals in the ${ }^{19}$ F-NMR. And similar results were obtained when $\alpha$-thioketone 79 and $\alpha$-thioalkane 80 were treated with $\mathrm{DBH} / \mathrm{Py}$.9HF under analogous reaction conditions. No fluorination was observed with either of the three substrates even after using excess amounts of $\mathrm{DBH}$ and Py.9HF, at higher temperatures and for prolonged reaction times. Thus it was implied that my protocol for the deseulfurizationdifluorination of secondary/internal thioethers works for compounds with only ester functional groups on the $\alpha$-carbon.

As a result of functional group similarities between esters and lactones, I then tried to extend the application of the desulfurization-defluorination methodology towards the synthesis of gem-difluorinated lactone derivatives. Thus, treatment of 2-phenylthio5-pentanolide 81 ${ }^{129}$ with DBH (4 equiv.) and Py.9HF (8 equiv.) in $\mathrm{CH}_{2} \mathrm{Cl}_{2}$ at $35^{\circ} \mathrm{C}$ for 2 $\mathrm{h}$, followed by aqueous workup gave yellow oil, which showed complex ${ }^{1} \mathrm{H}-\mathrm{NMR}$ 
(Scheme 12). The ${ }^{19} \mathrm{~F}-\mathrm{NMR}$ of the crude material showed triplets in the range of -100 ppm $(J=15.8 \mathrm{~Hz})$, in agreement with the literature ${ }^{19} \mathrm{~F}-\mathrm{NMR}$ peaks for gemdifluorolactones, ${ }^{130}$ thus indicating the presence of the gem-difluorinated product $\mathbf{8 2}$. Increase in duration of the reaction gave even more complex ${ }^{19} \mathrm{~F}$-NMR spectrum. Therefore, considering the volatile and unstable nature of the difluorolactones, I chose to pursue less volatile 2,3-dideoxy-2-thioribonolactone precursors of type $\mathbf{8 3}$.

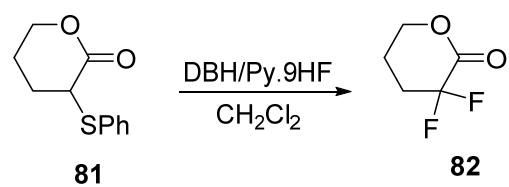

Scheme 12. Attempted synthesis of $\alpha, \alpha$-difluoro- $\delta$-valerolactone $\mathbf{8 2}$.

Thus, treatment of $(S)-(+)-2-$ phenylthio-4-benzyloxymethyl-4-butanolide $\mathbf{8 3}^{131}$ with DBH (4 equiv.) and Py.9HF (8 equiv.) in $\mathrm{CH}_{2} \mathrm{Cl}_{2}$ at $35{ }^{\circ} \mathrm{C}$ for $16 \mathrm{~h}$, followed by aqueous workup showed complex TLC and multiple products on ${ }^{1} \mathrm{H}$-NMR (Scheme 13). The ${ }^{19} \mathrm{~F}$-NMR of the crude material showed multiplets in the region of -140 ppm and $150 \mathrm{ppm}$. And HRMS showed $\mathrm{m} / \mathrm{z}$ corresponding to $\alpha$-fluorosulfide 84 and $\alpha$ fluorosulfoxide 85. This indicates that monofluorination occurred, albeit in very low yield.
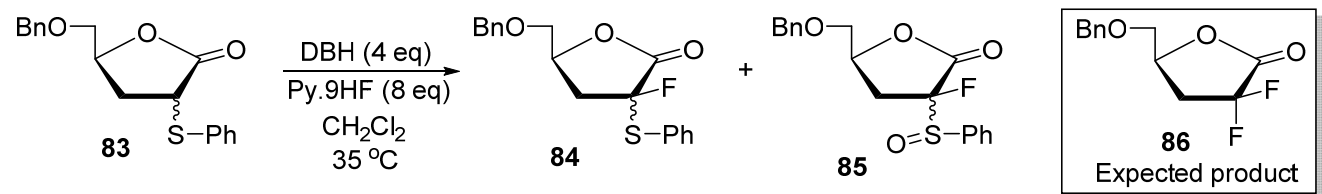

Scheme 13. Attempted synthesis of $\alpha, \alpha$-difluoro- $\gamma$-butyrolactone 86 . 


\subsubsection{Oxidative desulfurization-fluorination approaches with uridine derivatives}

Although my attempts in oxidative desulfurization-difluorination of 2,3-dideoxy2-(phenylthio)-2-S-ribonolactone precursor (83) were partially encouraging, I next attempted analogous fluorination on 2'-S-aryl-2'-thiouridine analogues 89/90 and 2'-Saryl-2'-deoxy-2'-fluoro-2'-thiouridine analogue 93, since the substrates were readily available for us (Scheme 14). The precursors 2'-S-(4-chlorophenyl)-2'-thiouridine 87 and 2'-S-(4-methoxyphenyl)-2'-thiouridine $\mathbf{8 8}$ were synthesized in three steps from uridine following the well-established procedure of preparing $2,2^{\prime}$-anhydroarabinouridine ${ }^{132}$ from uridine followed by ring opening with thiolates. ${ }^{133,134}$ The precursor 2'-S-(4chlorophenyl)-2'-thiouridine $\mathbf{8 7}$ was prepared by a slight modification of the published procedure. ${ }^{121}$ The 4-chlorothiphenol reagent was stirred with $\mathrm{PPh}_{3}$ in $\mathrm{DMF}$ for $30 \mathrm{~min}$ at room temperature before refluxing with 2,2'-anhydroarabinouridine, to reduce all the possible disulfide to the free thiol. Subsequent protections of 3',5'-hydroxyl groups and/or $N 3$ with either acetyl or benzyl protection groups gave the desired 2'-S-aryl-2'-thiouridine precursors 89/90. The second class of substrates required for desulfurization-fluorination reactions is $\alpha$-fluoro thioether derivatives $\mathbf{9 3}$, which can be synthesized from thioether 90 by oxidation to the corresponding sulfoxides and subsequent fluorination of sulfoxides $\mathbf{9 2}^{135,136}$ with $\mathrm{DAST} / \mathrm{SbCl}_{3}$, as reported. ${ }^{134}$ In addition, sulfone precursors for reductive desulfonylation-fluorination reactions were also readily prepared, following literature protocols. ${ }^{134}$ Thus, oxidation of the $2^{\prime}-S$-aryl-2'-thiouridine precursors $89 / 90$ with metachloroperoxybenzoic acid (mCPBA) at ambient temperature gave the corresponding 2'deoxy-2'-arylsulfonyluridine derivatives 91/92. Analogously, 2'-deoxy-2'-fluoro-2'-(4methoxyphenyl)sulfonyluridine derivative 95 was obtained by treatment of 2'-deoxy-2'- 
fluoro-2'-(4-methoxyphenyl)sulfonyluridine derivative 94 with mCPBA at ambient temperature.
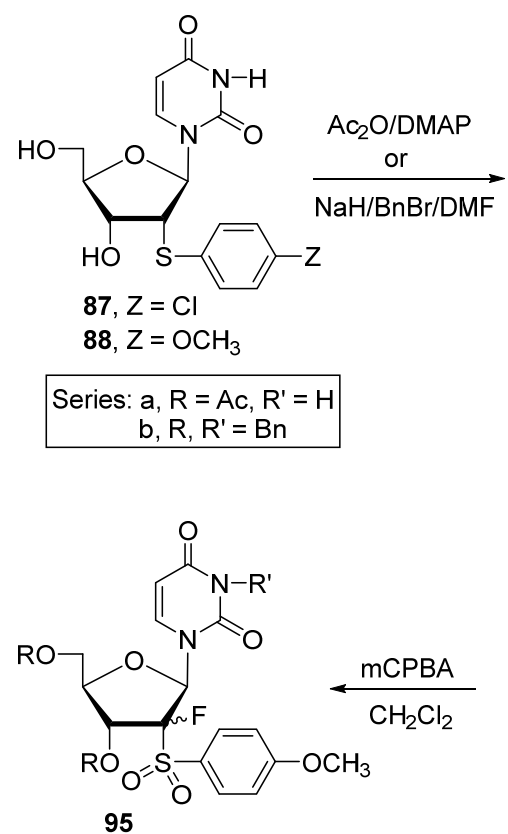

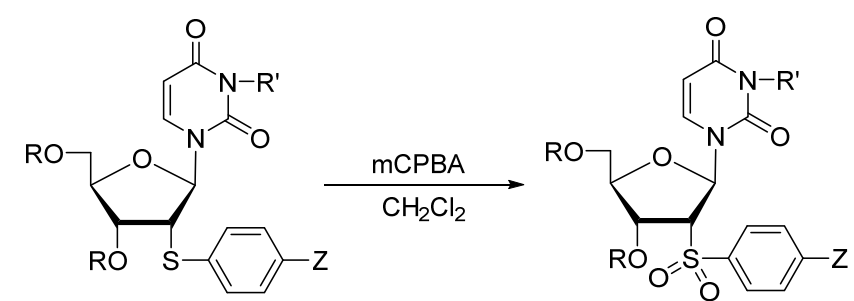

89, $\mathrm{Z}=\mathrm{Cl}$

$90, \mathrm{Z}=\mathrm{OCH}_{3}$

91, $\mathrm{Z}=\mathrm{Cl}$

92, $\mathrm{Z}=\mathrm{OCH}_{3}$

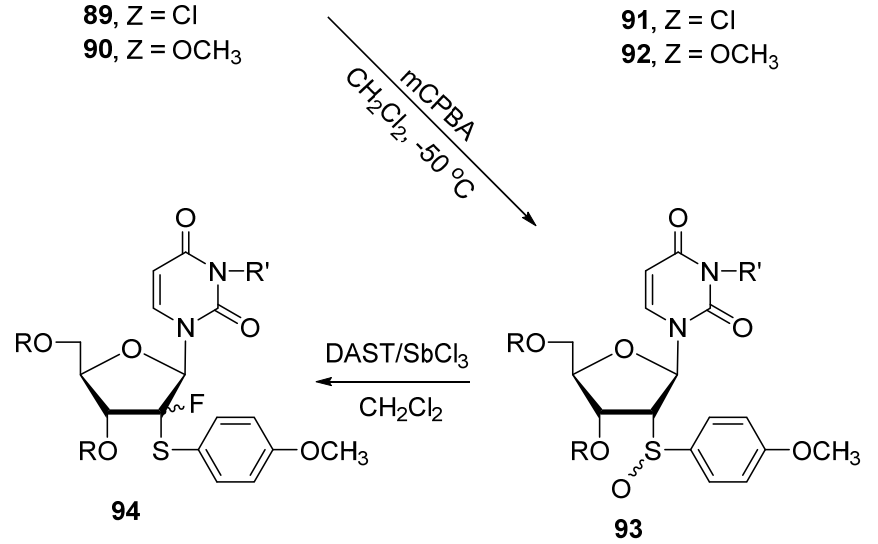

Scheme 14. Synthesis of 2'-arylthio substrates for the desulfurization-fluorination reactions.

Treatment of $3^{\prime}, 5^{\prime}$-di-O-acetyl-2'-S-(4-chlorophenyl)-2'-thiouridine $89 \mathbf{a}$ with DBH/Py. $9 \mathrm{HF}$ at $-78{ }^{\circ} \mathrm{C}$, under Argon atmosphere for $2 \mathrm{~h}$ showed three new spots on TLC (Scheme 15). Aqueous workup followed by column chromatography yielded three different products in $41 \%, 18 \%$ and $30 \%$ respectively. The first product was established to be 5-bromo-3',5'-di-O-acetyl-2'-S-(4-chlorophenyl)-2'-thiouridine $\quad(\mathbf{9 6 a}, \quad 41 \%)$. Signature peak ( $\mathrm{d}$ or $\mathrm{dd}$ ) for $\mathrm{H} 5$ at $5.67 \mathrm{ppm}$ in ${ }^{1} \mathrm{H}-\mathrm{NMR}$ was missing and the corresponding doublet for $\mathrm{H} 6$ (7.17 ppm) was collapsed to a singlet (6.98 ppm), implying a C5-brominated product, which probably was caused by DBH. The remaining two products were C5-brominated sulfoxide diastereoisomers [97 $(R / S-\mathrm{S})]$. Doublet of doublets for $\mathrm{H} 2$ ' was found at $3.92 \mathrm{ppm}$ for the faster moving sulfoxide and at 3.72 for 
the slower moving isomer. In comparison, peak for $\mathrm{H} 2$ ' for the C5-brominated product 96 was at $3.47 \mathrm{ppm}$, and for the substrate $\mathbf{8 9 a}$ was at $3.78 \mathrm{ppm}$.

Fluorination attempts of 89a employing Py.9HF/NBS also gave the corresponding 5-brominated derivative 96a as major product (conditions not shown in scheme), while no desired fluorination was observed $\left({ }^{19} \mathrm{~F}-\mathrm{NMR}\right.$; data not shown). Based on these findings, a novel and efficient protocol for $\mathrm{C} 5$-bromination of pyrimidine nucleosides and C8-bromination of purine nucleosides with DBH and/or Lewis acids has been developed. ${ }^{137}$ Analogous treatment of 89a with the recently developed NIS/DAST system ${ }^{138,139}$ at $\mathrm{rt}$ as well as at $35^{\circ} \mathrm{C}$ gave the corresponding 5 -iodinated analogue $96 \mathbf{b}$ in $73 \%$ and $60 \%$ isolated yields respectively, with no indication of the fluorinated products.

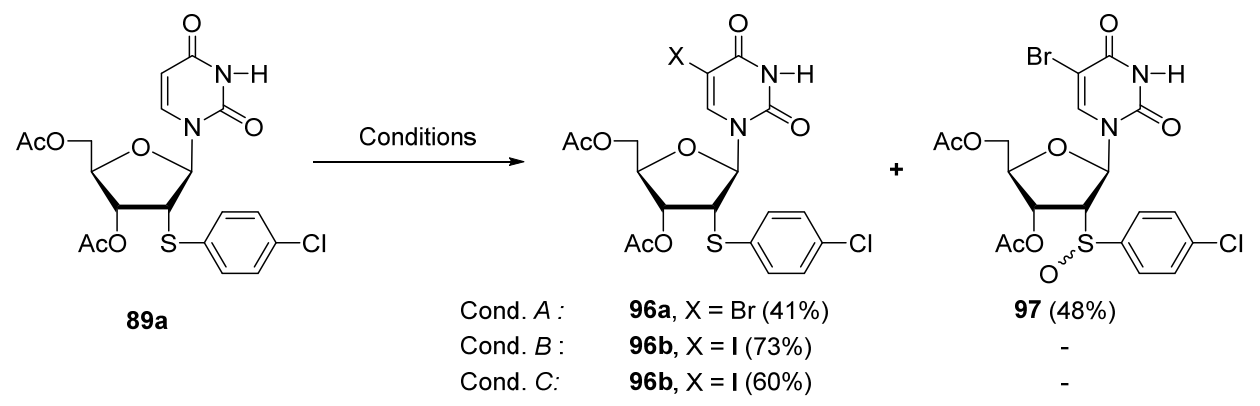

Scheme 15. Oxidative desulfurization-difluorination of 2'-S-aryl-2'-thiouridine analogue 89a. Conditions $A$ : DBH (1.1 eq), Py. $9 \mathrm{HF}$ (excess), $\mathrm{CH}_{2} \mathrm{Cl}_{2},-78^{\circ} \mathrm{C}, 2 \mathrm{~h}$; Conditions $B$ : NIS (3 eq), DAST (6 eq), $\mathrm{CH}_{2} \mathrm{Cl}_{2}, 0{ }^{\circ} \mathrm{C}(6 \mathrm{~h})$, then rt (32 h); Conditions $C$ : NIS (3 eq), $\operatorname{DAST}(6 \mathrm{eq}), \mathrm{CH}_{2} \mathrm{Cl}_{2}, 35^{\circ} \mathrm{C}, 24 \mathrm{~h}$.

Treatment of 89a with DBH (3 eq.)/Py.9HF (6 eq.) $/ \mathrm{CH}_{2} \mathrm{Cl}_{2} / 35{ }^{\circ} \mathrm{C} / 24$ h gave a complex reaction mixture showing formation of the 5-bromo-2'- $\alpha$-fluorosulfoxide 99a $\left(<10 \%\right.$ according to ${ }^{1} \mathrm{H},{ }^{19} \mathrm{~F}$ NMR of the crude; data not shown; Figure 21$)$. Changing the acetyl protection group for a benzyl group did not improve the outcome of the reaction. Treatment of the fully benzylated $\mathbf{8 9 b}$ with DBH (5 eq.)/Py.9HF (10 eq.) $/ \mathrm{CH}_{2} \mathrm{Cl}_{2} / 35$ 
${ }^{\circ} \mathrm{C} /$ overnight gave a complex mixture indicating the formation of 5-bromo-2'- $\alpha$ fluorosulfide 98 or 5-bromo-2'- $\alpha$-fluorosulfoxide $99 \mathbf{b}\left({ }^{1} \mathrm{H},{ }^{19} \mathrm{~F}-\mathrm{NMR}\right.$ of the crude).

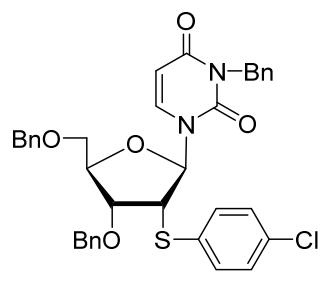

$89 b$

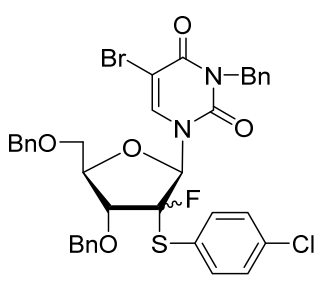

98

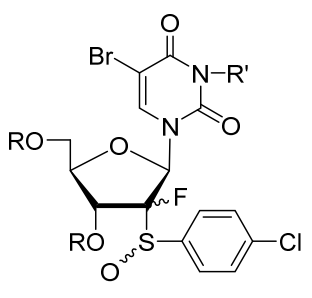

99a, R = Ac, $R^{\prime}=H$ 99b, $R=R^{\prime}=B n$

Figure 21. Products for attempted fluorination of 2'-S-(4-chlorophenyl)-2'-thiouridine derivatives 89a and 89b

Similarly, treatment of fully benzylated 2'-S-(4-methoxyphenyl)-2'-thiouridine 90b with NIS (2.1 eq.)/Py.9HF (3 eq.) gave the corresponding 5-iodocounterpart (100, $29 \%$ ) and the $\alpha$-fluorothioether (94b, 12\%) (Scheme 16). Analogous treatment of $\mathbf{9 0 b}$ with the recently developed NIS/DAST system ${ }^{138,139}$ yielded the $\alpha$-fluorothioether $94 \mathbf{b}$ in $44 \%$ isolated yield when 2.1 equiv. of NIS and 6 equiv. of DAST were used. Interestingly, the 5-iodo derivative $\mathbf{1 0 0}$ was not observed with NIS/DAST system. However, both the reactions failed to generate the desired geminal difluoro uridine product. On the other hand, treatment of $90 \mathbf{b}$ with DBH (3 eq.)/Py. $9 \mathrm{HF}\left(6\right.$ eq.) $/ 35{ }^{\circ} \mathrm{C}$ generated a complex reaction mixture Thus, it is noteworthy to conclude that NIS/DAST system provided clean conversion of sulfide $90 \mathrm{~b}$ to the mono-fluorinated analogue $94 \mathrm{~b}$ in respectable yield.

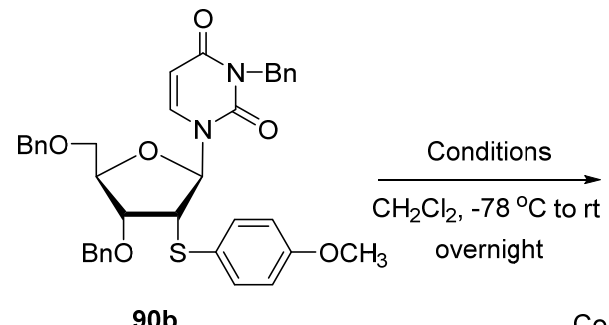

$90 \mathrm{~b}$

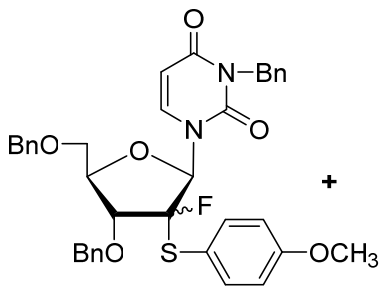

$94 b(12 \%)$

$94 b(44 \%)$

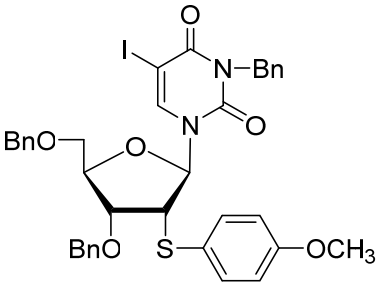

$100(29 \%)$ 
Scheme 16. Attempted oxidative desulfurization-fluorination of 2'-S-(4-methoxyphenyl)2 '-thiouridine analogue 90b. Conditions $A$ : NIS (2.1 eq), Py.9HF (3 eq); Conditions $B$ : NIS (2.1 eq), DAST (6 eq).

Next, the $\alpha$-fluorothioether $\mathbf{9 4 b}$, was also directly explored as substrate for the second fluorination step leading to the expected gem-difluorouridine derivative. Unfortunately, treatment of $94 \mathrm{~b}$ with $\mathrm{DBH} / \mathrm{Py} .9 \mathrm{HF}$ at $-78{ }^{\circ} \mathrm{C}$ gave the corresponding 5brominated derivative as major product $(\mathbf{1 0 1}, 50 \%)$, with no indication of the geminal difluoro product (Scheme 17). The introduction of the desired second fluorine atom was unsuccessful even when excess reagents, higher temperatures, and longer reaction times were employed.

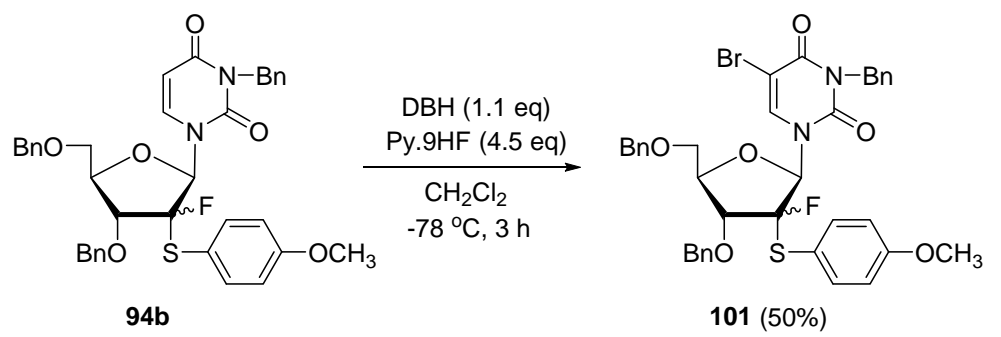

Scheme 17. Attempted oxidative desulfurization-fluorination of 2'-fluoro-2'-S-(4methoxyphenyl)-2'-thiouridine analogue 94b with DBH/Py.9HF.

\subsubsection{Reductive desulfonylation-fluorination approaches}

Since the oxidative desulfurization-difluorination approaches on 2'-arylthiouridine derivatives were overshadowed by the formation of 5-halogenated byproducts and were not very promising for the introduction of the geminal difluoro unit, I turned my attention to reductive fluorination approaches of 2'-arylsulfonyluridine substrates. Reductive desulfonylation-(di)fluorination protocols are to the best of my knowledge, unknown processes, while chemical and electrochemical-induced reductive desulfonylation reactions have been known for years. ${ }^{140-150}$ Chemical and electrochemical redox 
strategies have rarely been reported in nucleoside series, except some reductive dehalogenation or desulfonylation protocols en route to 2',3'-dideoxy-2',3'-didehydro nucleosides with anti-HIV and anti-HBV properties. ${ }^{151-160}$

This part of the dissertation was completed in collaboration with Dr. Maurice Medebielle of Université Claude Bernard Lyon 1, France; Dr. Gamal Giuglio and Dr. Julie Broggi of Aix-Marseille Université, France.

\subsubsection{Cyclic voltammetry studies of 2 '-arylsulfonyl uridine derivatives}

Initially, our collaborators performed cyclic voltammetry studies with various 2'deoxy-2'-S-(arylsulfonyl)-2'-thiouridine and 2'-deoxy-2'-fluoro-2'-S-(arylsulfonyl)-2'thiouridine substrates to find out the reduction potential at which the sulfone moiety could be cleaved. Sulfone derivatives 92a and 92b (see Scheme 14 for structures), were found to be reduced in two irreversible reduction steps in DMF containing $0.1 \mathrm{M} \mathrm{n}$ $\mathrm{Bu}_{4} \mathrm{NPF}_{6}$ on a glassy carbon electrode, at almost identical reduction potentials $[-2.73 \mathrm{~V}$ and $-2.95 \mathrm{~V}$ for $\mathbf{9 2 a}$; $-2.73 \mathrm{~V}$ and $-2.92 \mathrm{~V}$ for $\mathbf{9 2 b}$ (peak potentials at $0.2 \mathrm{~V} / \mathrm{s}$, Figure $22)$. For both substrates, the first irreversible reduction step $\left(E_{p c 1}\right)$ corresponded to the cleavage of the $\mathrm{C}^{2}$-S bond with the expulsion of the $p$-methoxybenzenesulfinate, ${ }^{161}$ that can be irreversibly oxidized at $+0.02 \mathrm{~V}\left(\mathrm{E}_{\mathrm{pa} 2}\right)$. The irreversibility of the first reduction step $\left(E_{p c 1}\right)$ is an indication that the first electron transfer is followed by a chemical reaction producing a new product that is in turn reduced at a more negative potential corresponding to the second reduction step $\left(\mathrm{E}_{\mathrm{pc} 2}\right)$. Additional irreversible oxidation steps, only observed after scanning first to reduction potentials and then switching to anodic values, located at +0.57 and $+0.81 \mathrm{~V}\left(\mathbf{9 2 a}, \mathrm{E}_{\mathrm{pa} 3}\right.$ and $\left.\mathrm{E}_{\mathrm{pa} 4}\right)$ and $+0.51 \mathrm{~V}\left(\mathbf{9 2 b}, \mathrm{E}_{\mathrm{pa} 3}\right)$ (peak potentials at $0.2 \mathrm{~V} / \mathrm{s}$ ) were also noticed. 


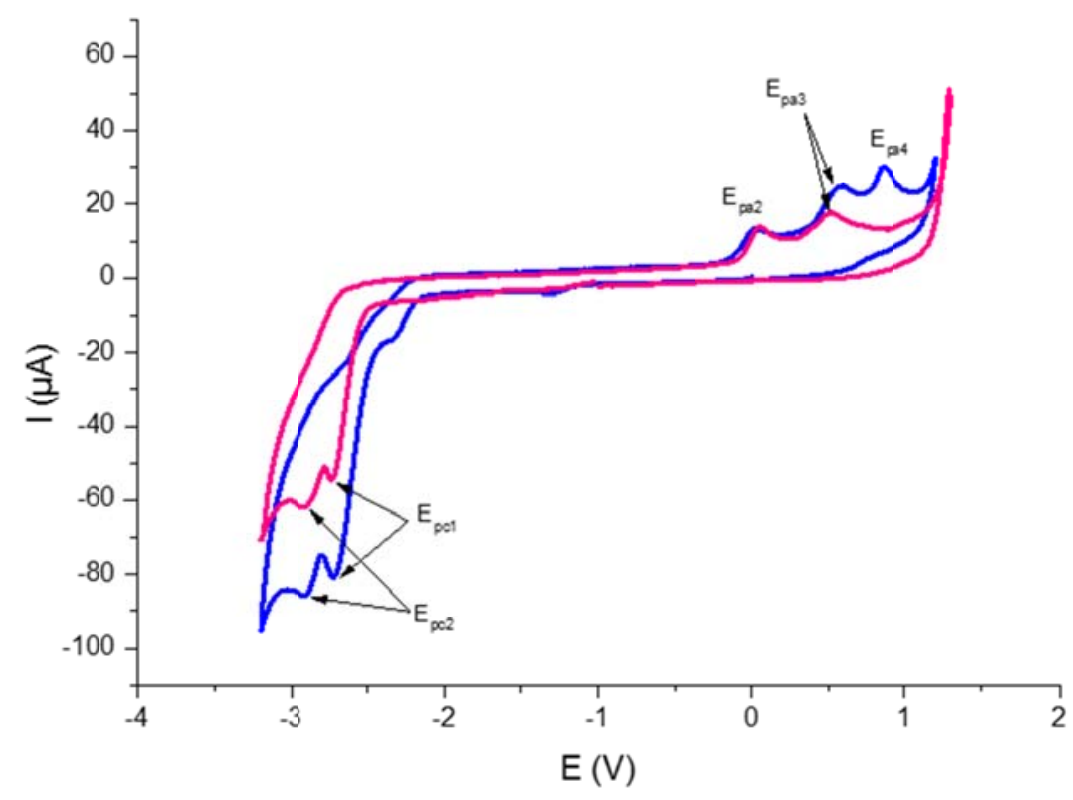

Figure 22. Cyclic voltammetry of $\alpha$-sulfones $92 \mathbf{a}(C=2.25 \mathrm{mM}$, blue curve) and 92b ( $C$ $=2.75 \mathrm{mM}$, pink curve); in DMF $+n-\mathrm{Bu}_{4} \mathrm{NPF}_{6} 0.1 \mathrm{M} ; \mathrm{v}=0.2 \mathrm{~V} / \mathrm{s}$.

Cyclic voltammetry of 2'- $\alpha$-fluorosulfone precursors 95a-b (see Scheme 14 for structures) was also investigated in DMF in order to estimate their reduction potentials. Both substrates are reduced irreversibly at potentials close to $-2.67 \mathrm{~V}\left(v s \mathrm{Ag} / \mathrm{Ag}^{+}\right)$ meaning that the reduction takes place at relatively high reduction potential not far from uracil moiety reduction (Figure 23). For both substrates an irreversible oxidation step is located at $+0.025 \mathrm{~V}$ only observed when scanning in the cathodic direction. None of the nucleosides are oxidized up to $+1.5 \mathrm{~V}$. 


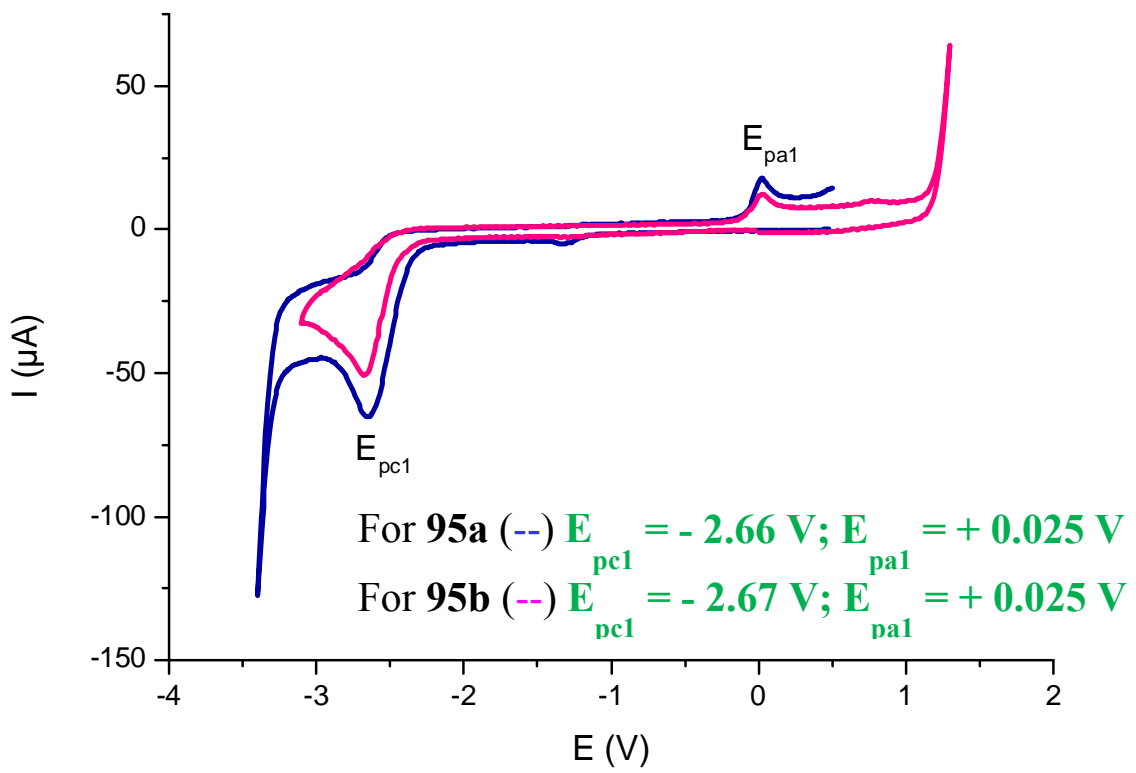

Figure 23. Cyclic voltammetry of $\alpha$-fluorosulfones 95a $(2.64 \mathrm{mM})$ and $95 \mathbf{b}(2.91 \mathrm{mM})$ in $\mathrm{DMF}+\mathrm{NBu}_{4} \mathrm{PF}_{6}$ 0.1 M; glassy carbon electrode.

The data obtained by cyclic voltammetry in DMF indicated that the cleavage of the C2'-S bond, although possible will require (i) quite negative potential under electrochemical activation and (ii) strong chemical reducing agents. Also glycosidic bond cleavage may operate as well at such negative potentials as it is apparently the case for substrates 92a-b. However, from cyclic voltammetry data, it is not obvious to conclude what the possible reduction products resulting after the expulsion of the $p$ methoxybenzenesulfinate are, at least on the time scale of the cyclic voltammetry. Tentative isolation and characterization of the reductive products, either with the use of chemical reducing agents or using electrochemical activation, was therefore necessary. 


\subsubsection{Reductive desulfonylation-fluorination studies of $2^{\prime}$-deoxy-2'-arylsulfonyl}

uridine and 2'-deoxy-2'-fluoro-2'-arylsulfonyl uridine substrates

During preparation of sulfone substrates for the reductive fluorination approaches,

I observed an interesting result. Purification of 3 ',5'-di- $O$-acetyl-2'-deoxy-2'-[(4chlorophenyl)sulfonyl]uridine (91a) on silica gel column resulted in the overall elimination of acetic acid to generate 2',3'-didehydro-2',3'-dideoxysulfone $\mathbf{1 0 2}$ as a major product, which has same $\mathrm{R}_{\mathrm{f}}$ value as starting material and thus inseparable (1.5:1 ratio of 102:91a; ${ }^{1} \mathrm{H}-\mathrm{NMR}$ ) (Scheme 18). Structure of the product was confirmed by ${ }^{1} \mathrm{H}-\mathrm{NMR}$ (doublet at $7.01 \mathrm{ppm}$ with coupling constant of $1.9 \mathrm{~Hz}$ for $\mathrm{H}^{\prime}$ ) and also by comparing spectral data with similar 2'-phenylselenonyl derivatives prepared by Chattopadhyaya, et al. ${ }^{162}$ Generation of the elimination product 102 was indicative of the increased acidity of $\mathrm{C} 2$ '-H in C2'-sulfones $91 \mathbf{a}$.
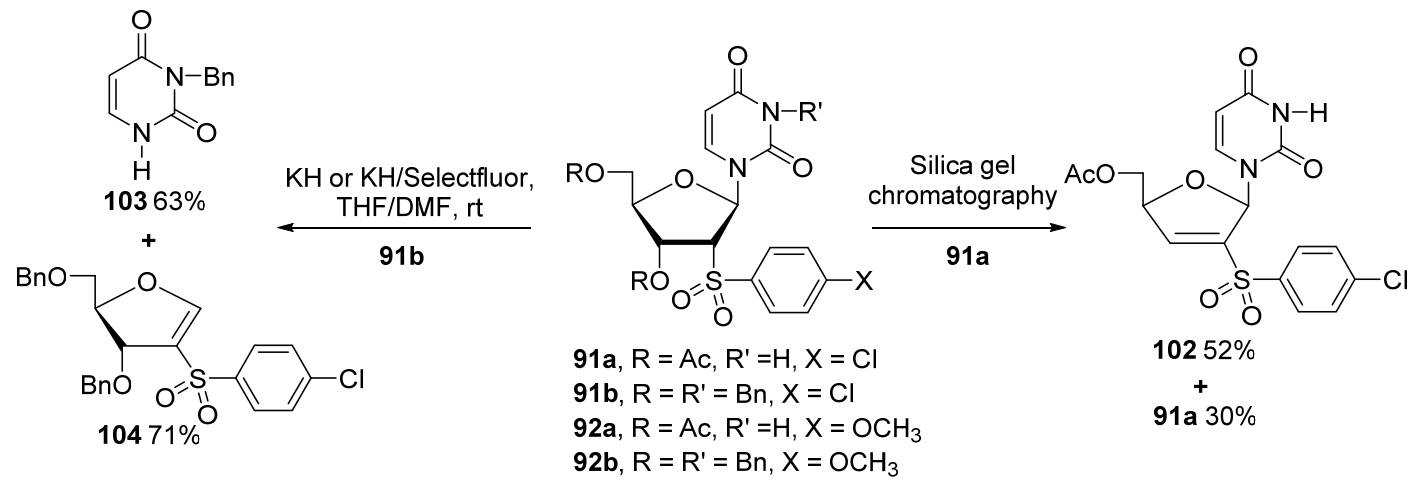

Scheme 18. Stability studies of sulfones 91 a-b on silica gel chromatography or with treatment of base.

To avoid elimination of the acetate group from C3', a stable benzyl protection group was employed ( $\mathrm{pKa}$ of $\mathrm{AcOH}=5 v s \mathrm{pKa}$ of $\mathrm{BnOH}=15)$. As expected, $N 3$-benzyl3',5'-di-O-benzyl-2'-deoxy-2'-[(4-chlorophenyl)sulfonyl]uridine (91b) with benzyl protecting group (poor leaving group) installed on $3^{\prime}, 5^{\prime}$ and $N 3$ positions was stable 
during silica gel column purification. Since the $\mathrm{C} 2{ }^{\prime}-\mathrm{H}$ in $\mathrm{C} 2^{\prime}-$ sulfones 91a-b is quite acidic, I envisioned abstraction of C2'-proton with base followed by entrapment of the resultant of $\mathrm{C} 2^{\prime}$-carbanion with fluoronium ion $\left(\mathrm{F}^{+}\right)$source. However, treatment of sulfone 91b with $\mathrm{KH}$ and Selectfluor in THF/DMF $\left(-78^{\circ} \mathrm{C}\right)$ led to the elimination of 3- $\mathrm{N}$ benzyluracil $103(63 \%)$ via the glycosidic bond cleavage (Scheme 18). I also isolated 3,5di-O-benzyl-1,2-dideoxy-1,2-didehydro-2-[(4-chlorophenyl)sulfonyl]ribose $\quad(\mathbf{1 0 4} ; 71 \%)$ from the reaction mixture, whose structure was established using spectroscopic data. The singlet from the olefinic proton $\mathrm{H} 1$ at $7.4 \mathrm{ppm}$ was diagnostic for the vinyl sulfone sugar 104. It was also found that treatment of sulfone 91b with base only, without Selectfluor, also affected glycosidic bond cleavage to give 103 and 104, consistent with base/Selectfluor system.

Since the base $/ \mathrm{F}^{+}$system proved to be too harsh for the sulfone substrates, I imagined an alternative reduction pathway implying the selective cleavage of the sulfone moiety using organic electron donors. Organic electron donors (OED) are powerful reducing agents able to selectively cleave $\mathrm{C}-\mathrm{X}$ (e.g., $\mathrm{X}=$ halogen) bonds by stepwise transfer of one or two electron(s) under mild reaction conditions. ${ }^{163-170}$ Previous literature studies report the efficient reduction of aryl iodides and bromides to aryl anions, as well as the reductive cleavage of phenylalkylsulfones in excellent yields. ${ }^{171}$ With redox potentials spanning from $-0.62 \mathrm{~V}$ to $-1.24 \mathrm{~V} v s \mathrm{SCE}$ in $\mathrm{DMF}(\sim-0.93 \mathrm{~V}$ to $-1.55 \mathrm{~V} v s$ $\mathrm{Ag} / \mathrm{Ag}^{+} 0.01 \mathrm{M}$ ) (Figure 24), OED could allow us to reductively cleave the aryl-alkyl sulfone in the 2'-sulfone precursors $92 \mathbf{a}-\mathbf{b}$ and $2^{\prime}-\alpha$-fluorosulfone precursors $95 \mathbf{a}-\mathbf{b} .^{172}$ Indeed, in view of the high reduction potential of the arylsulfone moiety compared to OED, transferring one electron would theoretically appear difficult. Nevertheless, as 
pointed out by Murphy et al., ${ }^{38}$ effective redox potentials of organic reducers in solution are much higher than their thermodynamic redox potential determined by electrochemical methods. It is explained by the formation of intimate charge-transfer complexes and ion pairing that eases the electron transfer. Additional $\pi-\pi$ stacking between the SED and nucleoside may help to form intimate complex and facilitate the reduction. Hopefully, the generated carbanion intermediate could then be used in electrophile trapping reactions.
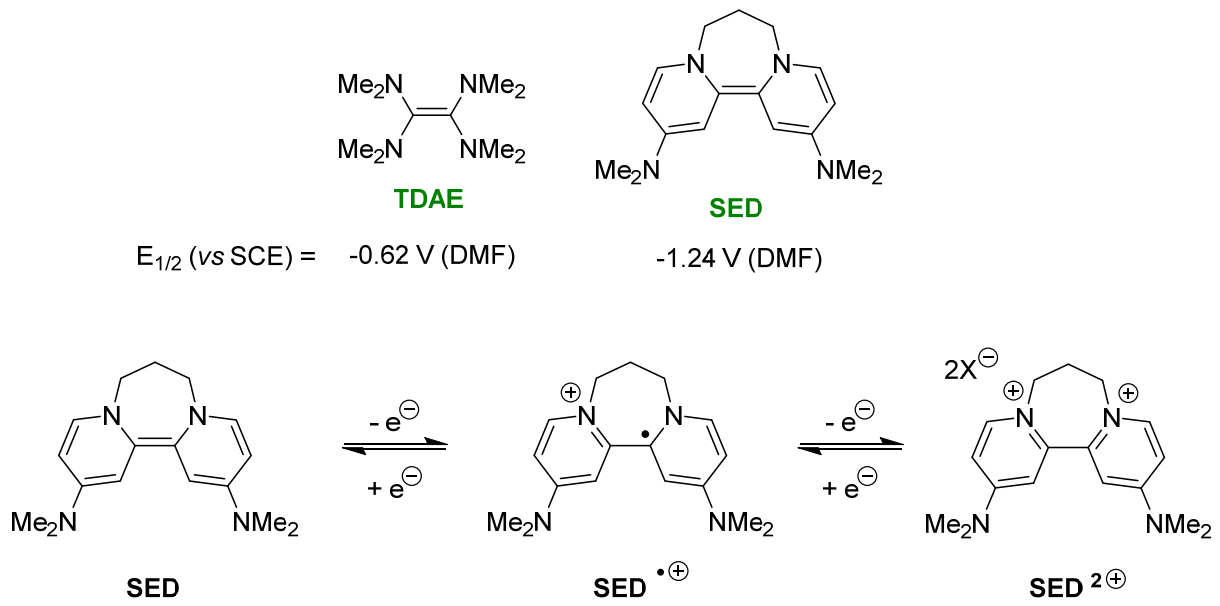

Figure 24. Structures of organic electron donors used for the reductive desulfonylation.

Thus, treatment of sulfone $\mathbf{9 2 a}$ was treated with tetrakis(dimethylamino)ethylene (TDAE) in DMF $\left(-78{ }^{\circ} \mathrm{C}\right.$ to $\left.\mathrm{rt}\right)$ for $1.25 \mathrm{~h}$ followed by aqueous workup and silica gel column chromatography gave furan derivative 105, the enol type (open chain sugar) product 106, and the 3'-acetoxy elimination product 107 as major products (Scheme 19). The anticipated reduction of sulfone moiety was never observed, indicating that the TDAE initially acted as a base and then probably as a reducing agent. It is noteworthy to mention that when 92a was treated with 4-dimethylamino pyridine (DMAP) in DMF at room temperature, almost quantitative formation of $\mathbf{1 0 5}$ was produced, a result supporting the basic pathway (not shown in scheme; data not given). 
Analogous treatment of 92a with one equivalent of the more powerful Murphy's Super Electron Donor $\quad\left(N, N, N^{\prime}, N^{\prime}\right.$-Tetramethyl-7,8-dihydro-6H-dipyrido[1,2-a;2',1'c][1,4]diazepine-2,12-diamine; SED) ${ }^{171}$ in DMF at ambient temperature for $15 \mathrm{~min}$ yielded furan derivative 105 (95\%). The nucleoside base uracil 105a was also identified (but not isolated) by ${ }^{1} \mathrm{H}-\mathrm{NMR}$ in the aqueous phase along with other impurities.
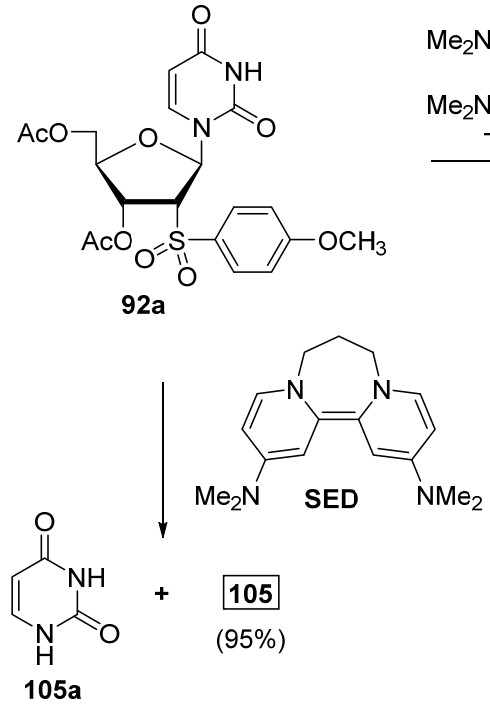

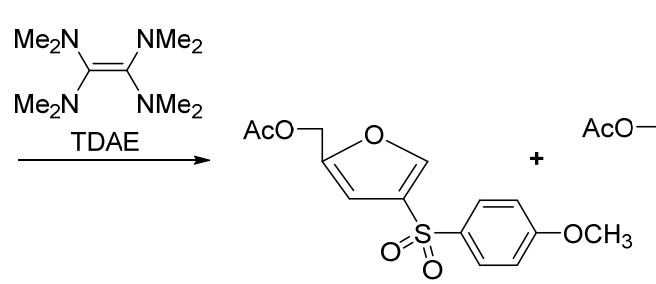

$105(54 \%)$

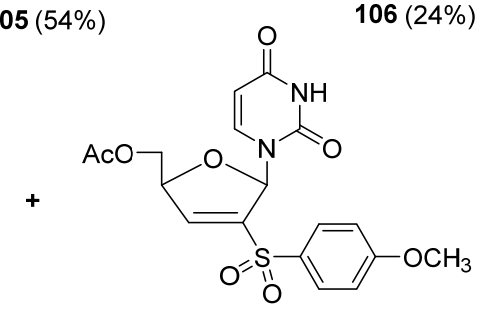

$107(40 \%)$

Scheme 19. Reduction studies of acetyl protected sulfone substrates 91a with TDAE and Murphy's SED.

Since the acetyl protection group in 92a is base labile and is prone to elimination from the intermediate C2'-carbanion, I decided to use benzylated sulfone substrates. However, treatment of $\quad N 3$-benzyl-3',5'-di-O-benzyl-2'-deoxy-2'-[(4chlorophenyl)sulfonyl]uridine (92b) with Murphy's reagent in DMF for 15 min at ambient temperature resulted in a similar, rapid glycosidic bond cleavage producing $3-\mathrm{N}-$ benzyluracil $103 \quad(69 \%)$ and 3,5-di-O-benzyl-1,2-dideoxy-1,2-didehydro-2-[(4methoxyphenyl)sulfonyl]ribose $(\mathbf{1 0 8} ; \mathbf{7 0 \%})$ respectively (Scheme 20). This result is in accordance with the result obtained when $\mathbf{9 2 b}$ was treated with base (Scheme 18) and indicated that SED (in stoichiometric amount) was probably acting exclusively as base 
and not as reducing agent. Also, analogous treatment of $\mathbf{9 2 b}$ with SED for $30 \mathrm{~min}$ at room temperature generated uracil derivative $\mathbf{1 0 3}$ (in $86 \%$ ), furan derivative $\mathbf{1 0 9}$ as a mixture with vinyl sulfone $\mathbf{1 0 8 .}$

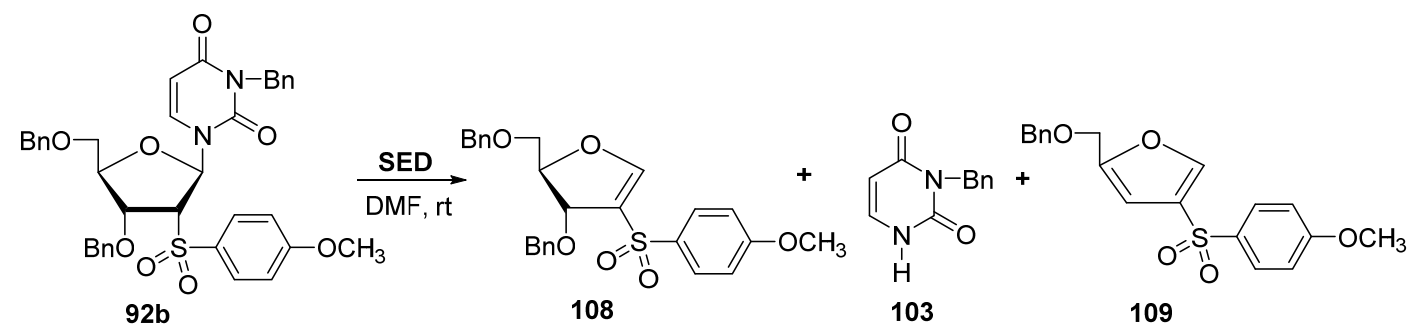

Scheme 20. Reduction studies of benzyl protected sulfone substrate 91b with Murphy's SED.

Since the 2'-sulfone substrates were too labile under the desired reaction conditions, the corresponding $\alpha$-fluorosulfone substrates (95a-b, see Scheme 14 for structures) were chosen for the further reductive-desulfonylation reactions. Initially, stability of the acetyl protected 2'-(4-methoxyphenylsulfonyl)-2'-deoxy-2'-fluorouridine 95a towards tetrakis(dimethylamino)ethylene (TDAE) was evaluated. Thus, treatment of 95a $\left(2^{\prime} R / S, \sim 1: 4.5\right)$ with 2 equiv. or 4 equiv. of TDAE in DMF at $-20{ }^{\circ} \mathrm{C}$ for $1 \mathrm{~h}$ or at room temperature for $3 \mathrm{~h}$ resulted in recovery of unchanged starting material 95a along with 3'-deacetylated byproduct. Longer reaction time (12 h) and higher temperature (60 ${ }^{\circ} \mathrm{C}$ ) produced only a mixture of mono- and di-deacetylated byproducts but no further degradation or glycosidic bond cleavage were observed. Replacement of DMF with $\mathrm{MeCN}$ gave similar results. Addition of TDAE at $0{ }^{\circ} \mathrm{C}$ or above did not cause the reduction of the sulfonyl moiety, indicating that TDAE should be added at low temperatures. Also, replacement of TDAE with other reducing agents such as samarium iodide did not affect the reduction of sulfonyl unit. 
On the other hand, treatment of $\alpha$-fluorosulfone derivative 95a with 1 equiv. of Murphy's Super Electron Donor (SED) in DMF at rt or $120{ }^{\circ} \mathrm{C}$, overnight gave the 3'deacetylated product (110) along with unchanged SM (Scheme 21). Similar results were obtained with increased equiv. of SED (3 eq.) at rt. However, previously known fluorovinyl compound $\mathbf{1 1 1}{ }^{173}$ was obtained in $46 \%$ yield when 95 a was treated with 3 eq. of SED (DMF, $120{ }^{\circ} \mathrm{C}$, overnight) after acidic workup $(10 \% \mathrm{HCl})$. The structure of 111 was established by ${ }^{19} \mathrm{~F}-\mathrm{NMR}(\delta-133.8 \mathrm{ppm}, \mathrm{t}, J=4.6 \mathrm{~Hz})$ and LC-MS $\left[\mathrm{ESI}^{+} \mathrm{m} / \mathrm{z} 271\right.$ $\left.(\mathrm{MH})^{+}\right]$. This result indicated that reductive cleavage of sulfone took place with excess SED at high temperature. Noticeably, when 95a was treated with 4-dimethylamino pyridine (DMAP) in DMF at room temperature, was recovered intact indicating that base-induced pathway is not operating with such $\alpha$-fluorosulfone.
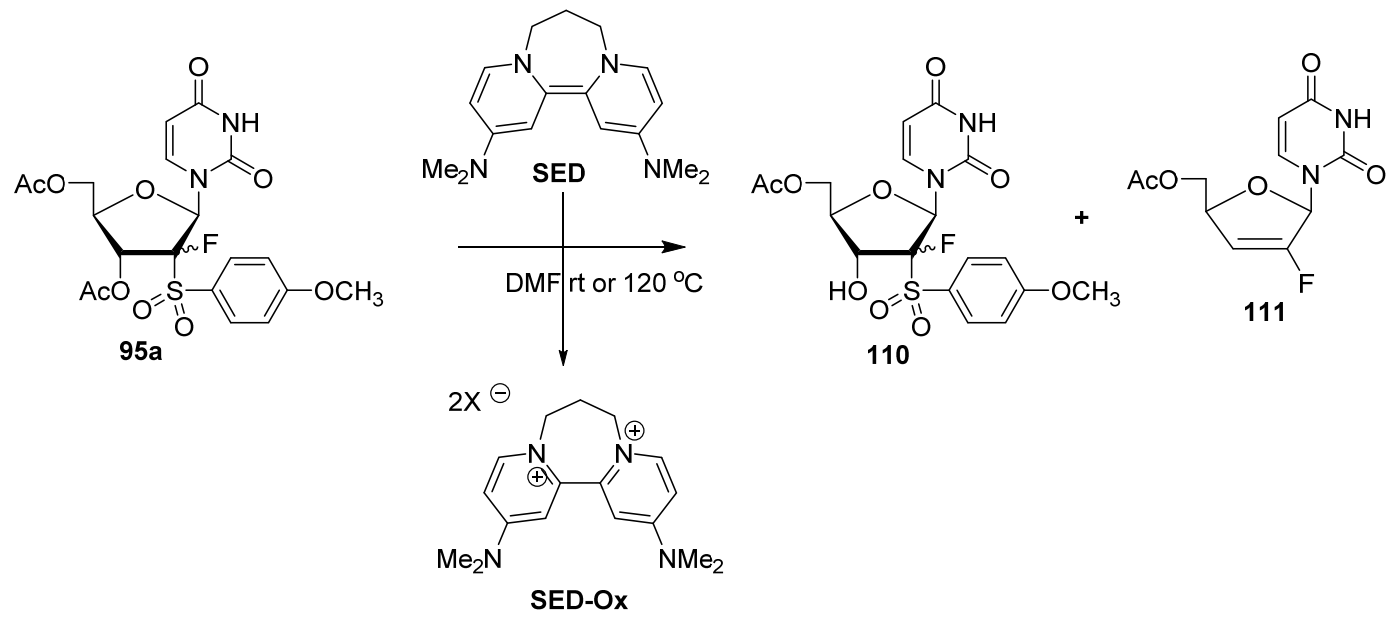

Scheme 21. Stability studies of acetyl protected $\alpha$-fluorosulfone 95a with Murphy's SED.

To avoid the base-promoted elimination of the 3'-acetyl protection group, benzyl protected $\alpha$-fluorosulfone derivative 95b was employed to study the reduction of sulfone with SED. However, treatment of N3-benzyl,3',5'-di-O-benzyl protected sulfone 95b under analogous reaction conditions ( 3 eq. SED, DMF, $120{ }^{\circ} \mathrm{C}, 3 \mathrm{~h}$ ) produced a complex 
reaction mixture (Scheme 22). Careful silica gel column chromatography allowed for separation of two major products, which are found to be glycosidic bond cleavage products furan 112 and 3-N-benzyluracil 103. Trace amounts of sulfone cleavage product 113 was also isolated from the column. Intriguingly, in the furan derivative 112 sulfone moiety was intact and elimination of fluorine was observed. Formation of $\mathbf{1 1 2}$ could have been happened from either the reduction of glycosidic bond followed by base induced fluoride elimination or vice versa.

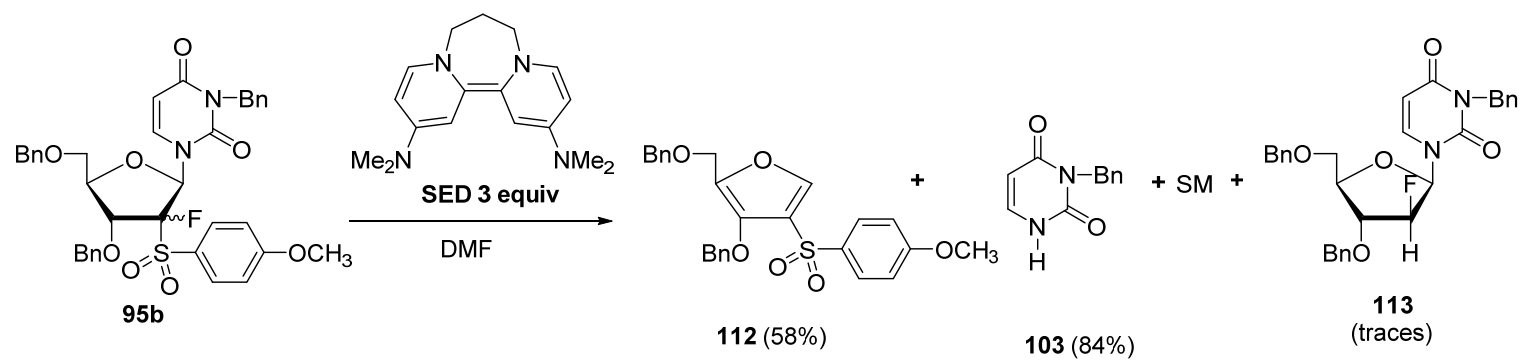

Scheme 22. Stability studies of benzyl protected $\alpha$-fluorosulfones 95b with Murphy's SED

Analogous treatment of $\mathbf{9 5 b}$ with 3 equiv. of SED in DMF at room temperature gave only trace amounts of $\mathbf{1 1 2}$ and $\mathbf{1 0 3}$ along with unchanged SM. Addition of degazed water at $80^{\circ} \mathrm{C}$ to the crude, in order to favour the reduction product $\mathbf{1 1 3}$ (to enhance $\mathrm{H}$ abstraction), did not change the outcome of the reaction. The elimination product 112 and 3- $N$-benzyluracil 103 were obtained in $80 \%$ and $60 \%$ isolated yields respectively.

Next, in order to prepare gem-difluorouridine analogues, I attempted to insert a second fluorine atom at C2'-position of 2'-arylsulfonyl-2'-deoxy-2'-fluorouridine derivative 95a using reductive-desulfonylation/fluorination approach. If successful this method could be expanded toward the synthesis of other 2'-alkyl-2'-deoxy-2'-fluoro uridine nucleosides. Especially an intriguing target in that class of nucleosides would be 
2'-C-methyl-2'-deoxy-2'-fluorouridine because of the potent anti-HCV activity possessed by the corresponding cytidine analogue (PSI 6130). ${ }^{5}$

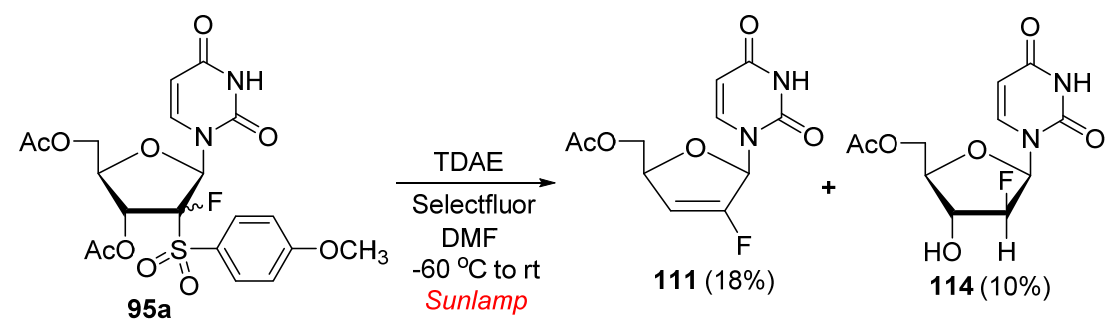

Scheme 23. Attempted synthesis of 2'-2"-difluorouridine by reductive desulfonylationfluorination of 2'-arylsulfonyl-2'-deoxy-2'-fluorouridine 95a with TDAE/Selectrfluor

Since 95a was barely reactive towards TDAE at low temperatures with no indication of the generation of putative $\mathrm{C} 2$ ' anion, I tried a combination of TDAE and UV light activation to enhance the electron transfer. Thus, treatment of 95a with 5 equiv. of TDAE at $-60{ }^{\circ} \mathrm{C}$ and Selectfluor under uv light irradiation produced a mixture of 2',3'dideoxy-2',3'-didehydro-2'-fluorouridine 111 and 1-(2-deoxy-2-fluoro- $\beta, D-$ arabinofuranosyl)uracil $\mathbf{1 1 4}$ in addition to the acetyl deprotected byproducts (Scheme 23). Interestingly, no significant by-products resulting from the glycoside bond cleavage was observed. It is noteworthy that when the TDAE was added at $0{ }^{\circ} \mathrm{C}$ or room temperature, neither $\mathbf{1 1 1}$ nor $\mathbf{1 1 4}$ were formed, which means the TDAE did not act as a reductant when added at higher remperatures. Furthermore, no formation of the target 2'deoxy-2',2'-difluorouridine derivative was observed, while the reduction of the employed electrophilic fluorine reagents was detected. 

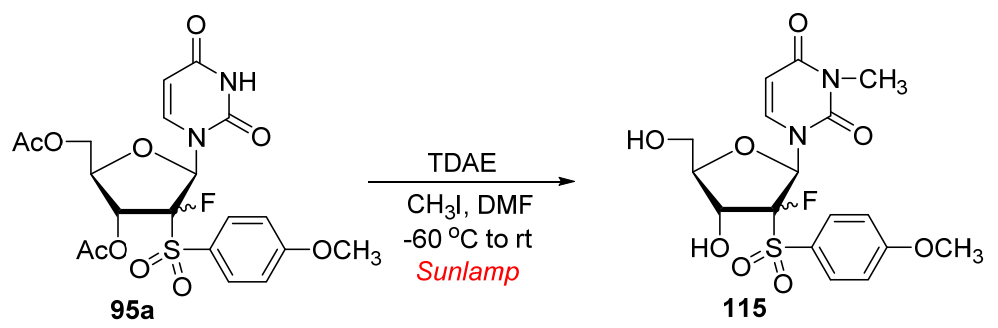

Scheme 24. Reductive-desulfonylation/methylation of 2'-arylsulfonyl-2'-deoxy-2'fluorouridine 95a with TDAE/MeI

Since fluoronium ion $\left(\mathrm{F}^{+}\right)$is the most difficult cation to work with, I chose to test our hypothesis using $\mathrm{CH}_{3}{ }^{+}$. However, treatment of 95a with TDAE/MeI under analogous reaction conditions yielded acetyl deprotected, $N 3$-methylated analogue 115 as the major product (Scheme 24).

\subsection{One electron oxidation of gemcitabine and analogues}

Our laboratory has a long history of studying the mechanism of ribonucleotide reductase (RNR) enzyme via chemical modeling studies. ${ }^{174,175}$ In collaboration with Prof. Stubbe of MIT, we have also been involved in studying mechanism-based inhibitors of RNR by $2^{\prime}$-azido-2'-deoxynucleostides ${ }^{176,177}$ and probing the mechanism of RNR catalyzed reaction with labeled natural substrates. ${ }^{178}$ Recently, in collaboration with Dr. Sevilla's group from Oakland University, we began investigating the generation of radicals upon $1 \mathrm{e}^{-}$oxidation of various nucleoside substrates. ${ }^{179}$

Building on this interest, I wanted to explore the possibility of formation of sugarbased radicals in the one-electron (1e') oxidation of 2'-fluorocytidine analogues such as 2'-fluoro-2'-deoxycytidine (FdC, 38), 2'-deoxy-2',2"-difluorocytidine ( $\mathrm{dFdC}$, gemcitabine, 1), and 2'-deoxy-2'-fluoro-2'-C-methylcytidine (MeFdC, PSI 6130, 39) (Figure 25). Each of the three substrates has different stereo and electronic properties which should interact 
with the resultant radical differently. Comparing to 2'-fluoro-2'-deoxycytidine, gemcitabine has an extra fluorine atom, which causes $\mathrm{H}^{\prime}$ to be more acidic because of its negative inductive effect (-I). Thus I was also hoping that we might capture and analyze the elusive C3' radical, postulated by Stubbe, et al. ${ }^{31}$ as a critical intermediate in the reduction of RNA monomer to DNA monomer. The presence of a positive inductive effect $(+\mathrm{I})$ causing methyl group makes PSI 6130 a versatile candidate and it would be interesting to study the influence of different substituents at 2'-position $\left(\mathrm{H} v s \mathrm{~F} v s \mathrm{CH}_{3}\right)$ on radical generation. Electron spin resonance (ESR) spectroscopy was employed to study the results generated during $1 \mathrm{e}^{-}$oxidation of the selected substrates.

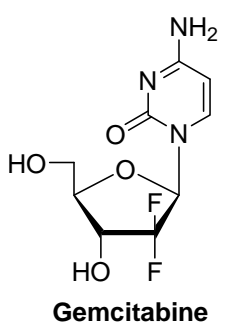

1

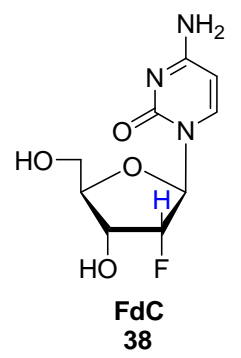

38

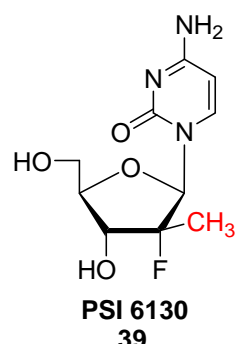

39

Figure 25. Selected substrates for $1 \mathrm{e}^{-}$oxidation studies

\subsubsection{Detection of $\mathrm{C} 2$ ' and $\mathrm{C} 3$ ' sugar radicals}

The ESR spectrum after $\gamma$-irradiation of 2'-deoxy-2'-fluorouridine 38 (7.5 M $\mathrm{LiCl} / \mathrm{D}_{2} \mathrm{O}$ sample of 2'-dC (2 mg/ml) at $\mathrm{pH}$ ca. 10) showed a central anisotropic doublet (ca. $16 \mathrm{G}$ ) assigned to $\alpha$ proton at $\mathrm{C} 5$ in the $2-\mathrm{F}-\mathrm{dC}$ pi-cation radical $\left(\mathrm{C}^{+}{ }^{+}\right) \mathbf{1 1 6}$ and is in keeping with the coupling reported for the $\mathrm{C} 5 \mathrm{-H}$ alpha proton coupling in the $\mathrm{dC}$ cation radical in single crystals (Scheme 25). ${ }^{180}$ 


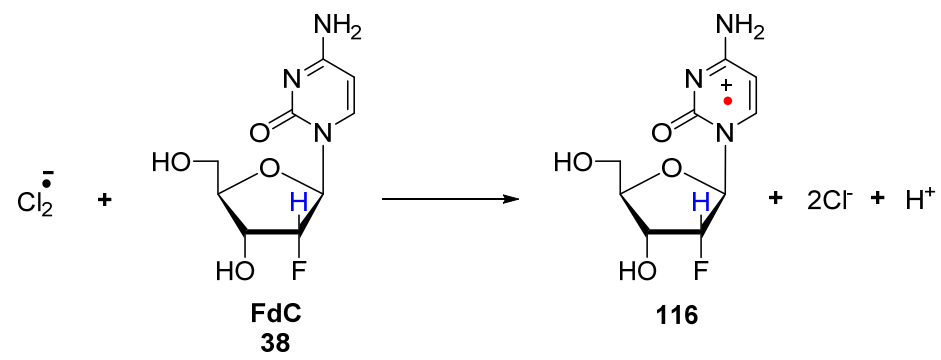

Scheme 25. One elctron oxidation of 2'-deoxy-2'-fluorocytidine

One-electron oxidation of gemcitabine 1 results in the formation of metastable pication radical 1a, which is unstable even at ca. $155 \mathrm{~K}$ (Scheme 26). The metastable $\mathrm{C}^{+}$ 1a quickly deprotonates at $\mathrm{C}^{\prime}$ in the sugar moiety producing $\mathrm{C} 3^{\prime} \bullet \mathbf{1 1 7}$ via a protoncoupled electron-transfer (PCET) mechanism. The presence of $2^{\text {nd }}$ fluorine atom at $2^{\prime}$ position may have increased the acidity of $\mathrm{C}^{\prime} \mathrm{H}$. Since the presence of one additional fluorine led to such a drastic behavior, I was very interested to study one electron oxidation of 2'-deoxy-2'-fluoro-2'-C-methylcytidine (PSI-6130; 39), which is very active against HCV. ${ }^{181}$ PSI 6130 has a methyl group (+I) instead of a fluorine atom (-I).

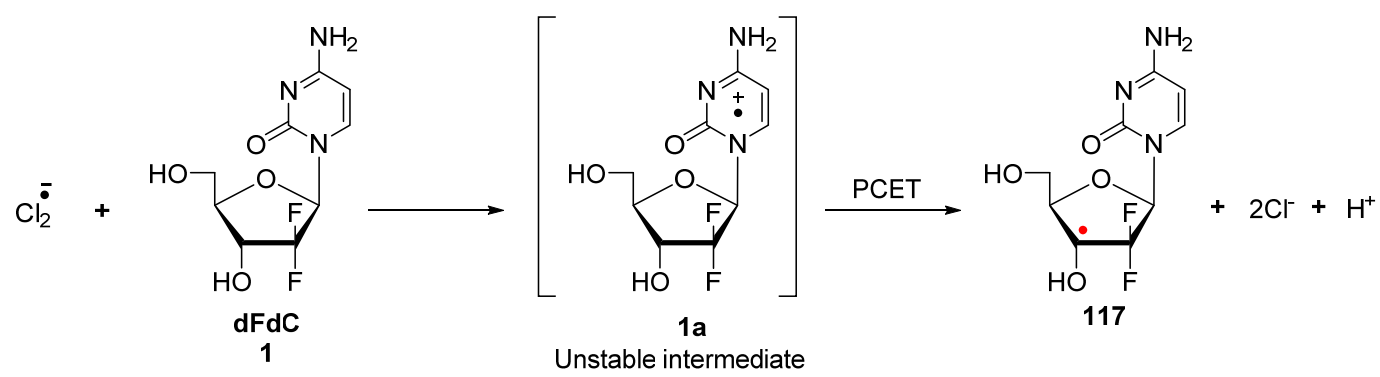

Scheme 26. One electron oxidation of gemcitabine

The anti-HCV analogue PSI-6130 (39) also generated C3'-radical 39a via pication radical 118, upon $\gamma$-irradiation. But C3'-radical in PSI-6130 was unstable and immediately converted to C2'-radical 119 via loss of hydrogen fluoride (Scheme 27). All the results were in accordance with theoretical model studies and ESR spectroscopy ${ }^{182}$ 
This is the first non-enzymatic example of C3'-radical studies on gemcitabine and PSI6130 and support the mechanism of inhibition of ribonucleotide reductase by these compounds.
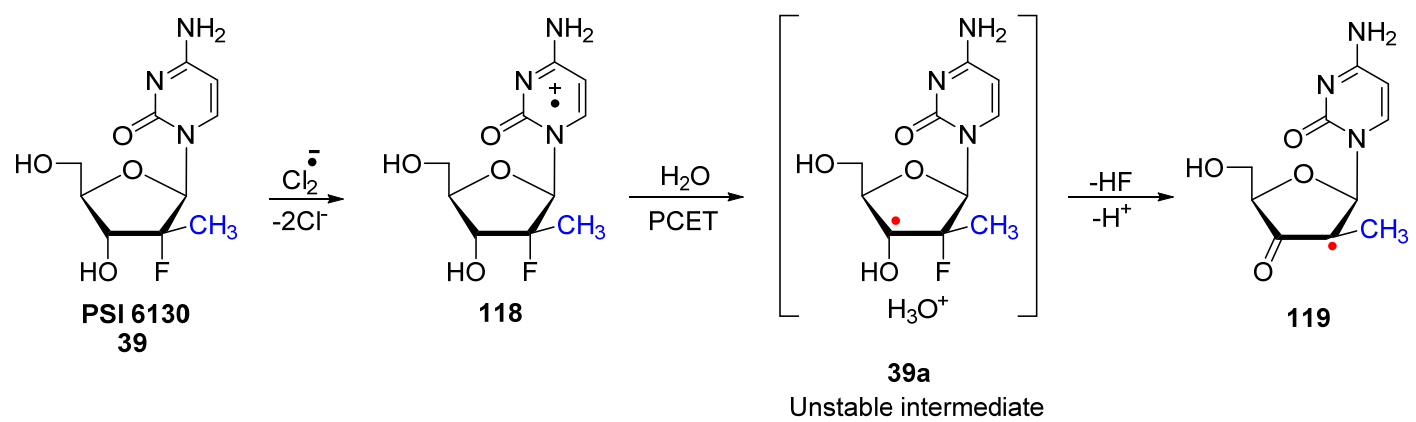

Scheme 27. One electron oxidation of PSI-6130

3.4. Synthesis and biological activity of 6-N-benzyl-7-deazapurine nucleoside derivatives

\subsubsection{Synthesis of $6-N$-benzyl-7-deazapurine nucleosides}

I wanted to prepare 6- $N$-benzylated 7-deazaadenosine analogues (122a-d) using the Dimroth rearrangement, which is widely studied on various adenine nucleosides and other heterocycles. ${ }^{115,183}$ Initial alkylation takes place at N1 when adenine nucleosides are treated with alkyl/aryl halides to form an N6-centered cationic intermediate (120a; Scheme 28). Treatment of the N1-alkylated intermediate $\mathbf{1 2 0 a}$ with base leads to ringopening, C-C bond rotation, and subsequent ring-closing to give the N6-alkylated adenosine product 121. Interesting thing to note in the Dimroth rearrangement sequence is that N1 of substrate becomes N6 in the product, which was established based on isotope labeling studies. ${ }^{184,185}$ 

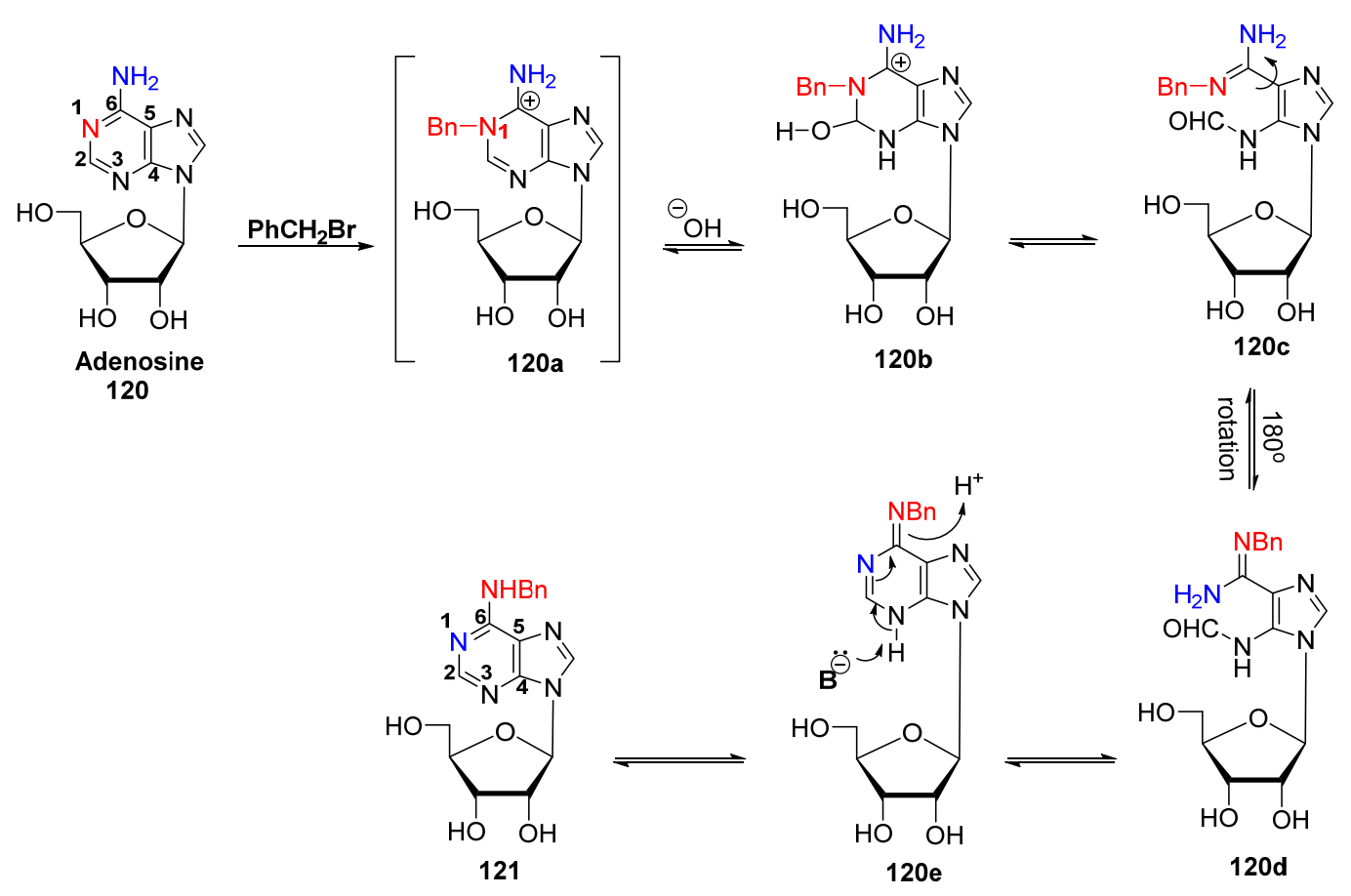

Scheme 28. General mechanism of Dimroth rearrangement on Adenosine ${ }^{184,185}$

Thus, treatment of tubercidin (19a) with benzyl bromide in DMF (48 h at $40{ }^{\circ} \mathrm{C}$ ) showed a baseline spot on TLC, which suggests ionic intermediate(s) (Scheme 29). Evaporation of solvent; treatment of crude with acetone and ether; and vacuum filtration gave a hygroscopic white precipitate. The ionic intermediate was immediately dissolved in methanol and refluxed with dimethylamine (2 M solution in THF) $\left(20 \mathrm{~h}\right.$ at $\left.65^{\circ} \mathrm{C}\right)$. TLC showed conversion of majority of the base line spot to a less polar product. Aqueous workup followed by column chromatography gave $4-N$-benzyltubericin 122a $(67 \%)$. Structure of the product was established by NMR and HRMS. For comparison, I synthesized the previously known 6- $N$-benzyladenosine $(\mathbf{1 2 1})^{115}$ from adenosine (120) by following same reaction conditions $\left(\mathrm{BnBr} / \mathrm{DMF}-\mathrm{Me}_{2} \mathrm{NH} / \mathrm{MeOH}\right)$. I noticed that the TLC during the course of both the reactions was very similar. Therefore it is reasonable to assume that initial alkylation occurred at $\mathrm{N} 3$ (same as ring nitrogen $\mathrm{N} 1$ in adenosine) in 
tubercidin, and treatment of the 3-N-benzyl intermediate with $\mathrm{Me}_{2} \mathrm{NH} / \mathrm{THF}$ in $\mathrm{MeOH}$ resulted in Dimroth-type rearrangement to give 4- $N$-benzyltubercidin (122a).
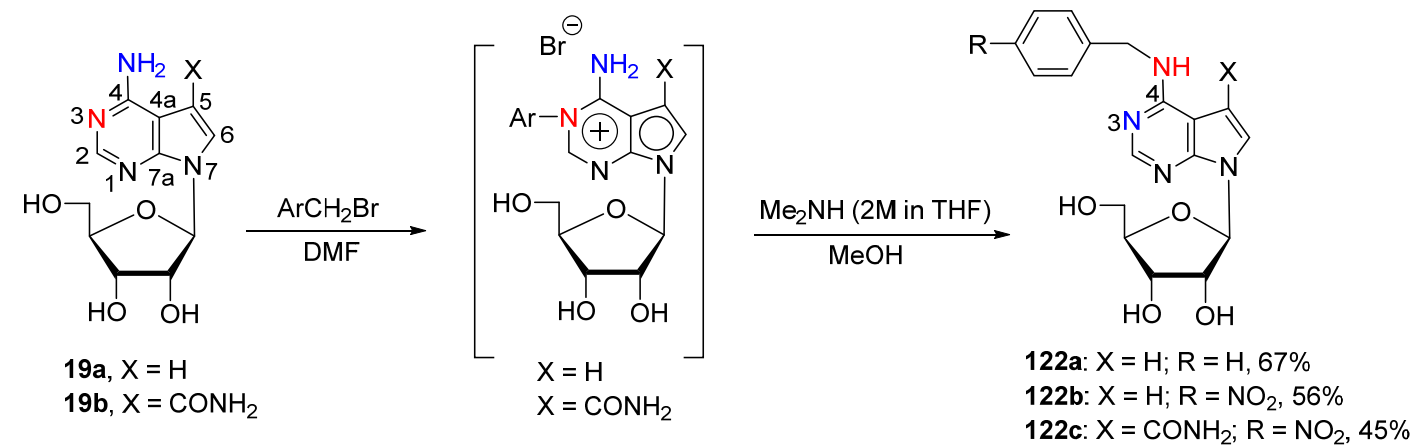

Scheme 29. Synthesis of 4- $N$-benzylated tubercidin and sangivamycin by Dimroth rearrangement approach.

It is well-established that the 6-N-(4-nitrobenzyl) derivatives of adenosine and other adenine nucleosides act as potent nucleoside transport inhibitors. ${ }^{119}$ To evaluate the nucleoside transport inhibition properties in a related system, I endeavored to synthesize 4-N-(4-nitrobenzyl) derivatives of the 7-deaza antibiotics. Thus, following the protocol for the synthesis of 122a, reaction of tubercidin 19a with 4-nitrobenzyl bromide ( $24 \mathrm{~h}$ at $80{ }^{\circ} \mathrm{C}$ ) followed by treatment of the corresponding N-3 alkylated cationic intermediate with $\mathrm{Me}_{2} \mathrm{NH} / \mathrm{MeOH}$ produced 4- $N$-(4-nitrobenzyl)tubercidin (122b, 56\%, Scheme 29). An analogous base line spot was observed when sangivamycin (19b) was treated with 4nitrobenzyl bromide $\left(48 \mathrm{~h}\right.$ at $\left.40{ }^{\circ} \mathrm{C}\right)$. Isolation of this ionic intermediate immediately followed by treatment with $\mathrm{Me}_{2} \mathrm{NH} / \mathrm{MeOH}$ yielded 4- $\mathrm{N}$-(4-nitrobenzyl)sangivamycin (122c, $45 \%)$. Structures of products $122 \mathbf{b}-\mathbf{c}$ were established by NMR and elemental analysis.

Since tubercidin and sangivamycin underwent Dimroth-type rearrangement when treated with $\mathrm{BnBr}$ followed by $\mathrm{Me}_{2} \mathrm{NH}$, I envisioned the synthesis of 4- $\mathrm{N}-(4-$ 
nitrobenzyl)toyocamycin (122d) via similar synthetic pathway. However, upon treatment of toyocamycin $(\mathbf{1 9 c})$ with 4-nitrobenzyl bromide $\left(63 \mathrm{~h}\right.$ at $\left.40{ }^{\circ} \mathrm{C}\right)$, a major less polar spot than substrate was observed on TLC, as opposed to a more polar spot in case of tubercidin and sangivamycin (Scheme 30). Isolation of the new spot by column chromatography and careful spectroscopic evaluation showed the compound as 4- $N$-(4nitrobenzyl)toyocamycin (122d; 46\%). Since there was no N3-benzylated cationic intermediate, there was no need for $\mathrm{Me}_{2} \mathrm{NH} / \mathrm{MeOH}$ treatment. Therefore, a direct alkylation of the exocyclic amine (N4) of toyocamycin was proposed for the formation of $122 d$.

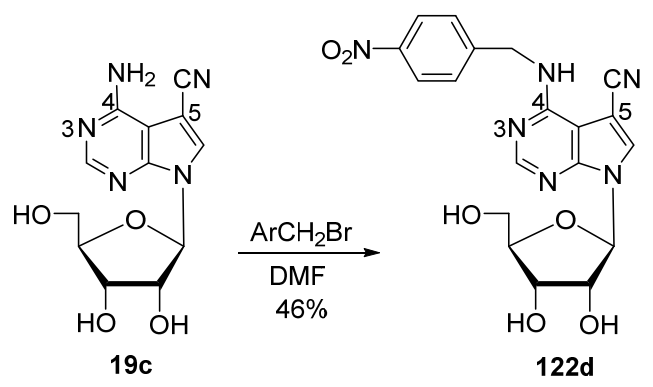

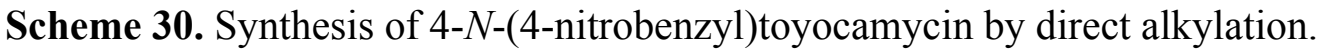

The direct alkylation of the exocyclic amino group of toyocamycin has not been previously noted. However, direct alkylation on the exocyclic amino group of adenine and guanine with quinone methides is known. ${ }^{186}$ The exocyclic amine nitrogen N4 may have become more nucleophilic than the endocylcic nitrogen $\mathrm{N} 3$, as a result of the electron withdrawing pull of the cyano group at $\mathrm{C} 5$. Another possibility could be that the cylindrical cyano group might exist in synperiplanar orientation with the exocyclic amine group, thereby diminishing the lone-pair donation on N4 toward N3 of the amidine, which is part of the planar hetrocyclic system. ${ }^{187}$ 
Alternatively, the preparation of 6- $N$-(4-nitrobenzyl)tubercidin derivative (122b) was envisioned based on synthesis of 6-fluorotubercidin analogue by diazotizationfluorodediazoniation ${ }^{120,188,189}$ followed by $\mathrm{S}_{\mathrm{N}} \mathrm{Ar}$ displacement of 6-fluoro group with 4nitrobenzylamine. ${ }^{120,190}$ Thus, using standard protocol, tubercidin (19a) was treated with acetic anhydride in pyridine to give 2',3',5'-tri- $O$-acetyltubercidin (123, 86\%; Scheme 31). The acetylated tubercidin (123) was then treated with sodium nitrite $\left(\mathrm{NaNO}_{2}\right)$ in freshly prepared $\sim 55 \%$ HF-pyridine at $-10{ }^{\circ} \mathrm{C}^{191,192}$ for $15 \mathrm{~min}$ to yield the protected 4 fluorotubercidin 124 (82\%), probably via diazotive-fluorodeamination. The mechanism of this reaction is expected to be similar to 'Balz-Schiemann' type reaction for the preparation of arylfluorides from arylamines using $\mathrm{NaNO}_{2}$ and $70 \%$ HF-pyridine. ${ }^{191}$ $\mathrm{NaNO}_{2}$ in the presence of acid $\left(\mathrm{H}^{+}\right)$generates nitrosonium ion $\left(\mathrm{NO}^{+}\right)$in situ and aryl- $\mathrm{NH}_{2}$ attacks the resultant $\mathrm{NO}^{+}$to form diazonium ion 123a subsequently. Loss of $\mathrm{N}_{2}$ followed by quenching of intermediate arylcation $\mathbf{1 2 3 b}$ with fluoride ion $\left(\mathrm{F}^{-}\right)$gives the product arylfluoride 124. I observed that the concentration of HF was crucial in the preparation of 124. When commercial $70 \%$ HF-pyridine reagent was used, the reaction did not yield the corresponding 4-fluoro product $\mathbf{1 2 4}$. This observation indicated that $\mathrm{pH}$ of the reaction, which in turn depends on the percent of HF used, was critical for such diazotivefluorodeamination reactions. ${ }^{192}$ 


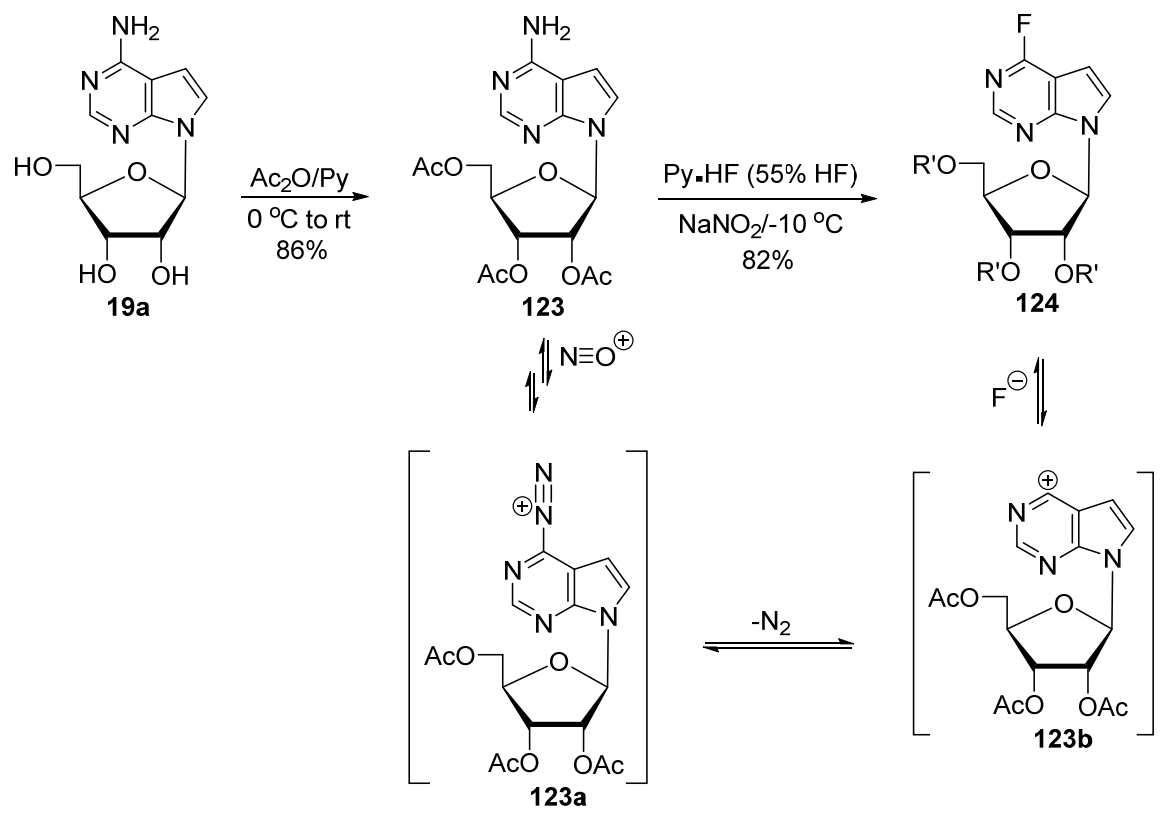

Scheme 31. Synthesis of $2^{\prime}, 3^{\prime}, 5^{\prime}$-tri- $O$-acetyl-4-fluorotubercidin (124) by diazotivefluorodeamination.

Treatment of 4-fluorotubercidin derivative $\mathbf{1 2 4}$ with 4-nitrobenzylamine hydrochloride in presence of trimethylamine $\left(\mathrm{Et}_{3} \mathrm{~N}\right)$ in $\mathrm{MeOH}$ gave 2',3',5'-tri- $O$-acetyl4- $N$-(4-nitrobenzyl)tubercidin $(\mathbf{1 2 5}, 47 \% ;$ Scheme 32$)$. Trimethylamine converts 4nitrobenzylamine hydrochloride to 4-nitrobenzylamine in situ, and the free amine subsequently displaces the fluoride ion, probably, by aromatic nucleophilic substitution $\left(\mathrm{S}_{\mathrm{N}} \mathrm{Ar}\right) .{ }^{120}$ Acetyl deprotection of compound 125 using methanolic amonia $\left(\mathrm{NH}_{3} / \mathrm{MeOH}\right)$ at ambient temperature gave $\mathbf{1 2 2 b}$ ( $85 \%$; overall $32 \%$ yield). Out of the two methods for the preparation of $\mathbf{1 2 2} \mathbf{b}$, Dimroth alkylation pathway (56\% yield) was better in terms of number of steps and overall yield. 


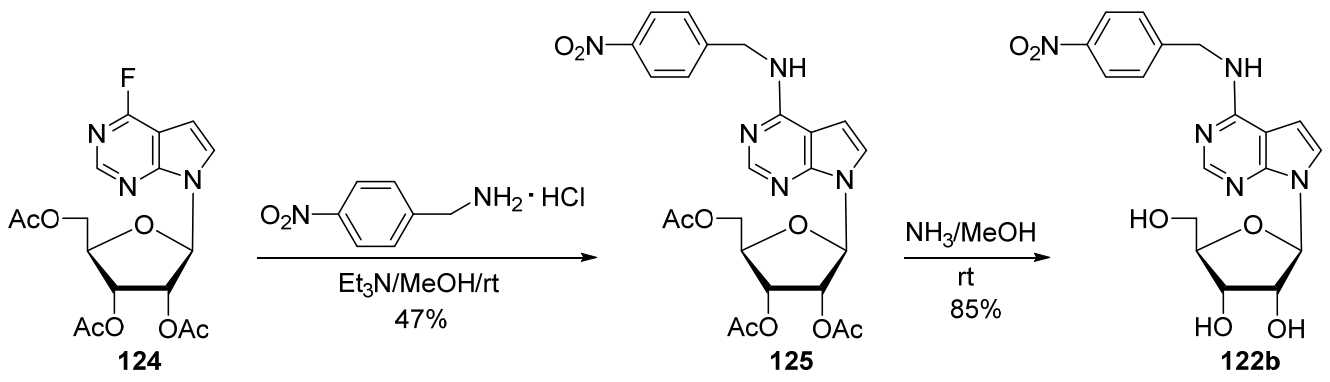

Scheme 32. Synthesis of 4- $N$-(4-nitrobenzyl)tubercidin (122b) from 2',3',5'-tri- $O$-acetyl4-fluorotubercidin (124).

\subsubsection{Biological activity of 6- $N$-benzyl-7-deazapurine nucleoside derivatives}

Nucleoside transport inhibition activities were measured in Dr. James D. Young's laboratory of University of Alberta. While antiviral and anti-proliferation activities were studied in Dr. Jan Balzarini's laboratory of Rega Institute for Medical Research.

\subsubsection{Nucleoside transport inhibition activity}

Inhibition of the initial rate of ${ }^{3} \mathrm{H}$-uridine $(20 \mu \mathrm{M})$ uptake by recombinant hENT1 produced in the Xenopus oocyte heterologous expression system was determined as described previously. ${ }^{118}$ The 4-N-(4-nitrobenzyl)tubercidin (122b) and 4- $N$-(4nitrobenzyl)sangivamycin (122c) fully inhibited labelled uridine uptake, whereas 4- $N$ benzyltubercidin (122a) and 4- $N$-(4-nitrobenzyl)toyocamycin (122d) analogues exhibited weak inhibition $(<45 \%)$. Dose-response evaluations indicated that sangivamycin analogue 122c $\left(\mathrm{IC}_{50}=123 \pm 31 \mathrm{nM}\right)$ was a better inhibitor of uridine transport by hENT1 than the tubercidin analogue 122b $\left(\mathrm{IC}_{50}>1000 \mathrm{nM}\right)$. However, the sangivamycin analogue 122c was a weaker inhibitor of hENT1-mediated transport than 6- $\mathrm{N}-(4-$ nitrobenzyl)adenosine, NBMPR, and other derivatives ${ }^{119}$ containing a nitrogen atom at the 7-position in the adenine ring. 


\subsubsection{Antiviral activity}

Table 7. Antiviral activity in human embryonic lung (HEL) cell cultures-part 1

\begin{tabular}{|c|c|c|c|c|c|}
\hline \multirow{2}{*}{ Compd } & \multicolumn{5}{|c|}{$\mathrm{EC}_{50}(\mu \mathrm{M})^{*}$} \\
\cline { 2 - 6 } & $\begin{array}{c}\text { HSV-1 } \\
(\mathrm{KOS})\end{array}$ & $\begin{array}{c}\text { HSV-2 } \\
(\mathrm{G})\end{array}$ & $\begin{array}{c}\text { Vaccinia } \\
\text { virus }\end{array}$ & $\begin{array}{c}\text { Vesicular } \\
\text { stomatitis virus }\end{array}$ & $\begin{array}{c}\text { HSV-1 } \\
\text { TK - KOS ACV }\end{array}$ \\
\hline 122a & $>100$ & $>100$ & $>100$ & $>100$ & $>100$ \\
\hline 122b & $>100$ & $>100$ & 34 & $>100$ & $>100$ \\
\hline 122c & $>100$ & $>100$ & 34 & $>100$ & $>100$ \\
\hline 122d & $>100$ & $>100$ & 100 & $>100$ & \\
\hline
\end{tabular}

*Effective concentration required to reduce virus plaque formation by $50 \%$.

Virus input was 100 plaque forming units (PFU).

The 4- $N$-benzyl-7-deazapurine derivatives (122a-d) weakly inhibited Herpes Simplex Virus (HSV; $1 \& 2)$ and Vesicular stomatitis virus $\left(\mathrm{EC}_{50}:>100 \mu \mathrm{M}\right)$ (Table 7). But Vaccinia virus was reasonably inhibited by 4- $N$-(4-nitrobenzyl)tubercidin (122b) and 4- $N$-(4-nitrobenzyl)sangivamycin $(\mathbf{1 2 2 c})\left(\mathrm{EC}_{50}: 34 \mu \mathrm{M}\right)$ and to a weak extent by $4-N-$ benzyltubercidin (122a) and 4- $N$-(4-nitrobenzyl)toyocmycin (122d) $\left(\mathrm{EC}_{50}:>100 \mu \mathrm{M}\right)$.

Cytomegalovirus (CMV) and Varicella Zoster Virus (VZV) were inhibited at $~ 20$ $\mu \mathrm{M}$ concentrations by 4- $N$-benzyltubercidin (122a), 4-N-(4-nitrobenzyl)sangivamycin (122c) and 4- $N$-(4-nitrobenzyl)sangivamycin (122d) analogues (Table 8). But 4- $N-(4-$ nitrobenzyl)tubercidin $(\mathbf{1 2 2 b})$ was not very potent $\left(\mathrm{EC}_{50}\right.$ : $\left.>100 \mu \mathrm{M}\right)$. 
Table 8. Antiviral activity human embryonic lung (HEL) cell cultures-part 2

\begin{tabular}{|c|c|c|c|c|}
\hline \multirow{2}{*}{ Compd } & \multicolumn{4}{|c|}{$\mathrm{EC}_{50}(\mu \mathrm{M})^{*}$} \\
\cline { 2 - 5 } & CMV & $\begin{array}{c}\text { CMV } \\
\text { (Davis } \\
\text { strain) }\end{array}$ & $\begin{array}{c}\text { VZV } \\
(\mathrm{TK}+169 \text { strain }) \\
\text { strain })\end{array}$ & $\begin{array}{c}\text { VZV } \\
\text { (TK - VZV strain) }\end{array}$ \\
\hline 122a & $>20$ & $>20$ & $>20$ & $>20$ \\
\hline 122b & $>100$ & $>100$ & $>100$ & $>20$ \\
\hline 122c & $>20$ & $>20$ & $>20$ & $>20$ \\
\hline 122d & $>20$ & $>20$ & $>20$ & \\
\hline
\end{tabular}

${ }^{*}$ Effective concentration required to reduce virus plaque formation by $50 \%$.

Virus input was 100 plaque forming units (PFU).

\subsubsection{Inhibition of Cell Proliferation}

Inhibition of the proliferation of murine leukemia (L1210) cells and human Tlymphocyte (CEM), cervix carcinoma (HeLa), prostate cancer (PC-3), and kidney carcinoma (Caki-1) cells by the 7-deazaadenine nucleoside analogues (122a-d) was evaluated (Table 9). The 4- $N$-benzyltubercidin (122a) showed marked inhibition of the proliferation of PC-3 cells $\left(\mathrm{IC}_{50}: 0.92 \mu \mathrm{M}\right)$ and $\mathrm{HeLa}$ cells $\left(\mathrm{IC}_{50}: 7.4 \mu \mathrm{M}\right)$ but no significant activity was found with its nitrobenzyl analogue $122 \mathrm{~b}\left(\mathrm{IC}_{50}:>50 \mu \mathrm{M}\right)$. The 4$N$-(4-nitrobenzyl)sangivamycin (122c) and 4-N-(4-nitrobenzyl)toyocamycin (122d) analogues inhibited proliferation of L1210, HeLa, and PC-3 cells at $\sim 0.9-9.4 \mu \mathrm{M}$ with the sangivamycin analogue 122c showing more potent effects $(0.92-3.4 \mu \mathrm{M})$. It is intriguing that cytostatic activity of the 6- $N$-benzyl-7-deazapurine analogues was highly dependent on the nature of the tumor cell lines. Proliferation of HeLa and PC-3 tumor cells was highly inhibited by $\mathbf{1 2 2 a}, \mathbf{1 2 2}$, and $\mathbf{1 2 2 d}$ whereas proliferation of L1210 cells 
was sensitive only to $\mathbf{1 2 2} \mathbf{c}$ and $\mathbf{1 2 2 d}$. The CEM and Caki-1 cells were weakly sensitive to the antiproliferative effects of any of the 6- $N$-benzyl-7-deazapurine compounds $\mathbf{1 2 2} \mathbf{a}-$ $122 d$.

Table 9. Inhibitory effects on the proliferation of cells in culture

\begin{tabular}{|c|c|c|c|c|c|}
\hline \multirow{2}{*}{ Compd } & \multicolumn{5}{|c|}{$\mathrm{IC}_{50}(\mu \mathrm{M})^{*}$} \\
\cline { 2 - 6 } & $\mathrm{L} 1210$ & $\mathrm{CEM}$ & $\mathrm{HeLa}$ & PC-3 & Caki-1 \\
\hline 122a & $172 \pm 47$ & $182 \pm 20$ & $7.4 \pm 2.2$ & $0.92 \pm 0.67$ & $116 \pm 23$ \\
\hline 122b & $125 \pm 28$ & $\geq 250$ & $143 \pm 4$ & $76 \pm 10$ & $132 \pm 30$ \\
\hline 122c & $0.92 \pm 0.04$ & $115 \pm 28$ & $1.8 \pm 0.2$ & $3.4 \pm 0.9$ & $116 \pm 23$ \\
\hline 122d & $5.5 \pm 1.5$ & $109 \pm 16$ & $9.4 \pm 3.0$ & $5.6 \pm 3.3$ & $98 \pm 10$ \\
\hline
\end{tabular}

* Half-maximal inhibitory concentration (IC50); data represent the mean SD of at least $\mathrm{n}=2-3$ independent experiments; Cell lines: murine leukemia (L1210); human CD4+ T-lymphocytes (CEM); human cervix carcinoma (HeLa); human prostate adenocarcinoma (PC-3); human kidney carcinoma (Caki-1).

\subsection{C7- and C8-modified-7-deazapurine nucleoside derivatives}

Building upon my interest in working with 7-deazaadenosine nucleosides, I envisioned the synthesis of various 7-substituted or 8-substituted 7-deazaadenosine analogues, which might have fluorescent properties.

\subsubsection{Strain promoted click reactions of 8-azido-7-deazanucleosides with} cyclooctynes

Initially, I imagined the conversion of 8-halo-7-deazapurines to the corresponding 8-azido-7-deazapurines, which could serve as substrates for Strain-promoted AzideAlkyne Cycloaddition reactions (SPAAC, Cu-free click chemistry) with 
cyclooctynes. ${ }^{193,194}$ I expect that the resulting triazolyl products might have fluorescent properties due to increased conjugation in the 7-deazapurine base part. The $\mathrm{Cu}$-free click chemistry is a rapidly growing field, with various applications for in vivo imaging emerging continuously over the past few years. ${ }^{193,195-199}$

Thus, 8-Bromotubercidin (126) was prepared by treatment of tubercidin 19a with $\mathrm{N}$-bromosuccinimide in presence of potassium acetate (KOAc) in DMF at ambient temperature $(30 \mathrm{~min})$, as reported in literature. ${ }^{200}$ I envisioned the preparation of 8-azido7-deazaadenosine derivatives (127-129, Scheme 33) by nucleophilic aromatic substitution of 8-bromo-7-deazaadenosine derivatives $(\mathbf{5 5}, \mathbf{5 6}$ and 126) with sodium azide. However, Attempts to synthesize 8-azidotubercidin via nucleophilic aromatic substitution of $\mathbf{1 2 6}$ with sodium azide were unsuccessful, even after using harsh conditions $\left(\mathrm{NaN}_{3}\right.$ (1-5 eq), DMF, rt- $153{ }^{\circ} \mathrm{C}, \mathrm{N}_{2}, 24 \mathrm{~h} ; \mathrm{NaN}_{3}$ (3 eq), TsOH (3 eq), EtOH, reflux, 24h). Lack of reaction is possibly a consequence of the low electron deficiency of the pyrrole ring in tubercidin 19a when compared to that of other 7-deazanucleosides 19b-c. To explain in other words, C8-bromination probably proceeds via electrophilic aromatic substitution, whereas $\mathrm{C} 8$-azidation is expected to proceed via nucleophilic aromatic substitution. I envisioned the presence of electron withdrawing groups in the pyrrole ring on 8-bromo-7-deaza nucleosides will enhance the electron deficiency, there by promoting nucleophilic displacement of bromide with azide. So I chose to pursue 8bromotoyocamycin and 8-bromosangivamycin substrates, both of which have an electron withdrawing substituent on the 7-position of the pyrrole ring. 

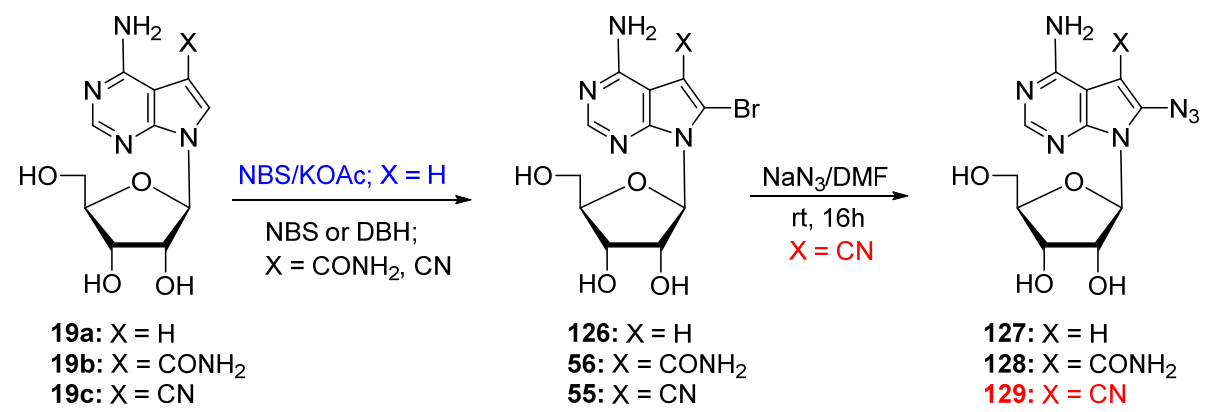

Scheme 33. Synthesis of 8-bromo-7-deazaadenosine and 8-azidotoyocamycin derivatives.

Treatment of 8-bromosangivamycin 56 with $\mathrm{NaN}_{3}$ in $\mathrm{DMF}$ at $70{ }^{\circ} \mathrm{C}$ for $16 \mathrm{hrs}$ gave a slightly more polar product, which was thought to be 8 -azidosangivamycin. UV spectra of the reactions always showed at least $12 \mathrm{~nm}$ bathochromic shift. However, ions corresponding to neither product (128) nor substrate (56) were detected in the highresolution mass spectroscopy (HRMS). Instead, peaks at m/z 258 and 317 were observed, which were unable to be identified with a list of possible products. Similar results were obtained when DMSO or $\mathrm{MeOH}$ were used as the reaction solvents.

Next, I synthesized 8-azidotoyocamycin $\mathbf{1 2 9}$ by treating 8-bromotoyocamycin $\mathbf{5 5}$ with $\mathrm{NaN}_{3}$ in $\mathrm{DMF}$ at room temperature for $16 \mathrm{~h}$. This transformation was light and, possibly, heat sensitive requiring the reaction, purification, and characterization to be carried out in the dark with limited heating to give 8-azidotoyocamycin (129; 46\%). The light sensitivity of the product also limited us in recording the analytical data for the compound. Moreover, this azidation (55 to $\mathbf{1 2 9}$ ) was unsuccessful in $\mathrm{MeOH}$ or water, indicating that polar aprotic solvents are probably the best solvents for these types of aromatic nucleophilic substitution reactions. 

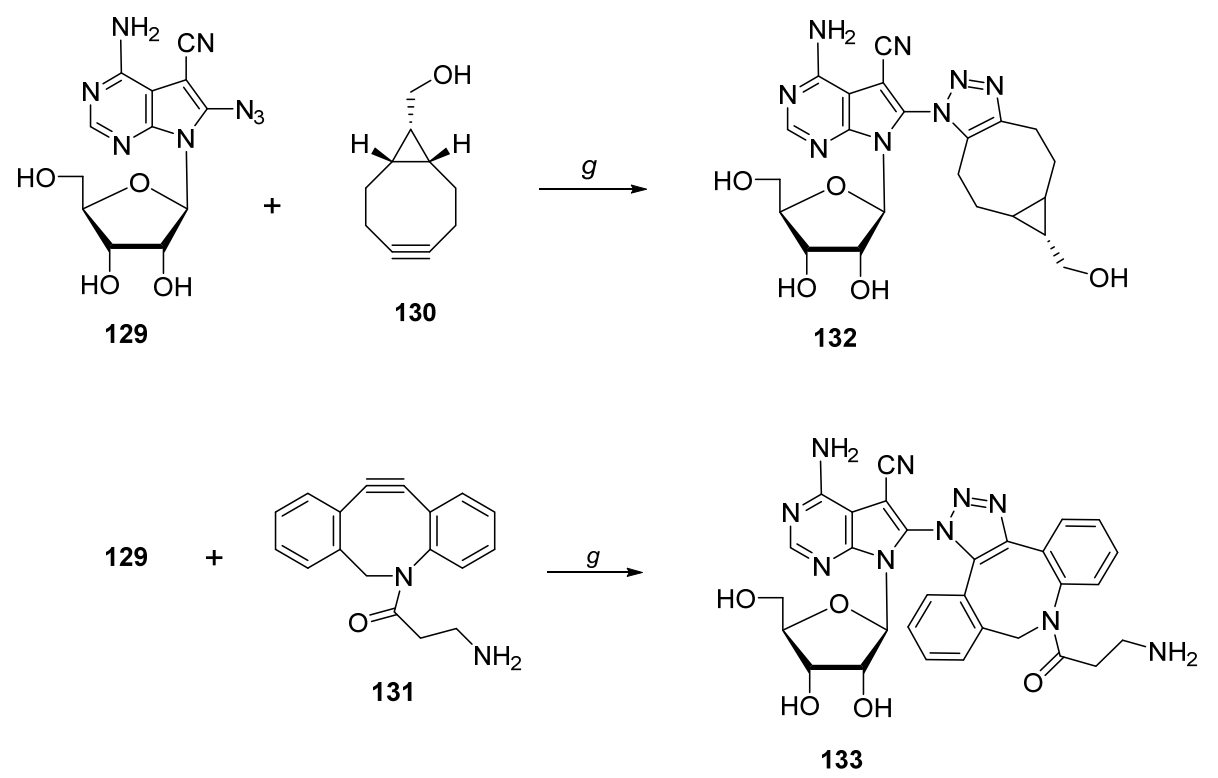

Scheme 34. Click reaction between 8-azidotoyocamycin and cyclooctynes $\mathbf{1 3 0}$ and 131 . Reagents and conditions: g) Cyclooctyne 130 or 131 (1 eq), $\mathrm{ACN}: \mathrm{H}_{2} \mathrm{O}(3: 1), \mathrm{rt}, 4 \mathrm{~h}$.

Having 8-azidotoyocamycin (129) in hand, my next goal was to see if the SPAAC reactions would take place between $\mathbf{1 2 9}$ and cyclooctynes. Thus, treatment of $\mathbf{1 2 9}$ with symmetrically fused cyclopropyl cyclooctyne $\mathbf{1 3 0}$ in an aqueous solution of acetonitrile $(\mathrm{ACN})$ at ambient temperature $(4 \mathrm{~h})$ gave the corresponding triazolyl product $132(59 \%$, Scheme 34). Analogous reaction of $\mathbf{1 2 9}$ with a strain modulated dibenzylcyclooctyne $\mathbf{1 3 1}$ produced triazole $133(47 \%)$. These preliminary results indicated that the SPAAC reactions were taking place as expected. With the extended conjugation in the deazapurine part, I expect the triazole products to have fluorescence properties and that could lead to various interesting biological applications.

\subsubsection{Attempted synthesis of 8-alkynyl-7-deazanucleosides via Sonagashira reaction}

Since the attempted synthesis of 8-azido analogues of tubercidin and sangivamycin were unsuccessful, I envisioned the synthesis of 8-vinylazido derivatives (136) from the corresponding 8-alkynyl-7-dezapurine derivatives (135), which in trun 
could be prepared in two steps via Sonagashira coupling of 8-halo-7-deazapurines $(\mathbf{5 5}, \mathbf{5 6}$ and 126) with trimethylsilylacetylene (Scheme 35). The vinylazides $\mathbf{1 3 6}$ could be used as substrates for strain-promoted click reactions to give the corresponding triazolyl products (137). Also, the crucial 8-alkynyl derivative $\mathbf{1 3 5}$ could also be converted to the corresponding halovinyl sulfone and $\beta$-keto sulfones (not shown in scheme). This part of the dissertation is envisioned based on recent literature relating to transformations of alkynes to the corresponding (i) halovinyl sulfones; ${ }^{201-203}$ (ii) $\beta$-keto sulfones; ${ }^{204}$ and (iii) vinylazides. $^{205}$
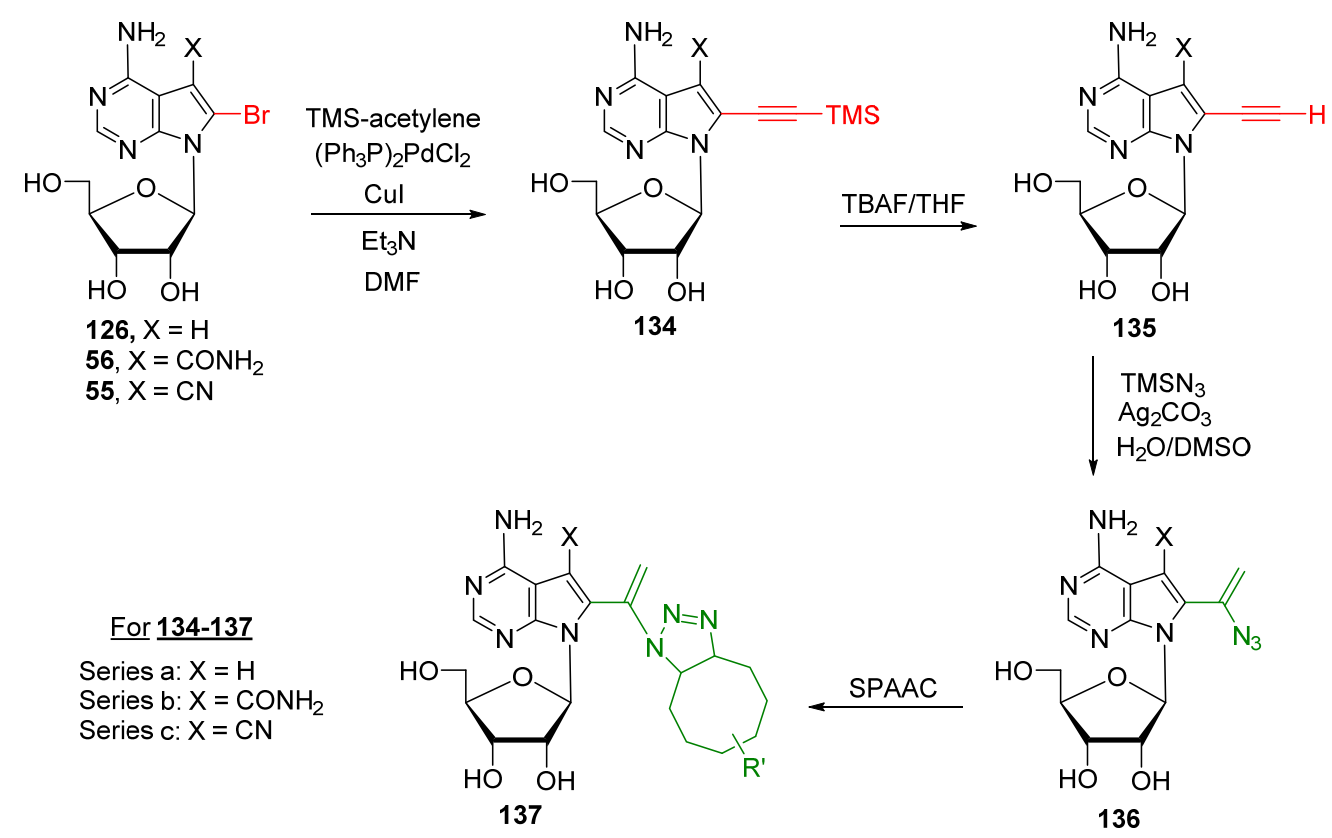

Scheme 35. Proposed scheme for the synthesis and subsequent transformations of 8alkynyl-7-deazapurine nucleoside analogues $\mathbf{1 3 5}$.

Initially, treatment of 8-bromotubercidin (126) with trimethylsilylacetylene (TMSA) in the presence of trimethylamine $\left(\mathrm{Et}_{3} \mathrm{~N}\right)$ and catalytic amounts of bis(triphenylphosphine)palladium dichloride $\left[\left(\mathrm{PPh}_{3}\right)_{2} \mathrm{PdCl}_{2}\right]$ and copper iodide (CuI) 
(anhydrous DMF, $110{ }^{\circ} \mathrm{C}$, sealed flask) showed unchanged starting material as major product (Scheme 35; Table 10, entry 1). Doubling the amounts of $\mathrm{CuI}$ and $\mathrm{Et}_{3} \mathrm{~N}$ did not change the outcome of the reaction (entry 2).

Table 10. Reaction conditions for the attempted Sonagashira cross-coupling reactions on 8-bromo tubercidin and toyocamycin ${ }^{\mathrm{a}}$

\begin{tabular}{|c|c|c|c|c|c|c|c|}
\hline Entry & Substrate & $\begin{array}{c}\left.\mathbf{P P h}_{3}\right)_{2} \mathbf{P d C l}_{\mathbf{2}} \\
(\mathrm{mol} \%)\end{array}$ & $\begin{array}{c}\mathbf{C u I} \\
(\mathrm{mol} \%)\end{array}$ & $\mathbf{E t}_{\mathbf{3}} \mathbf{N}$ & $\mathbf{T M S A}$ & Temp. & Time \\
\hline 1 & $\mathbf{1 2 6}$ & $3 \%$ & $9 \%$ & Excess & 3 eq. & $110{ }^{\circ} \mathrm{C}$ & $48 \mathrm{~h}$ \\
\hline 2 & $\mathbf{1 2 6}$ & $3 \%$ & $15 \%$ & Excess & 6 eq. & $110{ }^{\circ} \mathrm{C}$ & $48 \mathrm{~h}$ \\
\hline 3 & $\mathbf{1 2 6}$ & $10 \%$ & $20 \%$ & 4 eq. & 3 eq. & $50{ }^{\circ} \mathrm{C}$ & $16 \mathrm{~h}$ \\
\hline 4 & $\mathbf{1 2 6}$ & $15 \%$ & $30 \%$ & 11 eq. & 10 eq. & $50{ }^{\circ} \mathrm{C}$ & $5 \mathrm{~h}$ \\
\hline 5 & $\mathbf{5 5}$ & $1 \%$ & $2 \%$ & 7 eq. & 1.2 eq. & $80{ }^{\circ} \mathrm{C}$ & $48 \mathrm{~h}$ \\
\hline 6 & $\mathbf{5 5}$ & $10 \%$ & $20 \%$ & 5 eq. & 3 eq. & $50{ }^{\circ} \mathrm{C}$ & $24 \mathrm{~h}$ \\
\hline 7 & $\mathbf{5 5}$ & $20 \%$ & $10 \%$ & 5 eq. & 3 eq. & $50{ }^{\circ} \mathrm{C}$ & $24 \mathrm{~h}$ \\
\hline 8 & $\mathbf{5 5}$ & $15 \%$ & $30 \%$ & 14 eq. & 10 eq. & $50{ }^{\circ} \mathrm{C}$ & $22 \mathrm{~h}$ \\
\hline
\end{tabular}

${ }^{\mathrm{a}}$ Reactions were typically performed on $0.1 \mathrm{mmol}$ scale in anhydrous DMF. Reaction progress was monitored by TLC.

Treatment of 126 with 0.1 euqiv. of $\mathrm{Pd}$ and 0.2 equiv. $\mathrm{Cu}$ catalysts under analogous reaction conditions showed a minor less polar spot on TLC (entry 3). Encouraged by the observation, I treated 8-bromotubercidin 126 with 0.15 equiv. of Pd catalyst, 0.3 equiv. of $\mathrm{Cu}$ catalyst, 11 equiv. of $\mathrm{Et}_{3} \mathrm{~N}$, and 10 equiv. of TMSA in anhydrous DMF for 5 hrs at $50{ }^{\circ} \mathrm{C}$. TLC of the crude reaction mixture was complex, but there was a major less polar spot ( $\sim 50 \%$ in comparison with unchanged substrate) (entry 4). ${ }^{1} \mathrm{H}-\mathrm{NMR}$ of the isolated material showed $\sim 55: 45$ ratio of substrate to product (126:134a). The mixture of products was then treated with tetrabutylammonium fluoride (TBAF) and the major product was isolated by column chromatography. But ${ }^{1} \mathrm{H}-\mathrm{NMR}$ of 
the isolated spot showed absence of the characteristic acetylenic proton peak and was very similar to the ${ }^{1} \mathrm{H}$-NMR of 8 -bromotubercidin $\mathbf{1 2 6}$, and no signals for the 8-alkynyl product 134a were observed. Thus, it can be concluded that Sonagashira cross-coupling of 8-bromotubercidin with trimethylsilylacetylene is a low-yielding reaction.

Because of the ease of preparation and availability of precursors, I used 8halotoyocamycin derivatives for initial Sonagashira reactions before proceeding to 8halosonagashira substrates. However, analogous treatment of 8-bromotoyocamycin (55) with trimethylsilylacetylene $\left[\left(\mathrm{PPh}_{3}\right)_{2} \mathrm{PdCl}_{2} / \mathrm{CuI} / \mathrm{Et}{ }_{3} \mathrm{~N} / \mathrm{DMF} / 40{ }^{\circ} \mathrm{C}\right)$ also gave unchanged starting material as major product, even after varying the reaction conditions (Scheme 35; Table 10, entries 5-8).

To simplify the purification process, I decided to use protected 8-halo-7deazapurine derivatives as substrates. Thus, $2^{\prime}, 3^{\prime}, 5^{\prime}$-tri- $O$-acetyltoyocamycin (138) was prepared in $97 \%$ isolated yield by treating toyocamycin (19c) with $\mathrm{Ac}_{2} \mathrm{O} / \mathrm{Py}$ (Scheme 36). Treatment of 2',3',5'-tri- $O$-acetyltoyocamycin (138) with DBH (1.1 eq., $\mathrm{CH}_{2} \mathrm{Cl}_{2}, 18$ h) gave the corresponding 8-bromo-2',3',5'-tri-O-acetyltoyocamycin (139) in 79\% isolated yield. However, treatment of $\mathbf{1 3 9}(107 \mathrm{mg})$ with 0.02 equiv. of Pd catalyst, 0.1 equiv. of $\mathrm{Cu}$ catalyst, 0.1 equiv. of $\mathrm{Et}_{3} \mathrm{~N}$, and 4 equiv. of TMSA in anhydrous DMF for $19 \mathrm{~h}$ at 40 ${ }^{\circ} \mathrm{C}$ gave a complex reaction mixture. Silica gel column chromatography gave three major fractions. The NMR analysis showed the first two products to be unchanged starting material 139 (27 $\mathrm{mg}, 25 \%)$, and debrominated product $138(7 \mathrm{mg}, 8 \%)$. The third fraction (4 mg) was more polar than the substrate on TLC, was blue on TLC plate under $365 \mathrm{~nm}$ lamp. But ${ }^{1} \mathrm{H}-\mathrm{NMR}$ of this material did not have characteristic product peaks and structure of this blue spot could not be determined. 


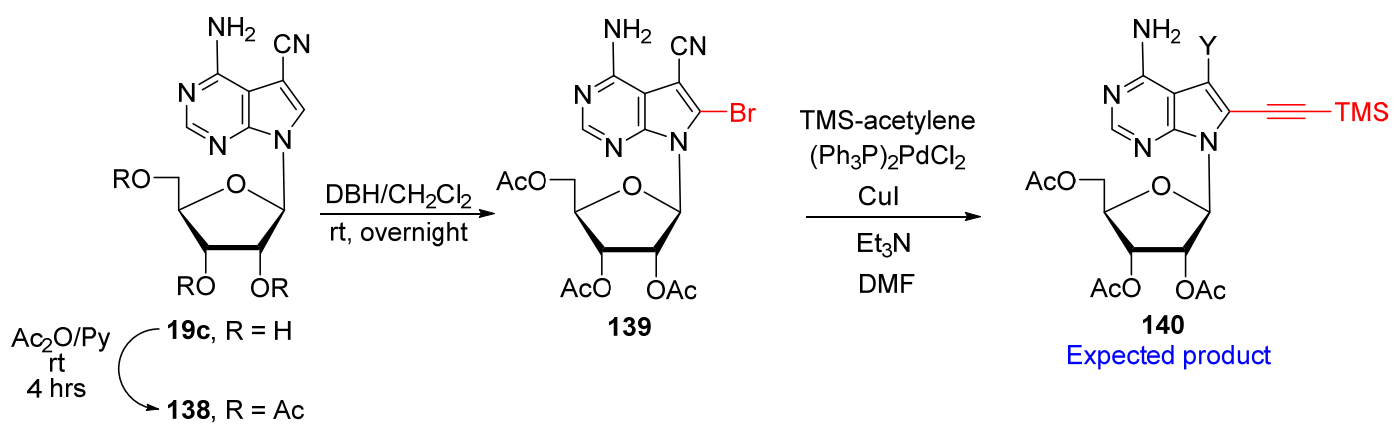

Scheme 36. Attempted synthesis of 8-alkynyltoyocamycin derivative $\mathbf{1 4 0}$ via sonagashira coupling.

As iodo is a better substrate than bromo in Sonagashira coupling, I envisioned the use of 8-iodo-7-deazapurine analogues as substrates. Thus, toyocamycin 19c was converted to the corresponding tri-O-(tert-butyldimethylsilyl) protected counterpart 141 using standard procedures (TBDMSCl/Imidazole/DMF/35 ${ }^{\circ} \mathrm{C} ; 58 \%$ ) (Scheme 37). The reaction was sluggish and required longer hours of stirring and more equivalents of reagents than usual. Treatment of silylated toyocamycin 141 with Lithium diisopropylamide (LDA, 5 equiv.) and iodine $\left(\mathrm{I}_{2}, 1.5\right.$ equiv.) in dry $\mathrm{THF}\left[-78{ }^{\circ} \mathrm{C}(2 \mathrm{~h})\right.$ to ambient (48 h)] gave the corresponding 8-iodotoyocamycin analogue 142 in 16\% isolated yield. Unchanged substrate 141 was also isolated form the column (58\%). However, treatment of 8-iodo analogue 142 with trimethylsilylacetylene, $\left(\mathrm{PPh}_{3}\right)_{2} \mathrm{PdCl}_{2}(10 \% \mathrm{~mol})$, $\mathrm{CuI}(20 \% \mathrm{~mol}), \mathrm{Et}_{3} \mathrm{~N}$ (excess), TMSA (4 equiv.) in $\mathrm{DMF}$ at $40{ }^{\circ} \mathrm{C}$ for $48 \mathrm{~h}$ gave unchanged starting material $\mathbf{1 4 2}$ as major product even after for 2 days. Strangely, no trace of deiodinated product 141 or acetylenic product 143 was observed on TLC. 


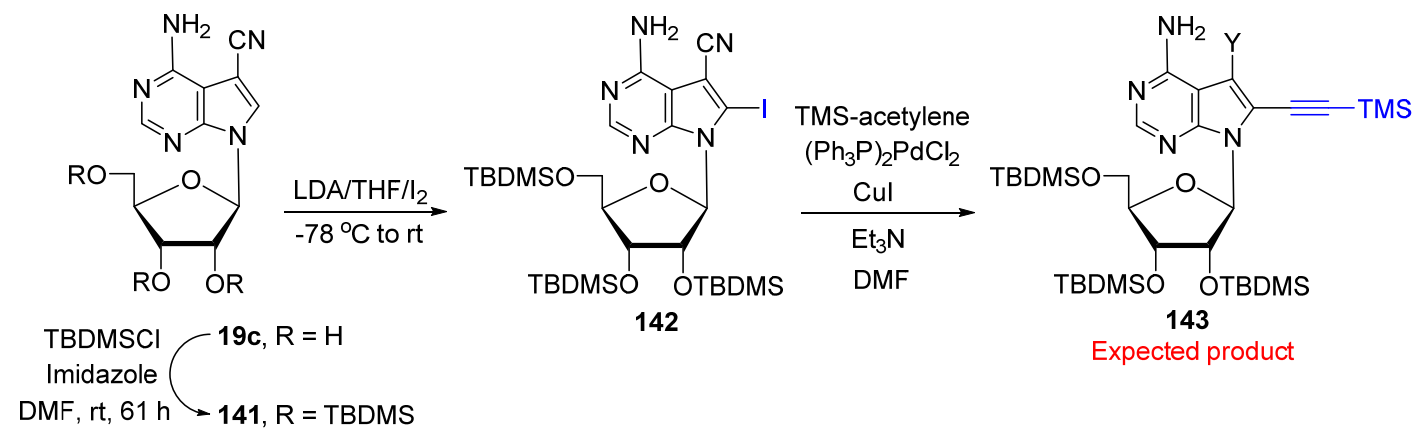

Scheme 37. Attempted synthesis of 8-alkynyltoyocamycin derivative 143 via sonagashira coupling.

Considering the cost of 7-deazapurine substrates, I stopped proceeding further in this direction.

\subsubsection{Iodine catalyzed direct $\mathrm{C}-\mathrm{H}$ activation of 7-deazapurine nucleosides}

Since I was unable to synthesize the 8-azido or the corresponding vinylazide analogues of tubercidin and sangivamycin, I explored other possibilities for incorporation of an aromatic moiety (e.g. triazolyl) based on direct on $\mathrm{C}-\mathrm{H}$ activation. ${ }^{206}$ Incidentally, a recent research paper by Dr. Yotphan, et al. described iodine-catalyzed direct activation of indoles with azoles mediated by tert-butylhydroperoxide (TBHP) (Scheme 38). ${ }^{207}$
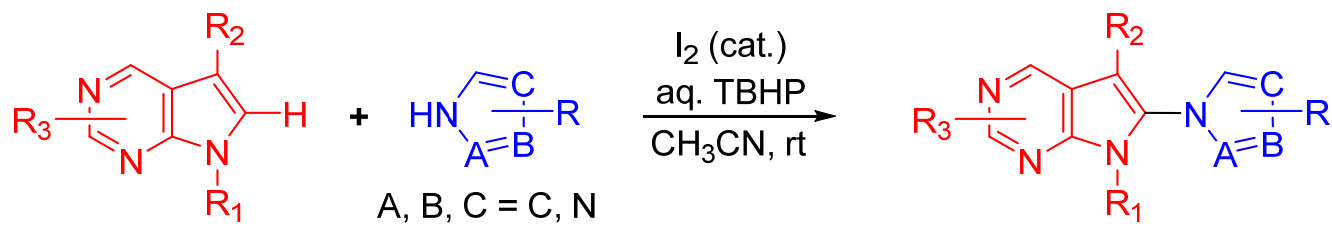

Scheme 38. Iodine catalyzed oxidative cross-coupling of Indoles and Azoles. ${ }^{207}$

Because tubercidin 19a is structurally similar to indole, I imagined oxidative cross-coupling of tubercidin with triazoles to generate the corresponding $\mathrm{C} 7$ and/or $\mathrm{C} 8$ triazolyl substituted analogues. Thus, initial treatment of tubercidin 19a with benzotriazole (2 equiv.), $\mathrm{I}_{2}$ (0.2 equiv.), and TBHP (5-6 M solution in decane, 1 equiv.) in 
anhydrous DMF at ambient temperature after $7 \mathrm{~h}$ showed unchanged tubercidin as the major product on TLC (Scheme 39). No product formation was observed even after stirring the reaction mixture at $40{ }^{\circ} \mathrm{C}$ for $7 \mathrm{hrs}$. Additional $\mathrm{I}_{2}$ ( 0.2 equiv.), and TBHP ( 1 equiv.) were added and the reaction mixture was stirred at $40{ }^{\circ} \mathrm{C}$ for $48 \mathrm{~h}$, by which time the TLC showed $\sim 15 \%$ conversion to a more polar product. Analogous treatment of tubercidin 19a with benzotriazole ( 2 equiv.), $\mathrm{I}_{2}$ (0.4 equiv.), and TBHP ( 2 equiv.) in anhydrous DMF at $35{ }^{\circ} \mathrm{C}$ for $72 \mathrm{~h}$ also showed $\sim 10 \%$ conversion to a less polar product. Additional TBHP ( 1 equiv.) was added and the reaction mixture was stirred at $35{ }^{\circ} \mathrm{C}$ for 24 h (total: $96 \mathrm{~h}$ ), by which time the TLC showed $\sim 30 \%$ conversion to a more polar product. The new spot was isolated by silica gel chromatography in $18 \%$ yield and was single product on ${ }^{1} \mathrm{H},{ }^{13} \mathrm{C}$ NMR. Comparison of $1 \mathrm{H}-\mathrm{NMR}$ data with substrate revealed the following: (i) singlet for $\mathrm{H} 2$ was still present (shifted to $8.22 \mathrm{ppm}$ from $8.05 \mathrm{ppm}$ ); (ii) Doublet for H8 (7.35 ppm) collapsed to a singlet (7.04 ppm); and (ii) doublet for H7 (at $7.6 \mathrm{ppm})$ is absent. This confirms the structure of the product to be 7(benzotriazolyl)tubercidin $\mathbf{1 4 4}$.
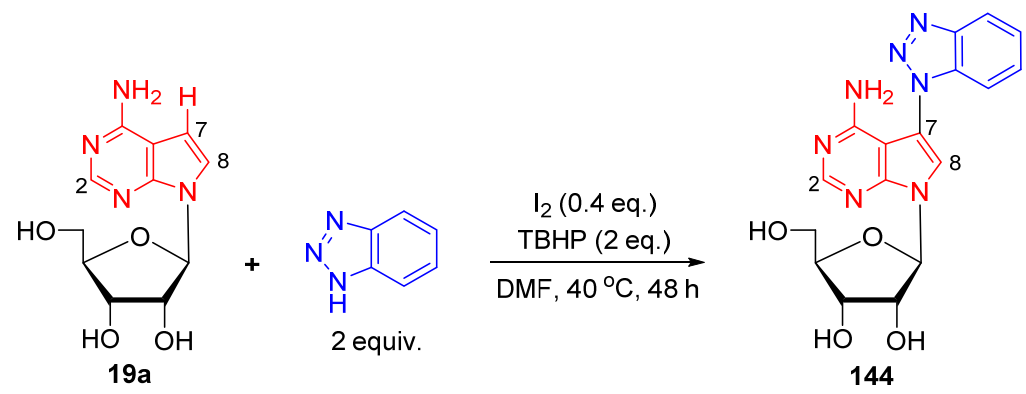

Scheme 39. Iodine catalyzed oxidative cross-coupling of tubercidin and benzotrizole.

Fluorescence analysis of the triazolyl compound $\mathbf{1 4 4}$ showed emission at $420 \mathrm{~nm}$ with the best quantum yield being $\sim 0.002$ units (in $\mathrm{MeOH}$ ). The fluorescence is stronger in basic $\mathrm{pH}$ between 7 and 12 and at $\mathrm{pH} \sim 2$, it is non-fluorescent. The average lifetime is 
about 3.8 ns with two well-defined lifetimes of 1 ns $(10 \%)$ and 4.1 ns $(90 \%)$. However, the compound seems to be highly sensitive to UV light, since increase in fluorescence upon irradiation with $280 \mathrm{~nm}$ light was observed.

Conversely, treatment of acetyl-protected tubercidin (123) with $\mathrm{I}_{2}(0.2$ eq.), TBHP (1eq.), in DMF at room temperature for $12 \mathrm{~h}$ gave a mixture of three products (Scheme 40). TLC of the reaction mixture showed $\sim 30 \%$ conversion to a less polar spot. Isolation of the new spot by column chromatography followed by ${ }^{1} \mathrm{H}-\mathrm{NMR}$ analysis showed the spot as a mixture of three different products (19\% yield, 60:25:15 mixture). It is suspected that the mixture of products are 7-substituted analogue 145, 8 -substituted counterpart 146 and probably 7,8-dibenzotriazolyltubercidin (not shown in scheme).
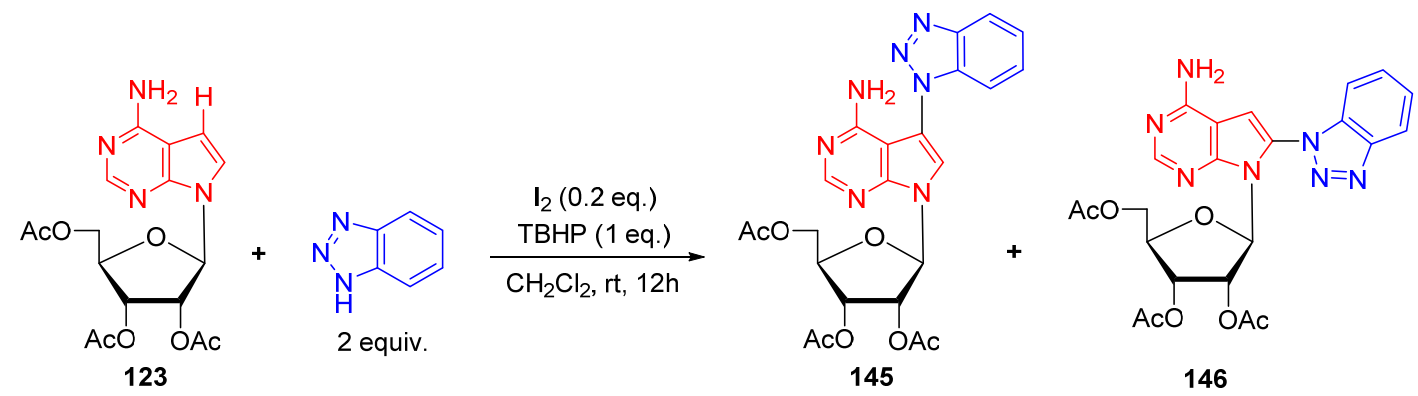

Scheme 40. Iodine catalyzed oxidative cross-coupling of acetylated tubercidin and benzotriazole.

In addition, treatment of sangivamycin (19b) with benzotriazole (2 eq.), $\mathrm{I}_{2}(0.4$ eq.), TBHP (2 eq.), in anhydrous DMF at $120{ }^{\circ} \mathrm{C}$ for $24 \mathrm{~h}$ showed unchanged starting material on TLC (Scheme 41). On the other hand, treatment of toyocamycin (19c) with benzotriazole (2 eq.), $\mathrm{I}_{2}$ (0.4 eq.), TBHP (2eq.), in anhydrous DMF at $80{ }^{\circ} \mathrm{C}$ for $48 \mathrm{hrs}$ resulted in $30 \%$ conversion to new spot on TLC. The isolated spot was not the expected product 147c and exact structure could not be established by spectroscopic data. These 
results reiterate the literature reports that indoles with electron deficient pyrrole rings react sluggishly with azoles. ${ }^{207}$
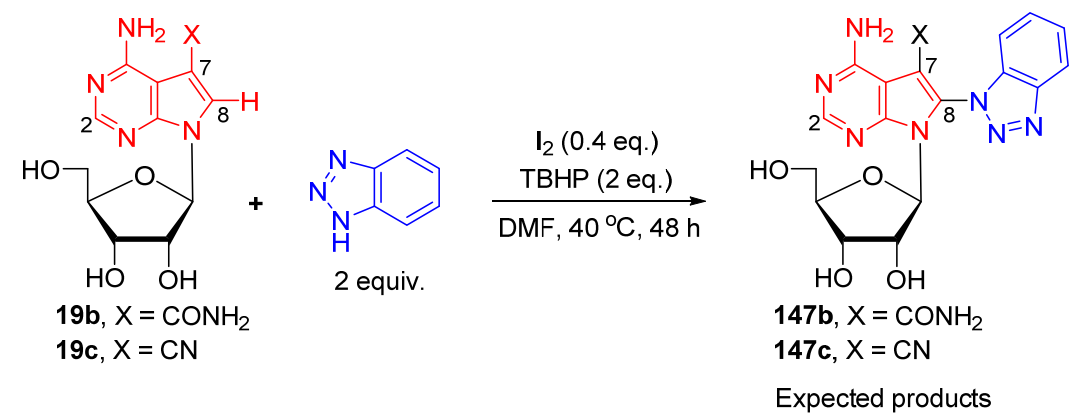

Scheme 41. Attempted synthesis of iodine catalyzed oxidative cross-coupling of sangivamycin or toyocamycin and benzotriazole.

\section{EXPERIMENTAL SECTION}

The ${ }^{1} \mathrm{H}(400 \mathrm{MHz}),{ }^{13} \mathrm{C}(100.6 \mathrm{MHz})$, and ${ }^{19} \mathrm{~F}(376 \mathrm{MHz}) \mathrm{NMR}$ spectra were recorded at ambient temperature in solutions of $\mathrm{CDCl}_{3}$ or DMSO- $d_{6}$. Reaction progress was monitored by TLC on Merck Kieselgel $60-\mathrm{F}_{254}$ sheets with product detection by $254-$ nm light. Products were purified by column chromatography using Merck Kiselgel 60 (230-400 mesh) or by automated flash chromatography using a CombiFlash system. UV spectra were recorded with a Varian Cary 100 Bio UV-visible spectrophotometer. Reagent grade chemicals were used and solvents were dried by reflux and distillation from $\mathrm{CaH}_{2}$ under $\mathrm{N}_{2}$ unless otherwise specified, and an atmosphere of $\mathrm{N}_{2}$ was used for reactions. Purity of the synthesized compounds was determined to be $\geq 95 \%$ by elemental analysis $(\mathrm{C}, \mathrm{H}, \mathrm{N})$ and/or HPLC on Phenomenex Gemini RP-C18 column with $\mathrm{CH}_{3} \mathrm{CN} / \mathrm{H}_{2} \mathrm{O}$ solvent system as mobile phase. Elemental analyses were performed by Galbraith Laboratories, Knoxville, TN. Mass spectra (MS) were obtained with atmospheric pressure chemical ionization (APCI) technique or electro-spray ionization 
(ESI) techniques. High-resolution mass spectra were obtained in ESI-TOF mode unless otherwise noted.

Chemical shifts $(\delta)$ are reported in parts per million (ppm) referenced to the residual solvent peak, and coupling constants $(J)$ are given in Hertz $(\mathrm{Hz})$. Multiplicity is reported using standard abbreviations: singlet (s); doublet (d); triplet (t); multiplet (m); broad (br); inverted commas indicate observed multiplicity. UV spectra were recorded with a Varian Cary 100 Bio UV-visible spectrophotometer.

Some of the data were reprinted with permission from the following papers:

(i) Adhikary, Amitava; Kumar, Anil; Rayala, Ramanjaneyulu; Hindi, Ragda M.; Adhikary, Ananya; Wnuk, Stanislaw F.; and Sevilla, Michael D., "One-electron oxidation of Gemcitabine and analogs: Mechanism of formation of $\mathrm{C}^{\prime}{ }^{\prime}$ and $\mathrm{C} 2{ }^{\prime}$ sugar radicals", J. Am. Chem. Soc. 2014, 136 (44), 15646-15653. Copyright $\mathbb{C}$ 2014, American Chemical Society.

(ii) Rayala, Ramanjaneyulu; Theard, Patricia; Ortiz, Heysell; Yao, Sylvia; Young, James D.; Balzarini, Jan; Robins, Morris J., Wnuk, Stanislaw F., "Synthesis of Purine and 7-Deazapurine Nucleoside Analogues of 6- $\mathrm{N}-(4-$ Nitrobenzyl)adenosine; Inhibition of Nucleoside Transport and Proliferation of Cancer Cells", ChemMedChem 2014, 9, 2186-2192. Copyright (C) 2014 WILEYVCH Verlag GmbH \& Co. KGaA, Weinheim.

(iii) Rayala, Ramanjaneyulu; Wnuk, Stanislaw F., "Bromination at C-5 of pyrimidine and C-8 of purine nucleosides with 1,3-dibromo-5,5-dimethylhydantoin", Tetrahedron Letters 2012, 53 (26), 3333-3336. Copyright (C) 2012, Elsevier Ltd.

\section{Cytostatic activity assays}


All assays were performed in 96-well microtiter plates. To each well of $200 \mu \mathrm{L}$ were added $(5-7.5) \times 10^{4}$ tumor cells and a given amount of the test compound. The cells were allowed to proliferate for $48 \mathrm{~h}$ (murine leukemia L1210), $72 \mathrm{~h}$ (human lymphocytic CEM), 96 h (human cervix carcinoma HeLa), 144 h (human prostate cancer PC-3), or $168 \mathrm{~h}$ (human kidney Caki-1) at $37^{\circ} \mathrm{C}$ in a humidified $\mathrm{CO}_{2}$-controlled atmosphere. At the end of the incubation period, the cells were counted in a Coulter counter. The $\mathrm{IC}_{50}(50 \%$ inhibitory concentration) was defined as the concentration of the compound that inhibited cell proliferation by $50 \%$.

General procedure for the bromination of protected nucleosides. $\mathrm{DBH}$ and/or TMSOTf were added to a stirred solution of substrate in $\mathrm{CH}_{2} \mathrm{Cl}_{2}$. The resulting brownishorange solution was stirred at room temperature for time given in the corresponding table (Tables 3, 4, and 5; Section 3.1.) or until TLC showed absence of starting material and formation of less polar product. The reaction mixture was diluted with $\mathrm{CHCl}_{3}$ and was washed with saturated $\mathrm{NaHCO}_{3} / \mathrm{H}_{2} \mathrm{O}$ and brine. The organic layer was dried $\left(\mathrm{MgSO}_{4}\right)$ and concentrated in vacuo to yield the corresponding brominated product as a colorless foam with purity over $98 \%\left({ }^{1} \mathrm{H}\right.$ NMR $)$.

\section{General procedure for the bromination of unprotected nucleosides.}

Procedure A. DBH was added to a stirred solution of substrate in DMF. The resulting pale-yellow solution was stirred at room temperature for time given in the corresponding table (Tables 3, 4, and 5; Section 3.1.) or until TLC showed absence of starting material and formation of less polar product. Volatiles were evaporated and the residue was coevaporated with $\mathrm{MeCN}$. The resulting pale solid was crystallized or purified by column chromatography to give the corresponding brominated product as colorless crystals. 
Procedure B. DBH was added to a stirred suspension/solution of substrate in $\mathrm{MeOH}$. The resulting pale solution was stirred at room temperature for time given in the corresponding table (Tables 3, 4, and 5; Section 3.1.) or until TLC showed absence of starting material and formation of less polar product. Products were isolated by (a) filtration, if the products precipitated from the reaction mixture; (b) if no was precipitate observed, then volatiles were evaporated and the residue was crystallized or column chromatographed to give the corresponding brominated product as colorless crystals. The isolated brominated products were usually $>98 \%$ pure by ${ }^{1} \mathrm{H}-\mathrm{NMR}$.

5-Bromo-2',3',5'-tri-O-acetyluridine (46a) ${ }^{64}$. UV (MeOH) $\lambda_{\max } 275 \mathrm{~nm}, \lambda_{\min } 240 \mathrm{~nm} ;{ }^{1} \mathrm{H}$ $\operatorname{NMR}\left(\mathrm{CDCl}_{3}\right) \delta 9.75($ br s, 1H, NH), $7.82(\mathrm{~s}, 1 \mathrm{H}, \mathrm{H} 6), 6.06$ (d, J=4.7 Hz, 1H, H1'), 5.34-5.29 (m, 2H, H2', H3'), 4.38-4.30 (m, 3H, H4', H5', H5"), 2.18 (s, 3H, Ac), 2.10 (s, 3H, Ac), 2.08 (s, 3H, Ac).

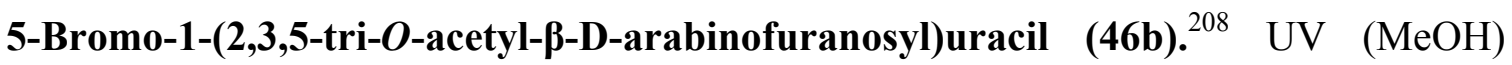
$\lambda_{\max } 276 \mathrm{~nm}, \lambda_{\min } 239 \mathrm{~nm} ;{ }^{1} \mathrm{H} \mathrm{NMR}\left(\mathrm{CDCl}_{3}\right) \delta 9.33$ (br s, 1H, NH), 7.77 (s, 1H, H6), $6.22\left(\mathrm{~d}, J=4.1 \mathrm{~Hz}, 1 \mathrm{H}, \mathrm{H} 1^{\prime}\right), 5.35$ (dd, $J=3.7,4.1 \mathrm{~Hz}, 1 \mathrm{H}, \mathrm{H} 2$ '), 5.04 (“q”, $J=1.9 \mathrm{~Hz}$ 1H, H3'), 4.38 (dd, $\left.J=5.8,12.1 \mathrm{~Hz}, 1 \mathrm{H}, \mathrm{H} 5^{\prime}\right), 4.32$ (dd, $\left.J=3.9,12.1 \mathrm{~Hz}, 1 \mathrm{H}, \mathrm{H} 5^{\prime \prime}\right), 4.16-$ $4.12(\mathrm{~m}, 1 \mathrm{H}, \mathrm{H} 4), 2.09$ (s, 3H, Ac), 2.07 (s, 3H, Ac), 1.98 (s, 3H, Ac); ${ }^{13} \mathrm{C}$ NMR $\left(\mathrm{CDCl}_{3}\right): \delta 170.5,169.6,168.6(3 \times \mathrm{Ac}), 158.6(\mathrm{C} 4), 149.2(\mathrm{C} 2), 139.8(\mathrm{C} 6), 96.3(\mathrm{C} 5$ ), $84.4\left(\mathrm{C} 1^{\prime}\right), 80.7\left(\mathrm{C}^{\prime}\right), 76.1\left(\mathrm{C}^{\prime}\right), 74.4\left(\mathrm{C}^{\prime}\right), 62.5\left(\mathrm{C} 5^{\prime}\right), 20.8,20.6,20.4$ (3 × Ac); MS (ESI) $m / z 447\left(100,\left[{ }^{79} \mathrm{Br}\right], \mathrm{MH}^{-}\right), 449\left(98,\left[{ }^{81} \mathrm{Br}\right], \mathrm{MH}^{-}\right)$.

5-Bromo-3',5'-di-O-acetyl-2'-deoxy-uridine (46c) ${ }^{64}$. UV (MeOH) $\lambda_{\max } 277 \mathrm{~nm}, \lambda_{\min } 241$ nm; ${ }^{1} \mathrm{H}$ NMR $\left(\mathrm{CDCl}_{3}\right) \delta 9.59$ (br s, 1H, NH), 7.89 (s, 1H, H6), 6.29 (“dd”, $J=5.8,8.0$ Hz, 1H, H1'), 5.24-5.21 (m, 1H, H3'), 4.40 (dd, $J=3.1,12.2$ Hz, 1H, H5'), 4.34-4.28 (m, 
2H, H4', H5"), 2.54 (ddd, $\left.J=2.3,5.8,14.3 \mathrm{~Hz}, 1 \mathrm{H}, \mathrm{H} 2^{\prime}\right), 2.23-2.15$ (m, 1H, H2"), 2.17 (s, 3H, Ac), 2.11 (s, 3H, Ac).

5-Bromouridine (46d) ${ }^{64}$. UV (MeOH) $\lambda_{\max } 279 \mathrm{~nm}, \lambda_{\min } 241 \mathrm{~nm} ;{ }^{1} \mathrm{H}$ NMR (DMSO- $\left.d_{6}\right) \delta$ 11.81 (br s, 1H, NH), 8.48 (s, 1H, H6), 5.73 (d, $J=4.5 \mathrm{~Hz}, 1 \mathrm{H}, \mathrm{H} 1$ '), 5.42 (d, $J=5.3 \mathrm{~Hz}$, $\left.1 \mathrm{H}, 2^{\prime} \mathrm{OH}\right), 5.27\left(\mathrm{t}, J=4.7 \mathrm{~Hz}, 1 \mathrm{H}, 5^{\prime} \mathrm{OH}\right), 5.07\left(\mathrm{~d}, J=5.4 \mathrm{~Hz}, 1 \mathrm{H}, 3^{\prime} \mathrm{OH}\right), 4.04$ (q, $J=$ $\left.4.9 \mathrm{~Hz}, 1 \mathrm{H}, \mathrm{H} 2^{\prime}\right), 3.98$ (q, $\left.J=5.0 \mathrm{~Hz}, 1 \mathrm{H}, \mathrm{H} 3^{\prime}\right), 3.88-3.85$ (m, 1H, H4'), 3.71-3.66 (m, 1H, H5'), 3.60-3.55 (m, 1H, H5").

5-Bromo-1-(ק-D-arabinofuranosyl)uracil (46e) ${ }^{209}$. UV (MeOH) $\lambda_{\max } 280 \mathrm{~nm}, \lambda_{\min } 242$ $\mathrm{nm} ;{ }^{1} \mathrm{H}$ NMR (DMSO-d $)_{6} \delta 11.82$ (br s, $\left.1 \mathrm{H}, \mathrm{NH}\right), 8.07$ (s, 1H, H6), 5.96 (d, $J=4.6 \mathrm{~Hz}$, 1H, H1'), 5.63 (d, $\left.J=5.3 \mathrm{~Hz}, 1 \mathrm{H}, 2^{\prime} \mathrm{OH}\right), 5.48\left(\mathrm{~d}, J=4.5 \mathrm{~Hz}, 1 \mathrm{H}, 3^{\prime} \mathrm{OH}\right), 5.17(\mathrm{t}, J=5.4$ $\mathrm{Hz}, 1 \mathrm{H}, 5$ 'OH), 4.03 (“q”, $J=4.5 \mathrm{~Hz}, 1 \mathrm{H}, \mathrm{H} 2$ '), 3.91 (q, $J=4.2 \mathrm{~Hz}, 1 \mathrm{H}, \mathrm{H} 3$ '), 3.74 (“q”, $J$ $\left.=4.5 \mathrm{~Hz}, 1 \mathrm{H}, \mathrm{H} 4{ }^{\prime}\right), 3.66-3.55\left(\mathrm{~m}, 1 \mathrm{H}, \mathrm{H} 5^{\prime}, \mathrm{H} 5^{\prime \prime}\right)$.

5-Bromo-2'-deoxyuridine (46f) ${ }^{64}$. UV (MeOH) $\lambda_{\max } 279 \mathrm{~nm}, \lambda_{\min } 241 \mathrm{~nm} ;{ }^{1} \mathrm{H} \mathrm{NMR}$ $\left(\mathrm{DMSO}-d_{6}\right) \delta 11.79(\mathrm{br} \mathrm{s}, 1 \mathrm{H}, \mathrm{NH}), 8.39(\mathrm{~s}, 1 \mathrm{H}, \mathrm{H} 6), 6.10\left(\mathrm{t}, J=6.5 \mathrm{~Hz}, 1 \mathrm{H}, \mathrm{H} 1^{\prime}\right), 5.25$ $\left(\mathrm{d}, J=4.3 \mathrm{~Hz}, 1 \mathrm{H}, 3^{\prime} \mathrm{OH}\right), 5.17\left(\mathrm{t}, J=4.8 \mathrm{~Hz}, 1 \mathrm{H}, 5^{\prime} \mathrm{OH}\right), 4.26-4.22\left(\mathrm{~m}, 1 \mathrm{H}, \mathrm{H} 3^{\prime}\right), 3.79$ (q, $J=3.2 \mathrm{~Hz}, 1 \mathrm{H}, \mathrm{H} 4 '), 3.66-3.54$ (m, 2H, H5', H5"), 2.18-2.08 (m, 2H, H2', H2").

5-Bromocytidine (47b) ${ }^{62}$. UV (MeOH) $\lambda_{\max } 289 \mathrm{~nm}, \lambda_{\min } 265 \mathrm{~nm} ;{ }^{1} \mathrm{H}$ NMR (DMSO- $d_{6}$ ) $\delta 8.39$ (s, 1H, H6), 7.83 (br s, 1H, NH), 6.99 (br s, 1H, NH), 5.71 (d, $J=3.2 \mathrm{~Hz}, 1 \mathrm{H}$, $\left.\mathrm{H}^{\prime}\right), 5.37$ (d, $\left.J=5.0 \mathrm{~Hz}, 1 \mathrm{H}, 2^{\prime} \mathrm{OH}\right), 5.23\left(\mathrm{t}, J=4.8 \mathrm{~Hz}, 1 \mathrm{H}, 5^{\prime} \mathrm{OH}\right), 5.00(\mathrm{~d}, J=5.4 \mathrm{~Hz}$, $\left.1 \mathrm{H}, 3^{\prime} \mathrm{OH}\right), 3.98-3.92\left(\mathrm{~m}, 1 \mathrm{H}, \mathrm{H} 2^{\prime}\right), 3.85-3.83(\mathrm{~m}, 1 \mathrm{H}, \mathrm{H} 3$ '), 3.70 (ddd, $J=2.7,4.8,12.1$ Hz, 1H, H5'), 3.56 (ddd, $J=2.5,4.9,12.1 \mathrm{~Hz}, 1 \mathrm{H}, \mathrm{H} 5 ")$.

4- $N$-Benzoyl-5-bromocytidine (48b). mp 193-195 ${ }^{\circ} \mathrm{C}$; UV (MeOH) $\lambda_{\max } 252,335 \mathrm{~nm}(\varepsilon$ 8900, 13 900), $\lambda_{\min }$ 228, $292 \mathrm{~nm}(\varepsilon 7300,4200) ;{ }^{1} \mathrm{H}$ NMR (DMSO- $\left.d_{6}\right) \delta 12.81$ (br s, $1 \mathrm{H}$, 
NH), 8.79 (s, 1H, H6), 8.10-8.24 (br s, 2H, Bz), 7.62 (t, $J=7.3 \mathrm{~Hz}, 1 \mathrm{H}, \mathrm{Bz}), 7.53$ (t, $J=$ $7.6 \mathrm{~Hz}, 2 \mathrm{H}, \mathrm{Bz}), 5.70$ (d, $\left.J=3.6 \mathrm{~Hz}, 1 \mathrm{H}, \mathrm{H} 1^{\prime}\right), 5.57$ (d, $\left.J=3.9 \mathrm{~Hz}, 1 \mathrm{H}, 2^{\prime} \mathrm{OH}\right), 5.41$ (t, $J=$ $\left.4.6 \mathrm{~Hz}, 1 \mathrm{H}, 5^{\prime} \mathrm{OH}\right), 5.10$ (d, $\left.J=5.9 \mathrm{~Hz}, 1 \mathrm{H}, 3^{\prime} \mathrm{OH}\right), 4.07-4.13\left(\mathrm{~m}, 1 \mathrm{H}, \mathrm{H} 2^{\prime}\right), 4.04$ ("q", $J=$ 5.9 Hz, 1H, H3'), 3.90-3.96 (m, 1H, H4'), 3.74-3.82 (m, 1H, H5'), 3.63 (ddd, $J=2.1,4.4$, 12.2 Hz, 1H, H5"); ${ }^{13} \mathrm{C}$ NMR (DMSO-d $) \quad \delta 177.8(\mathrm{Bz}), 154.5$ (C2), 147.2 (C4 ), 142.1 (C6), 136.1 (Bz), 132.8, 129.4, 128.4, 95.0 (C5), 89.7 (C1'), 84.5 (C4'), 74.2 (C2'), 68.6 (C3'), 59.5 (C5'); MS (ESI) m/z 426 (100, [ $\left.\left.{ }^{79} \mathrm{Br}\right], \mathrm{MH}^{+}\right), 428$ (98, [ $\left.\left.{ }^{81} \mathrm{Br}\right], \mathrm{MH}^{+}\right)$. Anal. Calcd for $\mathrm{C}_{16} \mathrm{H}_{16} \mathrm{BrN}_{3} \mathrm{O}_{6} \cdot 0.5 \mathrm{MeOH}$ (442.24): C, 44.81; H, 4.10; N, 9.50. Found: C, 44.62; H, 3.71; N, 9.13.

5'-O-(Tert-butyldimethylsilyl)-2',3'-O-isopropylideneuridine $(49 b)^{210} \cdot$ UV (MeOH) $\lambda_{\max } 276 \mathrm{~nm}, \lambda_{\min } 241 \mathrm{~nm} ;{ }^{1} \mathrm{H}$ NMR $\left(\mathrm{CDCl}_{3}\right) \delta 9.23($ br s, $1 \mathrm{H}, \mathrm{NH}), 7.91(\mathrm{~s}, 1 \mathrm{H}, \mathrm{H} 6), 5.91$ (d, $\left.J=3.1 \mathrm{~Hz}, 1 \mathrm{H}, \mathrm{H} 1^{\prime}\right), 4.73\left(\mathrm{dd}, J=2.3,6.2 \mathrm{~Hz}, 1 \mathrm{H}, \mathrm{H} 2{ }^{\prime}\right), 4.68(\mathrm{dd}, J=3.1,6.1 \mathrm{~Hz}, 1 \mathrm{H}$, H3'), 4.39 (“'q”, $J=2.4 \mathrm{~Hz}, 1 \mathrm{H}, \mathrm{H} 4$ '), 3.93 (dd, $J=2.1,11.7 \mathrm{~Hz}, 1 \mathrm{H}, \mathrm{H} 5$ '), 3.80 (dd, $J=$ 2.8, 11.7 Hz, 1H, H5"), 1.58 (s, 3H, $\left.\mathrm{CH}_{3}\right), 1.35$ (s, 3H, $\left.\mathrm{CH}_{3}\right), 0.90$ (s, 9H, 3 x CH $\left.\mathrm{CH}_{3}\right), 0.11$ (s, 6H, $\left.2 \times \mathrm{CH}_{3}\right)$.

8-Bromoadenosine (50b) ${ }^{211}$. UV (MeOH) $\lambda_{\max } 264 \mathrm{~nm}, \lambda_{\min } 232 \mathrm{~nm} ;{ }^{1} \mathrm{H}$ NMR (DMSO$\left.d_{6}\right) \delta 8.12(\mathrm{~s}, 1 \mathrm{H}, \mathrm{H} 2), 7.58\left(\mathrm{br} \mathrm{s}, 2 \mathrm{H}, \mathrm{NH}_{2}\right), 5.83$ (d, $J=6.8 \mathrm{~Hz}, 1 \mathrm{H}, \mathrm{H} 1$ '), 5.52 (dd, $J=$ 3.9, $\left.8.6 \mathrm{~Hz}, 1 \mathrm{H}, 5^{\prime} \mathrm{OH}\right), 5.48\left(\mathrm{~d}, J=6.3 \mathrm{~Hz}, 1 \mathrm{H}, 2^{\prime} \mathrm{OH}\right), 5.25\left(\mathrm{~d}, J=4.4 \mathrm{~Hz}, 1 \mathrm{H}, 3^{\prime} \mathrm{OH}\right)$, 5.09 (q, $\left.J=6.1 \mathrm{~Hz}, 1 \mathrm{H}, \mathrm{H} 2^{\prime}\right), 4.20-4.17$ (m, 1H, H3'), 3.99-3.96 (m, 1H, H4'), 3.68 (dt, $J$ =3.9, $\left.12.1 \mathrm{~Hz}, 1 \mathrm{H}, \mathrm{H} 5^{\prime}\right), 3.55-3.49$ (m, 1H, H5").

8-Bromo-2'-deoxyadenosine (51b) ${ }^{54} .{ }^{1} \mathrm{H}$ NMR (DMSO- $\left.d_{6}\right) \delta 8.11(\mathrm{~s}, 1 \mathrm{H}, \mathrm{H} 2), 7.51$ (br s, 2H, $\mathrm{NH}_{2}$ ), 6.29 (“dd”, $J=6.7,7.9 \mathrm{~Hz}, 1 \mathrm{H}, \mathrm{H} 1$ '), 5.34 (d, $\left.J=4.2 \mathrm{~Hz}, 1 \mathrm{H}, 3^{\prime} \mathrm{OH}\right), 5.29$ (“dd”, $\left.J=4.4,7.7 \mathrm{~Hz}, 1 \mathrm{H}, 5^{\prime} \mathrm{OH}\right), 4.50-4.46$ (m, 1H, H3'), 3.90-3.87 (m, 1H, H4'), 3.65 
(“'dt", $J=4.5,11.9 \mathrm{~Hz}, 1 \mathrm{H}, \mathrm{H} 5$ '), 3.51-3.45 (m, 1H, H5"), 3.28-3.21 (m, 1H, H2'), 2.19 (ddd, $J=2.7,6.5,13.2 \mathrm{~Hz}, 1 \mathrm{H}, \mathrm{H} 2 ")$.

8-Bromo-2',3',5'-tri-O-acetylguanosine (52b) ${ }^{212}$. UV (MeOH) $\lambda_{\max } 263 \mathrm{~nm}, \lambda_{\min } 220$ $\mathrm{nm} ;{ }^{1} \mathrm{H}$ NMR (DMSO- $d_{6}$ ) $\delta 10.95$ (br s, $1 \mathrm{H}, \mathrm{NH}$ ), 6.63 (br s, $2 \mathrm{H}, \mathrm{NH}_{2}$ ), 6.01 (“dd”, $J=$ 4.5, $6.3 \mathrm{~Hz}, 1 \mathrm{H}, \mathrm{H1}$ '), 5.88 (“d”, $J=4.4 \mathrm{~Hz}, 1 \mathrm{H}, \mathrm{H2}$ '), 5.65 (t, $J=6.3 \mathrm{~Hz}, 1 \mathrm{H}, \mathrm{H} 3$ '), 4.42 (dd, $\left.J=3.7,11.9 \mathrm{~Hz}, 1 \mathrm{H}, \mathrm{H} 5^{\prime}\right), 4.34-4.30\left(\mathrm{~m}, 1 \mathrm{H}, \mathrm{H} 4^{\prime}\right), 4.21$ (dd, $J=6.3,11.9 \mathrm{~Hz}, 1 \mathrm{H}$, H5"), 2.11 (s, 3H, Ac), 2.07 (s, 3H, Ac), 1.99 (s, 3H, Ac).

8-Bromoguanosine (53b) ${ }^{213}$. UV (MeOH) $\lambda_{\max } 261 \mathrm{~nm}, \lambda_{\min } 223 \mathrm{~nm} ;{ }^{1} \mathrm{H}$ NMR (DMSO$\left.d_{6}\right) \delta 10.87$ (br s, 1H, NH), 6.51 (br s, 2H, NH ${ }_{2}$ ), 5.68 (“d”, $J=6.3 \mathrm{~Hz}, 1 \mathrm{H}, \mathrm{H1}$ '), 5.44 (“d”, $J=6.2 \mathrm{~Hz}, 1 \mathrm{H}, \mathrm{H} 2$ '), 5.09 (d, $\left.J=5.0 \mathrm{~Hz}, 1 \mathrm{H}, 2^{\prime} \mathrm{OH}\right), 5.01$ (q, $J=6.0 \mathrm{~Hz}, 1 \mathrm{H}$, $\left.5^{\prime} \mathrm{OH}\right), 4.95\left(\mathrm{t}, J=5.9 \mathrm{~Hz}, 1 \mathrm{H}, 3^{\prime} \mathrm{OH}\right), 4.15-4.12\left(\mathrm{~m}, 1 \mathrm{H}, \mathrm{H} 3^{\prime}\right), 3.87-3.84\left(\mathrm{~m}, 1 \mathrm{H}, \mathrm{H}^{\prime}\right)$, 3.68-3.62 (m, 1H, H5'), 3.54-3.48 (m, 1H, H5").

8-Bromo-2'-deoxyguanosine (54b). ${ }^{214,215} \mathrm{UV}(\mathrm{MeOH}) \lambda_{\max } 261 \mathrm{~nm}, \lambda_{\min } 221 \mathrm{~nm} ;{ }^{1} \mathrm{H}$ NMR (DMSO- $d_{6}$ ) $\delta 10.80$ (br s, $1 \mathrm{H}, \mathrm{NH}$ ), 6.49 (br s, 2H, NH $\mathrm{N}_{2}$ ), 6.15 (“t”, $J=7.3 \mathrm{~Hz}, 1 \mathrm{H}$, $\left.\mathrm{H}^{\prime}\right), 5.25\left(\mathrm{~d}, J=4.3 \mathrm{~Hz}, 1 \mathrm{H}, 3^{\prime} \mathrm{OH}\right), 4.86\left(\mathrm{t}, J=5.9 \mathrm{~Hz}, 1 \mathrm{H}, 5^{\prime} \mathrm{OH}\right), 4.41-4.37(\mathrm{~m}, 1 \mathrm{H}$, H3'), 3.81-3.78 (m, 1H, H4'), 3.65-3.59 (m, 1H, H5'), 3.52-3.46 (m, 1H, H5"), 3.19-3.12 (m, 1H, H2'), 2.13-2.07 (m, 1H, H2").

\section{8-bromotoyocamycin (55).}

Method A. NBS (195.8 mg, $1.1 \mathrm{mmol})$ was added to a stirred solution of 19c $(291.3 \mathrm{mg}$, $1 \mathrm{mmol})$ in anhydrous DMF ( $8 \mathrm{~mL})$ in a flame dried flask and the resulting pale-yellow solution was stirred at room temperature for $2.5 \mathrm{~h}$, by which time TLC showed $>90 \%$ conversion to a less polar product. Volatiles were removed from the clear, brown solution using high vacuum rotary evaporator on a hot water bath $\left(<80{ }^{\circ} \mathrm{C}\right)$. The resulting brown 
gummy solid was purified using column chromatography $(10 \%, \mathrm{MeOH} / \mathrm{EtOAc})$ and recrystallizaed from $\mathrm{MeOH}$ to give $\mathbf{5 5}$ as a colorless solid (166.6 mg, 45\%): mp: 200-202 ${ }^{\circ} \mathrm{C}$; UV (MeOH): $\lambda_{\max } 286 \mathrm{~nm}(\varepsilon 15000), \lambda_{\min } 250 \mathrm{~nm}(\varepsilon 2200) ;{ }^{1} \mathrm{H}$ NMR (DMSO- $\left.d_{6}\right): \delta$ 8.20 (s, 1H, H2), 7.09 (br s, 2H, NH${ }_{2}$ ), 5.94 (d, $J=6.6 \mathrm{~Hz}, 1 \mathrm{H}, \mathrm{H} 1$ '), 5.46 (d, $J=6.2 \mathrm{~Hz}$, 1H, 2'-OH), 5.30-5.33 ("q", $\left.J=4.1 \mathrm{~Hz}, 1 \mathrm{H}, 5^{\prime}-\mathrm{OH}\right), 5.25$ (d, $\left.J=4.8 \mathrm{~Hz}, 1 \mathrm{H}, 3^{\prime}-\mathrm{OH}\right), 5.08$ (q, $\left.J=6.0 \mathrm{~Hz}, 1 \mathrm{H}, \mathrm{H2} 2^{\prime}\right), 4.21\left(\mathrm{~m}, 1 \mathrm{H}, \mathrm{H} 3^{\prime}\right), 3.96\left(\mathrm{q}, J=3.8 \mathrm{~Hz}, 1 \mathrm{H}, \mathrm{H} 4^{\prime}\right), 3.69$ (dt, $J$ $=4.20,12.0 \mathrm{~Hz}, 1 \mathrm{H}, \mathrm{H} 5$ '), 3.50-3.57 (m, 1H, H5"); ${ }^{13} \mathrm{C}$ NMR: $\delta=156.1,153.2,149.9$, 121.7, 114.1 (CN), 102.1, $91.0\left(\mathrm{Cl}^{\prime}\right), 87.4,86.5(\mathrm{C} 4 '), 71.1(\mathrm{C} 2 '), 70.6(\mathrm{C} 3 '), 62.0\left(\mathrm{C} 5^{\prime}\right)$. $\mathrm{R}_{\mathrm{f}}\left(\right.$ EtOAc: $\left.i \operatorname{PrOH}: \mathrm{H}_{2} \mathrm{O}, 4: 1: 2\right) 0.69\left(\mathrm{R}_{\mathrm{f}}\right.$ 19c 0.68$)$; HRMS (ESI): $\mathrm{m} / z[\mathrm{M}+\mathrm{H}]^{+}$calcd for $\mathrm{C}_{12} \mathrm{H}_{13} \mathrm{BrN}_{5} \mathrm{O}_{4}^{+}: 370.0145$ and 372.0125 ; found 370.0093 and 371.9937.

Method B. DBH (552 mg, $1.93 \mathrm{mmol})$ was added to a suspension of 19c (750 mg, 2.57 $\mathrm{mmol})$ in $\mathrm{MeOH}(120 \mathrm{~mL})$ in a flame dried flask and the resulting yellow suspension was stirred at room temperature for $5 \mathrm{~min}$, by which time the solution became $>80 \%$ clear. After 15 min TLC showed $>95 \%$ conversion to a less polar product and product began to solidify out of the solution. After 30 min the colorless solid was collected using vacuum filtration $(710 \mathrm{mg})$. Volatiles in the mother liquor were removed using rotary evaporator and the resulting colorless solid was recrystallized from $\mathrm{MeOH}(104 \mathrm{mg})$ to give $\mathbf{5 5}$ (814 $\mathrm{mg}, 85 \%)$ : characterization data were in agreement with those reported in method 1.

\section{8-bromosangivamycin (56).}

Method A. NBS (267.1 mg, $1.5 \mathrm{mmol}$ ) was added to a stirred solution of $\mathbf{1 9 b}(309.2 \mathrm{mg}$, $1 \mathrm{mmol})$ in anhydrous DMF $(8 \mathrm{~mL})$ in a flame dried flask and the resulting pale-yellow solution was stirred at room temperature for $1 \mathrm{~h}$, by which time TLC showed $>90 \%$ conversion to a less polar product. Volatiles were removed from the clear, brown solution 
using high vacuum rotary evaporator on a hot water bath $\left(<80{ }^{\circ} \mathrm{C}\right)$. The resulting brown gummy oil was column chromatographed $(15 \%, \mathrm{MeOH} / \mathrm{EtOAc})$ to give $\mathbf{5 6}$ as an offwhite solid (244.5 mg, 63\%): mp: $174-175^{\circ} \mathrm{C}$; UV (MeOH): $\lambda_{\max } 286 \mathrm{~nm}(\varepsilon 14100), \lambda_{\min }$ 256 nm ( $\varepsilon 5500) ;{ }^{1} \mathrm{H}$ NMR (DMSO- $\left.d_{6}\right): \delta 8.09$ (s, $1 \mathrm{H}, \mathrm{H} 2$ ), 8.00 (br s, $1 \mathrm{H}, \mathrm{NH}_{2}$ ), 7.76 (br s, $\left.1 \mathrm{H}, \mathrm{NH}_{2}\right), 5.99\left(\mathrm{~d}, J=6.6 \mathrm{~Hz}, 1 \mathrm{H}, \mathrm{H} 1^{\prime}\right), 5.55$ (dd, $\left.J=4.0 \mathrm{~Hz}, 1 \mathrm{H}, 5^{\prime}-\mathrm{OH}\right), 5.37$ (d, $J=$ $\left.6.3 \mathrm{~Hz}, 1 \mathrm{H}, 2^{\prime}-\mathrm{OH}\right), 5.18$ (d, $\left.J=4.6 \mathrm{~Hz}, 1 \mathrm{H}, 3^{\prime}-\mathrm{OH}\right), 5.13$ (q, $\left.J=6.1 \mathrm{~Hz}, 1 \mathrm{H}, \mathrm{H} 2^{\prime}\right), 4.20$ ("q", $J=4.2 \mathrm{~Hz}, 1 \mathrm{H}, \mathrm{H3}$ '), 3.95 (q, $J=3.5 \mathrm{~Hz}, 1 \mathrm{H}, \mathrm{H} 4$ '), 3.68 (dt, $J=3.4,12.0 \mathrm{~Hz}, 1 \mathrm{H}$, H5'), 3.49-3.55 (m, 1H, H5"); ${ }^{13} \mathrm{C}$ NMR: $\delta=165.8(\mathrm{C}=\mathrm{O}), 157.1,152.2,149.6,112.5$, 112.2, 90.5 (C1'), $86.2\left(\mathrm{C}^{\prime}\right), 71.1\left(\mathrm{C}^{\prime}\right), 70.8$ (C3'), 62.23 (C5'); $\mathrm{R}_{\mathrm{f}}\left(\right.$ EtOAc: $i \mathrm{PrOH}: \mathrm{H}_{2} \mathrm{O}$, 4:1:2) $0.45\left(\mathrm{R}_{\mathrm{f}}\right.$ 19b 0.35); HRMS (ESI): $m / z[\mathrm{M}+\mathrm{H}]^{+}$calcd for $\mathrm{C}_{12} \mathrm{H}_{15} \mathrm{BrN}_{5} \mathrm{O}_{5}^{+}: 388.0251$ and 390.0231; found 388.0265 and 390.0229 .

Method B. DBH (101.6 mg, $1.1 \mathrm{mmol}$ ) was added to a clear, colorless solution of 19b (100 mg, $0.0323 \mathrm{mmol})$ in $\mathrm{MeOH}(25 \mathrm{~mL})$ in a flame dried flask and the resulting yellow solution was stirred at room temperature for $30 \mathrm{~min}$, by which time TLC showed $>90 \%$ conversion to a less polar product. Volatiles were removed from the clear, yellow solution using rotary evaporator. The resulting off-white solid was purified using column chromatography (10\%, $\mathrm{MeOH} / \mathrm{EtOAc})$ to give $\mathbf{5 6}$ as a colorless solid $(49.2 \mathrm{mg}, 39 \%)$ : characterization data were in agreement with those reported in method 1.

Ethyl 2-(phenylthio)octanoate (72). Thiophenol (260 $\mu \mathrm{L}, 280 \mathrm{mg}, 2.54 \mathrm{mmol})$ was added to a stirred solution of $\mathrm{NaH}(60 \%$, dispersion in paraffin liquid; $100.4 \mathrm{mg}, 4.18$ mmol) in anhydrous DMF $(4 \mathrm{~mL})$ at $0{ }^{\circ} \mathrm{C}$. The resulting suspension was stirred at $0{ }^{\circ} \mathrm{C}$ for 30 minutes and at ambient temperature for 30 minutes, by which time bubbles $\left(\mathrm{H}_{2}\right.$ gas $)$ ceased. The reaction flask was chilled again and Ethyl 2-bromooctanoate $71 \mathbf{b}(540 \mu \mathrm{L}$, 
$630 \mathrm{mg}, 2.51 \mathrm{mmol}$ ) was added at $0{ }^{\circ} \mathrm{C}$. The resultant clear, colorless solution was stirred at $0{ }^{\circ} \mathrm{C}$ for 20 min and at ambient temperature for 2 hours, by which time TLC showed exclusive conversion to a slightly more polar spot. Volatiles were evaporated and coevaporated with toluene $(1 \mathrm{x})$ (vacuum pump) and the resulting pale gum was partitioned between $\mathrm{CHCl}_{3}(20 \mathrm{~mL})$ and $\mathrm{NH}_{4} \mathrm{Cl} / \mathrm{H}_{2} \mathrm{O}(20 \mathrm{~mL})$. The aqueous layer was extracted with $\mathrm{CHCl}_{3}(2 \times 5 \mathrm{~mL})$ and the combined organic phase was washed with $\mathrm{NaHCO}_{3} / \mathrm{H}_{2} \mathrm{O}(25$ $\mathrm{mL})$, brine $(25 \mathrm{~mL})$, and dried $\left(\mathrm{MgSO}_{4}\right)$. Volatiles were evaporated in vacuo and the residue was column chromatographed (10\% EtOAc in hexanes) to give $\mathbf{7 2}^{216}$ (633 $\mathrm{mg}$, 90\%) as a pale oil: ${ }^{1} \mathrm{H}$ NMR $\left(\mathrm{CDCl}_{3}\right) \delta$ 7.49-7.46 (m, 2H, Ph), 7.35-7.25 (m, 3H, Ph), 4.16-4.09 (m, 2H, $\mathrm{CH}_{2}$ ), 3.66 (dd, $\left.J=6.6,8.4 \mathrm{~Hz}, 1 \mathrm{H}, \mathrm{H} 2\right), 1.96-1.87$ (m, 1H, H3), 1.821.73 (m, 1H, H3'), 1.51-1.37 (m, 2H, H4, H4'), 1.36-1.26 (m, 6H, H5, H5', H6, H6', H7, $\mathrm{H} 7$ '), 1.19 (t, $\left.J=7.1 \mathrm{~Hz}, 3 \mathrm{H}, \mathrm{CH}_{3}\right), 0.90$ (“t”, $\left.J=6.8 \mathrm{~Hz}, 3 \mathrm{H}, \mathrm{CH}_{3}\right) ;{ }^{13} \mathrm{C} \mathrm{NMR}\left(\mathrm{CDCl}_{3}\right) \delta$ $172.4,133.8,132.7,128.9,127.7,61.0,50.9,31.7,31.5,28.8,27.2,22.5,14.1,14.0$.

Ethyl 2-((4-chlorophenyl)thio)hexanoate (73). Treatment of ethyl 2-bromohexanoate 71a (500 $\mu \mathrm{L}, 610.5 \mathrm{mg}, 2.74 \mathrm{mmol})$ with 4-chlorothiophenol/NaH/DMF as described for the preparation of 72 gave $\mathbf{7 3}^{217}$ as a pale yellow oil (763.6 mg, 97\%): ${ }^{1} \mathrm{H} \mathrm{NMR}\left(\mathrm{CDCl}_{3}\right)$ $\delta$ 7.41-7.37 (m, 2H, Ph), 7.30-7.26 (m, 2H, Ph), 4.17-4.09 (m, 2H, $\left.\mathrm{CH}_{2}\right), 3.61(\mathrm{dd}, J=$ 6.6, $8.4 \mathrm{~Hz}, 1 \mathrm{H}, \mathrm{H} 2), 1.94-1.84$ (m, 1H, H3), 1.81-1.69 (m, 1H, H3'), 1.51-1.27 (m, 4H, H4, H4', H5, H5'), 1.19 (t, $J=7.1 \mathrm{~Hz}, 3 \mathrm{H}, \mathrm{CH}_{3}$ ), 0.91 (“'t", $J=7.1 \mathrm{~Hz}, 3 \mathrm{H}, \mathrm{CH}_{3}$ ); ${ }^{13} \mathrm{C}$ $\operatorname{NMR}\left(\mathrm{CDCl}_{3}\right) \delta 172.1,134.11,134.10,132.1,129.0,61.1,51.0,31.3,29.4,22.2,14.1$, 13.8.

Ethyl 2-((4-chlorophenyl)thio)octanoate (74). Treatment of ethyl 2-bromooctanoate 71b $(540 \mu \mathrm{L}, 630 \mathrm{mg}, 2.51 \mathrm{mmol})$ with 4-chlorothiophenol/NaH/DMF as described for 
the preparation of 72 gave 74 as a colorless oil (664 mg, 84\%): ${ }^{1} \mathrm{H}$ NMR $\left(\mathrm{CDCl}_{3}\right) \delta 7.39-$ 7.37 (m, 2H, Ph), 7.27-7.24 (m, 2H, Ph), 4.15-4.07 (m, 2H, $\left.\mathrm{CH}_{2}\right), 3.60$ (dd, $J=6.7,8.3$ Hz, 1H, H2), 1.92-1.81 (m, 1H, H3), 1.77-1.68 (m, 1H, H3'), 1.48-1.35 (m, 2H, H4, H4'), 1.33-1.27 (m, 6H, H5, H5', H6, H6', H7, H7'), 1.18 (t, $J=7.1 \mathrm{~Hz}, 3 \mathrm{H}, \mathrm{CH}_{3}$ ), 0.87 (“‘t”, $J=$ $6.8 \mathrm{~Hz}, 3 \mathrm{H}, \mathrm{H} 8, \mathrm{H} 8$ ', H8"); ${ }^{13} \mathrm{C} \mathrm{NMR}\left(\mathrm{CDCl}_{3}\right) \delta 172.0,134.1,134.0,132.2,129.0,61.0$, $51.0,31.6,31.5,28.8,27.2,22.5,14.1,14.0$.

Ethyl 2-((4-methoxyphenyl)thio)hexanoate (75). Treatment of ethyl 2-bromohexanoate 71a $(500 \mu \mathrm{L}, 610.5 \mathrm{mg}, 2.74 \mathrm{mmol})$ with 4-methoxythiophenol/NaH/DMF as described for the preparation of $\mathbf{7 2}$ gave $\mathbf{7 5}^{218}$ as a colorless oil $(739.3 \mathrm{mg}, 96 \%)$ : ${ }^{1} \mathrm{H}$ NMR $\left(\mathrm{CDCl}_{3}\right)$ $\delta$ 7.36-7.31 (m, 2H, Ph), 6.78-6.74 (m, 2H, Ph), 4.02 (“q”, $J=7.2 \mathrm{~Hz}, 2 \mathrm{H}, \mathrm{CH}_{2}$ ), 3.41 (dd, $J=6.6,8.5 \mathrm{~Hz}, 1 \mathrm{H}, \mathrm{H} 2), 1.82-1.75$ (m, 1H, H3), 1.68-1.59 (m, 1H, H3'), 1.42-1.32 (m, 1H, H4), 1.30-1.21 (m, 3H, H4', H5, H5'), $1.10\left(\mathrm{t}, J=7.1 \mathrm{~Hz}, 3 \mathrm{H}, \mathrm{CH}_{3}\right), 0.82(\mathrm{t}, J=$ $\left.7.1 \mathrm{~Hz}, 3 \mathrm{H}, \mathrm{CH}_{3}\right) ;{ }^{13} \mathrm{C} \mathrm{NMR}\left(\mathrm{CDCl}_{3}\right) \delta 172.2,160.1,136.2,123.4,114.4,60.7,55.2$, $51.6,31.1,29.3,22.3,14.1,13.8$.

Typical procedure for preparation of ethyl difluoroalkanoate (76 and 77). DBH was added to a stirred solution of ester 72 or 73 ( $0.5 \mathrm{mmol})$ and Py.9HF (3 mmol) in $\mathrm{CH}_{2} \mathrm{Cl}_{2}$ $(2 \mathrm{~mL})$ at ambient temperature. The resulting brown solution was stirred at ambient temperature or at $35{ }^{\circ} \mathrm{C}$ for the respective times as shown in Table 1 . The reaction flask was cooled to room temperature, quenched by addition of ice-cold water, diluted with $\mathrm{CH}_{2} \mathrm{Cl}_{2}$, and neutralized with drop-wise addition of conc. $\mathrm{NH}_{4} \mathrm{OH}$. Organic layer was separated and aqueous layer was back extracted $\left(2 \mathrm{x} \mathrm{CH}_{2} \mathrm{Cl}_{2}\right)$. Combined organic layer was washed with $1 \mathrm{~N} \mathrm{HCl}$, brine, dried $\left(\mathrm{MgSO}_{4}\right)$ and concentrated in vacuo to give crude difluorinated product as a brown oil, with data as reported. ${ }^{219} \mathbf{7 6}^{219}$ had: ${ }^{1} \mathrm{H}$ NMR 
$\left(\mathrm{CDCl}_{3}\right) \delta 4.25\left(\mathrm{q},{ }^{3} J_{\mathrm{H}, \mathrm{H}}=7.2 \mathrm{~Hz}, 2 \mathrm{H}, \mathrm{CH}_{2}\right), 2.09-1.88\left(\mathrm{~m}, 2 \mathrm{H}, \mathrm{H} 3, \mathrm{H} 3{ }^{\prime}\right), 1.42-1.30(\mathrm{~m}$, 4H, H4, H4', H5, H5'), $1.28\left(\mathrm{t},{ }^{3} J_{\mathrm{H}, \mathrm{H}}=7.1 \mathrm{~Hz}, 3 \mathrm{H}, \mathrm{CH}_{3}\right), 0.85\left(\mathrm{t},{ }^{3} J_{\mathrm{H}, \mathrm{H}}=7.2 \mathrm{~Hz}, 3 \mathrm{H}, \mathrm{H} 6\right.$, H6', H6"); ${ }^{13} \mathrm{C} \mathrm{NMR}\left(\mathrm{CDCl}_{3}\right) \delta 164.4\left(\mathrm{t},{ }^{2} J_{\mathrm{F}, \mathrm{C}}=33.2 \mathrm{~Hz}, \mathrm{C} 1\right), 116.4\left(\mathrm{t},{ }^{1} J_{\mathrm{F}, \mathrm{C}}=249.8 \mathrm{~Hz}\right.$, C2), $63.0\left(\mathrm{CH}_{2}\right), 34.5\left(\mathrm{t},{ }^{2} J_{\mathrm{F}, \mathrm{C}}=23.2 \mathrm{~Hz}, \mathrm{C} 3\right), 23.5\left(\mathrm{t},{ }^{3} J_{\mathrm{F}, \mathrm{C}}=4.3 \mathrm{~Hz}, \mathrm{C} 4\right), 22.2(\mathrm{C} 5), 13.9$ $\left(\mathrm{CH}_{3}\right), 13.7(\mathrm{C} 6) ;{ }^{19} \mathrm{~F}$ NMR $\left(\mathrm{CDCl}_{3}\right) \delta-105.92 \mathrm{ppm}\left(\mathrm{t},{ }^{3} J_{\mathrm{F}-\mathrm{H}}=16.8 \mathrm{~Hz}\right) ; \mathrm{GC}-\mathrm{MS}\left(t_{\mathrm{R}}=7.5\right.$ $\min ) 151$ (1.1), 124 (11.3), 116 (18.2), 87 (44.9), 67 (20.9), 55 (3.6); $77^{219}$ had: ${ }^{1} \mathrm{H}$ NMR $\left(\mathrm{CDCl}_{3}\right) \delta 4.25\left(\mathrm{q},{ }^{3} \mathrm{~J}_{\mathrm{H}, \mathrm{H}}=7.2 \mathrm{~Hz}, 2 \mathrm{H}, \mathrm{CH}_{2}\right), 2.03-1.91(\mathrm{~m}, 2 \mathrm{H}), 1.45-$ $1.18(\mathrm{~m}, 11 \mathrm{H}), 0.81$ (“'t”, ${ }^{3} J_{\mathrm{H}, \mathrm{H}}=6.8 \mathrm{~Hz}, 3 \mathrm{H}, \mathrm{H} 6, \mathrm{H} 6$ ', H6"); ${ }^{13} \mathrm{C} \mathrm{NMR}\left(\mathrm{CDCl}_{3}\right) \delta 164.5$ (t, $\left.{ }^{2} J_{\mathrm{F}, \mathrm{C}}=33.0 \mathrm{~Hz}, \mathrm{C} 1\right), 116.4\left(\mathrm{t},{ }^{1} J_{\mathrm{F}, \mathrm{C}}=249.7 \mathrm{~Hz}, \mathrm{C} 2\right), 62.7\left(\mathrm{CH}_{2}\right), 34.5\left(\mathrm{t},{ }^{2} J_{\mathrm{F}, \mathrm{C}}=23.2 \mathrm{~Hz}\right.$, C3), 31.4, 28.7, 22.4, $21.4\left(\mathrm{t},{ }^{3} J_{\mathrm{F}, \mathrm{C}}=4.3 \mathrm{~Hz}, \mathrm{C} 4\right), 13.9 ;{ }^{19} \mathrm{~F} \mathrm{NMR}\left(\mathrm{CDCl}_{3}\right) \delta-105.89 \mathrm{ppm}$ $\left(\mathrm{t},{ }^{3} J_{\mathrm{F}-\mathrm{H}}=17.0 \mathrm{~Hz}\right)$.

5-O-Benzyl-2,3-dideoxy-2-fluoro-2-(phenylsulfanyl)ribose (84) and 5-O-Benzyl-2,3dideoxy-2-fluoro-2-(phenylsulfinyl)ribose (85). 83 (31 mg, $0.1 \mathrm{mmol}$ ) was treated with Py.9HF (185 $\mu \mathrm{L}, 0.8 \mathrm{mmol})$ and DBH (114 mg, $0.4 \mathrm{mmol})$ in anhydrous $\mathrm{CH}_{2} \mathrm{Cl}_{2}(3 \mathrm{~mL})$ according to general desulfurization-difluorination procedure gave $40 \mathrm{mg}$ of yellow oil after aqueous workup: ${ }^{19} \mathrm{~F}-\mathrm{NMR}\left(\mathrm{CDCl}_{3}\right) \delta-150.86$ (“t”, $1 \mathrm{~F}, J=26.4 \mathrm{~Hz}$ ), -149.33 (dd, 0.4F, $J=20.3,27.3 \mathrm{~Hz}$ ), -139.24 to -138.93 (m, 0.6 F); HRMS (ESI) $m / z 355.2857$ $[\mathrm{M}+\mathrm{Na}]^{+}$, calcd for $\mathrm{C}_{18} \mathrm{H}_{17} \mathrm{FNaO}_{3} \mathrm{~S}^{+}$355.0775; m/z $371.2611[\mathrm{M}+\mathrm{Na}]^{+}$, calcd for $\mathrm{C}_{18} \mathrm{H}_{17} \mathrm{FNaO}_{4} \mathrm{~S}^{+} 371.0724$.

2'-S-(4-Chlorophenyl)-2'-thiouridine (87). Slight modification of published procedure. ${ }^{133} \mathrm{PPh}_{3}(464.3 \mathrm{mg}, 1.77 \mathrm{mmol})$ was added to a stirred solution of 4chlorothiophenol $(1.28 \mathrm{~g}, 8.84 \mathrm{mmol})$ in anhydrous DMF $(10 \mathrm{~mL})$ and the resulting solution was stirred at ambient temperature for 30 minutes. 2,2'-anhydro-1- $\beta$-D- 
arabinofuranosyluracil ${ }^{220}(1 \mathrm{~g}, 4.42 \mathrm{mmol})$ was added to the reaction mixture and the resulting solution was refluxed $\left(153{ }^{\circ} \mathrm{C}\right)$ for $18 \mathrm{~h}$. Volatiles were evaporated, coevaporated with toluene $(2 \mathrm{x})$. The resultant brown gum was triturated with hexanes $(3 \mathrm{x})$ and the liquid was pipetted out. The remaining brownish gummy solid was triturated with ether and the resultant pale green solid was vacuum filtered, washed with minimal amount of ice-cold methanol to give 2'-S-(4-Chlorophenyl)-2'-thiouridine (87; $1.1 \mathrm{~g}, 67$ \%) as a colorless solid: ${ }^{1} \mathrm{H}$ NMR (DMSO- $\left.d_{6}\right)^{133} \delta 11.14$ (br s, $\left.1 \mathrm{H}, \mathrm{NH}\right), 7.61(\mathrm{~d}, J=8.1$ Hz, 1H, H6), 7.35 (d, $J=8.5 \mathrm{~Hz}, 2 \mathrm{H}, \mathrm{Ph}), 7.28$ (d, $J=8.5 \mathrm{~Hz}, 2 \mathrm{H}, \mathrm{Ph}), 6.33$ (d, $J=9.0$ $\left.\mathrm{Hz}, 1 \mathrm{H}, \mathrm{H1} 1^{\prime}\right), 5.91$ (d, $\left.J=5.6 \mathrm{~Hz}, 1 \mathrm{H}, 3^{\prime} \mathrm{OH}\right), 5.50$ (d, $\left.J=8.1 \mathrm{~Hz}, 1 \mathrm{H}, \mathrm{H} 5\right), 5.11$ (t, $J=5.0$ $\left.\mathrm{Hz}, 1 \mathrm{H}, 5^{\prime} \mathrm{OH}\right), 4.34$ (t, $\left.J=5.2 \mathrm{~Hz}, 1 \mathrm{H}, \mathrm{H} 3^{\prime}\right), 3.94-3.92\left(\mathrm{~m}, 1 \mathrm{H}, \mathrm{H} 4^{\prime}\right), 3.89$ (dd, $J=5.3$, $9.0 \mathrm{~Hz}, 1 \mathrm{H}, \mathrm{H} 2$ '), 3.59 (“"t”, $J=4.4 \mathrm{~Hz}, 2 \mathrm{H}, \mathrm{H} 5$ ', H5"); ${ }^{13} \mathrm{C}$ NMR (DMSO- $d_{6}$ ) $\delta 162.5$ (C4), $150.4(\mathrm{C} 2), 139.8(\mathrm{C} 6), 133.1(\mathrm{Ph}), 132.3(\mathrm{Ph}), 132.0(\mathrm{Ph}), 128.8(\mathrm{Ph}), 102.3(\mathrm{C} 5)$ 87.8 (C1'), 86.7 (C4'), $72.1\left(\mathrm{C}^{\prime}\right), 61.4\left(\mathrm{C} 5^{\prime}\right), 54.5\left(\mathrm{C}^{\prime}\right)$.

3',5'-di-O-Acetyl-2'-S-(4-chlorophenyl)-2'-thiouridine (89a). DMAP (18.3 mg, 0.15 mmol) was added to a stirred suspension of $87(1.1 \mathrm{~g}, 2.97 \mathrm{mmol})$ in $\mathrm{Ac}_{2} \mathrm{O}(842 \mu \mathrm{L}, 909$ $\mathrm{mg}, 8.91 \mathrm{mmol}$ ) and the resulting suspension was stirred at ambient temperature overnight $(15 \mathrm{~h}) . \mathrm{MeOH}$ was added, the reaction mixture was stirred at ambient temperature for $30 \mathrm{~min}$, and volatiles were evaporated (vacuum pump, $<25{ }^{\circ} \mathrm{C}$ ). $\mathrm{MeOH}$ was added and evaporated, and the resulting gum was partitioned between $\mathrm{CHCl}_{3}$ (50 $\mathrm{mL})$ and $\mathrm{H}_{2} \mathrm{O}(50 \mathrm{~mL})$. The aqueous layer was extracted with $\mathrm{CHCl}_{3}$, and the combined organic phase was washed with $\mathrm{NaHCO}_{3} / \mathrm{H}_{2} \mathrm{O}, 1 \mathrm{~N} \mathrm{HCl}$, brine, and dried $\left(\mathrm{MgSO}_{4}\right)$. Volatiles were evaporated in vacuo and the residue was dried on vacuum pump to give 3',5'-di-O-Acetyl-2'-S-(4-chlorophenyl)-2'-thiouridine (89a; $1.34 \mathrm{~g}, 99 \%)$ as a colorless 
foam, with sufficient purity to proceed to next step: ${ }^{1} \mathrm{H} \mathrm{NMR}\left(\mathrm{CDCl}_{3}\right) \delta 10.12(\mathrm{br} \mathrm{s}, 1 \mathrm{H}$, NH), $7.27(\mathrm{~d}, J=8.3 \mathrm{~Hz}, 2 \mathrm{H}, \mathrm{Ph}), 7.22(\mathrm{~d}, J=8.2 \mathrm{~Hz}, 1 \mathrm{H}, \mathrm{H6}), 7.14$ (d, $J=8.4 \mathrm{~Hz}, 2 \mathrm{H}$, $\mathrm{Ph}$ ), 6.14 (d, $J=8.5 \mathrm{~Hz}, 1 \mathrm{H}, \mathrm{H1}$ '), 5.63 (d, $J=8.2 \mathrm{~Hz}, 1 \mathrm{H}, \mathrm{H} 5), 5.38$ (“d”, $J=6.0 \mathrm{~Hz}$, 1H, H3'), 4.30-4.19 (m, 3H, H4', H5', H5"), 3.81 (“dd”, $J=6.3,8.2$ Hz, 1H, H2'), 2.07 (s, $\left.3 \mathrm{H}, \mathrm{CH}_{3}\right), 2.00\left(\mathrm{~s}, 3 \mathrm{H}, \mathrm{CH}_{3}\right) ;{ }^{13} \mathrm{C} \mathrm{NMR}\left(\mathrm{CDCl}_{3}\right) \delta 170.3,169.9(2 \times \mathrm{C}=\mathrm{O}), 163.2(\mathrm{C} 4)$, $150.4(\mathrm{C} 2), 139.2(\mathrm{C} 6), 134.6(\mathrm{Ph}), 134.2(\mathrm{Ph}), 130.6(\mathrm{Ph}), 129.4(\mathrm{Ph}), 103.4(\mathrm{C} 5), 89.0$ (C1'), 81.0 (C4'), 73.7 (C3'), 63.5 (C5'), 53.5 (C2'), 20.7, 20.6 (2 x s, 2 x CH 3 ).

N3-Benzyl-3',5'-di-O-benzyl-2'-S-(4-chlorophenyl)-2'-thiouridine (89b). NaH (60\%, dispersion in paraffin liquid; $216 \mathrm{mg}, 9 \mathrm{mmol}$ ) was added to a stirred solution of $\mathbf{8 7}$ (556.2 $\mathrm{mg}, 1.5 \mathrm{mmol})$ in anhydrous DMF $(6 \mathrm{~mL})$ at $0{ }^{\circ} \mathrm{C}$. The resulting suspension was stirred at $0{ }^{\circ} \mathrm{C}$ for 30 minutes and at ambient temperature for 30 minutes, by which time bubbles $\left(\mathrm{H}_{2}\right.$ gas) ceased. The reaction flask was chilled again and benzyl bromide (0.93 $\mathrm{mL}, 1.3 \mathrm{~g}, 7.8 \mathrm{mmol}$ ) was added at $0{ }^{\circ} \mathrm{C}$. Bubbles were observed for a few minutes once the ice-bath was removed and the resultant pale solution was stirred at ambient temperature for 4 hours, by which time TLC showed a major (90\%) less polar spot. Volatiles were evaporated and co-evaporated with toluene $(1 \mathrm{x})$ (vacuum pump) and the resulting syrup was partitioned between $\mathrm{CHCl}_{3}(20 \mathrm{~mL})$ and $\mathrm{NH}_{4} \mathrm{Cl} / \mathrm{H}_{2} \mathrm{O}(20 \mathrm{~mL})$. The aqueous layer was extracted with $\mathrm{CHCl}_{3}(2 \times 5 \mathrm{~mL})$ and the combined organic phase was washed with $\mathrm{NaHCO}_{3} / \mathrm{H}_{2} \mathrm{O}(25 \mathrm{~mL})$, brine $(25 \mathrm{~mL})$, and dried $\left(\mathrm{MgSO}_{4}\right)$. Volatiles were evaporated in vacuo and the residue was column chromatographed $(20 \%$ EtOAc in hexanes) to give 89b (827 mg, 86\%) as a colorless foam: ${ }^{1} \mathrm{H}$ NMR $\left(\mathrm{CDCl}_{3}\right) \delta$ 7.53-7.51 (m, 2H, Ph), 7.43-7.27 (m, 14H, Ph, H6), 7.15-7.11 (m, 2H, Ph), 6.93-6.90 (m, 2H, Ph), 6.47 (d, $J=8.3 \mathrm{~Hz}, 1 \mathrm{H}, \mathrm{H1}$ '), 5.33 (d, $J=8.1 \mathrm{~Hz}, 1 \mathrm{H}, \mathrm{H} 5), 5.05-4.97$ (m, 2H, benzylic), 
4.71-4.64 (m, 2H, benzylic), 4.56 (“d”, $J=11.0 \mathrm{~Hz}, 1 \mathrm{H}$, benzylic), 4.50 (“d”, $J=11.0$ Hz, 1H, benzylic), 4.33-4.30 (m, 2H, H3', H4'), 3.81-3.77 (m, 2H, H2', H5'), 3.60 (dd, $J=$ 1.7, $10.4 \mathrm{~Hz}, 1 \mathrm{H}, \mathrm{H} 5 ") ;{ }^{13} \mathrm{C} \mathrm{NMR}\left(\mathrm{CDCl}_{3}\right) \delta 162.0,150.9,137.4,137.2,137.1,136.8$, $133.9,133.8,131.7,129.5,129.1,128.8,128.6,128.4,128.1,128.0,127.8,127.7,102.3$ (C5), $90.2\left(\mathrm{Cl}^{\prime}\right), 82.3\left(\mathrm{C}^{\prime}\right), 80.3\left(\mathrm{C}^{\prime}\right), 73.9\left(\mathrm{CH}_{2}\right), 72.4\left(\mathrm{CH}_{2}\right), 70.6\left(\mathrm{C}^{\prime}\right), 55.7\left(\mathrm{C}^{\prime}\right)$, $44.1\left(\mathrm{CH}_{2}\right)$.

N3-Benzyl-3',5'-di-O-benzyl-2'-S-(4-methoxyphenyl)-2'-thiouridine (90b). Treatment of $\mathbf{8 8}^{134}$ (1.47 g, $\left.4.0 \mathrm{mmol}\right)$ with $\mathrm{NaH}(576 \mathrm{mg}, 24 \mathrm{mmol})$ and $\mathrm{BnBr}(2.5 \mathrm{~mL}, 3.6 \mathrm{~g}, 20.8$ mmol) as described for $\mathbf{8 7} \rightarrow \mathbf{8 9 b}$ gave $\mathbf{9 0 b}$ as a colorless foam $(2.2 \mathrm{~g}, 86 \%):{ }^{1} \mathrm{H}$ NMR $\left(\mathrm{CDCl}_{3}\right) \delta 7.58$ (“d”, $\left.J=6.9 \mathrm{~Hz}, 2 \mathrm{H}, \mathrm{Ph}\right), 7.40-7.23(\mathrm{~m}, 13 \mathrm{H}, \mathrm{Ph}), 7.14-7.11(\mathrm{~m}, 3 \mathrm{H}, \mathrm{Ph}$, H6), 6.56 (d, $J=8.8 \mathrm{~Hz}, 1 \mathrm{H}, \mathrm{H1}$ ), 6.33 (d, $J=8.7 \mathrm{~Hz}, 2 \mathrm{H}, \mathrm{Ph}), 5.11$ (d, $J=8.1 \mathrm{~Hz}, 1 \mathrm{H}$, H5), 5.04 (“d”, $J=13.5 \mathrm{~Hz}, 1 \mathrm{H}$, benzylic), 4.95 (“d”, $J=13.5 \mathrm{~Hz}, 1 \mathrm{H}$, benzylic), 4.64 (s, 2H, benzylic), 4.49 (“d”, $J=11.0 \mathrm{~Hz}, 1 \mathrm{H}$, benzylic), 4.39 (“d”, $J=11.0 \mathrm{~Hz}, 1 \mathrm{H}$, benzylic), 4.29 (d, $J=5.3 \mathrm{~Hz}, 1 \mathrm{H}, \mathrm{H} 4$ '), 4.25 (br s, H3'), 3.70-3.65 (m, 2H, H2', H5'),

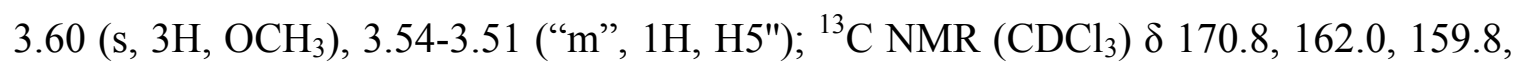
$151.1,137.4,136.9,135.3,129.8,128.6,128.5,128.3,128.2,127.9,127.8,127.8,127.7$, 123.3, 114.6, 102.0 (C5), $90.4\left(\mathrm{Cl}^{\prime}\right), 82.0\left(\mathrm{C}^{\prime}\right), 80.9\left(\mathrm{C}^{\prime}\right), 73.8\left(\mathrm{CH}_{2}\right), 72.2\left(\mathrm{CH}_{2}\right), 70.8$ (C5'), $56.3\left(\mathrm{C} 2^{\prime}\right), 55.4\left(\mathrm{OCH}_{3}\right), 44.1\left(\mathrm{CH}_{2}\right)$.

N3-Benzyl-3',5'-di-O-benzyl-2'-deoxy-2'-[(4-methoxyphenyl)sulfinyl]uridine

(R/S-S)]. MCPBA (750.7 $\mathrm{mg}$ of $70 \%$ reagent, $4.35 \mathrm{mmol})$ in $\mathrm{CH}_{2} \mathrm{Cl}_{2}(70 \mathrm{~mL})$ was added drop-wise to a stirred solution of $\mathbf{9 0 b}(2.2 \mathrm{~g}, 3.45 \mathrm{mmol})$ in $\mathrm{CH}_{2} \mathrm{Cl}_{2}(35 \mathrm{~mL})$ at $-50{ }^{\circ} \mathrm{C}$, and the temperature was allowed to rise to $-30{ }^{\circ} \mathrm{C}$ in $\sim 20$ minutes. TLC showed $>80 \%$ conversion to a more polar product. The solution was poured into $\mathrm{NaHCO}_{3} / \mathrm{H}_{2} \mathrm{O}(10 \mathrm{~mL})$. 
The aqueous layer was extracted with $\mathrm{CHCl}_{3}(2 \times 5 \mathrm{~mL})$ and the combined organic phase was washed with $\mathrm{H}_{2} \mathrm{O}(20 \mathrm{~mL})$, brine $(25 \mathrm{~mL})$, and dried $\left(\mathrm{MgSO}_{4}\right)$. Volatiles were evaporated in vacuo and the residue was column chromatographed (25\% EtOAc in hexanes) to give 93 (2' R/S-S, $\sim 1: 1)(1.8 \mathrm{~g}, 80 \%)$ as a colorless foam: ${ }^{1} \mathrm{H} \mathrm{NMR}\left(\mathrm{CDCl}_{3}\right) \delta$ 7.51-7.28 (m, 17.5H, Ph, H6), 7.10 (d, $J=7.8 \mathrm{~Hz}, 0.5 \mathrm{H}, \mathrm{H} 6), 7.03$ (d, $J=8.0 \mathrm{~Hz}, 0.5 \mathrm{H}$, H1'), $6.83(\mathrm{~d}, J=8.0 \mathrm{~Hz}, 0.5 \mathrm{H}, \mathrm{H1}$ '), 6.49 (d, $J=9.6 \mathrm{~Hz}, 1 \mathrm{H}, \mathrm{Ph}), 6.44(\mathrm{~d}, J=8.1 \mathrm{~Hz}$, $1 \mathrm{H}, \mathrm{Ph}), 5.36(\mathrm{~d}, J=7.7 \mathrm{~Hz}, 0.5 \mathrm{H}, \mathrm{H} 5), 5.04(\mathrm{~d}, J=8.1 \mathrm{~Hz}, 0.5 \mathrm{H}, \mathrm{H} 5), 4.96-4.26(\mathrm{~m}, 8 \mathrm{H}$, benzylic, $\mathrm{H} 2^{\prime}, \mathrm{H} 3$ '), 3.86-3.43 (m, 6H, $\mathrm{CH}_{3}, \mathrm{H} 4$ ', $\mathrm{H} 5$ ', $\left.\mathrm{H} 5 "\right)$;

${ }^{13} \mathrm{C}$ NMR $\left(\mathrm{CDCl}_{3}\right)$ for major isomer (extracted data): $\delta 162.9,161.6,150.6,137.11$, $137.10,137.0,136.5,132.5,129.8,128.8,128.6,128.44,128.38,128.2,127.9,127.2$, 114.6, $102.5(\mathrm{C} 5), 82.9\left(\mathrm{Cl}^{\prime}\right), 82.1\left(\mathrm{C}^{\prime}\right), 80.9\left(\mathrm{C}^{\prime}\right), 74.0\left(\mathrm{CH}_{2}\right), 73.4\left(\mathrm{CH}_{2}\right), 72.7\left(\mathrm{C}^{\prime}\right)$, $70.9\left(\mathrm{C}^{\prime}\right), 55.6\left(\mathrm{OCH}_{3}\right), 44.1\left(\mathrm{CH}_{2}\right)$.

3',5'-di-O-Acetyl-2'-deoxy-2'-[(4-chlorophenyl)sulfonyl]uridine (91a). MCPBA (70\% reagent, $250 \mathrm{mg}, 1.45 \mathrm{mmol})$ was added to a stirred solution of $\mathbf{8 9 a}(227.4 \mathrm{mg}, 0.5 \mathrm{mmol})$ in $\mathrm{CH}_{2} \mathrm{Cl}_{2}(15 \mathrm{~mL})$ and the resultant colorless solution was stirred at ambient temperature for $12 \mathrm{~h}$. TLC showed complete conversion to a more polar product. The reaction mixture was poured into $\mathrm{NaHCO}_{3} / \mathrm{H}_{2} \mathrm{O}(10 \mathrm{~mL})$. The aqueous layer was extracted with $\mathrm{CHCl}_{3}(2$ x $5 \mathrm{~mL}$ ) and the combined organic phase was washed with $\mathrm{H}_{2} \mathrm{O}(20 \mathrm{~mL})$, brine $(25 \mathrm{~mL})$, and dried $\left(\mathrm{MgSO}_{4}\right)$. Volatiles were evaporated in vacuo to give $91 \mathrm{a}(241 \mathrm{mg}, 99 \%)$ as a colorless foam. Data for the crude sample: ${ }^{1} \mathrm{H}$ NMR $\left(\mathrm{CDCl}_{3}\right) \delta 9.51(\mathrm{br} \mathrm{s}, 1 \mathrm{H}, \mathrm{NH}), 7.86$ (d, $J=8.6 \mathrm{~Hz}, 2 \mathrm{H}, \mathrm{Ph}), 7.55$ (d, $J=8.6 \mathrm{~Hz}, 2 \mathrm{H}, \mathrm{Ph}), 7.17$ (d, $J=8.2 \mathrm{~Hz}, 1 \mathrm{H}, \mathrm{H} 6), 6.15$ (d, $J=6.2 \mathrm{~Hz}, 1 \mathrm{H}, \mathrm{H1}$ '), 5.72-5.66 (m, 2H, H5, H3'), 4.6 (t, $\left.J=6.7 \mathrm{~Hz}, 1 \mathrm{H}, \mathrm{H} 2^{\prime}\right), 4.42$ (q, $\left.J=4.6 \mathrm{~Hz}, 1 \mathrm{H}, \mathrm{H} 4^{\prime}\right), 4.36$ (dd, $\left.J=3.7,12.5 \mathrm{~Hz}, 1 \mathrm{H}, \mathrm{H} 5^{\prime}\right), 4.25$ (dd, $J=4.9,12.2 \mathrm{~Hz}, 1 \mathrm{H}$, 
H5"), 2.09 (s, 3H, $\left.\mathrm{CH}_{3}\right), 2.07$ (s, 3H, $\left.\mathrm{CH}_{3}\right) ;{ }^{13} \mathrm{C} \mathrm{NMR}\left(\mathrm{CDCl}_{3}\right) \delta 170.4,169.9(2 \times \mathrm{C}=\mathrm{O})$, $162.9(\mathrm{C} 4), 149.6(\mathrm{C} 2), 141.7(\mathrm{C} 6), 141.2(\mathrm{Ph}), 136.9(\mathrm{Ph}), 130.2(\mathrm{Ph}), 130.1(\mathrm{Ph}), 103.5$ (C5), 87.7 (C1'), 80.9 (C4'), $71.2\left(\mathrm{C}^{\prime}\right), 65.1$ (C5'), 62.4 (C2'), 20.71, $20.70\left(2 \mathrm{x} \mathrm{CH}_{3}\right)$.

N3-Benzyl-3',5'-di-O-benzyl-2'-deoxy-2'-[(4-chlorophenyl)sulfonyl]uridine

(91b).

MCPBA (250.2 $\mathrm{mg}$ of $70 \%$ reagent, $1.45 \mathrm{mmol})$ in $\mathrm{CH}_{2} \mathrm{Cl}_{2}(6 \mathrm{~mL})$ was added drop-wise to a stirred solution of $\mathbf{8 9 b}(320.6 \mathrm{mg}, 0.50 \mathrm{mmol})$ in $\mathrm{CH}_{2} \mathrm{Cl}_{2}(4 \mathrm{~mL})$ and the resulting clear solution was stirred at ambient temperature overnight. Saturated $\mathrm{NaHCO}_{3} / \mathrm{H}_{2} \mathrm{O}(10$ $\mathrm{mL}$ ) was added, stirring was continued for $10 \mathrm{~min}$, and the organic layer was separated. The aqueous layer was extracted with $\mathrm{CHCl}_{3}(2 \times 5 \mathrm{~mL})$ and the combined organic phase was washed with $\mathrm{H}_{2} \mathrm{O}(20 \mathrm{~mL})$, brine $(25 \mathrm{~mL})$, and dried $\left(\mathrm{MgSO}_{4}\right)$. Volatiles were evaporated in vacuo and the residue was column chromatographed $(20 \%$ EtOAc in hexanes) to give $\mathbf{9 1 b}(269.3 \mathrm{mg}, 80 \%)$ as a colorless foam: ${ }^{1} \mathrm{H} \mathrm{NMR}\left(\mathrm{CDCl}_{3}\right) \delta 7.59-7.56$ (m, 2H, Ph), 7.55-7.51 (m, 2H, Ph), 7.48-7.28 (m, 14H, Ph, H6), 6.98-6.94 (m, 2H, Ph), $6.66(\mathrm{~d}, J=8.6 \mathrm{~Hz}, 1 \mathrm{H}, \mathrm{H} 1$ '), 5.37 (d, $J=8.2 \mathrm{~Hz}, 1 \mathrm{H}, \mathrm{H} 5), 5.08$ (“d”, $J=13.7 \mathrm{~Hz}, 1 \mathrm{H}$, benzylic), 5.02 (“d”, $J=13.7 \mathrm{~Hz}, 1 \mathrm{H}$, benzylic), 4.68 (“d”, $J=11.5 \mathrm{~Hz}, 1 \mathrm{H}$, benzylic), 4.63 (dd, $J=1.8,5.4 \mathrm{~Hz}, 1 \mathrm{H}, \mathrm{H} 3$ '), 4.58 (“d”, $J=11.5 \mathrm{~Hz}, 1 \mathrm{H}$, benzylic), 4.53 (“d”, $J=$ $10.9 \mathrm{~Hz}, 1 \mathrm{H}$, benzylic), 4.45 (“d”, $J=11.0 \mathrm{~Hz}, 1 \mathrm{H}$, benzylic), 4.24 (“d”, $J=1.9 \mathrm{~Hz}, 1 \mathrm{H}$, H4'), 4.09 (dd, $\left.J=5.4,8.6 \mathrm{~Hz}, 1 \mathrm{H}, \mathrm{H} 2^{\prime}\right), 3.70$ (dd, $\left.J=2.3,10.6 \mathrm{~Hz}, 1 \mathrm{H}, \mathrm{H} 5^{\prime}\right), 3.46$ (dd, $J$ $=2.0,10.6 \mathrm{~Hz}, 1 \mathrm{H}, \mathrm{H} 5 ") ;{ }^{13} \mathrm{C} \mathrm{NMR}\left(\mathrm{CDCl}_{3}\right) \delta 161.8,150.7,140.7,137.4,137.1$ (C6), $136.8,136.6,136.4,130.2,129.5,129.1,128.8,128.6,128.5,128.3,128.23,128.16$, 127.8, 103.0 (C5), 84.8 (C1'), $82.5\left(\mathrm{C}^{\prime}\right), 79.7\left(\mathrm{C}^{\prime}\right), 74.0\left(\mathrm{CH}_{2}\right), 73.1\left(\mathrm{CH}_{2}\right), 70.1\left(\mathrm{C}^{\prime}\right)$, $68.9\left(\mathrm{C}^{\prime}\right), 44.3\left(\mathrm{CH}_{2}\right)$.

N3-Benzyl-3',5'-di-O-benzyl-2'-deoxy-2'-[(4-methoxyphenyl)sulfonyl]uridine (92b). 
Treatment of 90b (32 mg, $0.05 \mathrm{mmol})$ with MCPBA (26 mg of 70\% reagent, $0.15 \mathrm{mmol}$ ) in $\mathrm{CH}_{2} \mathrm{Cl}_{2}(3 \mathrm{~mL})$ as described for $\mathbf{8 9 b} \rightarrow \mathbf{9 1 b}$ gave $92 \mathbf{b}(27 \mathrm{mg}, 81 \%)$ as a colorless foam: ${ }^{1} \mathrm{H}$ NMR $\left(\mathrm{CDCl}_{3}\right) \delta$ 7.61-7.60 (m, 2H, Ph), 7.51-7.48 (m, 2H, Ph), 7.43-7.25 (m, 13H, Ph), 7.10 (d, $J=8.2 \mathrm{~Hz}, 1 \mathrm{H}, \mathrm{H} 6), 6.75$ (d, $J=9.0 \mathrm{~Hz}, 1 \mathrm{H}, \mathrm{H1}$ '), 6.39-6.35 (m, 2H, $\mathrm{Ph}$ ), 5.16 (d, $J=8.1 \mathrm{~Hz}, 1 \mathrm{H}, \mathrm{H} 5), 5.07$ (“d”, $J=13.5 \mathrm{~Hz}, 1 \mathrm{H}$, benzylic), 4.99 (“d”, $J=$ 13.5 Hz, 1H, benzylic), 4.80 (“d”, $J=11.7 \mathrm{~Hz}, 1 \mathrm{H}$, benzylic), 4.65-4.62 (m, 2H, benzylic, H3'), 4.50 (“d”, $J=10.8 \mathrm{~Hz}, 1 \mathrm{H}$, benzylic), 4.39 (“d”, $J=10.8 \mathrm{~Hz}, 1 \mathrm{H}$, benzylic), 4.22 (“d”, $J=1.6 \mathrm{~Hz}, 1 \mathrm{H}, \mathrm{H} 4$ '), 4.05 (dd, $J=5.2,9.0 \mathrm{~Hz}, 1 \mathrm{H}, \mathrm{H} 2$ '), 3.67-3.63 (m, 4H, $\mathrm{OCH}_{3}$, H5'), $3.45(\mathrm{dd}, J=2.0,10.5 \mathrm{~Hz}, 1 \mathrm{H}, \mathrm{H} 5 ") ;{ }^{13} \mathrm{C} \mathrm{NMR}\left(\mathrm{CDCl}_{3}\right) \delta 171.1,163.9,161.9$, 150.7, 137.2 (C6), 137.0, 136.9, 136.6, 130.6, 130.4, 129.8, 128.8, 128.5, 128.4, 128.2, 128.1, 127.9, 114.2, $102.7(\mathrm{C} 5), 85.0\left(\mathrm{Cl}^{\prime}\right), 82.6\left(\mathrm{C}^{\prime}\right), 80.0\left(\mathrm{C}^{\prime}\right), 73.9\left(\mathrm{CH}_{2}\right), 73.1$ $\left(\mathrm{CH}_{2}\right), 70.4\left(\mathrm{C}^{\prime}\right), 68.4\left(\mathrm{C}^{\prime}\right), 55.8\left(\mathrm{OCH}_{3}\right), 44.3\left(\mathrm{CH}_{2}\right)$.

N3-Benzyl-3',5'-di-O-benzyl-2'-fluoro-2'-S-(4-methoxyphenyl)-2'-thiouridine (94b). DAST $(0.15 \mathrm{~mL}, 183 \mathrm{mg}, 1.14 \mathrm{mmol})$ was added to a mixture of $93\left(2^{\prime}-R / S-\mathrm{S}, \sim 1: 1\right)$ (326.4 $\mathrm{mg}, 0.5 \mathrm{mmol})$ and $\mathrm{SbCl}_{3}(23 \mathrm{mg}, 0.1 \mathrm{mmol})$ in $\mathrm{CH}_{2} \mathrm{Cl}_{2}(10 \mathrm{~mL})$, and the resulting pale solution was stirred at ambient temperature overnight $(13 \mathrm{~h})$. Cold saturated $\mathrm{NaHCO}_{3} / \mathrm{H}_{2} \mathrm{O}(10 \mathrm{~mL})$ was added carefully, stirring was continued for $30 \mathrm{~min}$, the organic layer was separated. The aqueous layer was extracted with $\mathrm{CHCl}_{3}(2 \times 5 \mathrm{~mL})$ and the combined organic phase was washed with $\mathrm{H}_{2} \mathrm{O}(20 \mathrm{~mL})$, brine $(25 \mathrm{~mL})$, dried $\left(\mathrm{MgSO}_{4}\right)$ and evaporated in vacuo to give yellow oil. Gradient flash chromatography (0 $\rightarrow 30 \%$ EtOAc in hexanes) gave $\mathbf{9 4 b}$ as a mixture of diastereomers $\left(2^{\prime}-R / S-\mathrm{S}, \sim 4: 1\right)$ (pale yellow foam 186.6 mg, 57\%): ${ }^{1} \mathrm{H}$ NMR $\left(\mathrm{CDCl}_{3}\right) \delta$ 7.55-7.26 (m, 18H, Ph, H6), 6.84 (“d”, $J=8.7 \mathrm{~Hz}, 2 \mathrm{H}, \mathrm{Ph}), 6.51$ (d, $\left.J=14.7 \mathrm{~Hz}, 0.8 \mathrm{H}, \mathrm{H1} 1^{\prime}\right), 6.40$ (br s, $\left.0.2 \mathrm{H}, \mathrm{H} 1^{\prime}\right), 5.68$ (d, $J=$ 
$8.1 \mathrm{~Hz}, 0.8 \mathrm{H}, \mathrm{H} 5), 5.41$ (d, $J=8.2 \mathrm{~Hz}, 0.2 \mathrm{H}, \mathrm{H} 5), 5.14-5.01$ (m, 1H, benzylic), 4.93-4.87 (m, 1H, benzylic), 4.68-4.43 (m, 4H, benzylic), 4.23-4.18 (m, 2H, H3', H4'), 3.91-3.79 (m, 4H, $\mathrm{CH}_{3}, \mathrm{H} 5$ '), 3.72-3.60 (m, 1H, H5"); ${ }^{19} \mathrm{~F}$ NMR $\left(\mathrm{CDCl}_{3}\right) \delta-132.53$ ppm (br s, $0.8 \mathrm{~F}),-131.16 \mathrm{ppm}$ (br s, 0.2F).

${ }^{13} \mathrm{C} \mathrm{NMR}\left(\mathrm{CDCl}_{3}\right)$ for major isomer (extracted data): $\delta 162.3,161.0,150.2,138.8,137.6$, $137.1,136.6,135.1,135.0,129.0,128.59,128.57,128.4,128.3,128.1,127.80,127.6$,

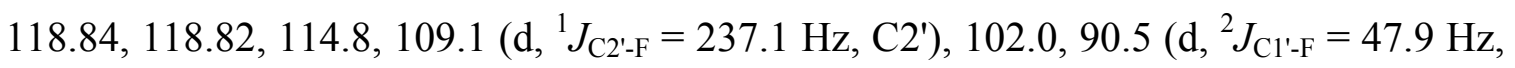
$\left.\mathrm{Cl}^{\prime}\right), 80.1(\mathrm{C} 4 '), 79.6\left(\mathrm{~d},{ }^{2} J_{\mathrm{C}^{\prime}-\mathrm{F}}=18.1 \mathrm{~Hz}, \mathrm{C} 3^{\prime}\right), 73.5\left(\mathrm{CH}_{2}\right), 73.1\left(\mathrm{CH}_{2}\right), 67.5\left(\mathrm{C} 5^{\prime}\right), 55.4$ $\left(\mathrm{CH}_{3}\right), 44.1\left(\mathrm{CH}_{2}\right)$.

\section{N3-Benzyl-3',5'-di-O-benzyl-2'-deoxy-2'-fluoro-2'-[(4-}

methoxyphenyl)sulfonyl]uridine (95b). MCPBA (241.6 $\mathrm{mg}$ of 70\% reagent, $1.4 \mathrm{mmol}$ ) in $\mathrm{CH}_{2} \mathrm{Cl}_{2}$ (5 mL) was added drop-wise to a stirred solution of 94 (327.4 $\left.\mathrm{mg}, 0.50 \mathrm{mmol}\right)$ in $\mathrm{CH}_{2} \mathrm{Cl}_{2}(3 \mathrm{~mL})$ and the resulting clear solution was stirred at ambient temperature overnight. Saturated $\mathrm{NaHCO}_{3} / \mathrm{H}_{2} \mathrm{O}(10 \mathrm{~mL})$ was added, stirring was continued for 10 min, and the organic layer was separated. The aqueous layer was extracted with $\mathrm{CHCl}_{3}(2$ x $5 \mathrm{~mL})$ and the combined organic phase was washed with $\mathrm{H}_{2} \mathrm{O}(20 \mathrm{~mL})$, brine $(25 \mathrm{~mL})$, and dried $\left(\mathrm{MgSO}_{4}\right)$. Volatiles were evaporated in vacuo and the residue was column chromatographed (20\% EtOAc in hexanes) to give $\mathbf{9 5 b}$ as a mixture of diastereomers (2'$R / S-\mathrm{S}, \sim 3: 1)$ (colorless foam, $298.7 \mathrm{mg}, 87 \%):{ }^{1} \mathrm{H} \mathrm{NMR}\left(\mathrm{CDCl}_{3}\right) \delta 7.90(\mathrm{~d}, J=8.4 \mathrm{~Hz}$, 0.5H, Ph), 7.78 (d, $J=8.3 \mathrm{~Hz}, 1.5 \mathrm{H}, \mathrm{Ph}), 7.54$ (d, $J=7.9 \mathrm{~Hz}, 1 \mathrm{H}, \mathrm{H} 6), 7.55-7.12$ (m, 15H, Ph), 6.95 (“d”, $J=8.9 \mathrm{~Hz}, 1.5 \mathrm{H}, \mathrm{Ph}$ ), 6.89 (“d”, $J=8.5 \mathrm{~Hz}, 0.5 \mathrm{H}, \mathrm{Ph}$ ), 6.70 (br s, $\left.0.25 \mathrm{H}, \mathrm{H} 1^{\prime}\right), 6.30(\mathrm{~d}, J=18.6 \mathrm{~Hz}, 0.75 \mathrm{H}, \mathrm{H1}$ ), 5.73 (d, $J=8.1 \mathrm{~Hz}, 0.75 \mathrm{H}, \mathrm{H} 5), 5.27$ (br s, $0.25 \mathrm{H}, \mathrm{H} 5), 5.06$ (d, $J=13.7 \mathrm{~Hz}, 0.75 \mathrm{H}$, benzylic), 5.00 (“d”, $J=13.7 \mathrm{~Hz}, 0.25 \mathrm{H}$, 
benzylic), 4.92-4.80 (m, 2H, benzylic, H3'), 4.58 (d, $J=11.6 \mathrm{~Hz}, 1 \mathrm{H}$, benzylic), 4.49$4.27\left(\mathrm{~m}, 3 \mathrm{H}\right.$, benzylic), 4.11-4.06 (m, 1H, H4), $3.90\left(\mathrm{~s}, 2.25 \mathrm{H}, \mathrm{CH}_{3}\right), 3.86(\mathrm{~s}, 0.75 \mathrm{H}$, $\mathrm{CH}_{3}$ ), 3.81-3.87 (m, 0.25H, H5'), 3.75 (dd, $J=2.3,11.2 \mathrm{~Hz}, 0.75 \mathrm{H}, \mathrm{H} 5$ '), 3.54 (“dd”, $J=$ 3.7, $11.1 \mathrm{~Hz}, 1 \mathrm{H}, \mathrm{H} 5 ") ;{ }^{19} \mathrm{~F}$ NMR $\left(\mathrm{CDCl}_{3}\right) \delta-158.89 \mathrm{ppm}($ (“t”, $J=16.3 \mathrm{~Hz}, 0.75 \mathrm{~F}),-$ $156.50 \mathrm{ppm}(\mathrm{d}, J=19.5 \mathrm{~Hz}, 0.25 \mathrm{~F})$.

${ }^{13} \mathrm{C} \mathrm{NMR}\left(\mathrm{CDCl}_{3}\right)$ for major isomer: $\delta$ 165.0, 150.2, $139.3(\mathrm{C} 6), 137.3,136.8,136.2$, $131.38,131.37,129.1,128.9,128.6,128.51,128.50,128.44,128.36,128.3,128.1,127.8$

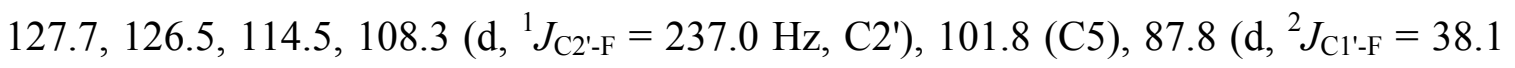
Hz, C1'), 79.5 (C4'), $75.5\left(\mathrm{~d},{ }^{2} J_{\mathrm{C}^{\prime}-\mathrm{F}}=15.2 \mathrm{~Hz}, \mathrm{C} 3^{\prime}\right), 73.8\left(\mathrm{CH}_{2}\right), 73.5\left(\mathrm{CH}_{2}\right), 67.1\left(\mathrm{C} 5^{\prime}\right)$, $55.9\left(\mathrm{CH}_{3}\right), 44.1\left(\mathrm{CH}_{2}\right)$.

5-Bromo-3',5'-di-O-acetyl-2'-S-(4-chlorophenyl)-2'-thiouridine (96a) and 5-Bromo3',5'-di-O-acetyl-2'-deoxy-2'-[(4-chlorophenyl)sulfinyl]uridine [97 (R/S-S)]. Py.9HF $(352 \mu \mathrm{L}, 1.53 \mathrm{mmol})$ was added to a chilled solution of DBH $(20.8 \mathrm{mg}, 0.073 \mathrm{mmol})$ in dry $\mathrm{CH}_{2} \mathrm{Cl}_{2}(1 \mathrm{~mL})$ at $-78{ }^{\circ} \mathrm{C}$. The resulting pale solution was stirred at $-78{ }^{\circ} \mathrm{C}$ for 10 minutes and a solution of substrate 89a $(30 \mathrm{mg}, 0.066 \mathrm{mmol})$ in dry $\mathrm{CH}_{2} \mathrm{Cl}_{2}(2 \mathrm{~mL})$ was added via syringe. The resultant orange solution was stirred at $-78{ }^{\circ} \mathrm{C}$ for $2 \mathrm{~h}$ and was brought to $-30{ }^{\circ} \mathrm{C}$ over 45 minutes. The reaction mixture was diluted with $\mathrm{CH}_{2} \mathrm{Cl}_{2}(5 \mathrm{~mL})$, washed with $\mathrm{NaHCO}_{3} / \mathrm{H}_{2} \mathrm{O}(5 \mathrm{~mL}), \mathrm{H}_{2} \mathrm{O}(5 \mathrm{~mL})$, brine $(5 \mathrm{~mL})$, dried $\left(\mathrm{MgSO}_{4}\right)$. Volatiles were evaporated in vacuo and the yellow residue was column chromatographed $(30 \% \rightarrow$ $60 \%$ EtOAc in hexanes) to give $96 \mathbf{a}(14.4 \mathrm{mg}, 41 \%)$ as a colorless oil. Also isolated were 97 (6.5 mg, 18\%, faster moving isomer) as a colorless oil and 97 (10.9 mg, 30\%, slower moving isomer) as a colorless oil. 
96a had: ${ }^{1} \mathrm{H}$ NMR $\left(\mathrm{CDCl}_{3}\right) \delta 8.48$ (br s, $\left.1 \mathrm{H}, \mathrm{NH}\right), 7.09-7.06(\mathrm{~m}, 2 \mathrm{H}, \mathrm{Ph}), 7.02-6.99(\mathrm{~m}$, 2H, Ph), 6.98 (s, 1H, H6), 5.94 (d, $J=8.1 \mathrm{~Hz}, 1 \mathrm{H}, \mathrm{H} 1$ '), 5.12 (dd, $J=2.6,5.9 \mathrm{~Hz}, 1 \mathrm{H}$, H3'), 4.12 (dd, $J=4.0,12.9$ Hz, 1H, H5'), 4.06-4.02 (m, 2H, H4', H5"), 3.47 (dd, J= 5.9, 8.0 Hz, 1H, H2'), 1.893-1.891 (“m”, 6H, 2 x $\left.\mathrm{CH}_{3}\right) ;{ }^{13} \mathrm{C} \mathrm{NMR}\left(\mathrm{CDCl}_{3}\right) \delta 170.03(\mathrm{C}=\mathrm{O})$, $169.98(\mathrm{C}=\mathrm{O}), 158.3,149.5,138.2(\mathrm{C} 6), 135.2,134.3(\mathrm{Ph}), 130.4,129.7(\mathrm{Ph}), 98.0(\mathrm{C} 5)$ $89.3\left(\mathrm{C}^{\prime}\right), 81.3\left(\mathrm{C}^{\prime}\right), 73.6\left(\mathrm{C}^{\prime}\right), 63.5\left(\mathrm{C}^{\prime}\right), 54.5\left(\mathrm{C}^{\prime}\right), 20.9\left(\mathrm{CH}_{3}\right), 20.6\left(\mathrm{CH}_{3}\right)$.

97 (faster moving isomer) had: ${ }^{1} \mathrm{H}$ NMR $\left(\mathrm{CDCl}_{3}\right) \delta 8.38$ (br s, $\left.1 \mathrm{H}, \mathrm{NH}\right), 7.56-7.50(\mathrm{~m}$, 4H, Ph), $7.10(\mathrm{~s}, 1 \mathrm{H}, \mathrm{H} 6), 5.89$ (d, $\left.J=4.0 \mathrm{~Hz}, 1 \mathrm{H}, \mathrm{H} 1^{\prime}\right), 5.51$ (t, $J=8.2 \mathrm{~Hz}, 1 \mathrm{H}, \mathrm{H} 3$ '), 4.45 (dd, $\left.J=2.8,12.3 \mathrm{~Hz}, 1 \mathrm{H}, \mathrm{H} 5^{\prime}\right), 4.40-4.36$ (m, 1H, H4'), 4.23 (dd, $J=4.8,12.3 \mathrm{~Hz}$, 1H, H5"), 3.92 (dd, $J=4.2,8.2 \mathrm{~Hz}, 1 \mathrm{H}, \mathrm{H} 2$ '), $2.29\left(\mathrm{~s}, 3 \mathrm{H}, \mathrm{CH}_{3}\right), 2.12\left(\mathrm{~s}, 3 \mathrm{H}, \mathrm{CH}_{3}\right) ;{ }^{13} \mathrm{C}$ NMR $\left(\mathrm{CDCl}_{3}\right) \delta 170.6(\mathrm{C}=\mathrm{O}), 170.4(\mathrm{C}=\mathrm{O}), 157.9,148.1,140.6(\mathrm{C} 6), 138.5,138.4$, $130.1(\mathrm{Ph}), 125.5(\mathrm{Ph}), 97.3(\mathrm{C} 5), 85.3\left(\mathrm{C} 1^{\prime}\right), 80.3$ (C4'), $72.1\left(\mathrm{C} 3{ }^{\prime}\right), 67.3\left(\mathrm{C} 2{ }^{\prime}\right), 62.1$ (C5'), $20.8\left(\mathrm{CH}_{3}\right), 20.6\left(\mathrm{CH}_{3}\right)$.

97 (slower moving isomer) had: ${ }^{1} \mathrm{H}$ NMR $\left(\mathrm{CDCl}_{3}\right) \delta 8.55$ (br s, $\left.1 \mathrm{H}, \mathrm{NH}\right), 7.59-7.56(\mathrm{~m}$, 2H, Ph), 7.42-7.39 (m, 2H, Ph), 7.15 (s, 1H, H6), 6.13 (d, J=8.4 Hz, 1H, H1'), 5.51 (dd, $\left.J=2.6,6.2 \mathrm{~Hz}, 1 \mathrm{H}, \mathrm{H} 3^{\prime}\right), 4.30\left(\mathrm{dd}, J=3.2,12.1 \mathrm{~Hz}, 1 \mathrm{H}, \mathrm{H} 5^{\prime}\right), 4.25$ (q, $J=2.9 \mathrm{~Hz}, 1 \mathrm{H}$, H4'), 4.17 (dd, $\left.J=2.9,12.1 \mathrm{~Hz}, 1 \mathrm{H}, \mathrm{H} 5^{\prime \prime}\right), 3.72$ (dd, $\left.J=6.2,8.3 \mathrm{~Hz}, 1 \mathrm{H}, \mathrm{H} 2^{\prime}\right), 2.13$ (s, $\left.3 \mathrm{H}, \mathrm{CH}_{3}\right), 2.11\left(\mathrm{~s}, 3 \mathrm{H}, \mathrm{CH}_{3}\right) ;{ }^{13} \mathrm{C} \mathrm{NMR}\left(\mathrm{CDCl}_{3}\right) \delta 169.8(\mathrm{C}=\mathrm{O}), 169.7(\mathrm{C}=\mathrm{O}), 157.5$, 148.7, 139.8 (C6), 139.0, 137.6, $130.1(\mathrm{Ph}), 127.1(\mathrm{Ph}), 98.2$ (C5), 83.1 (C1'), $81.6\left(\mathrm{C} 4{ }^{\prime}\right)$, $73.4\left(\mathrm{C}^{\prime}\right), 69.8\left(\mathrm{C}^{\prime}\right), 63.4\left(\mathrm{C}^{\prime}\right), 21.0\left(\mathrm{CH}_{3}\right), 20.6\left(\mathrm{CH}_{3}\right)$.

3',5'-di-O-Acetyl-5-iodo-2'-S-(4-chlorophenyl)-2'-thiouridine (96b). NIS (68 mg, 0.42 mmol) was added to a stirred solution of $89 \mathbf{a}(46 \mathrm{mg}, 0.1 \mathrm{mmol})$ and DAST ( $80 \mu \mathrm{L}, 0.6$ mmol) in anhydrous $\mathrm{CH}_{2} \mathrm{Cl}_{2}(2 \mathrm{~mL})$ at $0{ }^{\circ} \mathrm{C}$ and the resulting purple solution was stirred 
at $0{ }^{\circ} \mathrm{C}$ for $6 \mathrm{~h}$ and at ambient temperature for $32 \mathrm{~h}$ (total reaction time: $36 \mathrm{~h}$ ). The reaction was quenched by addition of sat. $\mathrm{Na}_{2} \mathrm{~S}_{2} \mathrm{O}_{3}(5 \mathrm{~mL})$, diluted with $\mathrm{CH}_{2} \mathrm{Cl}_{2}(5 \mathrm{~mL})$. Organic layer was separated and aqueous layer was back extracted $\left(2 \times \mathrm{CH}_{2} \mathrm{Cl}_{2}\right)$. Combined organic layer was washed with $\mathrm{NaHCO}_{3} / \mathrm{H}_{2} \mathrm{O}(10 \mathrm{~mL})$, brine $(10 \mathrm{~mL})$, dried $\left(\mathrm{MgSO}_{4}\right)$, and filtered. Volatiles were evaporated in vacuo and the brown residue was column chromatographed $(25 \% \rightarrow 50 \%$ EtOAc in hexanes) to give $96 \mathbf{b}(42.5 \mathrm{mg}, 73 \%)$ as a colorless oil.

Analogous treatment of 89a (46 mg, $0.1 \mathrm{mmol}$ ) with NIS (68 mg, $0.42 \mathrm{mmol}$ ) and DAST ( $80 \mu \mathrm{L}, 0.6 \mathrm{mmol})$ at $35{ }^{\circ} \mathrm{C}$ for $24 \mathrm{~h}$ gave $96 \mathbf{b}(35 \mathrm{mg}, 60 \%)$ as a pale-yellow oil. ${ }^{1} \mathrm{H}$ NMR $\left(\mathrm{CDCl}_{3}\right) \delta 9.07$ (br s, 1H, NH), 7.60 (s, 1H, H6), 7.39-7.35 (m, 2H, Ph), 7.31$7.28(\mathrm{~m}, 2 \mathrm{H}, \mathrm{Ph}), 6.23$ (d, $\left.J=8.4 \mathrm{~Hz}, 1 \mathrm{H}, \mathrm{H} 1^{\prime}\right), 5.43$ (dd, $J=2.2,5.8 \mathrm{~Hz}, 1 \mathrm{H}, \mathrm{H} 3$ '), 4.444.31 (m, 3H, H4', H5', H5"), 3.77 (dd, $J=5.9,8.3 \mathrm{~Hz}, 1 \mathrm{H}, \mathrm{H} 2$ '), 2.21 (s, 3H, CH 3 ), 2.19 $\left(\mathrm{s}, 3 \mathrm{H}, \mathrm{CH}_{3}\right) ;{ }^{13} \mathrm{C} \mathrm{NMR}\left(\mathrm{CDCl}_{3}\right) \delta 171.3,170.0(2 \times \mathrm{C}=\mathrm{O}), 159.2(\mathrm{C} 4), 149.8(\mathrm{C} 2), 143.3$ (C6), $135.2(\mathrm{Ph}), 134.3(\mathrm{Ph}), 130.4(\mathrm{Ph}), 129.8(\mathrm{Ph}), 89.0(\mathrm{C} 1 '), 81.3\left(\mathrm{C}^{\prime}\right), 73.7$ (C3'), 69.7 (C5), 63.6 (C5'), 54.5 (C2'), 21.1, 20.7 (2 x s, 2 x CH 3 ).

3-N-benzyl-3',5'-di-O-benzyl-5-bromo-2'-deoxy-2'-fluoro-2'-S-(4-chlorophenyl)-2'thiouridine (98). 89b (255 mg, $0.4 \mathrm{mmol}$ ) was treated with Py.9HF (920 $\mu \mathrm{L}, 4 \mathrm{mmol})$ and $\mathrm{DBH}(572 \mathrm{mg}, 2 \mathrm{mmol})$ in anhydrous $\mathrm{CH}_{2} \mathrm{Cl}_{2}(10 \mathrm{~mL})$ according to general desulfurization-difluorination procedure gave $405 \mathrm{mg}$ of yellow oil after aqueous workup. Column chromatography $(10 \% \rightarrow 70 \%$ EtOAc in hexanes $)$ gave a major fraction of $118 \mathrm{mg}$ as a pale-yellow oil: ${ }^{19} \mathrm{~F}-\mathrm{NMR}\left(\mathrm{CDCl}_{3}\right) \delta-127.53$ to $-127.24(\mathrm{~m}, 1 \mathrm{~F}),-130.84$ to $-130.62(\mathrm{~m}, 1 \mathrm{~F})$. 
and 3-N-benzyl-3',5'-di-O-benzyl-2'-fluoro-2'-S-(4-methoxyphenyl)-2'-thiouridine

(94b). NIS (95 mg, $0.42 \mathrm{mmol})$ was added to a stirred solution of 18 (128 mg, $0.2 \mathrm{mmol})$ and Py.9HF $(138 \mu \mathrm{L}, 0.6 \mathrm{mmol})$ in anhydrous $\mathrm{CH}_{2} \mathrm{Cl}_{2}(3 \mathrm{~mL})$ at $-78{ }^{\circ} \mathrm{C}$ in a poly propylene vessel and the resulting brown solution was brought to $\sim 5^{\circ} \mathrm{C}$ overnight $(16 \mathrm{~h})$. Stirring was continued at ambient temperature for $7 \mathrm{~h}$ (total reaction time: $23 \mathrm{~h}$ ). The reaction was quenched by addition of ice-cold water $(10 \mathrm{~mL})$, diluted with $\mathrm{CH}_{2} \mathrm{Cl}_{2}(5$ $\mathrm{mL}$ ), neutralized with drop-wise addition of conc. $\mathrm{NH}_{4} \mathrm{OH}$. Organic layer was separated and aqueous layer was back extracted $\left(2 \times \mathrm{CH}_{2} \mathrm{Cl}_{2}\right)$. Combined organic layer was washed with $1 \mathrm{~N} \mathrm{HCl}(10 \mathrm{~mL})$, brine $(10 \mathrm{~mL})$, dried $\left(\mathrm{MgSO}_{4}\right)$, and filtered. Volatiles were evaporated in vacuo and the brown residue was column chromatographed $(5 \% \rightarrow 20 \%$ EtOAc in hexanes) to give $\mathbf{1 0 0}(44 \mathrm{mg}, 29 \%)$ as a colorless oil and $\mathbf{9 4 b}(16 \mathrm{mg}, 12 \%)$ as a pale-yellow oil $(2 '-R / S-\mathrm{S}, \sim 1: 1)$.

Analogous treatment of $18(128 \mathrm{mg}, 0.2 \mathrm{mmol})$ with NIS (95 mg, $0.42 \mathrm{mmol})$ and DAST (160 $\mu \mathrm{L}, 1.2 \mathrm{mmol}$ ) followed by aqueous workup (sat. $\mathrm{Na}_{2} \mathrm{~S}_{2} \mathrm{O}_{3}$, sat. $\mathrm{NaHCO}_{3}$, brine, $\mathrm{MgSO}_{4}$ ) and column chromatography gave $\mathbf{9 4 b}(58 \mathrm{mg}, 44 \%$ ) as a pale-yellow oil $\left(2^{\prime}-R / S-\mathrm{S}, \sim 1: 1\right)$

100 had: ${ }^{1} \mathrm{H}$ NMR $\left(\mathrm{CDCl}_{3}\right) \delta$ 7.66-7.63 (m, 2H, Ph), 7.56 (s, 1H, H6), 7.44-7.31 (m, 13H, $\mathrm{Ph}), 7.12-7.10(\mathrm{~m}, 2 \mathrm{H}, \mathrm{Ph}), 6.51$ (d, $J=8.9 \mathrm{~Hz}, 1 \mathrm{H}, \mathrm{H1}$ ), 6.33-6.30 (m, 2H, Ph), 5.15 (“d”, $J=13.4 \mathrm{~Hz}, 1 \mathrm{H}$, benzylic), 5.02 (“d”, $J=13.3 \mathrm{~Hz}, 1 \mathrm{H}$, benzylic), 4.68-4.52 (m, 4H, benzylic), 4.33-4.25 (m, 2H, H4', H3'), 3.76-3.67 (m, 2H, H2', H5'), 3.66 (s, 3H, $\mathrm{OCH}_{3}$ ), $3.51(\mathrm{dd}, J=2.0,10.5 \mathrm{~Hz}, 1 \mathrm{H}, \mathrm{H} 5 ") ;{ }^{13} \mathrm{C} \mathrm{NMR}\left(\mathrm{CDCl}_{3}\right) \delta 159.8,159.1,150.8,142.2$ (C6), 137.22, 137.16, 136.2, 135.2, 130.4, 128.8, 128.6, 128.4, 128.2, 128.1, 128.06, 
127.8, 127.7, 123.0, 114.7, $90.2\left(\mathrm{Cl}^{\prime}\right), 82.1\left(\mathrm{C}^{\prime}\right), 80.7\left(\mathrm{C}^{\prime}\right), 73.8\left(\mathrm{CH}_{2}\right), 72.3\left(\mathrm{CH}_{2}\right)$, $70.5(\mathrm{C} 5), 68.9\left(\mathrm{C}^{\prime}\right), 56.4\left(\mathrm{C}^{\prime}\right), 55.5\left(\mathrm{OCH}_{3}\right), 46.0\left(\mathrm{CH}_{2}\right)$.

\section{3- $N$-benzyl-3',5'-di-O-benzyl-5-bromo-2'-fluoro-2'-S-(4-methoxyphenyl)-2'-}

thiouridine (101). Treatment of 94b (131 mg, $0.2 \mathrm{mmol})$ with DBH (172 mg, $0.6 \mathrm{mmol})$ and Py.9HF (280 $\mu \mathrm{L}, 1.2 \mathrm{mmol})$ at $-78^{\circ} \mathrm{C}$ according to the procedure described for 89a $\rightarrow \mathbf{9 6 a / 9 7}$ followed by column chromatography (15\% EtOAc in hexanes) gave $\mathbf{1 0 1}$ as a mixture of diastereomers $(2 '-R / S-\mathrm{S}, \sim 65: 35) \quad$ (pale-yellow oil, $82 \mathrm{mg}, 56 \%): \quad{ }^{1} \mathrm{H}$ NMR $\left(\mathrm{CDCl}_{3}\right) \delta 7.84(\mathrm{~s}, 1 \mathrm{H}, \mathrm{H} 6), 7.81(\mathrm{~d}, J=2.1 \mathrm{~Hz}, 0.2 \mathrm{H}, \mathrm{Ph}), 7.66(\mathrm{~d}, J=2.2 \mathrm{~Hz}, 0.8 \mathrm{H}, \mathrm{Ph})$, 7.49-7.23 (m, 17H, Ph), 6.78 (d, $J=8.7 \mathrm{~Hz}, 0.8 \mathrm{H}, \mathrm{Ph}), 6.75(\mathrm{~d}, J=8.7 \mathrm{~Hz}, 0.2 \mathrm{H}, \mathrm{Ph})$, 6.44 (d, $J=13.9 \mathrm{~Hz}, 0.8 \mathrm{H}, \mathrm{H1}$ '), 6.27 (br s, 0.2H, H1'), 5.09 (“d”, $J=13.6 \mathrm{~Hz}, 1 \mathrm{H}$, benzylic), 4.92-4.80 (m, 1H, benzylic), 4.73-4.65 (m, 1H, benzylic), 4.62-4.41 (m, 3H, benzylic), 4.18-4.09 (m, 2H, H3', H4'), $3.92\left(\mathrm{~s}, 0.6 \mathrm{H}, \mathrm{CH}_{3}\right), 3.91\left(\mathrm{~s}, 2.4 \mathrm{H}, \mathrm{CH}_{3}\right), 3.82-$ 3.72 (m, 1H, H5'), 3.61-3.53 (m, 1H, H5"); ${ }^{19} \mathrm{~F} \mathrm{NMR}\left(\mathrm{CDCl}_{3}\right) \delta-133.52 \mathrm{ppm}(\mathrm{br} \mathrm{s}, 0.8 \mathrm{~F})$, -131.57 ppm (br s, 0.2F).

${ }^{13} \mathrm{C}$ NMR $\left(\mathrm{CDCl}_{3}\right)$ for major isomer (extracted data): $\delta 158.4,157.2,149.4,138.1$, $137.79,137.76,137.3,136.8,135.9,134.1,134.0,129.3,128.6,128.5,128.4,128.3$, $128.2,128.1,128.0,127.9,120.24,120.23,112.2,112.0,108.7\left(\mathrm{~d},{ }^{1} J_{\mathrm{C} 2 '-\mathrm{F}}=239.1 \mathrm{~Hz}\right.$ C2'), 96.9, $90.4\left(\mathrm{~d},{ }^{2} J_{\mathrm{C} 1^{\prime}-\mathrm{F}}=47.3 \mathrm{~Hz}, \mathrm{C} 1^{\prime}\right), 80.3\left(\mathrm{C} 4{ }^{\prime}\right), 79.7\left(\mathrm{~d},{ }^{2} J_{\mathrm{C} 3^{\prime}-\mathrm{F}}=17.7 \mathrm{~Hz}, \mathrm{C} 3^{\prime}\right), 73.5$ $\left(\mathrm{CH}_{2}\right), 73.1\left(\mathrm{CH}_{2}\right), 67.0\left(\mathrm{C}^{\prime}\right), 56.4\left(\mathrm{CH}_{3}\right), 45.7\left(\mathrm{CH}_{2}\right)$.

5'-O-Acetyl-2',3'-dideoxy-2',3'-didehydro-2'-[(4-chlorophenyl)sulfonyl]uridine (or) 1-[5'-O-Acetyl-2',3'-dideoxy-2'-(4-chlorophenyl)sulfonyl- $\beta$-D-glycero-pent-2'enofuranosyl]uracil (102). mCPBA (70\% reagent, $250 \mathrm{mg}, 1.45 \mathrm{mmol})$ was added to a stirred solution of $89 \mathrm{a}(227.4 \mathrm{mg}, 0.5 \mathrm{mmol})$ in $\mathrm{CH}_{2} \mathrm{Cl}_{2}(15 \mathrm{~mL})$ and the resultant 
colorless solution was stirred at ambient temperature for $12 \mathrm{~h}$. TLC showed complete conversion to a more polar product. The reaction mixture was poured into $\mathrm{NaHCO}_{3} / \mathrm{H}_{2} \mathrm{O}$ $(10 \mathrm{~mL})$. The aqueous layer was extracted with $\mathrm{CHCl}_{3}(2 \times 5 \mathrm{~mL})$ and the combined organic phase was washed with $\mathrm{H}_{2} \mathrm{O}(20 \mathrm{~mL})$, brine $(25 \mathrm{~mL})$, and dried $\left(\mathrm{MgSO}_{4}\right)$. Volatiles were evaporated in vacuo to give 91a (241 mg, 99\%) as a colorless foam. Purification of this material on silica gel chromatography (50\% EtOAc in hexanes) gave 102 contaminated with $40 \%$ of 91 a (184 mg, $1.5: 1$ ratio of 102:91a): ${ }^{1} \mathrm{H} N M R\left(\mathrm{CDCl}_{3}\right) \delta$ 10.04 (s, 0.6H, NH), 9.99 (s, 0.4H, NH), 7.89-7.85 (m, 0.8H, Ph), 7.84-7.81 (m, 1.2H, $\mathrm{Ph}$ ), 7.57-7.53 (m, 2H, Ph), 7.36 (d, $J=8.1 \mathrm{~Hz}, 0.6 \mathrm{H}, \mathrm{H6}$ ), 7.28-7.27 (“m”, 0.6H, H1'), 7.19 (d, $J=8.2 \mathrm{~Hz}, 0.4 \mathrm{H}, \mathrm{H} 6), 7.01$ (“d”, $J=1.9 \mathrm{~Hz}, 0.6 \mathrm{H}, \mathrm{H} 3$ '), 6.21 (d, $J=6.4 \mathrm{~Hz}$, 0.4H, H1'), 5.72-5.66 (m, 1.4H, H3', H5), 5.15-5.11 (m, 0.6H, H4'), 4.64 (t, $J=6.8 \mathrm{~Hz}$, 0.4H, H2'), 4.46-4.22 (m, 2.4H, H4', H5', H5"), 2.09 (s, 1.8H, $\mathrm{CH}_{3}$ ), 2.08 (s, 1.2H, $\mathrm{CH}_{3}$ ), $2.07\left(\mathrm{~s}, 1.2 \mathrm{H}, \mathrm{CH}_{3}\right)$.

3- $N$-Benzyl uracil (103) and 3,5-di-O-benzyl-1,2-dideoxy-1,2-didehydro-2-[(4chlorophenyl)sulfonyl|ribose (104). A stirred solution of $91 \mathbf{b}(30 \mathrm{mg}, 0.045 \mathrm{mmol})$ and selectfluor (24 mg, $0.067 \mathrm{mmol})$ in dry DMF $(2 \mathrm{~mL})$ was added to a chilled suspension of $\mathrm{KH}(30 \mathrm{wt} \%$ dispersion in mineral oil; $2.5 \mathrm{mg}, 0.0613 \mathrm{mmol})$ in dry THF $(5 \mathrm{~mL})$ at -78 ${ }^{\circ} \mathrm{C}$. TLC after 30 minutes showed complete consumption of starting material and two new spots. The reaction mixture was slowly warmed to $0{ }^{\circ} \mathrm{C}$. Crude reaction mixture was partitioned between $\mathrm{CHCl}_{3}(5 \mathrm{~mL})$ and ice-cold $\mathrm{NH}_{4} \mathrm{Cl} / \mathrm{H}_{2} \mathrm{O}(5 \mathrm{~mL})$. The aqueous layer was extracted with $\mathrm{CHCl}_{3}(2 \times 2 \mathrm{~mL})$ and the combined organic phase was washed with $\mathrm{NaHCO}_{3} / \mathrm{H}_{2} \mathrm{O}(10 \mathrm{~mL})$, brine $(10 \mathrm{~mL})$, and dried $\left(\mathrm{MgSO}_{4}\right)$. Volatiles were evaporated in 
vacuo and the residue was column chromatographed $(5 \% \rightarrow 50 \%$ EtOAc in hexanes) to give $103(5.7 \mathrm{mg}, 63 \%)$ as colorless oil and $104(14.9 \mathrm{mg}, 71 \%)$ as a colorless foam.

Analogously, treatment of substrate $(30 \mathrm{mg}, 0.045 \mathrm{mmol})$ in dry THF $(2 \mathrm{~mL})$ with a chilled suspension of $\mathrm{KH}$ (30 wt\% dispersion in mineral oil; $2.5 \mathrm{mg}, 0.0613 \mathrm{mmol})$ in dry THF $(5 \mathrm{~mL})$ at $0{ }^{\circ} \mathrm{C}$ for 15 minutes followed by aqueous workup and column chromatography also gave 103 and 104 in similar yields.

103 had: $: 221{ }^{1} \mathrm{H}$ NMR $\left(\mathrm{CDCl}_{3}\right) \delta 9.48(1 \mathrm{H}$, br s, NH), 7.45-7.42 (m, 2H, Ph), 7.34-7.24 (m, 3H, Ph), 6.50 (dd, $J=3.7,7.5 \mathrm{~Hz}, 1 \mathrm{H}, \mathrm{H} 6), 5.79$ (d, $J=7.7 \mathrm{~Hz}, 1 \mathrm{H}, \mathrm{H} 5), 5.10$ (s, 2H, $\mathrm{CH}_{2}$ ).

104 had: ${ }^{1} \mathrm{H}$ NMR $\left(\mathrm{CDCl}_{3}\right) \delta 7.71(\mathrm{~d}, J=8.6 \mathrm{~Hz}, 2 \mathrm{H}, \mathrm{Ph}), 7.38(\mathrm{~s}, 1 \mathrm{H}, \mathrm{H} 1), 7.31-7.13(\mathrm{~m}$, 10H, Ph), 6.99-6.97 (“"m”, 2H, Ph), 4.81 (d, $J=2.9 \mathrm{~Hz}, 1 \mathrm{H}, \mathrm{H} 3$ ), 4.73-4.70 (m, 1H, H4), 4.45-4.39 (m, $\left.2 \mathrm{H}, \mathrm{CH}_{2}\right), 4.37-4.30\left(\mathrm{~m}, 2 \mathrm{H}, \mathrm{CH}_{2}\right), 3.42(\mathrm{dd}, J=5.4,10.3 \mathrm{~Hz}, 1 \mathrm{H}, \mathrm{H})$ ), $3.34\left(\mathrm{dd}, J=5.7,10.3 \mathrm{~Hz}, 1 \mathrm{H}, \mathrm{H} 5{ }^{\prime}\right) ;{ }^{13} \mathrm{C} \mathrm{NMR}\left(\mathrm{CDCl}_{3}\right) \delta 160.7(\mathrm{C} 1), 140.6(\mathrm{Ph}), 139.4$ $(\mathrm{Ph}), 137.2(\mathrm{Ph}), 137.0(\mathrm{Ph}), 129.2(\mathrm{Ph}), 128.9(\mathrm{Ph}), 128.6(\mathrm{Ph}), 128.4(\mathrm{Ph}), 128.1(\mathrm{Ph})$, $128.0(\mathrm{Ph}), 127.9(\mathrm{Ph}), 127.8(\mathrm{Ph}), 118.8(\mathrm{C} 2), 90.5(\mathrm{C} 4), 80.6(\mathrm{C} 3), 73.7\left(\mathrm{CH}_{2}\right), 71.0$ $\left(\mathrm{CH}_{2}\right), 68.7$ (C5). HRMS (ESI) $\mathrm{m} / z 493.0846[\mathrm{M}+\mathrm{Na}]^{+}$, calcd for $\mathrm{C}_{25} \mathrm{H}_{23} \mathrm{ClNaO}_{5} \mathrm{~S}^{+}$ 493.0847.

[4-[(4-Methoxyphenyl)sulfonyl]furan-2-yl]methyl acetate (105), (106) and 5'-OAcetyl-2',3'-dideoxy-2',3'-didehydro-2'-[(4-methoxyphenyl)sulfonyl]uridine (107). TDAE (0.24 mL, $1.04 \mathrm{mmol})$ was added to a stirred solution of $91 \mathrm{a}(100 \mathrm{mg}, 2.07 \mathrm{mmol})$ in DMF $(2 \mathrm{~mL})$ at $-78{ }^{\circ} \mathrm{C}$ and the reaction mixture was brought to ambient temperature over $1 \mathrm{~h} 15$ minutes and a $10 \% \mathrm{HCl}$ solution $(2 \mathrm{~mL})$ was added. The crude was extracted with EtOAc $(3 \mathrm{x})$ and the combined organic phase was dried $\left(\mathrm{Na}_{2} \mathrm{SO}_{4}\right)$. Volatiles were 
evaporated in vacuo and the residue was column chromatographed (Petroleum ether (PE) $100 \% \rightarrow$ EtOAc/PE $2 / 1 \rightarrow 100 \%$ EtOAc) to give $105(34.5 \mathrm{mg}, 54 \%), 106(21 \mathrm{mg}$, 24\%), and 107 (35 mg, 40\%) as colorless oils.

105 had: ${ }^{1} \mathrm{H}$ NMR $\left(\mathrm{CDCl}_{3}\right) \delta 7.93(\mathrm{~d}, J=0.8 \mathrm{~Hz}, 1 \mathrm{H}, \mathrm{H1}), 7.85-7.89(\mathrm{~m}, 2 \mathrm{H}, \mathrm{Ph}), 6.96-$ $7.00(\mathrm{~m}, 2 \mathrm{H}, \mathrm{Ph}), 6.56(\mathrm{~s}, 1 \mathrm{H}, \mathrm{H} 3), 4.97$ (s, 2H, H5, H5'), $3.85\left(\mathrm{~s}, 3 \mathrm{H}, \mathrm{OCH}_{3}\right), 2.05$ (s, 3H, Ac); ${ }^{13} \mathrm{C}$ NMR $\left(\mathrm{CDCl}_{3}\right) \delta 170.3(\mathrm{C}=\mathrm{O}), 163.8(\mathrm{Ph}), 152.4(\mathrm{C} 4), 145.7(\mathrm{C} 1), 132.9$ (C2), $131.1(\mathrm{Ph}), 129.8(\mathrm{Ph}), 114.7(\mathrm{Ph}), 108.7(\mathrm{C} 3), 57.4(\mathrm{C} 5), 55.8\left(\mathrm{OCH}_{3}\right), 20.8\left(\mathrm{CH}_{3}\right)$; MS (ESI) $m / z 328.17\left[\mathrm{M}+\mathrm{NH}_{4}\right]^{+}$, calcd for $\mathrm{C}_{14} \mathrm{H}_{18} \mathrm{NO}_{6} \mathrm{~S}^{+} 328.08$.

106 had: ${ }^{1} \mathrm{H}$ NMR $\left(\mathrm{CDCl}_{3}\right) \delta 9.00(\mathrm{br}, 1 \mathrm{H}, \mathrm{NH}), 7.76(\mathrm{~d}, J=8.8 \mathrm{~Hz}, 2 \mathrm{H}, \mathrm{Ph}), 7.58(\mathrm{~s}, 1 \mathrm{H}$, H1'), 6.97-6.99 (m, 3H, Ph, H6), 5.69 (br s, 1H, OH), 5.62 (dd, $J=1.2,8$ Hz, 1H, H5), 4.93-4.79 (m, 1H, H3'), 4.27 (dd, $\left.J=4.4,12.4 \mathrm{~Hz}, 1 \mathrm{H}, \mathrm{H} 5^{\prime}\right), 4.21$ (dd, $J=4.8,12.4 \mathrm{~Hz}$, 1H, H5"), $3.86\left(\mathrm{~s}, 3 \mathrm{H}, \mathrm{OCH}_{3}\right), 1.95(\mathrm{~s}, 3 \mathrm{H}, \mathrm{Ac}) ;{ }^{13} \mathrm{C} \mathrm{NMR}\left(\mathrm{CDCl}_{3}\right) \delta 170.4(\mathrm{C}=\mathrm{O}), 164.2$ (Ph), $162.6(\mathrm{C} 4), 160.3$ (C6, C2), 150.3 (C4'), $140.2\left(\mathrm{C}^{\prime}\right), 131.5(\mathrm{Ph}), 129.9(\mathrm{Ph}), 116.9$ (C1'), $114.9(\mathrm{Ph}), 103.7(\mathrm{C} 5), 88.7\left(\mathrm{C}^{\prime}\right), 63.4\left(\mathrm{C}^{\prime}\right), 55.6\left(\mathrm{OCH}_{3}\right), 20.5\left(\mathrm{CH}_{3}\right) . \mathrm{MS}(\mathrm{ESI})$ $m / z 440.04\left[\mathrm{M}+\mathrm{NH}_{4}\right]^{+}$, calcd for $\mathrm{C}_{18} \mathrm{H}_{22} \mathrm{~N}_{3} \mathrm{O}_{8} \mathrm{~S}^{+} 440.11$.

107 had: ${ }^{1} \mathrm{H}$ NMR $\left(\mathrm{CDCl}_{3}\right) \delta 9.23$ (br, 1H, NH), 7.79-7.75 (m, 2H, Ph), $7.24(\mathrm{~d}, J=8.4$ Hz, 1H, H6), 7.18 (t, $J=1.6 \mathrm{~Hz}, 1 \mathrm{H}, \mathrm{H} 3$ '), 7.03-6.99 (m, 3H, Ph, H1'), 5.55 (dd, $J=2.0$, $8.4 \mathrm{~Hz}, 1 \mathrm{H}, \mathrm{H} 5), 5.12-5.09$ (m, 1H, H4'), 4.41 (dd, $J=4.0,12.4$ Hz, 1H, H5'), 4.29 (dd, $J$

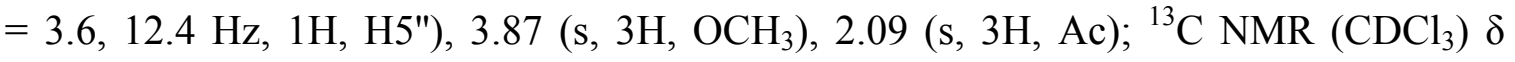
$170.1(\mathrm{C}=\mathrm{O}), 164.9(\mathrm{Ph}), 162.9(\mathrm{C} 4), 150.3(\mathrm{C} 2), 142.1(\mathrm{C} 6), 141.9(\mathrm{C} 2 '), 139.5\left(\mathrm{C} 3^{\prime}\right)$, $130.8(\mathrm{Ph}), 129.1(\mathrm{Ph}), 115.2(\mathrm{Ph}), 103.2(\mathrm{C} 5), 87.5\left(\mathrm{C} 1{ }^{\prime}\right), 82.8\left(\mathrm{C}^{\prime}\right), 63.9\left(\mathrm{C}^{\prime}\right), 56.1$ $\left(\mathrm{OCH}_{3}\right), 20.8$ (Ac). HRMS (ESI) $\mathrm{m} / z 423.0856[\mathrm{M}+\mathrm{H}]^{+}$, calcd for $\mathrm{C}_{18} \mathrm{H}_{19} \mathrm{~N}_{2} \mathrm{O}_{8} \mathrm{~S}^{+}$ 423.0857. 
[4-[(4-Methoxyphenyl)sulfonyl]furan-2-yl]methyl acetate (105) and uracil (105a). In a glove box, SED (31 mg, $0.1 \mathrm{mmol})$ was added to a solution of $91 \mathrm{a}(50 \mathrm{mg}, 0.1 \mathrm{mmol})$ in anhydrous DMF (4 mL) and stirred at ambient temperature for 15 minutes. Reaction flask was brought out of the glove box and water was added to the crude reaction mixture. The aqueous phase was extracted with $\mathrm{CH}_{2} \mathrm{Cl}_{2}(3 \mathrm{x})$, the combined organic phase was dried with $\mathrm{Na}_{2} \mathrm{SO}_{4}$ and volatiles were evaporated in vacuo to give 105 (29.4 mg, 95\%) as a colorless oil.

Acidification of the aqueous phase $(\mathrm{pH} \sim 5-6)$ followed by a second extraction with $\mathrm{CH}_{2} \mathrm{Cl}_{2}(2 \mathrm{x})$ gave a white solid. ${ }^{1} \mathrm{H} \mathrm{NMR}(\mathrm{MeOD})$ of the white solid revealed the presence of uracil 105a along with other impurities.

\section{3,5-di-O-Benzyl-1,2-dideoxy-1,2-didehydro-2-[(4-methoxyphenyl)sulfonyl]ribose}

(108), 2-[(benzyloxy)methyl]-4-[(4-methoxyphenyl)sulfonyl]furan (109) and 3-Nbenzyluracil (103). In a glove box, SED (22 $\mathrm{mg}, 0.067 \mathrm{mmol})$ was added to a stirred solution of 91b (45 mg, $0.07 \mathrm{mmol})$ in DMF (4 mL) and the reaction mixture was stirred at ambient temperature for 15 minutes. Reaction flask was brought out of the glove box and water was added to the crude reaction mixture. The aqueous phase was extracted with $\mathrm{CH}_{2} \mathrm{Cl}_{2}(3 \mathrm{x})$ and the combined organic phase was dried with $\mathrm{Na}_{2} \mathrm{SO}_{4}$. Volatiles were evaporated in vacuo and the residue was column chromatographed (PE 100\% $\rightarrow$ $\mathrm{PE} /$ EtOAc $9 / 1 \rightarrow$ EtOAC $100 \%)$ to give $\mathbf{1 0 8}(22 \mathrm{mg}, 70 \%)$ as a white gum and $\mathbf{1 0 3}(9.4$ mg, 69\%) as a white solid.

108 had: ${ }^{1} \mathrm{H}$ NMR $\left(\mathrm{CDCl}_{3}\right) \delta$ 7.83-7.79 (m, 2H, Ph), $7.42(\mathrm{~s}, 1 \mathrm{H}, \mathrm{H} 1), 7.37-7.31(\mathrm{~m}, 3 \mathrm{H}$, $\mathrm{Ph}), 7.26-7.24$ (m, 5H, Ph), 7.09-7.07 (m, 2H, Ph), 6.86-6.84 (m, 2H, Ph), 4.86 (d, J=3.2 $\mathrm{Hz}, 1 \mathrm{H}, \mathrm{H} 3), 4.77$ (td, $J=3.2,5.6 \mathrm{~Hz}, 1 \mathrm{H}, \mathrm{H} 4), 4.49$ (d, $\left.J=2.4 \mathrm{~Hz}, 2 \mathrm{H}, \mathrm{CH}_{2}\right), 4.40$ (s, 
$\left.2 \mathrm{H}, \mathrm{CH}_{2}\right), 3.81\left(\mathrm{~s}, 3 \mathrm{H}, \mathrm{OCH}_{3}\right), 3.48(\mathrm{dd}, J=5.6,10.4 \mathrm{~Hz}, 1 \mathrm{H}, \mathrm{H} 5), 3.40(\mathrm{dd}, J=5.6,10.4$ $\mathrm{Hz}, 1 \mathrm{H}, \mathrm{H} 5) ;{ }^{13} \mathrm{C} \mathrm{NMR}\left(\mathrm{CDCl}_{3}\right) \delta 163.3\left(\mathrm{C}^{\mathrm{Ph}}\right), 159.7(\mathrm{C} 1), 137.4\left(\mathrm{C}^{\mathrm{Ph}}\right), 137.3\left(\mathrm{C}^{\mathrm{Ph}}\right)$, $133.6\left(\mathrm{C}^{\mathrm{Ph}}\right), 129.8\left(2 \mathrm{CH}^{\mathrm{Ph}}\right), 128.7\left(2 \mathrm{CH}^{\mathrm{Ph}}\right), 128.4\left(2 \mathrm{CH}^{\mathrm{Ph}}\right), 128.1\left(3 \mathrm{CH}^{\mathrm{Ph}}\right), 128.0$ $\left(\mathrm{CH}^{\mathrm{Ph}}\right), 127.9\left(2 \mathrm{CH}^{\mathrm{Ph}}\right), 119.7(\mathrm{C} 2), 114.2\left(2 \mathrm{CH}^{\mathrm{Ph}}\right), 90.3(\mathrm{C} 3), 80.7(\mathrm{C} 4), 73.7\left(\mathrm{CH}_{2}\right)$, $70.8\left(\mathrm{CH}_{2}\right), 68.9(\mathrm{C} 5), 55.7\left(\mathrm{OCH}_{3}\right)$; HRMS (ESI) $\mathrm{m} / z 484.1789\left[\mathrm{M}+\mathrm{NH}_{4}\right]^{+}$, calcd for $\mathrm{C}_{26} \mathrm{H}_{30} \mathrm{NO}_{6} \mathrm{~S}^{+} 484.1788$.

Analogous treatment of and $91 \mathrm{~b}(50 \mathrm{mg}, 0.075 \mathrm{mmol})$ with SED (64 mg, 0.22 $\mathrm{mmol})$ in DMF (4 mL) for 30 minutes at room temperature gave $\mathbf{1 0 9}$ as a mixture with 108 (7.4 $\mathrm{mg}, 2: 1$ ratio of 109:108) as a colorless oil and $103(13 \mathrm{mg}, 86 \%)$ as a white solid.

109 had: ${ }^{1} \mathrm{H}$ NMR $\left(200 \mathrm{MHz}, \mathrm{CDCl}_{3}\right) \delta 7.93$ (s, 1H, H1), 7.91-7.84 (m, 2H, Ph), 7.367.30 (m, 5H, Ph), 7.01-6.96 (m, 2H, Ph), 6.49 (s, 1H, H3), 4.53 (s, 2H, $\left.\mathrm{CH}_{2}\right), 4.42$ (s, 2H, $\mathrm{CH}_{2}$ ), 4.14-4.03 (m, 2H, H5), 3.86 (s, 3H, OCH 3 ); $\mathrm{MS}$ (ESI) $m / z 376.17\left[\mathrm{M}+\mathrm{NH}_{4}\right]^{+}$, calcd for $\mathrm{C}_{19} \mathrm{H}_{22} \mathrm{NO}_{5} \mathrm{~S}^{+} 376.12$.

5'-O-Acetyl -2',3'-didehydro-2',3'-dideoxy-2'-fluorouridine (111) and 1-(5-O-Acetyl-

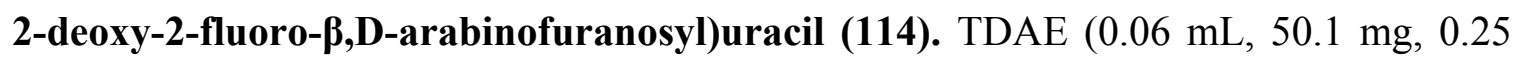
mmol) was added drop-wise via syringe to a stirred solution of 95a (95 mg, $0.19 \mathrm{mmol}$ ) in dry THF $(5 \mathrm{ml})$ at $-70^{\circ} \mathrm{C}$ under sunlamp irradiation. After $1 \mathrm{~h}$, Selectfluor $(131 \mathrm{mg}$, $0.37 \mathrm{mmol}$ ) was added and the sunlamp was turned off. The resulting mixture was stirred for $1 \mathrm{~h}$ at $-70^{\circ} \mathrm{C}$ and then overnight at ambient temperature. The reaction mixture was quenched with $3 \mathrm{ml}$ of aqueous $\mathrm{NH}_{4} \mathrm{Cl}$ and stirred for $30 \mathrm{~min}$ and then extracted with EtOAc. The combined organic layer was washed with $\mathrm{Na}_{2} \mathrm{CO}_{3} / \mathrm{H}_{2} \mathrm{O}$, brine and dried over 
$\mathrm{MgSO}_{4}$. Evaporation and column chromatography $\left(5 \% \mathrm{MeOH}\right.$ in $\left.\mathrm{CHCl}_{3}\right)$ gave $111(10$ mg: 18\%) and 114 (5 mg: 10\%).

111 was also obtained by another procedure (see Scheme 22). In a glove box, SED (68 mg, $0.24 \mathrm{mmol}, 3$ equiv.) was added to a stirred solution of 95a (40 mg, 0.08 mmol) in anhydrous DMF (4 mL) and the resulting dark brown solution was stirred at $120{ }^{\circ} \mathrm{C}$ for $18 \mathrm{~h}$. Reaction flask was brought out of the glove box, and $10 \% \mathrm{HCl}$ solution was added to the crude reaction mixture. Aqueous layer was extracted with $\mathrm{CH}_{2} \mathrm{Cl}_{2}(2 \mathrm{x})$. Combined organic layer was dried $\left(\mathrm{Na}_{2} \mathrm{SO}_{4}\right)$, filtered, and concentrated in vacuo to give a brown solid. $\mathrm{Et}_{2} \mathrm{O}$ was added to the solid and was filtered. Filtrate was concentrated in vacuo to give $111(<10 \mathrm{mg}, \sim 46 \%)$ along with other impurities. ${ }^{1} \mathrm{H}$ NMR of the black solid (DMSO- $d_{6}$ ) showed similar peaks to the ones obtained for the oxidized form of the $\operatorname{SED}\left(\mathrm{SED}^{2+}\right)$.

$\mathbf{1 1 1}^{173}$ had: ${ }^{1} \mathrm{H}$ NMR $\left(\mathrm{CDCl}_{3}\right) \delta 8.47(\mathrm{br} \mathrm{s}, 1 \mathrm{H}, \mathrm{NH}), 7.52(\mathrm{dd}, J=1.0,8.1 \mathrm{~Hz}, 1 \mathrm{H}, \mathrm{H} 6)$, 6.90-6.88 (m, 1H, H1'), $5.78(\mathrm{~d}, J=8.1 \mathrm{~Hz}, 1 \mathrm{H}, \mathrm{H} 5), 5.69(\mathrm{~m}, 1 \mathrm{H}, \mathrm{H} 3$ '), 5.06-5.02 (m, 1H, H4'), 4.35-4.21 (m, 2H, H5',5"), 2.11 (s, 3H, Ac); ${ }^{19} \mathrm{~F} \mathrm{NMR}\left(\mathrm{CDCl}_{3}\right) \delta-133.76(\mathrm{t}, J=$ 4.6 Hz, F2'); MS (EI) $m / z 271.09[\mathrm{M}+\mathrm{H}]^{+}$. calcd for $\mathrm{C}_{11} \mathrm{H}_{12} \mathrm{FN}_{2} \mathrm{O}_{5}{ }^{+} 271.07$.

114 had: ${ }^{1} \mathrm{H}$ NMR $\left(\mathrm{CDCl}_{3}\right) \delta 8.32$ (br s, $\left.1 \mathrm{H}, \mathrm{NH}\right), 7.51-7.53$ (m, 1H, H6), 6.22-6.28 (m, 1H, H1'), 5.76 (d, $J=8.1 \mathrm{~Hz}, 1 \mathrm{H}, \mathrm{H} 5), 5.06$ (d, $J=51.3 \mathrm{~Hz}, 1 \mathrm{H}, \mathrm{H} 2$ '), 4.43-4.29 (m, 3H, H3', H5', H5"), 4.21-4.19 (m, 1H, H4'), 2.12 (s, 3H, Ac); $\left.{ }^{13} \mathrm{C} \mathrm{NMR} \mathrm{(150} \mathrm{MHz,} \mathrm{CDCl}_{3}\right) \delta$ 170.9 (C=O), 162.7 (C4), 150.1 (C2), 140.9 (C6), 102.2 (C5), 94.4 (d, $J=191.8 \mathrm{~Hz}$, C2'), 84.7 (d, $\left.J=16.5 \mathrm{~Hz}, \mathrm{C} 1^{\prime}\right), 82.9$ (C4'), 75.4 (d, $J=26.5 \mathrm{~Hz}, \mathrm{C} 3$ '), 63.1 (C5'), 20.9 $\left(\mathrm{CH}_{3}\right) ;{ }^{19} \mathrm{~F} \mathrm{NMR}\left(\mathrm{CDCl}_{3}\right) \delta-199.91\left(\mathrm{~s}, \mathrm{~F} 2^{\prime}\right)$; MS (EI) $m / z 288.9[\mathrm{M}+\mathrm{H}]^{+}$, calcd for $\mathrm{C}_{11} \mathrm{H}_{14} \mathrm{FN}_{2} \mathrm{O}_{6}^{+} 289.08$. 
3-(benzyloxy)-2-[(benzyloxy)methyl]-4-[(4-methoxyphenyl)sulfonyl]furan (112). In a glove box, SED (62 mg, $0.22 \mathrm{mmol}$ ) was added to a solution of $\mathbf{9 5 b}(50 \mathrm{mg}, 0.073 \mathrm{mmol})$ in anhydrous DMF $(4 \mathrm{~mL})$ and the resulting solution was stirred at $120{ }^{\circ} \mathrm{C}$ for $3 \mathrm{~h}$. Reaction flask was brought out of the glove box, and water was added to the crude reaction mixture. The aqueous phase was extracted with $\mathrm{CH}_{2} \mathrm{Cl}_{2}(3 \mathrm{x})$ and the combined organic phase was dried with $\mathrm{Na}_{2} \mathrm{SO}_{4}$. Volatiles were evaporated in vacuo and the residue was column chromatographed (PE/EtOAc 9/1 $\rightarrow$ EtOAC 100\%) to give $112(19.6 \mathrm{mg}$, $58 \%)$ as a white gum and $\mathbf{1 0 3}(12.4 \mathrm{mg}, 84 \%)$ as a white solid.

Analogous treatment of $\mathbf{9 5 b}(58.3 \mathrm{mg}, 0.085 \mathrm{mmol})$ with SED $(72 \mathrm{mg}, 0.25$ mmol) at ambient temperature for $4 \mathrm{~h}$ showed only trace amounts of $\mathbf{1 1 2}$ and $\mathbf{1 0 3}$ on TLC. Addition of degazed water $(0.5 \mathrm{~mL}, 500 \mathrm{mg}, 27.75 \mathrm{mmol})$ followed by heating at $80{ }^{\circ} \mathrm{C}$ for 30 minutes gave, after workup and silica gel chromatography, $112(31.7 \mathrm{mg}$, $80 \%)$ and $\mathbf{1 0 3}(10.1 \mathrm{mg}, 60 \%)$.

112 had: ${ }^{1} \mathrm{H}$ NMR $\left(200 \mathrm{MHz}, \mathrm{CDCl}_{3}\right) \delta$ 7.94-7.87 (m, 2H, Ph), 7.83 (s, 1H, H1), 7.377.24 (m, 10H, Ph), 6.95-6.88 (m, 2H, Ph), 5.07 (s, 2H, $\left.\mathrm{CH}_{2}\right), 4.41$ (s, 2H, $\left.\mathrm{CH}_{2}\right), 4.17$ (s, 2H, $\left.\mathrm{CH}_{2}\right), 3.84\left(\mathrm{~s}, 3 \mathrm{H}, \mathrm{OCH}_{3}\right) ;{ }^{13} \mathrm{C} \mathrm{NMR}\left(50 \mathrm{MHz}, \mathrm{CDCl}_{3}\right) \delta 163.6(\mathrm{C} 3), 144.8(\mathrm{C} 1)$, $142.4(\mathrm{Ph}), 140.7(\mathrm{Ph}), 137.4(\mathrm{Ph}), 136.2(\mathrm{Ph}), 132.8(\mathrm{C} 4), 130.0(\mathrm{Ph}), 128.55(\mathrm{Ph})$, $128.53(\mathrm{Ph}), 128.48(\mathrm{Ph}), 128.0(\mathrm{Ph}), 127.9(\mathrm{Ph}), 125.6(\mathrm{C} 2), 114.3(\mathrm{Ph}), 77.3\left(\mathrm{CH}_{2}\right)$, $72.4\left(\mathrm{CH}_{2}\right), 61.1\left(\mathrm{CH}_{2}\right), 55.7\left(\mathrm{OCH}_{3}\right)$. HRMS (ESI) $\mathrm{m} / z 482.1632\left[\mathrm{M}+\mathrm{NH}_{4}\right]^{+}$calcd for $\mathrm{C}_{26} \mathrm{H}_{28} \mathrm{NO}_{6} \mathrm{~S}^{+} 482.1632$.

3- $N$-Methyl-2'-deoxy-2'-fluoro-2'-[(4-methoxyphenyl)sulfonyl]uridine (115). TDAE $(0.036 \mathrm{~mL}, 0.155 \mathrm{mmol})$ was added drop-wise via syringe to a stirred solution of $\mathbf{9 5 a}$ (15.4 $\mathrm{mg}, 0.031 \mathrm{mmol})$ in dry THF or DMF $(0.5 \mathrm{ml})$ at $-70^{\circ} \mathrm{C}$ under $\mathrm{N}_{2}$. UV sunlamp 
was switched on and after $1 \mathrm{~h}, \mathrm{CH}_{3} \mathrm{I}(44.4 \mathrm{mg}, 0.31 \mathrm{mmol})$ was added. The resulting mixture (yellowish with white fine solid) was stirred for $1 \mathrm{~h}$ at $-70^{\circ} \mathrm{C}$ and then overnight at ambient temperature. The reaction mixture was quenched with $3 \mathrm{ml}$ of aqueous $\mathrm{MeOH}$, stirred for $30 \mathrm{~min}$ and concentrated in vacuo. The crude product (100.8 mg), a yellowish solid, was washed with dichloromethane $(2 \times 5 \mathrm{~mL})$, filtered and the filtrate concentrated in vacuo to recover $42.9 \mathrm{mg}$ of a viscous orange. ${ }^{19} \mathrm{~F}-\mathrm{NMR}$ of this crude product indicated no starting material (a triplet centred at - $157 \mathrm{ppm}$ ) and a triplet centred at $161.42 \mathrm{ppm}$ with additional resonances at in the region -122 to $-126 \mathrm{ppm}$. Column chromatography $\left(5 \% \mathrm{MeOH}\right.$ in $\left.\mathrm{CHCl}_{3}\right)$ gave $115(10.2 \mathrm{mg}, \sim 79 \%)$ that was contaminated with an impurity, as the fastest moving fraction.

${ }^{1} \mathrm{H}$ NMR (300 MHz, $\left.\mathrm{CDCl}_{3}\right) \delta 7.75$ (d, 2H, $\left.J=6.9 \mathrm{~Hz}, \mathrm{Ph}\right), 7.68$ (d, 1H, $\left.J=8.7 \mathrm{~Hz}, \mathrm{H} 6\right)$, $6.98(\mathrm{~d}, 2 \mathrm{H}, J=6.9 \mathrm{~Hz}, \mathrm{Ph}), 6.40$ (d, 1H, $\left.J=20.4 \mathrm{~Hz}, \mathrm{H1} 1^{\prime}\right), 5.85$ (d, 1H, $\left.J=8.7 \mathrm{~Hz}, \mathrm{H} 5\right)$, $5.04\left(\mathrm{~m}, 1 \mathrm{H}, \mathrm{H} 3^{\prime}\right), 3.98-4.11\left(\mathrm{~m}, 3 \mathrm{H}, \mathrm{H} 4^{\prime}\right.$ and $\left.\mathrm{H}^{\prime}, 5{ }^{\prime}\right), 3.89\left(\mathrm{~s}, 3 \mathrm{H}, \mathrm{OCH}_{3}\right) ; 3.15(\mathrm{~s}, 3 \mathrm{H}$, $\left.\mathrm{NCH}_{3}\right) ;{ }^{19} \mathrm{~F}$ NMR $\left(282 \mathrm{MHz}, \mathrm{CDCl}_{3}\right) \delta-160.41(\mathrm{t}, J=19.5 \mathrm{~Hz}, \mathrm{~F} 2$ ') and $-160.75(\mathrm{t}, J=$ $19.8 \mathrm{~Hz}, \mathrm{~F} 2$ ') (ratio 1:0.16); MS (ESI) $m / z 431.1[\mathrm{M}+\mathrm{H}]^{+}, 453.1[\mathrm{M}+\mathrm{Na}]^{+}$.

General Procedure for cyclic voltammetry. Electrochemical measurements were performed using an EG \& G-Princeton Applied Research 263A all-in-one potentiostat, using a standard three-electrode setup with a glassy carbon electrode (working electrode, diameter $=3 \mathrm{~mm})$, platinum wire auxiliary electrode and a non-aqueous $\mathrm{Ag} / \mathrm{Ag}^{+}(0.01 \mathrm{M}$ $\left.\mathrm{AgNO}_{3}+0.1 \mathrm{M} n-\mathrm{Bu}_{4} \mathrm{NClO}_{4}\right)$ system in acetonitrile as the reference electrode. All solutions under the study were $0.1 \mathrm{M}$ in the supporting electrolyte $n-\mathrm{Bu}_{4} \mathrm{NPF}_{6}$ (Fluka puriss electrochemical grade) with the voltage scan rate of $0.2 \mathrm{~V} \mathrm{~s}-1$. Anhydrous DMF was obtained from Fisher Scientific. Solutions $(2.5 \mathrm{~mL})$ were thoroughly bubbled with 
dry argon for 15 minutes to remove oxygen before any experiment and kept under positive pressure of argon. Under these experimental conditions the ferrocene/ferricinium couple, used as internal reference for potential measurements, was located at $\mathrm{E}_{1 / 2}=+0.05$ $\mathrm{V}$ in DMF.

4-Benzylamino-7-(B-D-ribofuranosyl)pyrrolo[2,3-d]pyrimidine (122a). $\operatorname{BnBr}(345 \mu \mathrm{L}$, $496 \mathrm{mg}, 2.9 \mathrm{mmol}$ ) was added to a stirred solution of tubercidin (19a; $266 \mathrm{mg}, 1 \mathrm{mmol})$ in dried DMF (5 mL). After stirring for 48 hours at $40{ }^{\circ} \mathrm{C}$, TLC showed almost complete conversion to a more polar product. Volatiles were evaporated to $\sim 1 \mathrm{~mL}\left(<40{ }^{\circ} \mathrm{C}\right.$, vacuum pump) and the resulting syrup was added dropwise to dried acetone $(30 \mathrm{~mL})$ with vigorous stirring. $\mathrm{Et}_{2} \mathrm{O}(60 \mathrm{~mL})$ was added to the suspension, which was chilled for 20 min at $0{ }^{\circ} \mathrm{C}$ and vacuum filtered. The hygroscopic precipitate was quickly dissolved in $\mathrm{MeOH}(10 \mathrm{~mL})$ and $\mathrm{Me}_{2} \mathrm{NH} / \mathrm{THF}(2 \mathrm{M}, 8 \mathrm{~mL})$ was added. The resulting solution was stirred at reflux ( $65{ }^{\circ} \mathrm{C}$, oil bath) for $20 \mathrm{~h}$. TLC showed $\sim 80 \%$ conversion to less polar spot, and volatiles were evaporated and coevaporated with $\mathrm{MeOH}(2 \times)$. The residue was dissolved in warm $\mathrm{MeOH}(10 \mathrm{~mL}), \mathrm{H}_{2} \mathrm{O}(60 \mathrm{~mL})$ was added, and the solution was extracted with EtOAc $(5 \times 20 \mathrm{~mL})$. The combined organic phase was dried $\left(\mathrm{Na}_{2} \mathrm{SO}_{4}\right)$, concentrated in vacuo, coevaporated $(2 \times \mathrm{EtOH})$ and flash chromatographed (EtOAc) to give 122a (238 mg, 67\%) as a colorless oil: $\mathrm{UV}(\mathrm{MeOH}) \lambda_{\max } 276 \mathrm{~nm}, \lambda_{\min } 244 \mathrm{~nm} ;{ }^{1} \mathrm{H}$ NMR (DMSO- $\left.d_{6}\right) \delta 8.09-8.13(\mathrm{~m}, 2 \mathrm{H}, \mathrm{NH}, \mathrm{H} 2), 7.38(\mathrm{~d}, J=3.7 \mathrm{~Hz}, 1 \mathrm{H}, \mathrm{H} 6), 7.29-7.35$ (m, 4H, Ph), 7.22-7.25 (m, 1H, Ph), $6.67(\mathrm{~d}, J=3.4 \mathrm{~Hz}, 1 \mathrm{H}, \mathrm{H} 5), 6.01$ (d, $J=5.9 \mathrm{~Hz}, 1 \mathrm{H}$, H1'), 5.27-5.32 (m, 2H, 2'-OH, 5'-OH), 5.12 (d, $\left.J=4.3 \mathrm{~Hz}, 1 \mathrm{H}, 3^{\prime}-\mathrm{OH}\right), 4.70-4.78$ (m, 2H, $\mathrm{CH}_{2}$ ), 4.44 (q, $J=5.7 \mathrm{~Hz}, 1 \mathrm{H}, \mathrm{H} 2$ '), 4.09 (“q”, $J=4.1 \mathrm{~Hz}, 1 \mathrm{H}, \mathrm{H} 3$ '), 3.90 (q, $J=3.4$ $\left.\mathrm{Hz}, 1 \mathrm{H}, \mathrm{H} 4^{\prime}\right), 3.60-3.65$ (m, 1H, H5'), 3.50-3.56 (m, 1H, H5"); ${ }^{13} \mathrm{C}$ NMR (DMSO- $d_{6}$ ) $\delta$ 
156.1, 151.4, 149.5, 140.1, $128.2(\mathrm{Ph}), 127.1(\mathrm{Ph}), 126.6,122.3$ (C6), 103.4, $99.2(\mathrm{C} 5)$, 87.6 (C1'), 85.1 (C4'), 73.7 (C2'), 70.7 (C3'), $61.8\left(\mathrm{C}^{\prime}\right), 43.1\left(\mathrm{CH}_{2}\right)$; MS (ESI) $m / z 357$ (100\%, $\left.\mathrm{MH}^{+}\right)$, HRMS (ESI) $m / z 357.1581\left(\mathrm{MH}^{+}\right)$, calcd for $\mathrm{C}_{18} \mathrm{H}_{29} \mathrm{~N}_{4} \mathrm{O}_{4} 357.1563$.

4-(4-Nitrobenzylamino)-7-( $\beta$-D-ribofuranosyl)pyrrolo[2,3-d]pyrimidine

(122b).

Method A. Tubercidin (19a; $266 \mathrm{mg}, 1.0 \mathrm{mmol}$ ) was treated with 4-nitrobenzyl bromide (648 $\mathrm{mg}, 3.0 \mathrm{mmol}$ ) at $80{ }^{\circ} \mathrm{C}$ for $24 \mathrm{~h}$ as described above for 122a followed by addition of $\mathrm{MeOH}(15 \mathrm{~mL})$ and $\mathrm{Me}_{2} \mathrm{NH} / \mathrm{THF}(2 \mathrm{M}, 8 \mathrm{~mL})$. The reaction mixture was stirred at reflux for $20 \mathrm{~h}$; TLC showed $\sim 85 \%$ conversion to a less polar product $\mathbf{1 2 2 b}$ (244 $\mathrm{mg}$, $56 \%$, yellow oil): UV (MeOH) $\lambda_{\max } 278 \mathrm{~nm}, \lambda_{\min } 240 \mathrm{~nm} ;{ }^{1} \mathrm{H}$ NMR (DMSO- $\left.d_{6}\right) \delta 8.30(\mathrm{t}$, $J=6.1 \mathrm{~Hz}, 1 \mathrm{H}, \mathrm{NH}$ ), 8.19 (“d”, $J=8.8 \mathrm{~Hz}, 2 \mathrm{H}, \mathrm{Ph}), 8.12$ (s, 1H, H2), 7.58 (d, $J=8.8 \mathrm{~Hz}$, 2H, Ph), 7.43 (d, $J=3.7 \mathrm{~Hz}, 1 \mathrm{H}, \mathrm{H} 6), 6.69$ (d, $J=3.5 \mathrm{~Hz}, 1 \mathrm{H}, \mathrm{H} 5), 6.04$ (d, $J=6.3 \mathrm{~Hz}$, 1H, H1'), 5.28-5.30 (m, 2H, $2 \times \mathrm{OH}), 5.14(\mathrm{~s}, 1 \mathrm{H}, \mathrm{OH}), 4.80-4.91\left(\mathrm{~m}, 2 \mathrm{H}, \mathrm{CH}_{2}\right), 4.45$ (“'d", $\left.J=4.4 \mathrm{~Hz}, 1 \mathrm{H}, \mathrm{H} 2^{\prime}\right), 4.11-4.13$ (m, 1H, H3'), 3.92 (q, $J=3.5 \mathrm{~Hz}, 1 \mathrm{H}, \mathrm{H} 4$ '), 3.64 $\left(\mathrm{dt}, J=3.9,11.8 \mathrm{~Hz}, 1 \mathrm{H}, \mathrm{H} 5^{\prime}\right), 3.52-3.57(\mathrm{~m}, 1 \mathrm{H}, \mathrm{H} 5 ") ;{ }^{13} \mathrm{C}$ NMR $\left(\mathrm{DMSO}^{-} d_{6}-\mathrm{D}_{2} \mathrm{O}\right) \delta$ 155.8, 151.0, 148.8, 147.9, 146.3, $127.9(\mathrm{Ph}), 123.4(\mathrm{Ph}), 122.8$ (C6), 103.6, 99.3 (C5), 87.5 (C1'), 84.9 (C4'), 73.5 (C2'), $70.4\left(\mathrm{C}^{\prime}\right), 61.6\left(\mathrm{C}^{\prime}\right), 42.7\left(\mathrm{CH}_{2}\right)$; $\mathrm{MS}$ (ESI): $m / z 402$ $\left(100 \%, \mathrm{MH}^{+}\right)$. Anal. Calcd for $\mathrm{C}_{18} \mathrm{H}_{19} \mathrm{~N}_{5} \mathrm{O}_{6} \cdot 1.25 \mathrm{H}_{2} \mathrm{O}$ (423.89): $\mathrm{C}, 51.00 ; \mathrm{H}, 5.11 ; \mathrm{N}$, 16.52. Found: C, 51.05; H, 5.06; N, 16.03 .

Method B. Step a. $\mathrm{Ac}_{2} \mathrm{O}(377 \mu \mathrm{L}, 408 \mathrm{mg}, 4 \mathrm{mmol})$ was added to a stirred suspension of 19a $(266 \mathrm{mg}, 1 \mathrm{mmol})$ in dried pyridine $(5 \mathrm{~mL})$ at $0{ }^{\circ} \mathrm{C}$ (ice bath) and stirring was continued at $0{ }^{\circ} \mathrm{C}$ for $12 \mathrm{~h}$ and then at ambient temperature for $9 \mathrm{~h}$ (total reaction time: 21 h). $\mathrm{MeOH}$ was added, the reaction mixture was stirred at ambient temperature for $30 \mathrm{~min}$, and volatiles were evaporated (vacuum pump, $<25^{\circ} \mathrm{C}$ ). $\mathrm{MeOH}$ was added and 
evaporated, and the resulting gum was partitioned between $\mathrm{CHCl}_{3}(50 \mathrm{~mL})$ and $2 \%$ $\mathrm{AcOH} / \mathrm{H}_{2} \mathrm{O}(50 \mathrm{~mL})$. The aqueous layer was extracted with $\mathrm{CHCl}_{3}$, and the combined organic phase was washed with $\mathrm{NaHCO}_{3} / \mathrm{H}_{2} \mathrm{O}$, brine, and dried $\left(\mathrm{MgSO}_{4}\right)$. Volatiles were evaporated in vacuo and the residue was column chromatographed (EtOAc) to give $2^{\prime}, 3^{\prime}, 5^{\prime}$-tri- $O$-acetyltubercidin $(\mathbf{1 2 3} ; 337 \mathrm{mg}, 86 \%)$ as a colorless foam with data as reported. 222

Step $\boldsymbol{b} . \mathrm{NaNO}_{2}(66 \mathrm{mg}, 0.95 \mathrm{mmol})$ was added to a solution of $\mathbf{1 2 3}(150 \mathrm{mg}, 0.38 \mathrm{mmol})$ in freshly prepared $\sim 55 \% \mathrm{HF}$-pyridine ${ }^{192}(1.9 \mathrm{~mL})$ at $-10{ }^{\circ} \mathrm{C}$ in a sealed polypropylene vessel. The mixture was stirred at $-10{ }^{\circ} \mathrm{C}$ for $15 \mathrm{~min}$, and TLC showed almost complete conversion to a less polar spot. Ice $/ \mathrm{H}_{2} \mathrm{O}$ was added and the mixture was extracted with $\mathrm{CH}_{2} \mathrm{Cl}_{2}$. The combined organic phase was washed with $\mathrm{NaHCO}_{3} / \mathrm{H}_{2} \mathrm{O}$, brine, and dried $\left(\mathrm{Na}_{2} \mathrm{SO}_{4}\right)$. Volatiles were removed in vacuo, and the resulting brown oil was column chromatographed $(30 \%$ EtOAc in hexanes) to give 7-(2,3,5-tri- $O$-acetyl- $\beta$-Dribofuranosyl)-4-fluoropyrrolo[2,3- $d$ ]pyrimidine $(\mathbf{1 2 4} ; 124 \mathrm{mg}, 82 \%)$ as a colorless oil: $\mathrm{UV}(\mathrm{MeOH}) \lambda_{\max } 258 \mathrm{~nm}, \lambda_{\min } 233 \mathrm{~nm} ;{ }^{1} \mathrm{H} \mathrm{NMR}\left(\mathrm{CDCl}_{3}\right) \delta 8.53\left(\mathrm{~d},{ }^{4} J_{\mathrm{H}-\mathrm{F}}=0.5 \mathrm{~Hz}, 1 \mathrm{H}\right.$, H2), 7.37 (d, $J=3.8 \mathrm{~Hz}, 1 \mathrm{H}, \mathrm{H} 8), 6.66$ (d, $J=3.8 \mathrm{~Hz}, 1 \mathrm{H}, \mathrm{H} 7), 6.45$ (d, $J=6.0 \mathrm{~Hz}, 1 \mathrm{H}$, H1'), $5.74\left(\mathrm{t}, J=5.8 \mathrm{~Hz}, 1 \mathrm{H}, \mathrm{H} 2^{\prime}\right), 5.55$ (dd or $\left.\mathrm{m}, J=4.1,5.6 \mathrm{~Hz}, 1 \mathrm{H}, \mathrm{H} 3^{\prime}\right), 4.32-4.42$ (m, 3H, H4', H5', H5"), 2.12 (s, 3H, CH $\mathrm{CH}_{3}, 2.13$ (s, 3H, $\left.\mathrm{CH}_{3}\right), 2.02$ (s, 3H, $\left.\mathrm{CH}_{3}\right) ;{ }^{19} \mathrm{~F}$ NMR $\left(\mathrm{CDCl}_{3}\right) \delta-64.81 \mathrm{ppm}(\mathrm{s}) ;{ }^{13} \mathrm{C} \mathrm{NMR}\left(\mathrm{CDCl}_{3}\right) \delta$ 170.2, 169.6, $169.4(3 \times \mathrm{C}=\mathrm{O}), 162.3(\mathrm{~d}$, $\left.{ }^{1} J_{\mathrm{C}-\mathrm{F}}=253.8 \mathrm{~Hz}, \mathrm{C} 4\right), 155.1\left(\mathrm{~d},{ }^{3} J_{\mathrm{C}-\mathrm{F}}=11.9 \mathrm{~Hz}, \mathrm{C} 7 \mathrm{a}\right), 151.1\left(\mathrm{~d},{ }^{3} J_{\mathrm{C}-\mathrm{F}}=14.5 \mathrm{~Hz}, \mathrm{C} 2\right)$, $125.7\left(\mathrm{~d},{ }^{4} J_{\mathrm{C}-\mathrm{F}}=2.6 \mathrm{~Hz}, \mathrm{C} 6\right), 105.4\left(\mathrm{~d},{ }^{2} J_{\mathrm{C}-\mathrm{F}}=33.4 \mathrm{~Hz}, \mathrm{C} 4 \mathrm{a}\right), 99.6\left(\mathrm{~d},{ }^{3} J_{\mathrm{C}-\mathrm{F}}=4.9 \mathrm{~Hz}, \mathrm{C} 5\right)$, 86.1 (C1'), 79.9 (C4'), 73.1 (C2'), 70.1 (C3'), 63.3 (C5'), 20.7, 20.5, 20.3 (3 x s, 3 x CH 3 ); MS (ESI): $m / z 396\left(100 \%, \mathrm{MH}^{+}\right)$. 
Step c. Freshly distilled $\mathrm{Et}_{3} \mathrm{~N}(113 \mu \mathrm{L}, 82 \mathrm{mg}, 0.81 \mathrm{mmol})$ was added to a stirred suspension of 124 (93 mg, $0.23 \mathrm{mmol})$ and 4-nitrobenzylamine hydrochloride (67 mg, $0.35 \mathrm{mmol})$ in $\mathrm{MeOH}(3 \mathrm{~mL})$ and stirring was continued for $5 \mathrm{~h}$ at ambient temperature. Volatiles were evaporated in vacuo and the residue was column chromatographed (50\% EtOAc in hexanes) to give 2',3',5'-tri- $O$-acetyl-4- $N$-(4-nitrobenzyl)tubercidin (125; 58 $\mathrm{mg}, 47 \%)$ as a colorless oil: $\mathrm{UV}(\mathrm{MeOH}) \lambda_{\max } 277 \mathrm{~nm}, \lambda_{\min } 238 \mathrm{~nm} .{ }^{1} \mathrm{H} \mathrm{NMR}\left(\mathrm{CDCl}_{3}\right) \delta$ $8.36(\mathrm{~s}, 1 \mathrm{H}, \mathrm{H} 2), 8.17$ (d, $J=8.7 \mathrm{~Hz}, 2 \mathrm{H}, \mathrm{Ph}), 7.51(\mathrm{~d}, J=8.7 \mathrm{~Hz}, 2 \mathrm{H}, \mathrm{Ph}), 7.12(\mathrm{~d}, J=$ $3.768 \mathrm{~Hz}, 1 \mathrm{H}, \mathrm{H6}$ ), 6.42-6.46 (dd, 3.8, 6.0 Hz, 2H, H1', H5), 5.73 (t, J=5.8 Hz, 1H, H2'), 5.54-5.59 (m, 2H, H3', NH), 4.95 (d, $\left.J=6.1 \mathrm{~Hz}, 2 \mathrm{H}, \mathrm{CH}_{2}\right), 4.31-4.40$ (m, 3H, H4', H5', H5"), $2.14\left(\mathrm{~s}, 6 \mathrm{H}, 2 \times \mathrm{CH}_{3}\right), 2.04\left(\mathrm{~s}, 3 \mathrm{H}, \mathrm{CH}_{3}\right) ;{ }^{13} \mathrm{C} \mathrm{NMR}\left(\mathrm{CDCl}_{3}\right) \delta 170.4,169.7,169.5$ (3 x C=O), $156.0(\mathrm{C} 4), 152.3(\mathrm{C} 2), 150.8(\mathrm{C} 7 \mathrm{a}), 147.3(\mathrm{Ph}), 146.7(\mathrm{Ph}), 128.0(\mathrm{Ph}), 123.9$ (Ph), 121.5 (C6), 103.8 (C4a), 99.4 (C5), 85.4 (C1'), 79.5 (C4'), 73.1 (C2'), 70.8 (C3'), $63.5\left(\mathrm{C}^{\prime}\right), 44.2\left(\mathrm{CH}_{2}\right), 20.8,20.6,20.4\left(3 \times \mathrm{s}, 3 \times \mathrm{CH}_{3}\right)$. MS (ESI): $\mathrm{m} / z 528(100 \%$, $\left.\mathrm{MH}^{+}\right)$.

Step d. $\mathrm{NH}_{3} / \mathrm{MeOH}(5 \mathrm{~mL})$ was added to a stirred solution of $\mathbf{1 2 5}(54 \mathrm{mg}, 0.1 \mathrm{mmol})$ in $\mathrm{MeOH}(1 \mathrm{~mL})$ and stirring was continued at ambient temperature for $20 \mathrm{~h}$. Volatiles were evaporated and the residue was column chromatographed with a $2 \rightarrow 4 \%$ gradient of the upper phase of EtOAc/ $i-\mathrm{PrOH} / \mathrm{H}_{2} \mathrm{O}(4: 1: 2)$ in EtOAc to give 122b $(35 \mathrm{mg}, 85 \%)$ as a yellow oil.

\section{5-Carboxamido-4-(4-nitrobenzylamino)-7-( $\beta$-D-ribofuranosyl)pyrrolo[2,3-}

d]pyrimidine (122c). Sangivamycin $(\mathbf{1 9 b} ; 155 \mathrm{mg}, 0.5 \mathrm{mmol})$ was treated with 4nitrobenzyl bromide (162 $\mathrm{mg}, 1.5 \mathrm{mmol}$ ) for $26 \mathrm{~h}$ at $40{ }^{\circ} \mathrm{C}$ as described for 19a $\rightarrow \mathbf{1 2 2 a}$ and the alkylated intermediate was then stirred with $\mathrm{Me}_{2} \mathrm{NH} / \mathrm{THF}(2 \mathrm{M}, 6 \mathrm{~mL})$ and 
$\mathrm{MeOH}(12 \mathrm{~mL})$ for $45 \mathrm{~h}$ at ambient temperature. $\mathrm{Me}_{2} \mathrm{NH} / \mathrm{THF}(2 \mathrm{M}, 2 \mathrm{~mL})$ was added and the mixture was stirred at reflux for $32 \mathrm{~h}$ (total reaction time: $77 \mathrm{~h}$ ). TLC showed $\sim 80 \%$ conversion to the less polar $\mathbf{1 2 2}$, which was obtained as off-white crystals (101 mg, 45\%) after recrystallization from EtOH: mp 154-158 ${ }^{\circ} \mathrm{C}$ (dec.); UV (MeOH) $286 \mathrm{~nm}$ (ع 23100$), \lambda_{\min } 229 \mathrm{~nm}\left(\varepsilon\right.$ 8700); ${ }^{1} \mathrm{H}$ NMR (DMSO- $\left.d_{6}\right) \delta 10.29(\mathrm{t}, J=6.0 \mathrm{~Hz}, 1 \mathrm{H}, \mathrm{NH})$, 8.17-8.21 (m, 4H, Ph, H2, H6), 8.11 and $7.47\left(2 \times \mathrm{s}, 2 \times 1 \mathrm{H}, \mathrm{CONH}_{2}\right), 7.59(\mathrm{brd}, J=8.8$ Hz, 2H, Ph), 6.06 (d, $J=6.0 \mathrm{~Hz}, 1 \mathrm{H}, \mathrm{H1}$ '), 5.43 (d, $\left.J=6.3 \mathrm{~Hz}, 1 \mathrm{H}, 2^{\prime}-\mathrm{OH}\right), 5.20$ (d, $J=$ $5.0 \mathrm{~Hz}, 1 \mathrm{H}, 3$ '-OH), 5.09 (t, $J=5.8 \mathrm{~Hz}, 1 \mathrm{H}, 5$ '-OH), 4.90 (“d”, $J=6.2 \mathrm{~Hz}, 2 \mathrm{H}, \mathrm{CH}_{2}$ ), 4.37 (q, $J=5.8 \mathrm{~Hz}, 1 \mathrm{H}, \mathrm{H} 2$ ') 4.10 (“'q”, $J=4.5 \mathrm{~Hz}, 1 \mathrm{H}, \mathrm{H} 3$ '), 3.93 (q, $J=4.0 \mathrm{~Hz}, 1 \mathrm{H}, \mathrm{H} 4$ '), 3.61-3.67 (m, 1H, H5'), 3.53-3.58 (m, 1H, H5"); ${ }^{13} \mathrm{C}$ NMR (DMSO- $\left.d_{6}\right) \delta 166.5,156.5$, 152.6, 150.4, 148.0, 146.4, $128.0(\mathrm{Ph}), 125.7,123.6,110.9,101.7,87.2\left(\mathrm{Cl}^{\prime}\right), 85.3\left(\mathrm{C} 4^{\prime}\right)$, 73.9 (C2'), 70.5 (C3'), 61.9 (C5'), $42.9\left(\mathrm{CH}_{2}\right)$; MS (ESI) $\mathrm{m} / z 445\left(100 \%, \mathrm{MH}^{+}\right)$. Anal. Calcd for $\mathrm{C}_{19} \mathrm{H}_{20} \mathrm{~N}_{6} \mathrm{O}_{7} \bullet 1.5 \mathrm{H}_{2} \mathrm{O}$ (471.42): C, 48.41; H, 4.92; N, 17.83. Found: C, 48.59; $\mathrm{H}, 4.66 ; \mathrm{N}, 17.65$.

\section{5-Cyano-4-(4-nitrobenzylamino)-7-( $\beta$-D-ribofuranosyl)pyrrolo[2,3-d]pyrimidine}

(122d). Toyocamycin $(19 \mathrm{c} ; 146 \mathrm{mg}, 0.5 \mathrm{mmol})$ was heated with 4-nitrobenzyl bromide (364 mg, $1.5 \mathrm{mmol}$ ) in dried DMF $\left(3 \mathrm{~mL}\right.$ ) at $40{ }^{\circ} \mathrm{C}$ for $63 \mathrm{~h}$ (TLC showed $\sim 85 \%$ conversion to a less polar product). Volatiles were evaporated to $\sim 1 \mathrm{~mL}\left(<40{ }^{\circ} \mathrm{C}\right.$, vacuum pump) and this material was added dropwise to $20 \mathrm{~mL}$ of vigorously stirred dried acetone. $\mathrm{Et}_{2} \mathrm{O}(40 \mathrm{~mL})$ was added to the stirred suspension, which was chilled at $0{ }^{\circ} \mathrm{C}$ for 20 minutes and the precipitate was collected by vacuum filtration. Recrystallization from MeOH gave 122d (99 mg, 46\%) as colorless crystals: mp 214-216 ${ }^{\circ} \mathrm{C}$; $\mathrm{UV}(\mathrm{MeOH}) \lambda_{\max }$ 274, $236 \mathrm{~nm}\left(\varepsilon 22\right.$ 100, 18 900), $\lambda_{\min }$ 250, $228 \mathrm{~nm}\left(\varepsilon 12800,18\right.$ 000); ${ }^{1} \mathrm{H}$ NMR (DMSO- 
$\left.d_{6}\right) \delta 8.35(\mathrm{~s}, 1 \mathrm{H}, \mathrm{H} 2), 8.19-8.23(\mathrm{~m}, 3 \mathrm{H}, \mathrm{H} 6, \mathrm{Ph}), 7.59$ (d, $\left.J=8.6 \mathrm{~Hz}, 2 \mathrm{H}, \mathrm{Ph}\right), 6.87(\mathrm{~s}$, $1 \mathrm{H}, \mathrm{NH}), 5.93$ (d, $J=5.6 \mathrm{~Hz}, 1 \mathrm{H}, \mathrm{H1}$ '), 5.47 (d, $\left.J=6.0 \mathrm{~Hz}, 1 \mathrm{H}, 2^{\prime}-\mathrm{OH}\right), 5.35$ ("s", 2H, $\left.\mathrm{CH}_{2}\right), 5.21\left(\mathrm{~d}, J=5.0 \mathrm{~Hz}, 1 \mathrm{H}, 3^{\prime}-\mathrm{OH}\right), 5.09$ (t, $\left.J=5.4 \mathrm{~Hz}, 1 \mathrm{H}, 5 '-\mathrm{OH}\right), 4.31$ (q, $J=5.5$ Hz, 1H, H2'), 4.08 (q, $\left.J=4.6 \mathrm{~Hz}, 1 \mathrm{H}, \mathrm{H} 3^{\prime}\right), 3.92$ (q, $\left.J=3.7 \mathrm{~Hz}, 1 \mathrm{H}, \mathrm{H} 4^{\prime}\right), 3.62-3.68$ (m, 1H, H5'), 3.53-3.58 (m, 1H, H5"); ${ }^{13} \mathrm{C}$ NMR (DMSO- $\left.d_{6}-\mathrm{D}_{2} \mathrm{O}\right) \delta 152.6,149.4,146.7$, 144.9, 142.7, 129.4, $128.5(\mathrm{Ph}), 123.5(\mathrm{Ph}), 115.2,105.0,87.7\left(\mathrm{Cl}^{\prime}\right), 85.8$ (C4'), 85.5, 74.6 (C2'), $70.1\left(\mathrm{C}^{\prime}\right), 61.1\left(\mathrm{C}^{\prime}\right), 48.8\left(\mathrm{CH}_{2}\right)$; MS (ESI): $\mathrm{m} / z 427\left(100 \%, \mathrm{MH}^{+}\right)$. Anal. Calcd for $\mathrm{C}_{19} \mathrm{H}_{18} \mathrm{~N}_{6} \mathrm{O}_{6} \bullet 0.5 \mathrm{H}_{2} \mathrm{O}$ (435.39): C, 52.41; H, 4.40; N, 19.30. Found: C, 52.17; H, 4.29; N, 19.30 .

8-azidotoyocamycin (129). $\mathrm{NaN}_{3}(158.1 \mathrm{mg}, 2.43 \mathrm{mmol})$ was added to a stirred solution of 55 (300 mg, $0.810 \mathrm{mmol})$ in anhydrous DMF $(10 \mathrm{~mL})$ in a flame dried flask and the resulting colorless solution was stirred at room temperature in the dark for $16 \mathrm{~h}$, by which time the solution turned a brown-red color and UV showed $6 \mathrm{~nm}$ bathochromic shift in the $\lambda_{\max }$, indicating the conversion to product. Volatiles were removed from the clear, brown-red solution using high vacuum rotary evaporator on a hot water bath $\left(<80{ }^{\circ} \mathrm{C}\right)$ while in a dark room. The resulting brown gummy oil was purified using column chromatography in the dark (5\%, MeOH/EtOAc) to give $\mathbf{1 2 9}$ as an off white solid (123.2 mg, 46\%): HRMS (ESI): $m / z[\mathrm{M}+\mathrm{Na}]^{+}$calcd for $\mathrm{C}_{12} \mathrm{H}_{12} \mathrm{~N}_{8} \mathrm{NaO}_{4}{ }^{+}:$355.0874; found 355.0952 .

Click product (132). Cyclooctyne $130(9.04 \mathrm{mg}, 0.060 \mathrm{mmol})$ was added to a stirred solution of $129(20 \mathrm{mg}, 0.060 \mathrm{mmol})$ in $\mathrm{ACN}$ and $\mathrm{H}_{2} \mathrm{O}$ (3:1) in a flask and the resulting clear, colorless solution was stirred at room temperature for $4 \mathrm{~h}$, by which time TLC showed $>80 \%$ conversion to product to a more polar product. Volatiles were removed 
using high vacuum rotary evaporator and a hot water bath $\left(<80{ }^{\circ} \mathrm{C}\right)$. The resulting yellow oil was purified using column chromatography $(10 \%$, EtOAc/MeOH) giving 132 as an off white solid (17 mg, 59\%). This solid was then re-purified using RP-HPLC (20\% CAN in $\mathrm{H}_{2} \mathrm{O}$ ) to give $\mathbf{1 3 2}$ as an off white gummy solid (9.6 mg, 33\%). $\mathrm{R}_{\mathrm{f}}\left(\right.$ EtOAc: $i \mathrm{PrOH}: \mathrm{H}_{2} \mathrm{O}$, 4:1:2) 0.49; HRMS (ESI): $m / z[M+H]^{+}$calcd for $\mathrm{C}_{22} \mathrm{H}_{27} \mathrm{~N}_{8} \mathrm{O}_{5}{ }^{+}:$483.2099; found 483.2087.

Click product (133). Cyclooctyne $131(16.6 \mathrm{mg}, 0.060 \mathrm{mmol})$ was added to a stirred solution of 129 (20 mg, $0.060 \mathrm{mmol})$ in $\mathrm{ACN}$ and $\mathrm{H}_{2} \mathrm{O}$ (3:1) in a flask and the resulting clear, pale red solution was stirred at room temperature for $4 \mathrm{~h}$, by which time TLC showed $>80 \%$ conversion to product to a more polar product almost on the baseline. Volatiles were removed using high vacuum rotary evaporator and a hot water bath $(<80$ $\left.{ }^{\circ} \mathrm{C}\right)$. The resulting pale red oil was purified using column chromatography $(17.5 \%$, EtOAc/MeOH) giving $\mathbf{1 3 3}$ as an off white gummy solid (17.1 $\mathrm{mg}, 47 \%) . \mathrm{R}_{\mathrm{f}}$ (EtOAc: $i \mathrm{PrOH}: \mathrm{H}_{2} \mathrm{O}, 4: 1: 2$ ) 0.13; HRMS (ESI): $\mathrm{m} / z[\mathrm{M}+\mathrm{H}]^{+}$calcd for $\mathrm{C}_{30} \mathrm{H}_{29} \mathrm{~N}_{10} \mathrm{O}_{5}^{+}$: 609.2317; found 609.2352.

2',3',5'-tri-O-acetyltoyocamycin. (138). $\mathrm{Ac}_{2} \mathrm{O}(380 \mu \mathrm{L}, 4 \mathrm{mmol})$ was added to a stirred solution of $19 \mathrm{c}(292 \mathrm{mg}, 1 \mathrm{mmol})$ in anhydrous pyridine $(5 \mathrm{~mL})$ at $0{ }^{\circ} \mathrm{C}$ (ice bath) and stirring was continued at $0{ }^{\circ} \mathrm{C}$ for $1 \mathrm{~h}$ and then at ambient temperature for $3 \mathrm{~h}$ (total reaction time: $4 \mathrm{~h}$ ). $\mathrm{MeOH}$ was added, the reaction mixture was stirred at ambient temperature for $30 \mathrm{~min}$, and volatiles were evaporated (vacuum pump, $<25{ }^{\circ} \mathrm{C}$ ). $\mathrm{MeOH}$ was added and evaporated, and the resulting gum was partitioned between $\mathrm{CHCl}_{3}(25$ $\mathrm{mL})$ and $2 \% \mathrm{AcOH} / \mathrm{H}_{2} \mathrm{O}(25 \mathrm{~mL})$. The aqueous layer was extracted with $\mathrm{CHCl}_{3}$, and the combined organic phase was washed with $\mathrm{NaHCO}_{3} / \mathrm{H}_{2} \mathrm{O}$, brine, and dried $\left(\mathrm{MgSO}_{4}\right)$. 
Volatiles were evaporated in vacuo and the residue was column chromatographed (70\% EtOAc in hexanes) to give 2',3',5'-tri- $O$-acetyltoyocamycin $(\mathbf{1 3 8} ; 405 \mathrm{mg}, 97 \%)$ as a colorless foam: ${ }^{1} \mathrm{H}$ NMR $\left(\mathrm{CDCl}_{3}\right) \delta 8.24(\mathrm{~s}, 1 \mathrm{H}, \mathrm{H} 2), 7.72(\mathrm{~s}, 1 \mathrm{H}, \mathrm{H} 8), 6.37\left(\mathrm{~s}, 2 \mathrm{H}, \mathrm{NH}_{2}\right)$, $6.30\left(\mathrm{~d}, J=5.4 \mathrm{~Hz}, 1 \mathrm{H}, \mathrm{H1}\right.$ '), $5.66(\mathrm{~d}, J=5.5 \mathrm{~Hz}, \mathrm{H} 2 '), 5.48$ (d, $\left.J=5.1 \mathrm{~Hz}, \mathrm{H} 3{ }^{\prime}\right), 4.38$ (“"q", $J=3.9 \mathrm{~Hz}, \mathrm{H} 4$ '), 4.33-4.32 (“"m", 2H, H5', H5"), 2.08 (s, 3H, $\mathrm{CH}_{3}$ ), 2.06 (s, 3H, $\left.\mathrm{CH}_{3}\right), 2.00\left(\mathrm{~s}, 3 \mathrm{H}, \mathrm{CH}_{3}\right)$.

8-Bromo-2',3',5'-tri-O-acetyltoyocamycin (139). DBH (157 mg, $0.55 \mathrm{mmol})$ was added to a stirred solution of $\mathbf{1 3 8}(209 \mathrm{mg}, 0.5 \mathrm{mmol})$ in $\mathrm{CH}_{2} \mathrm{Cl}_{2}(4 \mathrm{~mL})$ and the resulting brown solution was stirred at ambient temperature for 18 hours. The reaction mixture was partitioned between $\mathrm{CH}_{2} \mathrm{Cl}_{2}(16 \mathrm{~mL})$ and $\mathrm{NaHCO}_{3} / \mathrm{H}_{2} \mathrm{O}(25 \mathrm{~mL})$. The aqueous layer was extracted with $\mathrm{CH}_{2} \mathrm{Cl}_{2}$, and the combined organic phase was washed with brine and dried $\left(\mathrm{MgSO}_{4}\right)$. Volatiles were evaporated in vacuo and the residue was column chromatographed (50\% EtOAc in hexanes) to give 139 (195 $\mathrm{mg}, 79 \%)$ as a brown oil with data as reported. ${ }^{223}$

2',3',5'-tri-O-(tert-butyldimethylsilyl)toyocamycin (141). Imidazole (1.02 g, 15 mmol) and TBDMSCl (1.09 g, $7.2 \mathrm{mmol})$ was added to a stirred solution of 19c $(583 \mathrm{mg}, 2$ mmol) in anhydrous DMF (6 $\mathrm{ml})$ and the resulting suspension was stirred at ambient temperature for $24 \mathrm{~h}$ and then at $35{ }^{\circ} \mathrm{C}$ for $12 \mathrm{~h}$, by which time TLC showed $\sim 40 \%$ unchanged substrate and two less polar spots. A second portion of imidazole (1.02 g, 15 mmol) and TBDMSCl (1.09 g, $7.2 \mathrm{mmol})$ were added and the resulting suspension was stirred at $35{ }^{\circ} \mathrm{C}$ for $24 \mathrm{~h}$ (total reaction time: $60 \mathrm{~h}$ ), by which time TLC showed $80 \%$ conversion to a major less polar spot. Volatiles were evaporated and co-evaporated with toluene (high vacuum rotavap, $<40{ }^{\circ} \mathrm{C}$ ). Crude pale gum was partitioned between $\mathrm{CHCl}_{3}$ 
$(50 \mathrm{~mL})$ and brine $(50 \mathrm{~mL})$. The aqueous layer was extracted with $\mathrm{CHCl}_{3}$, and the combined organic layer was dried over anhydrous $\mathrm{MgSO}_{4}$. Volatiles were evaporated in vacuo and the residue was column chromatographed (25\% EtOAc in hexanes) to give $141(736 \mathrm{mg}, 58 \%)$ as a colorless oil: ${ }^{1} \mathrm{H}$ NMR $\left(\mathrm{CDCl}_{3}\right) \delta 8.30(\mathrm{~s}, 1 \mathrm{H}, \mathrm{H} 2), 8.13(\mathrm{~s}, 1 \mathrm{H}$, H8), 6.27 (s, 2H, NH 2$), 6.18$ (d, $J=4.1 \mathrm{~Hz}, 1 \mathrm{H}, \mathrm{H1}$ '), 4.32 (d, $J=4.2 \mathrm{~Hz}, \mathrm{H} 2$ '), 4.21 (d, $J$ $=4.4 \mathrm{~Hz}, \mathrm{H} 3$ '), $4.12-4.10$ (“'m”, 1H, H4'), 4.02 (dd, $J=2.8,11.6 \mathrm{~Hz}, 1 \mathrm{H}, \mathrm{H} 5$ '), 3.78 (dd, $J$ $=1.8,11.6 \mathrm{~Hz}, 1 \mathrm{H}, \mathrm{H} 5 "), 0.97(\mathrm{~s}, 9 \mathrm{H}, t \mathrm{But}), 0.89(\mathrm{~s}, 9 \mathrm{H}, t \mathrm{But}), 0.80(\mathrm{~s}, 9 \mathrm{H}, t \mathrm{But}), 0.16(\mathrm{~s}$, $\left.3 \mathrm{H}, \mathrm{CH}_{3}\right), 0.15\left(\mathrm{~s}, 3 \mathrm{H}, \mathrm{CH}_{3}\right), 0.06\left(\mathrm{~s}, 3 \mathrm{H}, \mathrm{CH}_{3}\right), 0.05\left(\mathrm{~s}, 3 \mathrm{H}, \mathrm{CH}_{3}\right),-0.04\left(\mathrm{~s}, 3 \mathrm{H}, \mathrm{CH}_{3}\right),-$ $0.14\left(\mathrm{~s}, 3 \mathrm{H}, \mathrm{CH}_{3}\right)$.

8-Iodo-2',3',5',-tri-O-(tert-butyldimethylsilyl)toyocamycin (142). LDA (2 M solution in THF, $560 \mu \mathrm{L}, 1.1 \mathrm{mmol})$ was added to a stirred solution of $\mathbf{1 4 1}(139.5 \mathrm{mg}, 0.22 \mathrm{mmol})$ in dry THF $(2 \mathrm{~mL})$ at $-78{ }^{\circ} \mathrm{C}$. After $\sim 1 \mathrm{~h}$ at $-78{ }^{\circ} \mathrm{C}$, iodine $(84 \mathrm{mg}, 0.33 \mathrm{mmol})$. The resultant brown solution was stirred at $-78{ }^{\circ} \mathrm{C}$ for $2 \mathrm{~h}$ and at ambient temperature for 48 hours (total reaction time: $51 \mathrm{~h})$. Reaction mixture was portioned between EtOAc $(10 \mathrm{~mL})$ and $2 \% \mathrm{AcOH} / \mathrm{H}_{2} \mathrm{O}(10 \mathrm{~mL})$. Aqueous layer was extracted with EtOAc. Combined organic layer was washed with brine $(20 \mathrm{~mL})$, dried $\left(\mathrm{MgSO}_{4}\right)$, filtered and concentrated in vacuo, and column chromatographed (10\% EtOAc in hexanes) to give $142(27.3 \mathrm{mg}$, $16 \%)$ and $141(82.3 \mathrm{mg}, 58 \%)$ as brown oils.

142 had: ${ }^{1} \mathrm{H}$ NMR $\left(\mathrm{CDCl}_{3}\right) \delta 8.40(\mathrm{~s}, 1 \mathrm{H}, \mathrm{H} 2), 8.07\left(\mathrm{~s}, 1 \mathrm{H}, \mathrm{NH}_{2}\right), 6.15(\mathrm{~d}, J=4.5 \mathrm{~Hz}, 1 \mathrm{H}$, H1'), 4.78 (s, 1H, NH$\left.)_{2}\right), 4.27$ (d, $\left.J=4.3 \mathrm{~Hz}, \mathrm{H} 2^{\prime}\right), 4.16\left(\mathrm{~d}, J=4.3 \mathrm{~Hz}, \mathrm{H} 3{ }^{\prime}\right), 4.06-4.03$ (“m”, 1H, H4'), 3.94 (dd, $J=3.0,11.5 \mathrm{~Hz}, 1 \mathrm{H}, \mathrm{H} 5$ '), 3.72 (dd, $J=2.1,11.5 \mathrm{~Hz}, 1 \mathrm{H}, \mathrm{H} 5$ "), 0.91 (s, 9H, $t \mathrm{But}$ ), 0.84 (s, 9H, $t \mathrm{But}$ ), 0.74 (s, 9H, $t \mathrm{But}$ ), 0.10 (s, 3H, $\mathrm{CH}_{3}$ ), 0.09 (s, 3H, 
$\left.\mathrm{CH}_{3}\right), 0.00\left(\mathrm{~s}, 3 \mathrm{H}, \mathrm{CH}_{3}\right), 0.01\left(\mathrm{~s}, 3 \mathrm{H}, \mathrm{CH}_{3}\right),-0.12\left(\mathrm{~s}, 3 \mathrm{H}, \mathrm{CH}_{3}\right),-0.24\left(\mathrm{~s}, 3 \mathrm{H}, \mathrm{CH}_{3}\right)$; HRMS (ESI) $m / z 745.4651\left[\mathrm{M}-\mathrm{CH}_{3}+\mathrm{H}\right]^{+}$, calcd for $\mathrm{C}_{29} \mathrm{H}_{52} \mathrm{IN}_{5} \mathrm{O}_{4} \mathrm{Si}_{3} 745.9249$.

7-(1H-benzo[d][1,2,3]triazol-1-yl)tubercidin (144). Tert-butyl hydroperoxide $(85 \mu \mathrm{L}$, $0.75 \mathrm{mmol}$ ) and iodine $(38 \mathrm{mg}, 0.15 \mathrm{mmol}$ ) were added to a stirred suspension of 19a (100 mg, $0.38 \mathrm{mmol})$ and benzotriazole $(89.5 \mathrm{mg}, 0.75 \mathrm{mmol})$ in anhydrous DMF $(2 \mathrm{~mL})$. The resulting dark brown solution was stirred at $35{ }^{\circ} \mathrm{C}$ for $72 \mathrm{~h}$, by which time TLC showed $\sim 10 \%$ conversion to a less polar product. A second portion of TBHP ( $85 \mu \mathrm{L}, 0.75$ mmol) was added and the resulting dark brown solution was stirred at $35{ }^{\circ} \mathrm{C}$ for $24 \mathrm{~h}$ (total reaction time: $96 \mathrm{~h}$ ). Volatiles were evaporated and co-evaporated with toluene (high vacuum rotavap, $<50{ }^{\circ} \mathrm{C}$ ). The resulting brown gum was column chromatographed (5\% $\mathrm{MeOH}$ in EtOAc) to give $\mathbf{1 4 4}(26 \mathrm{mg}, 18 \%)$ as a brown gum. This brown gum was then injected into a semi-preparative HPLC column (Phenomenex Gemini RP-C18 column; $5 \mu, 25 \mathrm{~cm} \times 1 \mathrm{~cm}$ ) via a $5 \mathrm{~mL}$ loop and was eluted with an isocratic mobile phase mixture $20 \% \mathrm{CH}_{3} \mathrm{CN}$ in $\mathrm{H}_{2} \mathrm{O}$ at a flow rate of $1.5 \mathrm{~mL} / \mathrm{min}$ to give $\mathbf{1 4 4}\left(t_{\mathrm{R}}=21 \mathrm{~min}\right)$ as a white powder: $\mathrm{UV}(\mathrm{MeOH}) \lambda_{\max } 278 \mathrm{~nm}(\varepsilon=16700), \lambda_{\min } 240 \mathrm{~nm}(\varepsilon=8000) ;{ }^{1} \mathrm{H}$ NMR (DMSO- $\left.d_{6}\right) \delta 8.50(\mathrm{~d}, 1 \mathrm{H}, J=8.3 \mathrm{~Hz}, \mathrm{Ph}), 8.22(\mathrm{~s}, 1 \mathrm{H}, \mathrm{H} 2), 7.70-7.67(\mathrm{~m}, 1 \mathrm{H}, \mathrm{Ph})$, 7.62-7.52 (m, 4H, Ph, $\mathrm{NH}_{2}$ ), 7.04 (s, 1H, H8), 5.58 (dd, J=3.5,8.8, 3H, 5'-OH), 5.23 (d, $J=6.9 \mathrm{~Hz}, 1 \mathrm{H}, \mathrm{H1}$ '), 5.20 (d, $\left.J=6.4 \mathrm{~Hz}, 1 \mathrm{H}, 2^{\prime}-\mathrm{OH}\right), 4.92$ (“dd”, $J=6.4,11.2 \mathrm{~Hz}, 3$ '-OH, H2'), 3.82 (“brs”, 1H, H3'), 3.75 (“d”, J=3.7, $6.2 \mathrm{~Hz}, \mathrm{H} 4$ '), 3.43 (dt, J=3.6,11.9 Hz, H5'), 3.28-3.22 (m, 1H, H5"); ${ }^{13} \mathrm{C}$ NMR (DMSO- $d_{6}$ ): $\delta$ 158.22, 153.13 (C2), 148.82, 144.52, 135.13, $129.42(\mathrm{Ph}), 125.63,125.10(\mathrm{Ph}), 119.70(\mathrm{Ph}), 110.51(\mathrm{Ph}), 102.04,99.48(\mathrm{C} 8)$, $88.20\left(\mathrm{C}^{\prime}\right), 85.97\left(\mathrm{C} 4^{\prime}\right), 71.31\left(\mathrm{C} 2^{\prime}\right), 70.77\left(\mathrm{C} 3^{\prime}\right), 62.12$ (C5'); HRMS (ESI): $\mathrm{m} / \mathrm{z}$ $384.1391[\mathrm{M}+\mathrm{H}]^{+}$, calcd for $\mathrm{C}_{17} \mathrm{H}_{17} \mathrm{~N}_{7} \mathrm{O}_{4} 384.1415$. 


\section{CONCLUSION}

In conclusion, I developed a novel desulfurization-difluorination method for the synthesis of $\alpha, \alpha$-difluoro esters from the corresponding $\alpha$-arylthio esters, wherein the thiol group is present on the secondary internal carbon. 1,3-Dibromo-5,5dimethylhydantoin (DBH) was used as the oxidant $\left(\mathrm{Br}^{+}\right)$and $\mathrm{Py} .9 \mathrm{HF}$ was the fluoride ion $\left(\mathrm{F}^{-}\right)$source. Arylthio esters with hydrogen as well as a ring deactivating chloro substituent at the para position of the aromatic ring were converted to the corresponding gemdifluoro esters under mild reaction conditions. However, the presence of a ring activating methoxy substituent on the para position of the aromatic ring caused the reaction to be sluggish and the difluorination was observed in low yields. Expansion of this desulfurization-difluorination methodology towards the thioether substrates having aldehyde, ketone, and unactivated alkane functional groups on the adjacent carbon was unsuccessful. Also, treatment of lactones under similar reaction conditions gave low yield conversion to the corresponding $\alpha$-fluoro sulfides and $\alpha$-fluoro sulfoxides. Attempted synthesis of gem-difluorouridine derivatives from the corresponding 2'-arylthio uridine or 2'-fluoro-2'-arylthio uridine precursors was unsuccessful and resulted mostly in halogenation of the pyrimidine ring at the $\mathrm{C}-5$ and monofluorination at $\mathrm{C} 2$ ', without desulfurization. However, treatment of the fully benzylated uridine substrate bearing a $p$ methoxyphenylthioether substituent at the C2' with combination of NIS and DAST gave a moderate but encouraging yield (44\%) of the corresponding monofluorinated thioether without any appreciable oxidation of thioether and iodination of the pyrimidine ring.

Chemical reduction protocols in combination with cyclic voltammetry were employed for reductive desulfonylation of 2'-arylsulfonyl-2'-deoxyuridines as a possible 
alternative process towards incorporation of fluorine and other substituents at the $\mathrm{C} 2$ '. A critical impact on the outcome of these reactions was the choice of the protecting groups. Thus, 3',5'-O-diacetylated substrates 91a were found to decompose readily into the corresponding vinyl sulfone $\mathbf{1 0 2}$ during silica gel column purification, whereas the fully benzylated substrate $91 \mathbf{b}$ was prone to uracil elimination in the presence of strong base. The cleavage of the $\mathrm{C} 2$ '-S was found to occur at a relatively high cathodic potential close to $-2.4 \mathrm{~V} v s \mathrm{SCE}$, with the expulsion of the corresponding sulfinate, meaning that strong chemical reducing agents or selective electrochemical reductions were required. Interestingly the protecting group (Bn or $\mathrm{Ac}$ ) had no impact on the reduction potential. Reactions of 2'-arylsulfonyl-2'-deoxy-2'-fluorouridines with using Organic Electron Donors (OEDs) under different conditions (excess of reducing agents, temperature, $u v$ light activation) gave products resulting from the elimination of either acetate anion from $\mathrm{C} 3$ ' position or uracil from $\mathrm{C} 1$ ' upon reduction of the $\mathrm{C} 2$ '-S bond leading to furan-type products. Interestingly, less powerful reducing-agent TDAE under UV light activation was found to cleave the $\mathrm{C} 2$ '-sulfonyl bond to give 2',3'-unsaturated 2'-fluorouridine (18\%) and 2'-fluoro-2'-deoxyuridine (10\%) products. Tentative trapping of the resulting C2'anion under these uv light conditions either with Selectfluor or MeI were however unsuccessful.

Bromination at $\mathrm{C} 5$-position of pyrimidine nucleosides such as uridine, 2'deoxyuiridine, arabinouridine, cytidine, and N4-benzoylcytidine were achieved under mild reaction conditions using DBH. Also, transformation of purine nucleosides such as adenosine, 2'-deoxuadenosine, guanosine, and 2'-deoxyguanosine to their corresponding 8-brominated counterparts with DBH. Although purine nucleosides required higher 
amounts of reagents and produced brominated products in lower yields when compared to that of the pyrimidine counterparts $(47-98 \%$ vs $70-98 \%)$. Increase in temperature and presence of Lewis acids such as TMSOTf and TsOH increased the rate of bromination reaction and reduced the equivalents of DBH reagent required. The DBH bromination protocol is bench friendly, with most conversions taking place at ambient temperature and producing the brominated products in moderate to high yields. Also, acid labile protection groups such as isopropylidine, and base labile protection groups such as acetyl, benzoyl, and silyl were found to be stable during the course of bromination. In addition, I developed novel NBS or DBH mediated bromination methodology for the synthesis of previously known 8-bromotoyocamycin and 8-bromosangivamycin. This methodology offers mild and improved synthetic alternative from previous reaction conditions. I also found that DBH-bromination of various unprotected nucleosides proceeded efficiently in $\mathrm{MeOH}$, avoiding the need to use high-boiling and expensive solvent DMF.

Novel 6-N-benzyltubercidin and 6- $N$-(4-nitrobenzyl) analogues of tubercidin and sangivamycin were synthesized by initial alkylation at N1 with respective benzyl bromide followed by $\mathrm{Me}_{2} \mathrm{NH}$ mediated Dimroth rearrangement. However, no evidence of formation of an initial N1-alkylated cationic intermediate was observed on TLC upon treatment of toyocamycin with 4-nitrobenzyl bromide. Isolated less polar product indicated direct alkylation on the exocyclic amino group to give 4- $\mathrm{N}-(4-$ nitrobenzyl)toyocamycin. Alternatively, 6- $N$-(4-nitrobenzyl)tubercidin was also prepared by (i) conversion of acetylated tubercidin to its 6-fluorocounterpart via Balz-Schiemann type fluoro-diazotization with $\mathrm{NaNO}_{2} / \mathrm{Py} .9 \mathrm{HF}\left(55 \% \mathrm{HF}\right.$ ); (ii) $\mathrm{S}_{\mathrm{N}} \mathrm{Ar}$ displacement of the 6-fluoro group by 4-nitrobenzylamine; (iii) deacetylation with $\mathrm{NH}_{3} / \mathrm{MeOH}$. The 6- $N$-(4- 
nitrobenzyl) derivatives of tubercidin and sangivamycin inhibited cross-membrane transport of labelled uridine by the human equilibrative nucleoside transporter hENT1 at $>1 \mu \mathrm{M}$ and $\sim 120 \mathrm{nM}$, respectively. Inhibition of the proliferation of L1210, HeLa, and PC-3 tumor cells in culture was observed with 6- $N$-benzyltubercidin and the 6- $N-(4-$ nitrobenzyl) derivatives of sangivamycin and toyocamycin at $0.92-9.4 \mu \mathrm{M}$ concentrations.

Novel 8-azidotoyocamycin was synthesized by treatment of 8-bromotoyocamycin with sodium azide. But the azide product was light sensitive and decomposed after exposure to light. Strain promoted click chemistry of 8-azidotoyocamycin with cyclooctynes gave the corresponding 8-triazolyl derivatives in moderate yields. Iodine mediated $\mathrm{CH}$ arylation of tubercidin with benzotriazole gave the corresponding 7substituted benzotriazolyl product, which showed emission at $420 \mathrm{~nm}$ with a quantum yield of $0.002 \mathrm{~s}$.

\section{REFERENCES}

(1) Levene, P. A.; Jacobs, W. A. Ber. Dtsch. Chem. Ges. 1909, 42, 1198.

(2) Avery, O. T.; MacLeod, C. M.; McCarty, M. J. Exp. Med. 1944, 79, 137.

(3) Watson, J. D.; Crick, F. H. C. Nature (London, U. K.) 1953, 171, 737.

(4) Parker, W. B. Chem. Rev. 2009, 109, 2880.

(5) Wang, P.; Chun, B.-K.; Rachakonda, S.; Du, J.; Khan, N.; Shi, J.; Stec, W.; Cleary, D.; Ross, B. S.; Sofia, M. J. J. Org. Chem. 2009, 74, 6819.

(6) Anderson, D. L. Drugs Today 2009, 45, 331.

(7) Mueller, K.; Faeh, C.; Diederich, F. Science 2007, 317, 1881.

(8) O'Hagan, D. J. Fluorine Chem. 2010, 131, 1071. 
(9) Purser, S.; Moore, P. R.; Swallow, S.; Gouverneur, V. Chem. Soc. Rev. 2008, 37, 320.

(10) Smart, B. E. Journal of Fluorine Chemistry 2001, 109, 3.

(11) Qiu, X.-L.; Xu, X.-H.; Qing, F.-L. Tetrahedron 2010, 66, 789.

(12) Hertel, L. W.; Kroin, J. S.; Misner, J. W.; Tustin, J. M. J. Org. Chem. 1988, 53, 2406.

(13) Gesto, D. S.; Cerqueira, N. M. F. S. A.; Fernandes, P. A.; Ramos, M. J. Curr. Med. Chem. 2012, 19, 1076.

(14) Montgomery, J. A.; Shortnacy-Fowler, A. T.; Clayton, S. D.; Riordan, J. M.; Secrist, J. A., III J. Med. Chem. 1992, 35, 397.

(15) Bonate, P. L.; Arthaud, L.; Cantrell, W. R., Jr.; Stephenson, K.; Secrist, J. A., III; Weitman, S. Nat. Rev. Drug Discovery 2006, 5, 855.

(16) Plunkett, W.; Huang, P.; Xu, Y.-Z.; Heinemann, V.; Grunewald, R.; Gandhi, V. Semin. Oncol. 1995, 22, 3.

(17) Manegold, C. Expert Rev. Anticancer Ther. 2004, 4, 345.

(18) Mini, E.; Nobili, S.; Caciagli, B.; Landini, I.; Mazzei, T. Ann Oncol 2006, 17 Suppl 5, v7.

(19) Elnaggar, M.; Giovannetti, E.; Peters, G. J. Curr. Pharm. Des. 2012, 18, 2811.

(20) de Sousa Cavalcante, L.; Monteiro, G. Eur. J. Pharmacol. 2014, 741, 8.

(21) Brown, K.; Dixey, M.; Weymouth-Wilson, A.; Linclau, B. Carbohydr. Res. 2014, $387,59$.

(22) Saischek, G.; Saischek, E. WO 2007/053869 A2, 2007.

(23) Heinemann, V.; Schulz, L.; Issels, R. D.; Plunkett, W. Semin. Oncol. 1995, 22, 11.

(24) Ruiz van Haperen, V. W. T.; Veerman, G.; Vermorken, J. B.; Peters, G. J. Biochem. Pharmacol. 1993, 46, 762.

(25) Heinemann, V.; Xu, Y. Z.; Chubb, S.; Sen, A.; Hertel, L. W.; Grindey, G. B.; Plunkett, W. Mol. Pharm. 1990, 38, 567.

(26) Plunkett, W.; Huang, P.; Xu, Y.-Z.; Heinemann, V.; Grunewald, R.; Gandhi, V. Semin. Oncol. 1995, 22, 3. 
(27) Baker, C. H.; Banzon, J.; Bollinger, J. M.; Stubbe, J.; Samano, V.; Robins, M. J.; Lippert, B.; Jarvi, E.; Resvick, R. J. Med. Chem. 1991, 34, 1879.

(28) Silva, D. J.; Stubbe, J.; Samano, V.; Robins, M. J. Biochemistry 1998, 37, 5528.

(29) van der Donk, W. A.; Yu, G. X.; Perez, L.; Sanchez, R. J.; Stubbe, J.; Samano, V.; Robins, M. J. Biochemistry 1998, 37, 6419.

(30) Wang, J.; Lohman, G. J. S.; Stubbe, J. Biochemistry 2009, 48, 11612.

(31) Artin, E.; Wang, J.; Lohman, G. J. S.; Yokoyama, K.; Yu, G. X.; Griffin, R. G.; Bar, G.; Stubbe, J. Biochemistry 2009, 48, 11622.

(32) Eklund, H.; Uhlin, U.; Farnegardh, M.; Logan, D. T.; Nordlund, P. Prog Biophys Mol Bio 2001, 77, 177.

(33) Stubbe, J.; van der Donk, W. A. Chem. Biol. 1995, 2, 793.

(34) Wilkinson, J. A. Chemical Reviews 1992, 92, 505.

(35) Resnati, G. Tetrahedron 1993, 49, 9385.

(36) Lal, G. S.; Pez, G. P.; Syvret, R. G. Chemical Reviews 1996, 96, 1737.

(37) Tozer, M. J.; Herpin, T. F. Tetrahedron 1996, 52, 8619.

(38) Kirk, K. L. Organic Process Research \& Development 2008, 12, 305.

(39) Kuroboshi, M.; Kanie, K.; Hiyama, T. Adv. Synth. Catal. 2001, 343, 235.

(40) Hugenberg, V.; Haufe, G. J. Fluorine Chem. 2012, 143, 238.

(41) Sondej, S. C.; Katzenellenbogen, J. A. J. Org. Chem. 1986, 51, 3508.

(42) Hugenberg, V.; Haufe, G. Synlett 2009, 106.

(43) Hugenberg, V.; Wagner, S.; Kopka, K.; Schober, O.; Schaefers, M.; Haufe, G. J. Org. Chem. 2010, 75, 6086.

(44) Ayuba, S.; Fukuhara, T.; Hara, S. Org. Lett. 2003, 5, 2873.

(45) Ayuba, S.; Hiramatsu, C.; Fukuhara, T.; Hara, S. Tetrahedron 2004, 60, 11445.

(46) Fukuhara, T.; Hara, S. Synlett 2009, 198.

(47) Fukuhara, T.; Hara, S. J. Org. Chem. 2010, 75, 7393. 
(48) Ayuba, S.; Yoneda, N.; Fukuhara, T.; Hara, S. Bull. Chem. Soc. Jpn. 2002, 75, 1597.

(49) Hara, S.; Monoi, M.; Umemura, R.; Fuse, C. Tetrahedron 2012, 68, 10145.

(50) Shishimi, T.; Hara, S. J. Fluorine Chem. 2014, 168, 55.

(51) Srivastava, P. C.; Robins, R. K.; Meyer, R. B. In Chemistry of Nucleosides and Nucleotides; Townsend, L. B., Ed.; Plenum Press: New York, 1988; Vol. 1, p 113.

(52) Ueda, T. In Chemistry of Nucleosides and Nucleotides; Townsend, L. B., Ed.; Plenum Press: New York, 1988; Vol. 1, p 1.

(53) Agrofoglio, L. A.; Gillaizeau, I.; Saito, Y. Chem. Rev. 2003, 103, 1875.

(54) Clima, L.; Bannwarth, W. Helv. Chim. Acta 2008, 91, 165.

(55) Machida, H.; Sakata, S. In Nucleosides and Nucleotides as Antitumor and Antiviral Agents; Chu, C. K., Baker, D. C., Eds.; Plenum Press: New York, 1993, p 245.

(56) Robins, M. J.; Barr, P. J. J. Org. Chem. 1983, 48, 1854.

(57) De Clercq, E.; Descamps, J.; Balzarini, J.; Giziewicz, J.; Barr, P. J.; Robins, M. J. J. Med. Chem. 1983, 26, 661.

(58) McGuigan, C.; Yarnold, C. J.; Jones, G.; Velázquez, S.; Barucki, H.; Brancale, A.; Andrei, G.; Snoeck, R.; De Clercq, E.; Balzarini, J. J. Med. Chem. 1999, 42, 4479 .

(59) Mercer, J. R.; Xu, L. H.; Knaus, E. E.; Wiebe, L. I. J. Med. Chem. 1989, 32, 1289.

(60) Beltz, R. E.; Visser, D. W. J. Am. Chem. Soc. 1955, 77, 736.

(61) Srivastava, P. C.; Nagpal, K. L. Experientia 1970, 26, 220.

(62) Kumar, V.; Yap, J.; Muroyama, A.; Malhotra, S. V. Synthesis 2009, 3957.

(63) Ryu, E. K.; MacCoss, M. J. J. Org. Chem. 1981, 46, 2819.

(64) Asakura, J.; Robins, M. J. J. Org. Chem. 1990, 55, 4928.

(65) Ross, S. A.; Burrows, C. J. Tetrahedron Lett. 1997, 38, 2805.

(66) Fukuhara, T. K.; Visser, D. W. J. Am. Chem. Soc. 1955, 77, 2393.

(67) Holmes, R. E.; Robins, R. K. J. Am. Chem. Soc. 1964, 86, 1242. 
(68) Markish, I.; Arrad, O. Ind. Eng. Chem. Res. 1995, 34, 2125.

(69) Virgil, S. C. Encyclopedia of Reagents for Organic Synthesis 2001, DOI: 10.1002/047084289X.rd038.

(70) Alam, A. Synlett 2005, 2005, 2403.

(71) Auerbach, J.; Weissman, S. A.; Blacklock, T. J.; Angeles, M. R.; Hoogsteen, K. Tetrahedron Lett. 1993, 34, 931.

(72) Eguchi, H.; Kawaguchi, H.; Yoshinaga, S.; Nishida, A.; Nishiguchi, T.; Fujisaki, S. Bull. Chem. Soc. Jpn. 1994, 67, 1918.

(73) Herault, X.; Bovonsombat, P.; McNelis, E. Org. Prep. Proced. Int. 1995, 27, 652.

(74) Chassaing, C.; Haudrechy, A.; Langlois, Y. Tetrahedron Lett. 1997, 38, 4415.

(75) Alam, A.; Takaguchi, Y.; Ito, H.; Yushida, T.; Tsuboi, S. Tetrahedron 2005, 61, 1909.

(76) Shibatomi, K.; Zhang, Y.; Yamamoto, H. Chem. Asian J. 2008, 3, 1581

(77) Alam, A.; Takaguchi, Y.; Stuboi, S. Synth. Commun. 2005, 35, 1329.

(78) Khazaei, A.; Zolfigol, M. A.; Rostami, A. Synthesis 2004, 2959.

(79) Chen, Z.-Z.; Guan, X.-X.; Zheng, Z.-B.; Zou, X.-Z. J. East China Normal Univ.; Natural Science 2010, 7, 125.

(80) Suhadolnik, R. J. Nucleoside Antibiotics; Wiley-Interscience, 1970.

(81) Suhadolnik, R. J. Nucleosides as Biological Probes; Wiley, 1979.

(82) Seela, F.; Budow, S.; Peng, X. Curr. Org. Chem. 2012, 16, 161.

(83) Seela, F.; Peng, X.; Budow, S. Curr. Org. Chem. 2007, 11, 427.

(84) Seela, F.; Peng, X. Curr. Top. Med. Chem. (Sharjah, United Arab Emirates) 2006, $6,867$.

(85) Gerster, J. F.; Carpenter, B.; Robins, R. K.; Townsend, L. B. J. Med. Chem. 1967, 10,326 .

(86) Tolman, R. L.; Robins, R. K.; Townsend, L. B. J. Heterocycl. Chem. 1967, 4, 230.

(87) Tolman, R. L.; Robins, R. K.; Townsend, L. B. J. Amer. Chem. Soc. 1969, 91, 2102. 
(88) Hinshaw, B. C.; Gerster, J. F.; Robins, R. K.; Townsend, L. B. J. Heterocycl. Chem. 1969, 6, 215.

(89) Uematsu, T.; Suhadolnik, R. J. J. Med. Chem. 1973, 16, 1405.

(90) Maruyama, T.; Wotring, L. L.; Townsend, L. B. J. Med. Chem. 1983, $26,25$.

(91) Bergstrom, D. E.; Brattesani, A. J.; Ogawa, M. K.; Reddy, P. A.; Schweickert, M. J.; Balzarini, J.; De Clercq, E. J. Med. Chem. 1984, 27, 285.

(92) De Clercq, E.; Balzarini, J.; Madej, D.; Hansske, F.; Robins, M. J. J. Med. Chem. 1987, 30, 481.

(93) Turk, S. R.; Shipman, C.; Nassiri, R.; Genzlinger, G.; Krawczyk, S. H.; Townsend, L. B.; Drach, J. C. Antimicrob. Agents Chemother. 1987, 31, 544.

(94) Gupta, P. K.; Daunert, S.; Nassiri, M. R.; Wotring, L. L.; Drach, J. C.; Townsend, L. B. J. Med. Chem. 1989, 32, 402.

(95) Robins, M. J.; Wilson, J. S.; Madej, D.; Low, N. H.; Hansske, F.; Wnuk, S. F. J. Org. Chem. 1995, 60, 7902.

(96) Bookser, B. C.; Matelich, M. C.; Ollis, K.; Ugarkar, B. G. J. Med. Chem. 2005, 48,3389 .

(97) Zhang, X.; Jia, D.; Liu, H.; Zhu, N.; Zhang, W.; Feng, J.; Yin, J.; Hao, B.; Cui, D.; Deng, Y.; Xie, D.; He, L.; Li, B. PLoS ONE 2013, 8, 1.

(98) Stockwin, L.; Yu, S.; Stotler, H.; Hollingshead, M.; Newton, D. BMC Cancer 2009, 9, 63 .

(99) Choi, B. Y.; Lee, C.-H. Bioorg. Med. Chem. Lett. 2010, 20, 3880.

(100) Wu, R.; Smidansky, E. D.; Oh, H. S.; Takhampunya, R.; Padmanabhan, R.; Cameron, C. E.; Peterson, B. R. J. Med. Chem. 2010, 53, 7958.

(101) De Clercq, E.; Robins, M. J. Antimicrob. Agents Chemother. 1986, 30, 719.

(102) Varaprasad, C. V. N. S.; Ramasamy, K. S.; Girardet, J.-L.; Gunic, E.; Lai, V.; Zhong, W.; An, H.; Hong, Z. Bioorg. Chem. 2007, 35, 25.

(103) Ding, Y.; An, H.; Hong, Z.; Girardet, J.-L. Bioorg. Med. Chem. Lett. 2005, 15, 725.

(104) Eldrup, A. B.; Prhavc, M.; Brooks, J.; Bhat, B.; Prakash, T. P.; Song, Q.; Bera, S.; Bhat, N.; Dande, P.; Cook, P. D.; Bennett, C. F.; Carroll, S. S.; Ball, R. G.; Bosserman, M.; Burlein, C.; Colwell, L. F.; Fay, J. F.; Flores, O. A.; Getty, K.; 
LaFemina, R. L.; Leone, J.; MacCoss, M.; McMasters, D. R.; Tomassini, J. E.; von Langen, D.; Wolanski, B.; Olsen, D. B. J. Med. Chem. 2004, 47, 5284.

(105) Olsen, D. B.; Eldrup, A. B.; Bartholomew, L.; Bhat, B.; Bosserman, M. R.; Ceccacci, A.; Colwell, L. F.; Fay, J. F.; Flores, O. A.; Getty, K. L.; Grobler, J. A.; LaFemina, R. L.; Markel, E. J.; Migliaccio, G.; Prhavc, M.; Stahlhut, M. W.; Tomassini, J. E.; MacCoss, M.; Hazuda, D. J.; Carroll, S. S. Antimicrob. Agents Chemother. 2004, 48, 3944.

(106) Bhattacharya, B. K.; Rao, T. S.; Revankar, G. R. J. Chem. Soc., Perkin Trans. 1 1995, 1543 .

(107) Bhattacharya, B. K.; Ojwang, J. O.; Rando, R. F.; Huffman, J. H.; Revankar, G. R. J. Med. Chem. 1995, 38, 3957.

(108) Ojwang, J. O.; Bhattacharya, B. K.; Marshall, H. B.; Korba, B. E.; Revankar, G. R.; Rando, R. F. Antimicrob. Agents Chemother. 1995, 39, 2570.

(109) Ugarkar, B. G.; Castellino, A. J.; DaRe, J. M.; Kopcho, J. J.; Wiesner, J. B.; Schanzer, J. M.; Erion, M. D. J. Med. Chem. 2000, 43, 2894.

(110) Boyer, S. H.; Ugarkar, B. G.; Solbach, J.; Kopcho, J.; Matelich, M. C.; Ollis, K.; Gomez-Galeno, J. E.; Mendonca, R.; Tsuchiya, M.; Nagahisa, A.; Nakane, M.; Wiesner, J. B.; Erion, M. D. J. Med. Chem. 2005, 48, 6430.

(111) Naus, P.; Pohl, R.; Votruba, I.; Dzubak, P.; Hajduch, M.; Ameral, R.; Birkus, G.; Wang, T.; Ray, A. S.; Mackman, R.; Cihlar, T.; Hocek, M. J. Med. Chem. 2010, 53,460 .

(112) Bourderioux, A.; Naus, P.; Perlikova, P.; Pohl, R.; Pichova, I.; Votruba, I.; Dzubak, P.; Konecny, P.; Hajduch, M.; Stray, K. M.; Wang, T.; Ray, A. S.; Feng, J. Y.; Birkus, G.; Cihlar, T.; Hocek, M. J. Med. Chem. 2011, 54, 5498.

(113) Naus, P.; Caletkova, O.; Konecny, P.; Dzubak, P.; Bogdanova, K.; Kolar, M.; Vrbkova, J.; Slavetinska, L.; Tloust'ova, E.; Perlikova, P.; Hajduch, M.; Hocek, M. J. Med. Chem. 2014, 57, 1097.

(114) Miles, R. W.; Samano, V.; Robins, M. J. J. Am. Chem. Soc. 1995, 117, 5951.

(115) Robins, M. J.; Trip, E. M. Biochemistry 1973, 12, 2179.

(116) Young, J. D.; Yao, S. Y. M.; Baldwin, J. M.; Cass, C. E.; Baldwin, S. A. Mol. Aspects Med. 2013, 34, 529.

(117) Jordheim, L. P.; Durantel, D.; Zoulim, F.; Dumontet, C. Nat. Rev. Drug Discov. 2013, 12, 447. 
(118) Griffiths, M.; Beaumont, N.; Yao, S. Y. M.; Sundaram, M.; Boumah, C. E.; Davies, A.; Kwong, F. Y. P.; Coe, I.; Cass, C. E.; Young, J. D.; Baldwin, S. A. Nat. Med. 1997, 3, 89.

(119) Robins, M. J.; Asakura, J.-i.; Kaneko, M.; Shibuya, S.; Jakobs, E. S.; Agbanyo, F. R.; Cass, C. E.; Paterson, A. R. P. Nucleosides and Nucleotides 1994, 13, 1627.

(120) Robins, M. J.; Peng, Y.; Damaraju, V. L.; Mowles, D.; Barron, G.; Tackaberry, T.; Young, J. D.; Cass, C. E. J. Med. Chem. 2010, 53, 6040.

(121) Young, J. D.; Yao, S. Y. M.; Cass, C. E.; Baldwin, S. A.; : Red Cell Membrane Transport in Health and Disease, Bernhardt, I., Ellory, J. C., (Eds.), SpringerVerlag, Berlin: 2003, p 321.

(122) Hugenberg, V.; Wagner, S.; Kopka, K.; Schober, O.; Schafers, M.; Haufe, G. J Org Chem 2010, 75, 6086.

(123) Unsuccessful attempt of bromination of inosine with NBS in DMF has been reported. ${ }^{61}$

(124) Tolman, R. L.; Robins, R. K.; Townsend, L. B. J. Amer. Chem. Soc. 1969, 91, 2102.

(125) Tolman, R. L.; Robins, R. K.; Townsend, L. B. J. Heterocycl. Chem. 1971, 8, 703.

(126) Chassaing, C.; Haudrechy, A.; Langlois, Y. Tetrahedron Lett. 1997, 38, 4415.

(127) Biswas, S.; Dahlstrand, C.; Watile, R. A.; Kalek, M.; Himo, F.; Samec, J. S. M. Chem. Eur. J. 2013, 19, 17939.

(128) Aveniente, M.; Pinto, E. F.; Santos, L. S.; Rossi-Bergmann, B.; Barata, L. E. S. Bioorg. Med. Chem. 2007, 15, 7337.

(129) Kato, M.; Ouchi, A.; Yoshikoshi, A. Bull. Chem. Soc. Jpn. 1991, 64, 1479.

(130) Moens, M.; Verniest, G.; De Schrijver, M.; ten Holte, P.; Thuring, J.-W.; Deroose, F.; De Kimpe, N. Tetrahedron 2012, 68, 9284.

(131) Tomioka, K.; Ishiguro, T.; Iitaka, Y.; Koga, K. Tetrahedron 1984, 40, 1303.

(132) Hampton, A.; Nichol, A. W. Biochemistry 1966, 5, 2076.

(133) Matsuda, A.; Miyasaka, T. Heterocycles 1983, 20, 55.

(134) Robins, M. J.; Mullah, K. B.; Wnuk, S. F.; Dalley, N. K. J. Org. Chem. 1992, 57, 2357. 
(135) McCarthy, J. R.; Peet, N. P.; LeTourneau, M. E.; Inbasekaran, M. J. Am. Chem. Soc. 1985, 107, 735.

(136) Wnuk, S. F.; Robins, M. J. J. Org. Chem. 1990, 55, 4757.

(137) Rayala, R.; Wnuk, S. F. Tetrahedron Lett. 2012, 53, 3333.

(138) Xu, B.; Unione, L.; Sardinha, J.; Wu, S.; Ethève-Quelquejeu, M.; Pilar Rauter, A.; Blériot, Y.; Zhang, Y.; Martín-Santamaría, S.; Díaz, D.; Jiménez-Barbero, J.; Sollogoub, M. Angew. Chem. Int. Ed. 2014, 53, 9597.

(139) Chen, H.; Hu, Z.; Zhang, J.; Liang, G.; Xu, B. Tetrahedron 2015, 71, 2089.

(140) Lebouc, A.; Martigny, P.; Carlier, R.; Simonet, J. Tetrahedron 1985, 41, 1251.

(141) Wnuk, S. F.; Robins, M. J. J. Am. Chem. Soc. 1996, 118, 2519.

(142) Najera, C.; Yus, M. Tetrahedron 1999, 55, 10547.

(143) Wnuk, S. F.; Rios, J. M.; Khan, J.; Hsu, Y.-L. J. Org. Chem. 2000, 65, 4169.

(144) Schoenebeck, F.; Murphy, J. A.; Zhou, S.-Z.; Uenoyama, Y.; Miclo, Y.; Tuttle, T. J. Am. Chem. Soc. 2007, 129, 13368.

(145) Coeffard, V.; Thobie-Gautier, T.; Beaudet, I.; Le Grognec, E.; Quintard, J.-P. Eur. J. Org. Chem. 2008, 383.

(146) Senboku, H.; Nakahara, K.; Fukuhara, T.; Hara, S. Tetrahedron Lett. 2010, 51, 435.

(147) Nielsen, M.; Jacobsen, C. B.; Holub, N.; Paixao, M. W.; Joergensen, K. A. Angew. Chem., Int. Ed. 2010, 49, 2668.

(148) Viaud, P.; Coeffard, V.; Thobie-Gautier, C.; Beaudet, I.; Galland, N.; Quintard, J.-P.; Le Grognec, E. Org. Lett. 2012, 14, 942.

(149) Xuan, J.; Li, B.-J.; Feng, Z.-J.; Sun, G.-D.; Ma, H.-H.; Yuan, Z.-W.; Chen, J.-R.; Lu, L.-Q.; Xiao, W.-J. Chem. - Asian J. 2013, 8, 1090.

(150) Yang, D.-T.; Meng, Q.-Y.; Zhong, J.-J.; Xiang, M.; Liu, Q.; Wu, L.-Z. Eur. J. Org. Chem. 2013, 2013, 7528.

(151) Clive, D. L. J.; Wickens, P. L.; Sgarbi, P. W. M. The Journal of Organic Chemistry 1996, 61, 7426.

(152) Robins, M. J.; Lewandowska, E.; Wnuk, S. F. J. Org. Chem. 1998, 63, 7375. 
(153) Robins, M. J.; Wilson, J. S.; Madej, D.; Low, N. H.; Hansske, F.; Wnuk, S. F. J. Org. Chem. 1995, 60, 7902.

(154) Mengel, R.; Seifert, J. M. Tetrahedron Lett. 1977, 4203.

(155) Adachi, T.; Iwasaki, T.; Inoue, I.; Miyoshi, M. J. Org. Chem. 1979, 44, 1404.

(156) Amino, Y.; Iwagami, H. Chem. Pharm. Bull. 1991, 39, 622.

(157) Johansen, O.; Holan, G.; Marcuccio, S. M.; Mau, A. W. H. Aust. J. Chem. 1991, $44,37$.

(158) Manchand, P. S.; Belica, P. S.; Holman, M. J.; Huang, T. N.; Maehr, H.; Tam, S. Y. K.; Yang, R. T. J. Org. Chem. 1992, 57, 3473.

(159) Johansen, O.; Marcuccio, S. M.; Mau, A. W. H. Aust. J. Chem. 1994, 47, 1843.

(160) Guo, Z.; Sanghvi, Y. S.; Brammer, L. E., Jr.; Hudlicky, T. Nucleosides, Nucleotides Nucleic Acids 2001, 20, 1263.

(161) Liu, J.; Zhuang, S.; Gui, Q.; Chen, X.; Yang, Z.; Tan, Z. European Journal of Organic Chemistry 2014, 2014, 3196.

(162) Tong, W.; Xi, Z.; Gioeli, C.; Chattopadhyaya, J. Tetrahedron 1991, 47, 3431.

(163) Hoffmann, R. W. Angew. Chem. 1968, 80, 823.

(164) Hoffmann, R. W. Angew. Chem. Int. Ed. Engl. 1968, 7, 754.

(165) Wiberg, N. Angew. Chem. 1968, 80, 809.

(166) Wiberg, N. Angew. Chem. Int. Ed. Engl. 1968, 7, 766.

(167) Zhou, S.; Farwaha, H.; Murphy, J. A. Chimia 2012, 66, 418.

(168) Murphy, J. A. J. Org. Chem. 2014, 79, 3731.

(169) Doni, E.; Murphy, J. A. Chem. Commun. (Cambridge, U. K.) 2014, 50, 6073.

(170) Broggi, J.; Terme, T.; Vanelle, P. Angew. Chem., Int. Ed. 2014, 53, 384.

(171) Murphy, J. A.; Garnier, J.; Park, S. R.; Schoenebeck, F.; Zhou, S.-z.; Turner, A. T. Org. Lett. 2008, 10, 1227.

(172) In view of the high reduction potential of the arylsulfone moiety compared to OED, even transferring one electron would theoretically appear difficult. Nevertheless, it is well known that electron transfer through a mediator, such as a charge-transfer complex, in solution is frequently achieved more easily (i.e. at a 
less negative potential) than would be expected from the bare electrochemical data (explained by the formation of intimate complexes and ion pairing).

(173) Martin, J. A.; Bushnell, D. J.; Duncan, I. B.; Dunsdon, S. J.; Hall, M. J.; Machin, P. J.; Merrett, J. H.; Parkes, K. E. B.; Roberts, N. A.; et, a. J. Med. Chem. 1990, $33,2137$.

(174) Robins, M. J.; Guo, Z.; Samano, M. C.; Wnuk, S. F. J. Am. Chem. Soc. 1999, 121, 1425.

(175) Dang, T. P.; Sobczak, A. J.; Mebel, A. M.; Chatgilialoglu, C.; Wnuk, S. F. Tetrahedron 2012, 68, 5655.

(176) Fritscher, J.; Artin, E.; Wnuk, S.; Bar, G.; Robblee, J. H.; Kacprzak, S.; Kaupp, M.; Griffin, R. G.; Bennati, M.; Stubbe, J. J. Am. Chem. Soc. 2005, 127, 7729.

(177) Wnuk, S. F.; Chowdhury, S. M.; Garcia, P. I., Jr.; Robins, M. J. J. Org. Chem. 2002, 67, 1816 .

(178) Zipse, H.; Artin, E.; Wnuk, S.; Lohman, G. J. S.; Martino, D.; Griffin, R. G.; Kacprzak, S.; Kaupp, M.; Hoffman, B.; Bennati, M.; Stubbe, J.; Lees, N. J. Am. Chem. Soc. 2009, 131, 200.

(179) Adhikary, A.; Kumar, A.; Heizer, A. N.; Palmer, B. J.; Pottiboyina, V.; Liang, Y.; Wnuk, S. F.; Sevilla, M. D. J. Am. Chem. Soc. 2013, 135, 3121.

(180) Close, D. M.; Bernhard, W. A. J. Chem. Phys. 1979, 70, 210.

(181) Clark, J. L.; Hollecker, L.; Mason, J. C.; Stuyver, L. J.; Tharnish, P. M.; Lostia, S.; McBrayer, T. R.; Schinazi, R. F.; Watanabe, K. A.; Otto, M. J.; Furman, P. A.; Stec, W. J.; Patterson, S. E.; Pankiewicz, K. W. J. Med. Chem. 2005, 48, 5504.

(182) Adhikary, A.; Kumar, A.; Rayala, R.; Hindi, R. M.; Adhikary, A.; Wnuk, S. F.; Sevilla, M. D. J. Am. Chem. Soc. 2014, 136, 15646.

(183) Dimroth, O. Justus Liebigs Ann. Chem. 1909, 364, 183.

(184) Engel, J. D. Biochem. Biophys. Res. Commun. 1975, 64, 581.

(185) Fujii, T.; Itaya, T. Heterocycles 1998, 48, 359.

(186) Pande, P.; Shearer, J.; Yang, J.; Greenberg, W. A.; Rokita, S. E. J. Am. Chem. Soc. 1999, 121, 6773.

(187) Zhong, M.; Robins, M. J. J. Org. Chem. 2006, 71, 8901.

(188) Robins, M. J.; Uznański, B. Can. J. Chem. 1981, 59, 2608. 
(189) Liu, J.; Robins, M. J. Org. Lett. 2005, 7, 1149.

(190) Liu, J.; Robins, M. J. J. Am. Chem. Soc. 2007, 129, 5962.

(191) Olah, G. A.; Welch, J. T.; Vankar, Y. D.; Nojima, M.; Kerekes, I.; Olah, J. A. J. Org. Chem. 1979, 44, 3872.

(192) Bookser, B. C.; Ugarkar, B. G.; Matelich, M. C.; Lemus, R. H.; Allan, M.; Tsuchiya, M.; Nakane, M.; Nagahisa, A.; Wiesner, J. B.; Erion, M. D. J. Med. Chem. 2005, 48, 7808.

(193) Baskin, J. M.; Prescher, J. A.; Laughlin, S. T.; Agard, N. J.; Chang, P. V.; Miller, I. A.; Lo, A.; Codelli, J. A.; Bertozzi, C. R. Proc. Natl. Acad. Sci. U. S. A. 2007, $104,16793$.

(194) Lutz, J.-F. Angew. Chem., Int. Ed. 2008, 47, 2182.

(195) Laughlin, S. T.; Baskin, J. M.; Amacher, S. L.; Bertozzi, C. R. Science (Washington, DC, U. S.) 2008, 320, 664.

(196) Campbell-Verduyn, L. S.; Mirfeizi, L.; Schoonen, A. K.; Dierckx, R. A.; Elsinga, P. H.; Feringa, B. L. Angew. Chem., Int. Ed. 2011, 50, 11117.

(197) Marks, I. S.; Kang, J. S.; Jones, B. T.; Landmark, K. J.; Cleland, A. J.; Taton, T. A. Bioconjugate Chem. 2011, 22, 1259.

(198) Koo, H.; Lee, S.; Na, J. H.; Kim, S. H.; Hahn, S. K.; Choi, K.; Kwon, I. C.; Jeong, S. Y.; Kim, K. Angew. Chem., Int. Ed. 2012, 51, 11836.

(199) Heuer-Jungemann, A.; Kirkwood, R.; El-Sagheer, A. H.; Brown, T.; Kanaras, A. G. Nanoscale 2013, 5, 7209.

(200) Bergstrom, D. E.; Brattesani, A. J. Nucleic Acids Res. 1980, 8, 6213.

(201) Sawangphon, T.; Katrun, P.; Chaisiwamongkhol, K.; Pohmakotr, M.; Reutrakul, V.; Jaipetch, T.; Soorukram, D.; Kuhakarn, C. Synth. Commun. 2013, 43, 1692.

(202) Li, X.; Shi, X.; Fang, M.; Xu, X. J. Org. Chem. 2013, 78, 9499.

(203) Gao, Y.; Wu, W.; Huang, Y.; Huang, K.; Jiang, H. Org. Chem. Front. 2014, 1, 361.

(204) Lu, Q.; Zhang, J.; Zhao, G.; Qi, Y.; Wang, H.; Lei, A. J. Am. Chem. Soc. 2013, 135,11481 .

(205) Liu, Z.; Liao, P.; Bi, X. Org. Lett. 2014, 16, 3668. 
(206) Liang, Y.; Wnuk, S. Molecules 2015, 20, 4874.

(207) Beukeaw, D.; Udomsasporn, K.; Yotphan, S. J. Org. Chem. 2015, 80, 3447.

(208) Saladino, R.; Mezzetti, M.; Mincione, E.; Palamara, A. T.; Savini, P.; Marini, S. Nucleosides Nucleotides 1999, 18, 2499.

(209) Kumar, R.; Wiebe, L. I.; Knaus, E. E. Can. J. Chem. 1994, 72, 2005.

(210) Kotra, L.; Pai, E. F.; Paige, C. J.; Bello, A. M. WO 2008/083465 A1, 2008

(211) Lin, T. S.; Cheng, J. C.; Ishiguro, K.; Sartorelli, A. C. J. Med. Chem. 1985, 28, 1481 .

(212) Niles, J. C.; Wishnok, J. S.; Tannenbaum, S. R. Chem. Res. Toxicol. 2000, 13, 390.

(213) Lin, T. S.; Cheng, J. C.; Ishiguro, K.; Sartorelli, A. C. J. Med. Chem. 1985, 28, 1194.

(214) Lin, T. S.; Cheng, J. C.; Ishiguro, K.; Sartorelli, A. C. J. Med. Chem. 1985, 28, 1194.

(215) Gillet, L. C. J.; Schaerer, O. D. Org. Lett. 2002, 4, 4205.

(216) Watanabe, M.; Ezoe, Y.; Isozaki, M.; Kasahara, T.; Hayashi, S.; Tamamura, K. Proc. Sch. Sci. Tokai Univ. 1995, 30, 143.

(217) Lau, J.; Kodra, J. T.; Guzel, M.; Santosh, K. C.; Mjalli, A. M. M.; Andrews, R. C.; Polisetti, D. R.; Novo Nordisk A/S, Den. . 2003, p 175 pp.

(218) Aranapakam, V.; Grosu, G. T.; Davis, J. M.; Hu, B.; Ellingboe, J.; Baker, J. L.; Skotnicki, J. S.; Zask, A.; DiJoseph, J. F.; Sung, A.; Sharr, M. A.; Killar, L. M.; Walter, T.; Jin, G.; Cowling, R. J. Med. Chem. 2003, 46, 2361.

(219) Yang, Z. Y.; Burton, D. J. J. Org. Chem. 1992, 57, 5144.

(220) Hampton, A.; Nichol, A. W. Biochemistry 1966, 5, 2076.

(221) Mulchande, J.; Martins, L.; Moreira, R.; Archer, M.; Oliveira, T. F.; Iley, J. Org. Biomol. Chem. 2007, 5, 2617.

(222) Nowak, I.; Conda-Sheridan, M.; Robins, M. J. J. Org. Chem. 2005, 70, 7455.

(223) Chung, F.-L.; Earl, R. A.; Townsend, L. B. J. Org. Chem. 1980, 45, 4056. 
VITA

\section{RAMANJANEYULU RAYALA}

$2002-2005$

B.Sc., Chemistry

Kakatiya University, Warangal, India

$2006-2008$

M.Sc., Chemistry

Osmania University, Hyderabad, India

$2008-2010$

Chemistry Lecturer

KLR Degree College, Palwancha, india

$2010-2015$

Doctoral Candidate

Florida International University, Miami, Florida, USA

$2011-12$

"Outstanding Organic Chemistry Teaching Assistant" Award

2014-2015

Dissertation Year Fellowship award

American Chemical Society

\section{PUBLICATIONS AND PRESENTATIONS}

Adhikary, Amitava; Kumar, Anil; Rayala, Ramanjaneyulu; Hindi, Ragda M.; Adhikary, Ananya; Wnuk, Stanislaw F.; and Sevilla, Michael D., "One-electron oxidation of Gemcitabine and analogs: Mechanism of formation of C3' and C2' sugar radicals", J. Am. Chem. Soc. 2014, 136 (44), 15646-15653.

Rayala, Ramanjaneyulu; Theard, Patricia; Ortiz, Heysell; Yao, Sylvia; Young, James D.; Balzarini, Jan; Robins, Morris J., Wnuk, Stanislaw F., "Synthesis of Purine and 7Deazapurine Nucleoside Analogues of 6-N-(4-Nitrobenzyl)adenosine; Inhibition of Nucleoside Transport and Proliferation of Cancer Cells", ChemMedChem 2014, 9, 21862192.

Rayala, Ramanjaneyulu; Wnuk, Stanislaw F., "Bromination at C-5 of pyrimidine and C-8 of purine nucleosides with 1,3-dibromo-5,5-dimethylhydantoin", Tetrahedron Letters 2012, 53 (26), 3333-3336.

Rayala, Ramanjaneyulu; Theard, Patricia; Ortiz, Heysell; Wnuk, Stanislaw F.; Robins, Morris J., "Synthesis of 6- $\mathrm{N}$-substituted 7-deazapurine nucleoside antibiotics: Potential 
nucleoside transport inhibitors", 247 ${ }^{\text {th }}$ ACS National Meeting \& Exposition, Dallas, TX, United States, March 16-20, 2014.

Rayala, Ramanjaneyulu; Giuglio, Gamal; Broggi, Julie; Medebielle, Maurice; Wnuk, Stanislaw F., "Reductive desulfonylation of 2'-(arylsulfonyl)-2'-deoxy-2'-fluorouridine derivatives with tetrakis(dimethylamino)ethylene", $245^{\text {th }}$ ACS National Meeting \& Exposition, New Orleans, LA, United States, April 7-11, 2013.

Rayala, Ramanjaneyulu; Wnuk, Stanislaw F., "Bromination at C-5 of pyrimidine and C-8 of purine nucleosides with 1,3-dibromo-5,5-dimethylhydantoin", $243^{\text {rd }}$ ACS National Meeting \& Exposition, San Diego, CA, United States, March 25-29, 2012. 